\title{
e norden
}

\section{Polar Law Textbook II}
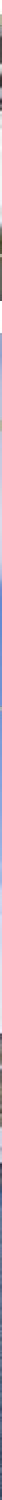

U nordon 



\section{Polar Law Textbook II}

Editor Natalia Loukacheva

TemaNord 2013:535 
Polar Law Textbook II

Editor Natalia Loukacheva

ISBN 978-92-893-2550-9

http://dx.doi.org/10.6027/TN2013-535

TemaNord 2013:535

(C) Nordic Council of Ministers 2013

Layout: Hanne Lebech

Cover photo: ImageSelect

Print: Rosendahls-Schultz Grafisk

Copies: 316

Printed in Denmark

This publication has been published with financial support by the Nordic Council of Ministers. However, the contents of this publication do not necessarily reflect the views, policies or recommendations of the Nordic Council of Ministers.

www.norden.org/en/publications

\section{Nordic co-operation}

Nordic co-operation is one of the world's most extensive forms of regional collaboration, involving Denmark, Finland, Iceland, Norway, Sweden, and the Faroe Islands, Greenland, and Åland.

Nordic co-operation has firm traditions in politics, the economy, and culture. It plays an important role in European and international collaboration, and aims at creating a strong Nordic community in a strong Europe.

Nordic co-operation seeks to safeguard Nordic and regional interests and principles in the global community. Common Nordic values help the region solidify its position as one of the world's most innovative and competitive.

\section{Nordic Council of Ministers}

Ved Stranden 18

DK-1061 Copenhagen $\mathrm{K}$

Phone (+45) 33960200

www.norden.org 


\section{Contents}

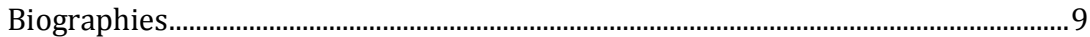

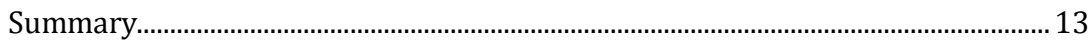

1. Polar Law Developments and Major Trends

Natalia Loukacheva ……......................................................................................... 17

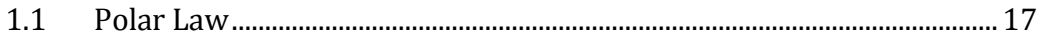

1.2 Major Trends and Arctic Geo-politics..................................................... 19

1.3 The Main Pillars of Development....................................................................25

1.4 Recent Developments..................................................................................... 28

2. Security in the Arctic

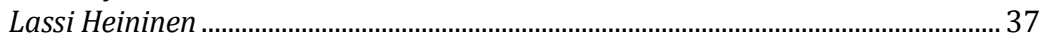

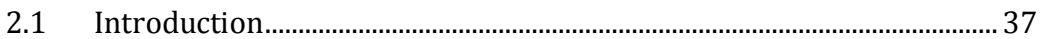

2.2 Definition of Security..................................................................................... 38

2.3 Environmental Security in the Arctic ......................................................... 40

2.4 Human Security in the Arctic......................................................................... 43

$2.5 \quad$ Energy Security in the Arctic ....................................................................... 45

2.6 Traditional Security in the Arctic ............................................................... 46

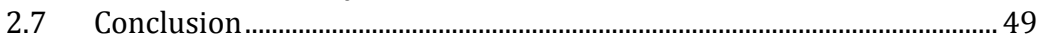

3. The Agreement on Cooperation on Aeronautical and Maritime Search and Rescue in the Arctic - A New Chapter in Polar Law

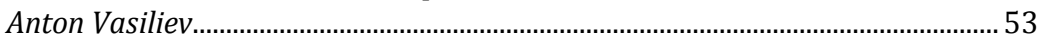

3.1 Introduction............................................................................................53

3.2 The Arctic Council and its Agenda on EPPR.............................................. 54

3.3 The Development of the SAR Instrument Proposal ....................................... 55

3.4 The SAR Instrument Task Force and its Work …………………………..... 56

3.5 Key Features of the SAR Agreement ..........................................................5 5

3.6 Key Provisions of the SAR Agreement.......................................................59

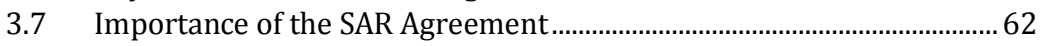

3.8 Conclusion...................................................................................................... 64

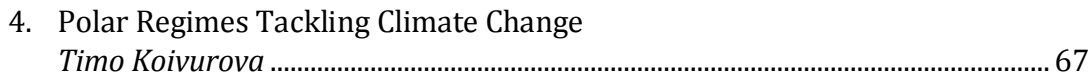

4.1 General Framework of Climate Regime in the Polar Regions..................67

4.2 Arctic Council and Climate Change..................................................................70

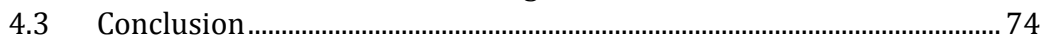


5. The International Legal Regime of the Continental Shelf with Special Reference to the Polar Regions

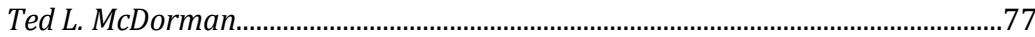

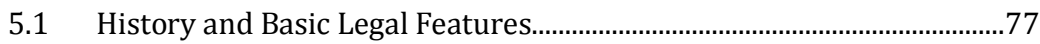

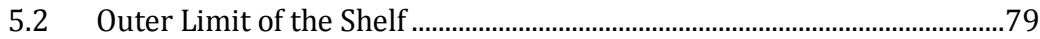

5.3 The Continental Shelf in the Arctic............................................................85

5.4 The Continental Shelf in the Antarctic? .....................................................

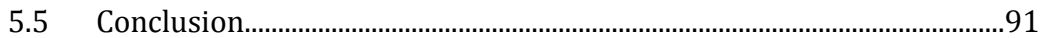

6. Arctic Biodiversity and Marine Wildlife

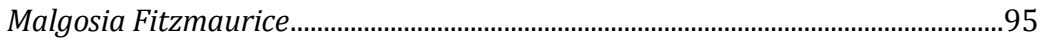

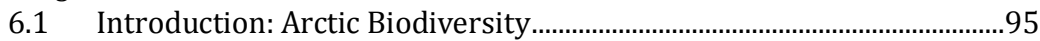

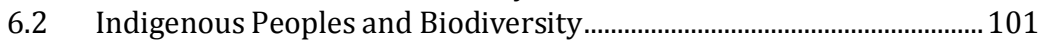

6.3 International Instruments Relevant to the Protection of Arctic

Biodiversity and Marine Wildlife................................................................ 102

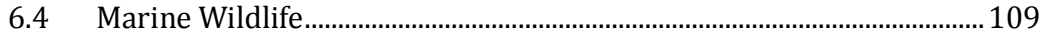

6.5 Regional Treaties..................................................................................... 113

6.6 Relevant Conventions not Directly Aimed at the Protection of Biodiversity .............................................................................................. 117

6.7 Non-Binding ("soft law") Instruments......................................................118

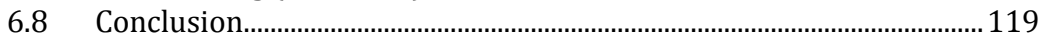

7. Polar Bears and International Law

Nigel Bankes............................................................................................................ 123

7.1 Agreement on the Conservation of Polar Bears ……............................. 123

7.2 Discussion of Polar Bear in other International Fora........................... 125

8. The Antarctic Treaty System and the Regulation of Antarctic Tourism

Kees Bastmeijer.

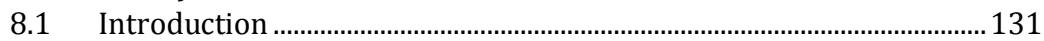

8.2 The Antarctic Treaty System and Tourism ............................................ 132

8.3 "Phases" of Tourism Management in the Antarctic between 1990

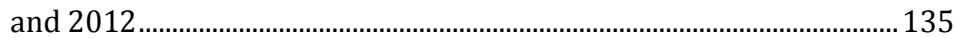

8.4 Regulating Tourism in Antarctica: Outstanding Questions for the

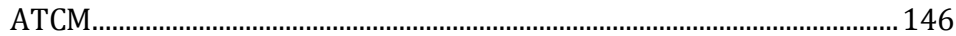

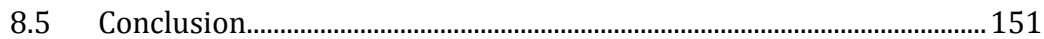

9. Renewable Energy in the Arctic: Regulatory Frameworks

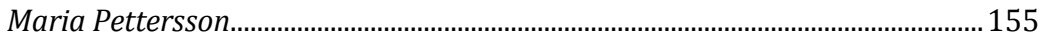

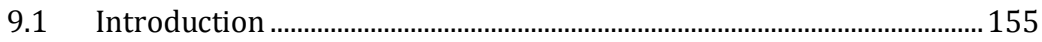

9.2 Renewable Energy in the Arctic .................................................................. 156

9.3 Legal Functions in Relation to the Extraction and Exploitation of

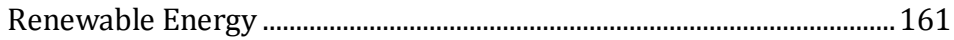

9.4 The Future of Renewable Energy Development in the Arctic -

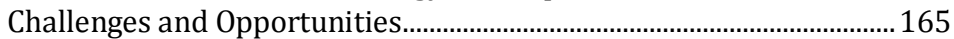

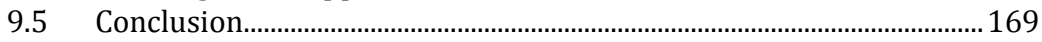


10. Oil and Gas Regulation in the United States Arctic Offshore

Betsy Baker

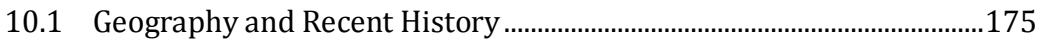

10.2 Jurisdiction, Legal and Regulatory Framework …..................................177

10.3 Conclusion.................................................................................................181

11. Good Governance in the Arctic

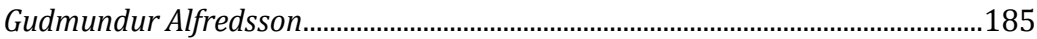

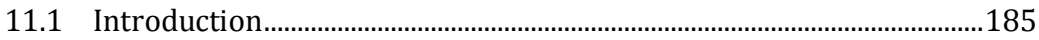

11.2 Links to Human Rights and Democracy....................................................186

11.3 The Good Governance Guidelines .............................................................187

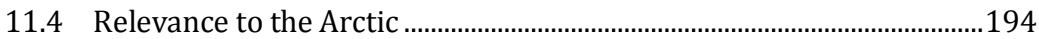

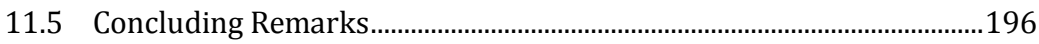

12. Destiny or Dream Sharing Resources, Revenues and Political Power in Nunavut Devolution

Tony Penikett

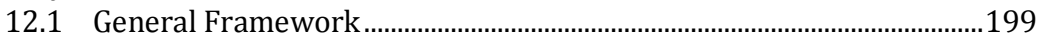

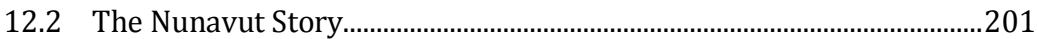

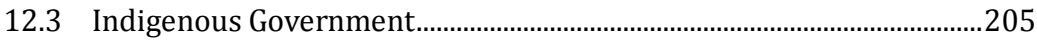

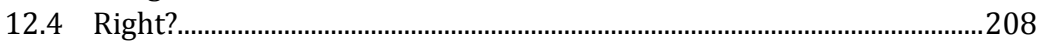

12.5 Revenues and the Stakes.........................................................................210

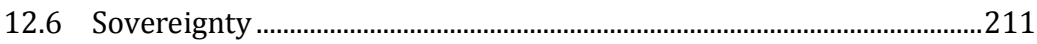

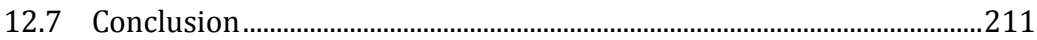

13. Faroese Governance

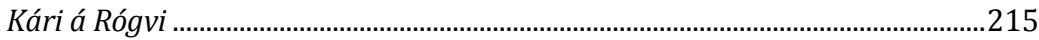

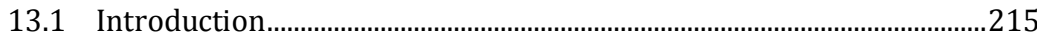

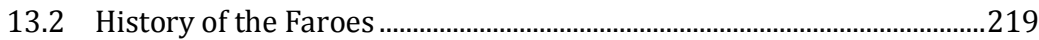

$13.320^{\text {th }}$ Century Developments and Home Rule............................................222

13.4 Economic Development...........................................................................222

13.5 Resources...............................................................................................22

13.6 Faroese Law and Authorities...................................................................228

13.7 Modern Legal System and Developments................................................232

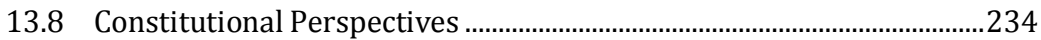

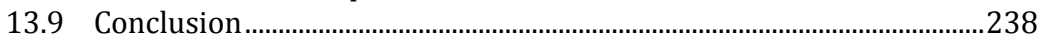


14. Greenland and the United Nations Declaration on the Rights of Indigenous Peoples

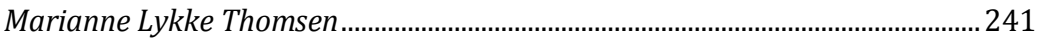

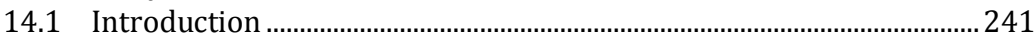

14.2 From Provincial Council to Self-Government.......................................... 243

14.3 Indigenous Peoples Coming Together ......................................................24

14.4 Inuit Hospitality and Partnership with Denmark ....................................246

14.5 Moving the Work to the United Nations................................................. 251

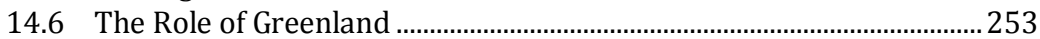

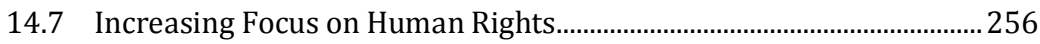

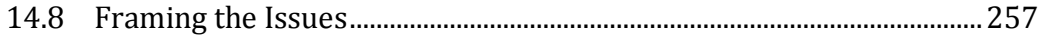

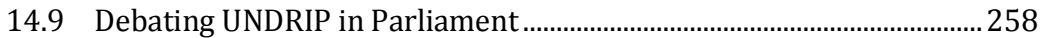

14.10 Language and Cultural Identity in Greenland .........................................261

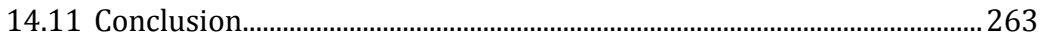

15. Sámi Rights and Sámi Law in Norway

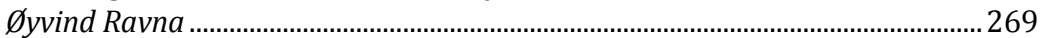

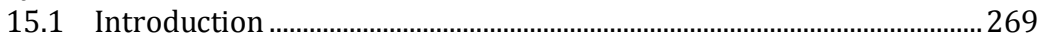

15.2 Legal Developments Regarding Sámi in Norway .................................... 271

15.3 International Law .................................................................................... 282

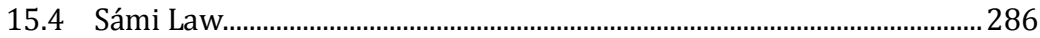

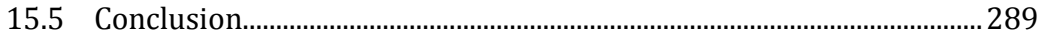

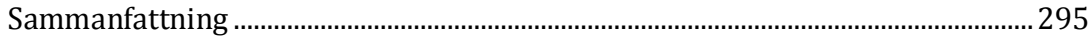

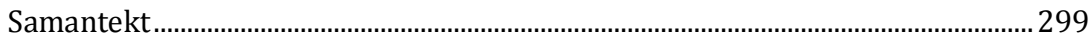




\section{Biographies}

Gudmundur Alfredsson, S.J.D., Professor, Faculty of Humanities and Social Sciences, Polar Law Program, University of Akureyri, Iceland and Faculty of Law, University of Strasbourg, France. Editor-in-Chief, The Yearbook of Polar Law, Martinus Nijhoff Publishers; Expert member of the Danish-Greenlandic Self-Governance Commission (2004-08); Member of the Working Group on Constitutional and International Law of the all-Greenlandic Self-Governance Commission (2001-03), and Member of a working group of the North-Atlantic Group in the Danish Folketing (2003-04). Dr. Alfredsson is the author of many publications in the area of international human rights law.

Betsy B. Baker, Doctor of Jurisprudence (Christian-Albrechts-Universität, Germany) and J.D. (University of Michigan), is an associate Professor, Vermont Law School, and Senior Fellow for Oceans and Energy at the school's Institute for Energy and the Environment. She is on leave for the 2012-2013 academic year as Visiting Scholar with the U.S. Extended Continental Shelf Task Force in Washington D.C. at the U.S. Department of State, Office of Ocean and Polar Affairs. Dr. Baker publishes widely on law and regulation in the Arctic, has prepared papers for the Inuit Circumpolar Council and the Arctic Council on resource development laws in Greenland and Russia, on marine scientific research, and other topics. Current projects include: co-leading the Arctic Council's PAME Arctic Ocean Review Phase II Report and authoring the report's Offshore Oil and Gas chapter as well as work on the legal status of sea ice. Dr. Baker was a member of the science crew on USCGC Healy Arctic Ocean extended continental shelf mapping 2008 and 2009 cruises, and a Dickey Research Fellow, Institute of Arctic Studies, Dartmouth College (2009-2010). She chairs the Arctic Oil and Gas working group of the Arctic Law Thematic Network of the University of the Arctic.

Nigel Bankes is a Professor of Law at the University of Calgary, Calgary, Alberta, Canada where he holds the chair in natural resources law. He is also an adjunct professor of law at the University of Tromsø. He was the lead author of Ch.6 "Legal Systems" in the Arctic Human Development Report, (Akureyri: Stefansson Arctic Institute, 2004) and is the former editor of the Journal of Energy and Natural Resources Law published by the International Bar Association.

Kees Bastmeijer, Ph.D., is a Professor of Nature Conservation and Water Law at the Tilburg Law School of the Tilburg University (The Netherlands). His research relates to international, European, and domestic environmental law, with a special emphasis on nature conservation law. Dr. Bastmeijer is the author of The Antarctic Environmental Protocol and its Domestic Legal Implementation, (The Hague: Kluwer Law International, 2003), and of numerous publications on legal developments relating to the Polar Regions, both the Antarctic and the Arctic (for free downloads, see: http://papers.ssrn.com/sol3/cf_dev/AbsByAuth.cfm?per_id=617336). Dr. Bastmeijer 
is a member of the editorial boards of the Yearbook of Polar Law (Brill/Martinus Nijhoff) and of the Polar Journal (Taylor \& Francis/Routledge). He is an annual report Contributor for the Yearbook of International Environmental Law (Oxford University Press) and is a member of the Steering Group of the Social Science Action Group of the Scientific Committee for Antarctic Research. He is also a board member of the IUCN Netherlands Committee. As an advisor to the Dutch government, Dr. Bastmeijer has participated in Antarctic Treaty Consultative Meetings since 1992.

Malgosia Fitzmaurice, Ph.D., holds a chair in public international law at the Department of Law, Queen Mary, University of London and has taught extensively at numerous international law schools. She is also a Nippon Professor of Marine Environmental Protection at the International Maritime Law Institute in Malta. Dr.Fitzmaurice specialises in international environmental law, the law of treaties, and indigenous peoples' rights. She has published widely on various topics in international environmental law including on the rights of Indigenous peoples and species in the Arctic. She is the Editor-in-Chief of the International Community Law Review and was a CoRapporteur of the International Law Association Committee on Non-State Actors. She is also editor in chief of a book series - Queen Mary Studies in International Law (Martinus Nijhoff Brill Publishers). Her most recent monograph is Contemporary Issues in International Environmental Law, Edward Elgar Publisher, 2009.

Lassi Heininen, Ph.D., is a Professor (of Arctic Politics) at the University of Lapland, and Docent (Adjunct Professor) (of Geopolitics) at the University of Oulu, Finland. He is also Visiting Professor at the University of Akureyri, Iceland; Adjunct Faculty at the Frost Centre for Canadian Studies, Trent University, Canada; Associate Researcher at the Centre for Geopolitical Studies, University of Quebec, in Montreal; and Director of the International Summer School in Karelia at Petrozavodsk State University, Russia. Dr. Heininen teaches and lectures regularly abroad and supervises PhD students from Finland and other Arctic countries. His research fields include IR, Geopolitics, Security Studies, Environmental Politics, Russian Studies, Northern and Arctic Studies, and Political History. He is the author of more than 200 scientific publications and the Editor of the Arctic Yearbook. His most recent books are Arctic Strategies and Policies: Inventory \& Comparative Study (Akureyri: NRF 2011) and Globalization and the Circumpolar North (edited with C. Southcott), University of Alaska Press, 2010. Dr. Heininen is actively involved in speaking at international scientific conferences, seminars and workshops. He is the organiser of the Calotte Academy and Northern Research Forum's Open Assemblies. He is also the chairman of the Northern Research Forum's Steering Committee.

Timo Koivurova, LL.D., is a Research Professor and Director of the Northern Institute for Environmental and Minority Law, Arctic Centre/University of Lapland, Rovaniemi, Finland. Dr. Koivurova has led several large international Polar Law related research projects, is the author of many publications and has participated in many Arctic and international policy processes. He is an editor-in-chief - together with Professor Gudmundur Alfredsson - of the Yearbook of Polar Law. He also chairs the Arctic Law Thematic Network Group of the University of the Arctic. 
Natalia Loukacheva, Ph.D., S.J.D., is the editor of this textbook. She is the first visiting Fridtjof Nansen Professor of Arctic Studies and also a visiting professor of Polar Law (University of Akureyri, Iceland), Research Associate, Munk School of Global Affairs (University of Toronto), Adjunct Professor, Osgoode Hall Law School LL.M. programme on energy and infrastructure, (York University), Research Fellow, the Canadian Defence and Foreign Affairs Institute (Calgary), and Associate Scientist with Stefansson Arctic Institute. She was the first Director of the Polar Law Programme at the University of Akureyri, Iceland (2008-10). Dr. Loukacheva specialises in international and comparative constitutional law, with research interest in the Arctic. She is the author of The Arctic Promise: Legal and Political Autonomy of Greenland and Nunavut (University of Toronto Press, 2007), the editor of the Polar Law Textbook (Nordic Council of Ministers, TemaNord 538, 2010), special editor, the Yearbook of Polar Law, Vol. 2, 2010, and guest editor of the Arctic Review on Law and Politics, No. 2, 2012. Since 2012 she has also served as an Associate editor of the Arctic Review on Law and Politics. Dr. Loukacheva chairs the Thematic Network group on Legal Issues in the Arctic of the Northern Research Forum and the Arctic Governance group of the Arctic Law Thematic Network of the University of the Arctic.

Ted L.McDorman is a Professor at the Faculty of Law, University of Victoria, Victoria, British Columbia and a member (non-practising) of the Bar of Nova Scotia. He has written widely on ocean law and policy having published over 100 articles, chapters in books, etc. Since 2000, he has been editor-in-chief of the quarterly journal Ocean Development and International Law. From 2002-2004 and 2011-2013, Professor McDorman was the "academic-in-residence" at the Bureau of Legal Affairs, Canadian Department of Foreign Affairs and International Trade. From January-May 2007, he was the Fulbright Visiting Chair in Canada-U.S. Relations at the Woodrow Wilson International Center for Scholars in Washington D.C.

Tony Penikett is a well-known political authority and expert on Northern and Aboriginal treaty issues. As legislator, mediator and negotiator, he has worked on devolution issues in the Yukon, NWT and Nunavut. He served for 18 years in the Yukon Legislative Assembly (five terms as MLA for Whitehorse West (1978-1995) and two as Premier of Yukon (1985-1992), seven years as a senior official in the Saskatchewan and British Columbia governments, and 11 years as a private-sector mediator and negotiator. Penikett is the author of Reconciliation: First Nations Treaty Making, Douglas \& McIntyre, 2006. He is also the author of two films: The Mad Trapper for BBC TV/Time Life Films and La Patrouille Perdue, for ORTF France, as well as a prizewinning play, Separatism Comes to Squatters Row.

Maria Pettersson, LL.D. and M.Sc in Economics, currently works as a researcher at the Department of Social Sciences at Luleå University of Technology in the North of Sweden. Dr. Pettersson specialises in environmental and natural resources law. Her research is primarily focused on the function of law in relation to natural resources management and utilisation, often considering climate change. Examples of Dr.Pettersson's research areas include: renewable energy development, especially wind power; energy planning and permitting processes; mining; forest governance; and biodiversity protection. Dr. Pettersson is also responsible for the master's programme in Environmental and Natural Resources law at Luleå University of Technology. 
Øyvind Ravna is a Professor and Doctor of Jurisprudence at the Faculty of Law, University of Troms $\emptyset$. He is of Sami origin, raised on the banks of the Tana River in the Norwegian part of Sápmi. Dr. Ravna headed the research group on Sámi and indigenous law at the University of Tromsø during the period 2008-2012. Since 2011 Professor Ravna has also chaired the indigenous rights' group of the Arctic Law Thematic Network of the University of the Arctic. His field of research is indigenous law, human rights and property law, especially protection and recognition of culture, land rights and the Sámi livelihoods, including the impact of the recently adopted Finnmark Act. He has published extensively on these topics. Dr. Ravna is editor-in-chief of the Arctic Review on Law Politics. He has also worked as a land judge in the Sámi areas of Norway and been engaged in research for the Sámi Law Committee and the Finnmark Commission. Dr. Ravna has also published several documentary books and participated in documentary film-making regarding, among other things, land consolidation, and the situation of indigenous peoples' in Russia.

Kári á Rógvi, Ph.D., Lecturer in law, Faculty of Humanities, University of the Faroe Islands, Tórshavn; External Lecturer, University of Copenhagen; Editor-in-Chief of Faroese Law Review; Former Member of Løgtingið (Faroese Parliament) and Faroese Constitutional Committee. Dr. Kári á Rógvi is the author of many publications on Faroese law. His most recent work is with Bárður Larsen Fyrisitingarlóg, Fróðskaparsetur Føroya, Tórshavn 2012, a Faroese Textbook on Administrative Law.

Marianne Lykke Thomsen is Senior Policy Advisor in the Department of Foreign Affairs of the Government of Greenland. She has a background in Inuit Studies and has lived in Nuuk since 1987. She has advised the Government of Greenland on foreign policy issues since 1994. Previous to this she held the position of environmental coordinator with the Inuit Circumpolar Council. Marianne Lykke Thomsen is the coordinator of the Government of Greenland's engagement with the United Nations, in particular with respect to the promotion and protection of the rights of indigenous peoples. She has also been part of the Arctic Council process for many years and is currently serving as the Head of Delegation for the Kingdom of Denmark to the Sustainable Development Working Group of the Arctic Council.

Anton Vasiliev, Ph.D., is Ambassador at Large, responsible for Arctic cooperation, at the Ministry of Foreign Affairs of the Russian Federation. In the period 2009-2011 he served as a Co-Chair of the Arctic Council Task Force that negotiated the first ever pan-Arctic legally binding document - Agreement on Cooperation on Aeronautic and Maritime Search and Rescue in the Arctic. He has published widely on matters of international cooperation and developments in the Arctic, the Arctic Council and the Barents-Euro-Arctic Council. Dr.Vasiliev is a Senior Arctic Official of the Russian Federation and has represented Russia in the Arctic Council since 2008. 


\title{
Summary
}

\author{
Natalia Loukacheva
}

Developments in the Arctic and Antarctica continue to be the subject of growing public interest and academic, political, scientific, and media discourse. The global magnitude of the changes that are currently taking place in the Polar Regions, also influence legal developments. Furthermore, the growing importance of both the Arctic and the Antarctica in various areas of global, regional, national and sub-national development requires further inquiry into the role of law in dealing with many of the current and emerging issues relevant to both Poles. Although law is not a panacea for all issues, it has its own role to play in dealing with many of them.

A broad overview of Polar law issues was presented in the pioneering Polar Law Textbook, N. Loukacheva ed. Copenhagen: Nordic Council of Ministers, Tema Nord 538: 2010 (www.norden.org). This new textbook further draws upon Polar law as an evolving and developing field of studies which is gaining increasing recognition and intersects with many other areas in the social sciences and humanities. This Polar Law Textbook covers a number of topical issues and new developments that were not discussed in the 2010 book. All chapters were written in the period September 2012 to February 2013 and bring a wealth of new information together on Polar law.

Since our productive cooperation in 2009-2010, the Nordic Council of Ministers (NCM), under the auspices of its Arctic Cooperation Programme, has continued to show leadership in the promotion of legal values within the Nordic, Arctic and global community by endorsing the Polar Law Textbook II project. This initiative was housed in 2012-2013 by the Master's Programme in Polar Law run by the University of Akureyri, Iceland. The new textbook project was led by Dr. Natalia Loukacheva who also served as the book editor. The textbook is the outcome of a broad colla- 
boration process and of efficient teamwork between an international group of 15 well-known experts in the area of Polar law and related studies, including: academics, politicians, practitioners, and Arctic indigenous peoples (see biographies). This cooperation was possible due to our shared belief that despite existing resources, there is further need to advance legal information and knowledge globally.

The NCM provided generous support to enable this educational tool to be produced. It can be ordered in hard copy form from the NCM and, importantly, it is also electronically available on the NCM website to encourage all readers interested in Polar law to access this book freely. It is hoped that this will enable readers located in remote Arctic areas, and across the globe, to have better access to the legal educational tools and information presented herein.

The main objectives of this textbook are: to disseminate new knowledge on the most topical legal and political developments in the Polar Regions; to further promote legal and inter-disciplinary education in and for remote Northern areas; to strengthen cooperation within the Nordic region and with interested stakeholders (e.g., the textbook is useful for the Arctic Council and its working groups, University of the Arctic, and many educational programmes globally). It is also hoped that this textbook will provide the basis for future long distance courses in Polar law and that it will also facilitate Nordic synergy and inter-disciplinary dialogue by advancing further collaboration within the Nordic/Arctic region and beyond. In spite of its primary educational focus, this textbook contains useful information for both lawyers and non-lawyers, as well as for others interested in the subject of Polar law. It explores a variety of legal issues in the Arctic and Antarctica, but also covers the relevant aspects of geopolitics, security, governance, search and rescue, resources, biodiversity, and other political developments.

Structurally, the book is written as a textbook where all chapters have, to a certain degree, been written in the form of lectures and include information for further reading. The textbook is divided into 15 chapters the scope of which focuses on questions of: Polar law, geo-politics, security, and the Arctic Council (e.g., its search and rescue agreement, climate change initiatives, etc.)) (see chapters by Loukacheva, Heininen, Vasiliev and Koivurova); issues of environmental law, climate change, resources, 
energy, biodiversity and continental shelves (see chapters by Baker, Bankes, Bastmeijer, Fitzmaurice, Koivurova, McDorman and Pettersson); developments in governance (self-governance, good governance, devolution), Human Rights and the rights of indigenous peoples (see chapters by Alfredsson, K. á Rógvi, Penikett, Ravna, and Lykke Thomsen). Despite its comprehensiveness, this textbook is limited in scope necessarily leaving room for further research and collaboration in the field of Polar law.

The opinions expressed in this textbook do not necessarily reflect the position of the NCM. The contributors hope that this book will encourage those interested in Polar law to pursue further studies, research or participation in the many, both Arctic and Antarctic-related, initiatives currently ongoing.

Further information about this textbook can be received from the textbook editor Dr. Natalia Loukacheva at natalial@unak.is or at n.loukacheva@ utoronto.ca or from the website of the NCM www.norden.org 



\section{Polar Law Developments and Major Trends}

Natalia Loukacheva

\subsection{Polar Law}

The growing importance of both Polar Regions in various areas of global, regional, national and sub-national development necessitates that further inquiry be made into the role of law in addressing the many current and emerging issues relevant to the Arctic and Antarctica. In light of the fundamental changes taking place in these areas, law is not a panacea for all questions, but it has its own important role to play in dealing with many of them. It should be noted however that generalisations on this issue are not feasible as each legal challenge may require a specific solution and a detailed analysis of the case in question.

Current Polar law developments also indicate that both Polar Regions will continue to be the focus of growing political, international, scientific, media and public discourse for the foreseeable future. Polar law is an evolving area of study which is in the process of gaining increased recognition and significance at the academic level and in international fora. Although various approaches exist to the understanding of Polar law, "broadly speaking, "polar law" is a developing field of law that deals with the international and domestic legal regimes that are applicable to the Arctic or the Antarctic, or both" (Loukacheva in Polar Law Textbook 2010:13). For example, it covers international law treaties that address specific issues related to each Polar Region (i.e., the Convention on the Conservation of Antarctic Marine Living Resources; the Agreement on the Conservation of Polar Bears (the Arctic)); international treaties that apply to both Polar Regions (i.e., the United Nations Convention on the Law of 
the Sea). Polar law also covers the domestic law of the Arctic States and others with special reference to the Arctic, or certain regulations resultant from the Antarctic Treaty Consultative Meetings incorporated into the national legal systems of respective Consultative parties and, in some cases, non-consultative parties. The sub-national legislation of Arctic jurisdictions and the Aboriginal (customary law) of Arctic indigenous peoples should, in addition, also be considered here as they form an important part of the Polar law framework.

Conceptually, Polar law includes both "hard law" - legally binding (e.g., the Antarctic Treaty of 1959, etc.)) and "soft-law" - non-legally binding (e.g., various Memorandums of Understanding concluded by Arctic stakeholders; declarations of the Arctic Council, etc.) instruments. It embraces a "bipolar" approach - considers legal regimes for the South and North Poles, and intersects with several branches of law (e.g., Human Rights Law, Constitutional Law, Law of the Sea, Environmental Law, Resources Law, Wildlife Law, Transportation Law, Aboriginal Law, Trade Law, Law of Sustainable Development, to name but a few).

Polar law is also developing as an educational tool and discipline internationally (e.g., Polar Law programme at the University of Akureyri, Iceland; Law of the Sea programme at the University of Troms $\varnothing$, Norway; specialised courses and programmes at the University of Lapland, Finland and at several Universities in Canada; numerous international Polar law related conferences and workshops; specialised recently established publications like the Yearbook of Polar Law (Akureyri, Iceland \& Rovaniemi, Finland); The Arctic Review on Law and Politics (Norway); The Arctic Herald (Russia); Northern Public Affairs (Canada), the Polar Journal (Australia); the Arctic Yearbook (University of the Arctic and Northern Research Forum), and specialised networks (e.g., the Arctic Law Thematic Network of the University of the Arctic (Rovaniemi, Finland), Thematic Network Group on Legal Issues in the Arctic of the Northern Research Forum, (Akureyri, Iceland, etc.)).

Polar law is also developing as a practical tool and as a useful instrument in dealing with various legal and related issues both internationally and domestically. Furthermore, as a discipline, Polar law is closely intertwined with several areas of the social sciences and humanities (e.g., International Relations, Political Science, Economics, Human Geography, 
etc.). It is evident that a multi-disciplinary approach and the gaining/sharing of information with other sciences are going to influence the future development of Polar law.

Despite some obvious similarities between both the Arctic and Antarctica, de facto, there are differences in their legal regimes. These differences can, in part, be explained by the vivid distinctions that can be drawn between the Poles (see Polar Law Textbook 2010). Nevertheless, changes in these areas suggest that there are issues of common concern which affect further legal and other developments (e.g., climate change, environmental matters, biodiversity, questions of "sovereignty" - stewardship, shipping, etc.).

A broad overview of Polar law questions was given in the pioneering 2010 Polar Law Textbook (see: www.norden.org). This new textbook reflects on information mainly from September 2012 to February 2013 and covers topics that were not previously discussed thus illustrating the wealth of new information available on Polar law and the constant evolution of this field of studies.

\subsection{Major Trends and Arctic Geo-politics}

Recent Polar law developments have been sharpened by the magnitude of the changes occurring in both Polar Regions and globally. Polar law intersects with other areas and, arguably, its development is significantly influenced by global and many geo-political trends. It should be noted however that the definition of geopolitics, which has multiple approaches, is beyond the scope of this study.

This section attempts to analyse some of those trends, predominantly in the Arctic context, although Antarctica is also important. Antarctic geopolitics are strongly influenced by several factors, including: the sovereignty provisions of Article IV of the Antarctic Treaty of 1959, which "froze" claims to territorial sovereignty for the duration of the Treaty; by science, which contributes to the exercise of geopolitical power; global environmental and resource discourse/concerns (e.g., ozone depletion, climate change, etc.); implications of growing tourism activities not just for the environment but also for geopolitical and legal issues in relation to the Antarctic Treaty System (ATS), etc. Furthermore, the shift in geopolitics is defined by the fact 
that they are not as state-centric as before (Chaturvedi 2009). New concerns and questions which impact the legal and geopolitical framework of the South Pole are emerging (e.g., continental shelf issues, climate change, jurisdictional issues of tourism, the development of bio-prospecting, or the role and status of NGOs in the geopolitical scene and the ATS, etc.,) (see Koivurova, McDorman and Bastmeijer in this textbook).

The current situation in the Arctic and the emergence of a new geopolitical framework are being tested by a raft of challenges heightened by globalisation, climate change, uncertainty in respect of just how some of these issues may unfold, and by the shifting geopolitical, security and economic environment in the region. To some degree these challenges have modified existing views, concerns, legal disagreements and political collaboration among several Arctic States and other interested stakeholders. This in turn led to a greater legal, political and scientific discourse over emerging and clashing Arctic interests and the need for more coherent policies and responses to the growing multitude of Arctic issues. It also led to the emergence of a diverse number of actors among Arctic, non-Arctic States, a supranational entity like the EU, sub-national units, indigenous groups and Northerners, etc., who are keen to have a greater say in the political, resource, economic, social development, possible claims, cooperation, and other key initiatives that are relevant to the North.

To date, numerous scientific, trade, economic, industrial, military, social, political, environmental and legal activities in the region indicate that we are in the midst of a tremendous process of transformation that will influence the Arctic long into the future, as well as its peoples and developments well beyond the Arctic rim. Although the Arctic States cooperate and agree on many fundamental issues, important concerns as regards the impacts of this "transformation" on the North nevertheless remain. Thus, there is a need to find feasible common solutions for an adequate sustainnable development, environmental stability and security, adaptation to climate and other changes, human capital and capacity-building.

Arguably, the main pillars of this transformation are focused on:

- New geo-politics, including security and Arctic policies;

- Addressing existing and emerging environmental matters;

- Solving outstanding jurisdictional disagreements; 
- Resource development (both renewable and non-renewable), control, supply and sustainable use;

- New shipping routes and questions of navigation, transportation, marine regulation, search and rescue activities, Arctic Ocean governance, biodiversity, etc.;

- New intellectual frontiers for scientific, knowledge-based technologies, research and collaboration;

- Innovation in Arctic governance (its process, structures, and practices); the human rights approach to dealing with Arctic matters;

- Preparedness and capacity to tackle future challenges and concerns, with respect to the local and global outcomes of Arctic developments.

In addition, legal issues and Arctic geopolitics are interconnected with a number of developments that are influenced by several pivotal factors, such as:

The drastic environmental change caused by ongoing climate change, environmental pollution and hazards (e.g., Persistent Organic Pollutants (POPs), Arctic haze, heavy metals (i.e., Mercury), Black Carbon, etc.). The outcomes of the human-induced actions that raised transnational and regional interest in various areas of development (i.e., human, industrial, technological, resource sourcing, increasing tourism and shipping/navigation, etc.) in the context of ecological fragility, and threats to the vulnerable biodiversity, wildlife, eco-balance and traditional ways of life of Arctic peoples.

The unprecedented geo-political changes that are signified by shifting geopolitical realities and the interests of Arctic and some non-Arctic States; new approaches to multilateral/ bi-lateral diplomacy, partnerships and collaboration with special reservation to the national interest, decision-making, geopolitical advantages and responses to security threats and risks, to ensure peace and stability in the region.

Technical and knowledge-generating capacity evolution which in light of these multiple changes served as a catalyst for the integration of science, diplomacy and policies, framed the region as a new intellectual frontier with opportunities for multi-disciplinary research, innovation, knowhow, and technology (i.e., digital democracy, tele-medicine, long-distance high tech education, video-conferences, satellites, etc.). 
A new era of Arctic politics and the role of the region in global affairs, the increasing importance of legal instruments and regimes in tackling pending and emergent juridical matters are also issues that may potentially impact the region.

This listing of major factors is not exhaustive and is also significantly shaped by a range of general and Arctic-specific issues. As such, the Arctic geopolitical framework is currently influenced by:

- Unpredictability and uncertainty over how geopolitical matters may unfold in light of the ongoing evolution of Arctic and global politics and interests, and the difficulties inherent in generating precise scientific or other data due to technological, security or political limitations; the shortcomings associated with evaluations on the costs and benefits of conducting projects with a high price tag - uncertainty regarding the outcome of risks versus benefits (e.g., fluctuations in the global prices of some resources; information on potentially vast untapped Arctic offshore resources precipitated media speculation about "the race" for their control in the areas beyond the current national jurisdictions of the Arctic States). In addition, a certain amount of misrepresentation and misunderstanding occurred in respect of various Arctic-related developments due to the superficial collection and presentation of information by some media sources and the creation of the "media" frenzy over questions that in reality entail routine legal developments (e.g., speculation over possible conflicts on overlapping continental shelf entitlements). Clearly, the inadequate level of public knowledge on Arctic matters could have an influence on the political behaviour of Arctic stakeholders and may cause unnecessary tensions to emerge in respect of certain geopolitical issues. Moreover, Arctic geopolitics are particularly conditioned by political correctness and are thus quite sensitive to "unexpected" policy-statements, or to seemingly innocuous omissions made by politicians, influential public figures, or the media. 
- The increasing complexity of the issues and networks that form Arctic geo-political settings and their inter-connectivity with other matters (i.e., legal, economic, social) presents another area of concern. This often leads to a certain measure of issue inter-dependence between those areas/questions and the necessity for a multifaceted approach to their resolution.

- The rapidity of the demographic, human, cultural, economic, environmental, ecological, and political changes often simply overwhelm the available measures to address them adequately, the capacity of institutional instruments and the adaptive capability of stakeholders involved in geo-politics to respond properly to these developments.

- The dynamic character of Arctic geopolitics and their development as a process, but with only some degree of flexibility and limitations (e.g., national concerns of Arctic States). The constant transformation and evolution of Arctic politics, Arctic governance and its institutions, thus calls for a re-evaluation of geopolitical settings and innovation in decision-making; the re-distribution of power and control by several stakeholders in and beyond the region and the need to maintain a balance among the international, regional, sub-regional, national and local interests and activities of the state and non-state actors involved in the region's geopolitics (e.g., devolution processes versus centralisation; the gap between traditional hunting practices and knowledge of Arctic indigenous peoples and the pressure for modern industrial economic development, scientific findings or legal regulations (bans) in respect of certain species - i.e., polar bears, seals, whales, etc.).

- By global pressures (e.g., globalisation, climate change, global trade, etc.,) which have profound ramifications for the region, and, vice versa. For example, the increasing importance of the Arctic in global affairs and forums, global interest in the Arctic as a new frontier for resources, energy supply and security, have positioned the Arctic as an important region within the newly emerging geostrategic framework.

- The particularities of Arctic development with respect to geography, demography, climate, human capital, diversity, economics (e.g., the dominant role of the public sector), infrastructure, means/costs of communication and politics have also contributed to the changing geopolitical nature of the region. Despite the existence of some 
opportunities for economic and social development a number of wellknown shortcomings exist in respect of human, political and economic capacity-building across many parts of the region. Those shortcomings do not help Northerners in their aspirations to have a greater say in how major Arctic-related issues develop, or to create a better dialogue and/or partnership with regional, national and global communities. Existing challenges such as: unemployment, poverty, poor housing and living conditions, health and other social ills, and the continuing high level of dependency on welfare or external funds/transfers, as well as limited opportunities for sustainable existence and business in many parts of the region, also influence geo-political trends. As far as Arctic politics are concerned, one can argue that underdeveloped and the still nascent/ad hoc structure of Arctic institutions and regulatory regimes, as well as the non-implementation or usage of existing mechanisms, hamper the legitimacy of these instruments/measures and their capacity to deal with changes and thus, often, present a challenge to geo-political development.

Despite all of this the emergence of civil society in the Arctic and of a new generation of political actors represented by indigenous leaders and other Northerners, has had a pivotal significance for geopolitics in the Arctic. There is no doubt that with the new found political maturity of Northern activists and the evolution of their political movement, after decades of decolonisation, negotiations and the recognition of the rights of Arctic indigenous peoples, these powerful new voices have an increasingly important influence over the development of geopolitical settings that are inclusive of the interests and concerns of Arctic peoples. Furthermore, the trans-national and multi-layered nature of Arctic geopolitics and the global nature of the issues in question point to the growing cooperation of Arctic and non-Arctic actors. This trend is set to continue in the near future as is the need for inclusiveness in respect of the different stakeholders able to contribute to these Arctic-related issues. In other words, we will continue to witness increasingly multidimensional collaboration among the Arctic and non-Arctic States, NGOs, civil society and others in addressing common values, interests and other relevant issues globally and locally. In so doing, however, the overcoming of disagreements and 
clashes of interest among various Arctic and non-Arctic actors, state and non-state organisations, indigenous groups, Northerners and national/local interests presents a particular challenge to the stability and coherence of geo-politics in the region. Last but not least, security issues and in particular the need for a broad understanding of existing and emergent security threats (e.g., environmental, climate change, energy or food security, terrorism, etc.), in the context of a new geopolitical paradigm are also crucial in the formation of the geo-political framework.

Clearly, all of these factors and trends leave room for further analysis. The Arctic is a distinct region in global and regional politics; a region of great diversity which is manifested at several levels. In many ways the Arctic is different from the Antarctic (for detailed comparisons of both Polar Regions see Polar Law Textbook 2010). In the next section we will look at the main pillars of recent Polar law developments with reference, where feasible, also to the Antarctic.

\subsection{The Main Pillars of Development}

The pillars of contemporary development are conditioned by several general trends, which, in a nutshell, can be summarised as:

- The growth of multilateral diplomacy, cooperation, inclusiveness and partnership with a variety of Arctic and non-Arctic stakeholders (the same is relevant to the Antarctic).

- The growing importance of civil society, non-state actors and their organisations in addressing matters of relevance to the Arctic.

- The need for a common policy and shared responsibility for a number issues of common concern in light of ongoing transformation in both Polar Regions (e.g., environment, the role of both Poles in the face of global changes, transportation/navigation, etc.).

- The need for a proactive approach and preparedness for forthcoming challenges and the emergence of opportunities to the common benefit of all interested in developments in both Polar Regions. 
- The increasing necessity for innovation, knowledge-building, and research capacities to fill existing and emerging gaps (new scientific data, information, and research collaboration among various sciences, including law). For example, how to deal with challenges of Antarctic and Arctic biodiversity in light of climate change, or with new realities of shipping and navigation? Is current scientific data adequate and scientific knowledge sufficient to support existing legal disagreements or other developments in the Arctic?

The necessity of new approaches to the re-distribution of power, policymaking and control over regulation and administration of certain issues (e.g., the potential for mining in Antarctica may become a key issue in the future, etc.). With these trends in mind current Polar law developments are arguably now centred on several areas which will continue to form the crux of geopolitical and legal debate in the near future. These areas are as follows:

Environment - (e.g., environmental protection, conservation, and monitoring, issues of pollution, biodiversity, wildlife, climate change, environmental law instruments and measures - both the Arctic and the Antarctic). Both Poles are sensitive to changes in global eco-systems. Thus, for example, increased activities in shipping and tourism suggest the need for further consideration and regulation with regards to vulnerable and fragile eco-bio systems. Furthermore, environmental hazards and concerns in and beyond the Arctic and Antarctica and their connectivity to global chains (e.g., the risk of oil spills, the ramifications of global climate change), create new challenges to the frameworks of Arctic and Antarctic governance. Specifically on biodiversity and climate change issues see the chapters by Fitzmaurice, Bankes and Koivurova in this textbook.

Resources - both regions are currently experiencing a number of general issues relating to resources. As noted previously, mineral development in the Antarctic is currently forbidden but it may become an issue in the future. Clearly, the topics of resource riches, rights, access, extraction, control, sharing and redistribution of benefits, preservation, impacts on livelihood and other areas of development in the Arctic are likely to remain focal points in the legal and geopolitical discourse. However, in both Polar Regions, matters of genetic and bio resources, fish stocks, certain marine mammals, water, 
tourism, etc., share common concerns and thus benefit from lessons that can be learned from scientific and ecosystem-based management practices versus other measures, sustainable use and environmental protection. Thus, to reflect on recent developments in this area, in their chapters, Bankes, Baker, Bastmeijer, Fitzmaurice, and Pettersson analyse various aspects of renewable and non-renewable resources in the Polar Regions.

Governance - in both Polar areas this term may cover various dimensions (e.g., marine, scientific, energy, continental shelf, climate, indigenous (the Arctic), resource, environmental, institutional, etc.), questions of ocean governance (e.g., shipping, navigation, transportation), environmental security and protection, and jurisdictional capacity, governmental mechanisms, the practices of the Antarctic Treaty System and institutions of Arctic governance (including devolution and self-government processes - e.g., Canadian North (Yukon, NWT and Nunavut) (see Penikett in this textbook), Greenland's 2009 self-government agreement (see Kleist in Polar Law Textbook 2010), the legal and political evolution of the Faroe Islands (see K. á Rógvi in this textbook), the implementation of principles of good governance (see Alfredsson in this textbook)). Despite some similarities (i.e., the desire of sub-national authorities to assume greater responsibility over their own lives primarily by means of the transfer of essential jurisdictions e.g., resources, from the centre to sub-national governments), in each entity devolution has its own variables relating to the particularities of the local and national constitutional, economic, and political settings. Usually, high hopes are raised in connection with devolution and self-governance as it often augurs the prospect of a more prosperous and sustainable future for local communities. Important developments are also occurring in the field of human rights - Arctic indigenous peoples' rights that can be regarded within the framework of indigenous governance. As Ravna shows in his detailed analysis of Saami legal status, their rights and customary law in Norway, and Lykke Thomsen in her analysis of rights of the Inuit of Greenland in light of the UN Declaration on the Rights of Indigenous Peoples, despite some progress in the recognition of indigenous rights, significant issues for further concern and consideration remain (see Ravna and Lykke Thomsen in this textbook). 
Each of these aspects can be regarded under a "governance" umbrella and taken together they constitute core legal and political issues. A special sub-set of questions is also covered by security and airspace developments (on security in the Arctic see Heininen in this textbook).

Finally, this chapter will look at some of the most recent developments that have taken place in Polar law since 2010. Importantly, all of the trends and developments described here are often interconnected with each other and thus they should be seen in the context of a comprehensive overview.

\subsection{Recent Developments}

Since the 2010 publication of the Polar Law Textbook several important events have taken place in the field of Polar law.

One set of developments occurred in the area of Arctic governance. Although its framework is still marked by great complexity while, in addition, operating at several, often ad hoc levels, fundamental changes have occurred in one of its key institutions - the Arctic Council. Despite continuing criticism since in creation in 1996 the Council has, time and again, proven its ability to function quite effectively as well as being open to further change which may in the future even lead to its becoming a fullyfledged international organisation.

Since the 2009 Tromsø Declaration the Council has introduced several important reforms which have changed its architecture and jurisdiction. Such reforms specifically concern the 2011 decision taken at the Ministerial meeting in Nuuk to establish the Arctic Council's permanent secretariat and launch it no later than at the next Ministerial meeting (i.e., in 2013). This secretariat is expected to bring more continuity and efficiency to the Council's operational capacity (interestingly, the ATS has had such a body for almost ten years); the elaboration of agreed criteria for the Arctic Council observers; the launching of the first-ever collective financial foundation of the Council - the Project Support Instrument to finance the Council's environmental projects; and, most interestingly for Polar law development, this relates to the historic first ever binding Agreement under the auspices of the Council. Thus, in May 2011 the pioneering Agreement on Cooperation on Aeronautical and Maritime Search and Rescue in the Arctic opened a new 
chapter in Polar law (see Vasiliev in this textbook). In May 2013 a new legally binding agreement on the prevention of marine oil pollution and response in the Arctic, came into existence as a result of the Council's diligent work and success; its ability to show leadership, finding a compromise and cooperation on common issues of vital importance despite the potential for clashes over internal national interests and agendas.

The significance of these two agreements cannot be overstated. Concluded under the auspices of the Arctic Council by eight Arctic States, these initiatives indicate that the Council has evolved from its advisory mandate into a more influential body able to react and be responsive to the most telling challenges facing the region both in terms of practical and political significance. Although both agreements contain some legally nonbinding appendixes, they are based on existing international treaties and domestic legislation dealing with the subject matter of these documents, and are binding on the Arctic States that endorsed them under the aegis of the Council. These agreements prove that, while remaining a "soft-law" body, the Council has "moved" to the use of "hard-law" instruments on issues of relevance to both the Circumpolar Region and to the international community more generally.

Reforms of the Council also show that it is becoming the key player in the institutional structure of Arctic governance and that the time has come for deeper cooperation with others to avoid much of the criticism in respect of overlapping and the lack of a clear agenda in dealing with issues of shared responsibility and concern. It still however remains to be seen whether the Council will broaden its mandate to include traditional security issues (for example, the 2012 Goose Bay meeting of chiefs of defence of the Arctic States - members of the Arctic Council, has given an impetus within the Council to discussion of the expansion of its thematic scope to address even issues of military security which are currently excluded from the Council's mandate). Clearly, even now, in light of its main focus on the environment, climate change and sustainable development, indirectly, the Arctic Council already deals with security and other questions of safety in the region. Another unresolved concern here was the matter of "inclusiveness" in respect of non-Arctic actors having access to the Council's "club." Should the Council embrace all non-Arctic actors, which applied for observer status or which have al- 
ready been granted, on an ad hoc basis, temporary observer status (e.g., the European Commission) ${ }^{1}$ in the Council's activities given the fact that it is impossible to do any kind of business in the Arctic "unilaterally," or there are other avenues for cooperation with de facto non-Arctic players? In other words, reform of the Council remains a "work in progress" but the results will have a major geopolitical impact on the state of affairs in the region and beyond the Arctic rim. In this respect the Antarctic governance situation is much less "pressurised".

Another interesting trend is the need to deal with the new role of nonstate actors and civil society in the process of Arctic cooperation and governance. Clearly, it is not only about the role of states any more, although all eight Arctic States continue to play a major role, both domestically (e.g., in responding to the transformation of the Arctic and in setting out new priorities all of them have revised or issued new Arctic policies from 2007-2013; most of the Arctic States are now also displaying increased military capacities, including improved military vessels, icebreaker's fleets and equipment, military activities in the High North, enhanced air patrolling, etc., as part of the process of asserting their sovereignty) and internationally (states are major actors and each Arctic State is searching for its special niche and for greater credibility in dealing with Arctic-related matters). Furthermore, Denmark, Finland and Sweden, as EU members, will need to coordinate their Arctic policies with the EU's own Arctic policy which is presently under development; there are questions also over the potential roles of Norway and Iceland which have European Economic Area (EEA) agreements with the EU (Iceland has started a process of negotiation towards EU accession but its outcome remains unclear at the current time of writing). Interesting questions also arise in light of Greenland's self-governance and its special arrangements with the EU. If Greenland is to become a new Arctic State, the role of this Arctic entity may become pivotal to the region.

\footnotetext{
${ }^{1}$ Although ad hoc observer status in the Arctic Council is no longer granted, a special exclusion was made in Nuuk in May 2011 vis-a-vis 5 "old observer applicants" - the European Commission, Italy, China, Japan, and South Korea -after decision on new observers was taken at the Arctic Council Kiruna Ministerial meeting on May 15, 2013, the European Commission still holds it.
} 
Today's geopolitical reality also points to the aspirations of several non-Arctic States (e.g., China, Japan, S. Korea, India) and international and/or supranational organisations like the EU to become greater players in Arctic affairs. The EU has made several statements and undertaken numerous studies to prove that in spite of the lack of geographic proximity (with the exception of Sweden, Finland and Denmark/Greenland although Greenland is not a part of the EU), the Union has its own expertise and role to play in the Arctic.

Despite these developments, it is also clear that we are witnessing the growing importance and activism of, for example, indigenous organisations in the lobbying of their interests and in partaking in decision-making that concerns their homelands. For instance, the temporary suspension in 2012 of the activities of the Russian Association of Indigenous Peoples of the North and Far East (RAIPON) as a result of internal conflicts and politics in Russia, was given international resonance on the part of other international indigenous groups and Arctic stakeholders, including an agreed statement of the Arctic Council in support of this organisation. Furthermore, there are numerous examples of region to region or informal collaboration of non-state stakeholders in advancing their needs and interests at the economic, cultural, educational, scientific and political levels internationally.

Notwithstanding existing differences in national priorities and positions among the Arctic States (e.g., Arctic Ocean States vs. non-coastal Arctic States) and well-developed state level cooperation, non-state collaboration will continue to influence the state of affairs in the region, and, to a certain degree, all these Arctic stakeholders and others are interdependent and share common areas of concern or benefits that may be best delivered by means of multilateral dialogue and partnerships. Thus, on the one hand, the Arctic States will have to find a balance in addressing matters of cooperation with non-Arctic States and among each other; on the other hand, they will also need to enhance collaboration with their subregional units, indigenous and other NGOs and NPOs. These developments suggest that the structure of Arctic governance shall continue to be shaped by agendas of many multi-level governance participants operating 
within the context of various forms of collaboration within and beyond the Arctic rim.

Another set of developments took place under legal and political frameworks. Legal and political challenges in both Poles have been extensively studied. Politically, new areas of cooperation have emerged. Thus, as already mentioned, in 2012 the first ever meeting of the chiefs of defence of all eight Arctic States was initiated by Canada and took place in Goose Bay. It shows that we are moving to more trust and partnership even in such a traditionally sensitive area as military collaboration; this is something which promises to change our understanding of security in the North.

The most recent developments also deal with the resolution of some long-standing legal disagreements. Thus, in September 2010 after 40 years of negotiations Norway and Russia signed the Treaty on Maritime Delimitation and Cooperation in the Barents Sea and the Arctic Ocean which was subsequently ratified by both states and entered into force and is seen by experts as an example of successful diplomacy and fruitful cooperation for the benefit of both nations.

In November 2012 Canada and Denmark reached an important albeit tentative agreement on the establishment of the maritime boundary in the Lincoln Sea (the body of water north of Ellesmere Island and Greenland). Once ratified, this agreement will modernise provisions of the 1973 Agreement between the Government of the Kingdom of Denmark and the Government of Canada relating to the Delimitation of the Continental Shelf between Greenland and Canada which created the current boundary south of the Lincoln Sea. Another long-standing disagreement over Hans Island was excluded from these negotiations and at the time of writing is still unresolved.

The well-publicised matter of the extension of continental shelves in the Arctic is taking place within a process specified by the UN Convention on the Law of the Sea. Of all Arctic States that are expected to extend their shelves beyond 200 nautical miles at the current time of writing Norway is the only one that has received recommendations on its 2009 submission and has proceeded to delineate its outer limit; Russia is expected to re-submit additional data in 2014, while Canada and Denmark are preparing to do so in 2013 and 2014 respectively. It is expected that United States may ratify UNCLOS in the near future, albeit it already collects all required data to sustain its possible submission to the commission on the 
limits of the continental shelf. As analysed by McDorman in this textbook, the question of continental shelves is also relevant to the South Pole, although at the moment, it presents greater interest in the Arctic as there is currently a "race" there among the Arctic Ocean states to collect the necessary geological and other scientific data to assist their entitlement applications. There may be some areas of overlap with respect to the Lomonosov and Mendeleev ridges but this is not expected to cause any international conflict.

Another important development focuses on the significant projected increase in Polar shipping and the navigation and transportation issues that follow from this. Due to climatic change, the reduction of sea ice, the growing global demand for resources and advanced technology (e.g., better vessels and more efficient ice-breakers) and the prospects of new shipping routes are more promising than ever. For example, the Northern Sea Route (NSR) in Russia is rapidly becoming a new "Panama canal" in the North and it is no accident that in 2012 new legislation on the NSR was introduced and entered into force in early 2013.

At the global level, the development of an adequate and efficient Polar shipping regime which would guarantee security, reliability, environmental stability and safety with the growth of trade/commercial, tourism and even military shipping, is important. For example, with regards to the Arctic, important recommendations on a more effective Arctic Ocean governance regime were issued (e.g., the 2009 Arctic Marine Shipping Assessment (AMSA) report of the Arctic Council).

Furthermore, although there are procedures in place for vessels that operate both in the Arctic and Antarctica - "the Practical Guidelines for Ballast Water Exchange in Antarctic waters" (see Koivurova in Polar Law Textbook 2010), unresolved issues remain with regards to shipping (e.g., the need for legislation on marine protected areas as a protective measure from shipping in the Arctic). Thus, expectations are high in relation to the adoption, by the International Maritime Organisation (IMO), of a legallybinding Polar Code by 2015-2016 that would replace the 2009 shipping guidelines which apply to both Poles but are not legally-binding.

In addition, important legislative initiatives are currently being forwarded within the various Arctic States at the domestic level (e.g., Russia 
is currently working on a new law dealing with its Arctic Zone which will define the special or beneficial treatment given to its Arctic regions).

To conclude, improved shipping and resource accessibility precipitated by climatic change and various technological advances presents new challenges for both Polar Regions and puts "pressure" on some Arctic States to resolve existing disagreements before this "new" reality emerges. We are thus clearly in an era of transformation regionally, nationally and globally with both positive and negative impacts on the Poles. For Polar law, in light of this situation, the tendency from states to deal with long unresolved legal and political disagreements as soon as possible is set to continue.

Although both Poles share some commonalities, developments at each pole are happening under different legal regimes. Thus, for a number of reasons, there are no prospects of an Arctic Treaty similar to that in the Antarctic; we could, however, see the development of several legal regimes for specific issues (e.g., Fisheries). One option here is to employ an eco-system based management approach via a regional agreement on fisheries. The development of an adequate scientific plan for Arctic fisheries may therefore be essential in addressing the challenges of IUU (illegal, unreported, and unregulated) fishing and the conduct of sustainable fisheries (e.g., concerns for over-fishing/over-exploitation of fish and marine Arctic resources, emergence of new species, etc.).

Furthermore, the legal entrenchment of the principle of demilitarisation in the Arctic, as is the case with respect to the South Pole, is simply not possible. Although in the Arctic, the trend towards increasing military capabilities is manifested within legitimate frameworks under the banner of national security and ensuring peace and stability in the region. Moreover, as far as the matter of sovereignty is concerned, in the Antarctic it is "frozen" by Art. IV of the 1959 Treaty (for detailed explanations of this issue see Polar Law Textbook 2010 \& Chaturvedi 2009); in the Arctic, territorial sovereignty claims have now been settled except for the longpending dispute between Canada and Denmark over Hans Island. The assertion of Arctic sovereignty marks the political agenda of some Arctic States (e.g., Canada), although this is manifested by increasing consideration of the assertion of stewardship in the region as opposed to overuse of the rather ambiguous term, "sovereignty". 
Another important area is that of resource development. In addition to the current focus on untapped fossil-fuels and minerals in the Arctic, water and bio-resources are set to gain greater strategic importance in both Polar Regions. In that regard, questions of ownership, resource benefits, and the legal status of icebergs, the value, protection and usage of fresh water, ice, snow etc., may raise legal and/or political issues while presenting economic opportunities, for instance in relation to the further development of bio-prospecting and genetic resources - as they can generate opportunities for new sources of energy, produce pharmaceutical breakthroughs and positively impact the food production and other industries.

Global pressures in both Polar Regions are becoming more evident than ever, thus, Polar law will continue to develop in the nexus with politics, various sciences and as a part of a process of legal globalisation.

\section{Further reading}

Polar Law Textbook, Natalia Loukacheva ed. (Copenhagen: Nordic Council of Ministers, TemaNord 538:2010) www.norden.org

The Yearbook of Polar Law, 2009-2013 (Boston-Leiden: Martinus Nijhoff Publishers) www.brill.nl/pola

Arctic Review on Law and Politics, 2010-2013 (Oslo: Gyldendal Publishers) www.gyldendal.no/arcticreview

The Arctic Herald, 2012-2013 (Moscow: International Publishing House Arktika) www.arctic-herald.ru

The Arctic Yearbook, Lassi Heininen ed. (Akureyri: Northern Research Forum and University of the Arctic, 2012).

www.arcticyearbook.com

The Polar Journal, 2011-2013 (Routledge: Taylor \& Francis).

Nigel Bankes, Timo Koivurova et al. "Legal Systems," Ch. in Joan Nymand Larsen et al eds. Arctic Human Development Report II, forthcoming in 2014.

Sanjay Chaturvedi. "Antarctica," in Kitchin, R. \& Nigel Thrift (eds.), International Encyclopedia of Human Geography, Vol. 1. (Oxford: Elsevier 2009):133-139.

\section{Questions}

- How will Polar law (which areas) develop further in the light of ongoing changes taking place in both Polar Regions?

- What are the most important new issues in the field of Polar law?

- What can the Polar Regions learn from each other in terms of legalpolitical frameworks? 



\section{Security in the Arctic}

Lassi Heininen

\subsection{Introduction}

Over the course of the last decade the Arctic has witnessed a manifold growth in its geostrategic importance and in the level of global interest directed toward the region. This new found interest has undoubtedly influenced changes in Northern security (see Heininen 2010). This chapter aims to look at various aspects and features of Northern security, or security of the Arctic region, as an appreciation of these basic security issues is essential for a broader understanding of the state of Arctic affairs as security ultimately has an impact on many of the other developments that concern the entire North.

Looking back we can see that the current situation in respect of Northern security has been shaped by global political developments. In the 1990s a significant change occurred in the international system, as well as in its security environment, when the Cold War (period) ended and the Soviet Union collapsed. This saw an initial reduction in military and political tension, and was followed by international cooperation, (strategic) partnerships, and stability. A period of disarmament followed, which included significant arms control actions such as the Comprehensive Test Ban Treaty of 1996, and culminating in the 2010 START - Strategic Arms Reduction - Treaty between the Russian Federation and the USA. This basic change in the distribution of power at the system level saw the emergence of a new kind of dominance by one superpower, the USA. At the same time, we experienced a modernisation of the military with economic and technical developments emphasising quality over quantity and a reform of military alliances, such as, for instance the North Atlantic Trea- 
ty Organisation (NATO) which became a global actor with the extension of its activities "out of area".

In combination these factors precipitated something of a global geopolitical transformation from confrontation to collaboration and ultimately had a direct impact on the Arctic region and on Northern security calculations in particular. As a result of these changes, the scope of security in the Arctic moved from a traditionally military logic to one centred on other less tangible aspects, such as the environment, which is of vital importance to the residents and people(s) of the North. It was indeed no accident that it was among Northerners in the late 1980s that growing concern emerged in respect of long-range (air and water) pollution and radioactivity which was, ultimately, reflected in the "environmental awakening" in international affairs and specifically by the emerging discourse on environmental security. The result was that Northern security became both more comprehensive and complex as it now encompasses not only traditional military concerns but also other and broader issues relating for instance to environmental and human issues such as the impact of climate change (Heininen 2013). To understand the current security context in the Arctic one has thus first to understand the nature of security and its emerging general definitions.

\subsection{Definition of Security}

What is security? Unfortunately there is no single answer to this question. The reality is that security is not an objective concept but rather is a relative one and thus is socially constructed. In addition it includes aspects relating to individual, societal and environmental security. To begin to conceptualise this the term "securitisation" was coined which, in the opaque language of security discourse, is meant to signify that almost all issues are not increasingly "securitised", as the Copenhagen School (on security studies) has argued (e.g., Buzan 1991). Security is, however, a complex notion which can also include nationalistic and militaristic aspects (e.g., environmental security risks as a result of military activities) (Deudney 1999). There are thus many ways to understand, determine and interpret "security". 
When defining security - the basic starting point is often: Whose security are we talking about? Several actors and subjects (of security) exist, even the "owners" of security can, to some extent, also be identified. They are: the state - a nation, an individual/citizen, society, the international community/humankind.

Unlike traditional military security which dominated for many years and in line with which the state, defined by the political and economic elite(s), is the main subject, gradually, it became evident that there is a need to broaden the interpretation of this approach into a more comprehensive concept. Thus, security became increasingly viewed from a broader perspective with different subjects of security now recognised. Accordingly, human beings as well as peoples/nations should be determined as the subjects of security. This approach, however, makes it difficult to have an objective definition of security, especially in terms of what it is that is to be secured. Currently, there are several ongoing discourses on security and its concepts - e.g., the main ones include tradition$\mathrm{al} /$ national security, environmental/ecological security, human security, civil/civic security, energy security, and also "economic" security, "cyber" security and "climatic" security, etc.

With regards to the Arctic, it is also relevant to consider "regional security" which is based on regional particularities (Bailes \& Cottey 2006) such as institutional and international cooperation and region-building, all of which are affected by globalisation and by global pressures and flows of globalisation, etc. These factors are significant in the Arctic context and help us to define certain special features of Northern security (see Heininen 2010):

- The so-called technology model of geopolitics - which states that if technology allows it, any part of the physical space of the earth can, and will, be used for military purposes - has been implemented in the Arctic since the second World War (e.g., installations of the nuclear weapon systems during Cold War);

- Relationship between the environment and security/the military (e.g., environmental degradation of radar stations from the DEW Line in North America); 
- Indigenous peoples and the military (e.g., conflict of interests between military training and reindeer herding in some Northern parts of Fennoscandia);

- Nuclear safety (e.g., dumped radioactive waste, accidents with nuclear submarines);

- Energy security (e.g., danger and risk of oil spills); and

- The physical impact of climate change and the related "uncertainties" (e.g., the traditional diet of some Arctic indigenous peoples is in a danger).

Another important factor as regards to Arctic security relates to the fact that there are several types of security, and "Northern security" (or securities) is potentially impacted by all of them. On the one hand, these numerous types of security are closely related to each other while, on the other, they are intertwined with both regional and global issues. Arguably, most worldwide global problems, or threats, which impact the Circumpolar North - either by being physically present in the region, (e.g., the case of nuclear weapons, and long-range air and water pollution), or through various indirect impacts (e.g., the scarcity of resources, climate change) deal with security and include a security aspect. This chapter further explores some of these types.

\subsection{Environmental Security in the Arctic}

"Environmental security" is intertwined with the environment and environmental issues, such as nature protection (e.g., Dalby 2002). Environmental degradation has impacted the Arctic region for decades. However, its threat was only really recognised and understood as late as the 1980s, mainly due to the clear impact long-range air and water pollution from southern latitudes began to have on the northernmost latitudes. The most notable examples here include: persistent organic pollutants (POPs), air pollution and mercury, radioactivity in some parts of the Arctic, and the phenomenon of Arctic haze. For instance, DDT and PCB as POPs were transported as long-range contaminants from the agricultural and industrialised areas in the mid-latitudes of Europe and North America to the 
Arctic by sea currents and air masses (AMAP 2002). Furthermore, the impacts of long-range air and water pollution, and nuclear safety, became the first reason for environmental concern among Northerners as well as the first indicator of the existence of acute global environmental problems in the highest latitudes of the globe (Heininen 2013). All of this also indicated that environmental or ecological security was becoming increasingly relevant to the general welfare of the Arctic.

Clearly, the notions of security and the environment share a number of vital interrelations. For example, because of the multi-functional environmental impacts of the military in peacetime, one can define the following main aspects of environmental security (see: Galtung 1982; Westing 1989; Heininen 1994):

- Use of strategic minerals (i.e., copper, lead), of energy (i.e., oil as fuel), of land, water and air (for bases, infrastructure, patrolling and exercises), of intellectual resources, and of toxics, chemicals, and radioactive materials;

- Pollution and $\mathrm{CO}^{2}$ emissions;

- Nuclear and other accidents; and

- Implications of disarmament (e.g., pressures on the environment due to the destruction of a chemical weapon etc.).

Regardless of military activities, other aspects of environmental security in the Arctic are related to the exploitation of (non-renewable) natural resources (e.g., oil and natural gas) via activities such as: mining and oil drilling, industrial activities, transportation and traffic, the settlements and infrastructure. Moreover, real environmental concern exists over the possibility of future oil spills as a result of, for example, the growing transportation of heavy oil and liquid gas (LNG) from the Barents Sea area to Central and Southern Europe and North America, in addition to the potential consequences of other intensive sea traffic issues.

Furthermore, at the turn of the century nuclear safety became a symbol or metaphor of the new brand of international cooperation on the Arctic environment and environmental protection, even influencing the security discourse among the Arctic States (e.g., Heininen \& Segerståhl 2002). This was prompted by the problem of radioactivity in the Arctic, 
particularly in the Barents Sea region. Since the 1990s this trans-national problem had arisen as a result of several events (i.e., dumped nuclear waste and nuclear tests in the region; the leaking UK nuclear power station (Sellafield) on the coast of the Irish Sea). In addition other problematic spots also require further measures (e.g., Andreeva Bay storage facility for radioactive waste-nuclear fuel from the Northern Fleet in Russia). Due to this, nuclear safety, i.e., issues relating to nuclear waste, spent fuel and nuclear weapons and plants, became an urgent item on the political agenda of the Arctic States. To date, the issue has mostly been kept under control, but because of its complexity and multi-functional impacts on both humans and the environment, it will likely remain an important matter for Arctic environmental security for the foreseeable future.

Another important aspect of security in the Arctic deals with climatic change and its physical impacts in, and beyond, the region (e.g., ACIA 2004). It already threatens the security of many Northern peoples and individuals in the Arctic and beyond, and there is no doubt that climate change has (had) a special influence on re-defining Northern security, as well as on the state of security in the Arctic. It is also manifested in why it was so relevant to (re)define security and to promote the concept of comprehensive security (Heininen 2010). In particular it reveals that the main reason behind this concept relates to our concern with the environment and nature as essential prerequisites for human existence.

Over the course of the past two decades numerous studies and the record of ongoing cooperation among Arctic indigenous peoples on climate change issues have revealed several impacts on Northerners and their livelihoods with regards to security (i.e., food security, fishing, hunting, reindeer herding - ability to maintain traditional ways of life, etc.). The environmental security concerns of Northerners have in addition been raised with regards to POPs and other matters.

Thus, there is clearly now growing concern on the part of Arctic indigenous peoples over environmental issues perhaps encapsulated in a rising environmental "consciousness" primarily targeted against the modern socio-economic development, related in particular to uncontrolled industrialisation and urbanisation, and the consequent degradation of the environment, and increasing vulnerability to natural and technological 
hazards, unsustainable natural resource extraction as well as the related political issues of instability and social unrest.

All in all, concern with the state of the environment is both natural and essential to the survival of Northern indigenous peoples and other Northerners. The current state of the Arctic ecosystem with all the pollution and various other risks and threats, such as climate change, provides a concrete example of environmental security in general. In particular, it shows how important it can be to the region and its people(s). All of this also illustrates how closely environmental and human security are connected. Thus, this chapter will now seek to further explore the basic features of human security in the Arctic.

\subsection{Human Security in the Arctic}

The concept of "human security" focuses on individuals and their everyday security needs rather than on a nation or society as a whole. Here individuals are the subject of security. The implementation of comprehensive security includes a reference to the practical issues impacting a human beings' life, such as ensuring good health and social and economic wellbeing as well as the ability to live ones' life in peace without interruption from conflict, war or violence. Thus, it entails the everyday security of ordinary people which is affected by traffic pollution or other kinds of environmental degradation; industry or other large-scale processes utilising natural resources, poverty, hunger, thirst, or personal violence, and, more recently, by the physical impacts of climate change or other rapid environmental changes. On the other hand, comprehensive security also includes more immaterial values like political freedom, democracy, human rights, and freedom from a range of threats and risks, such as disasters, pollution and other environmental problems, hunger and starvation, diseases or other illness, and terrorism. It can also be interpreted to include cultural survival, freedom of expression and security of communication (e.g., Poverty\&Environmental Times 2004, 6). Thus, human security also includes the linkage to human rights. Broadly speaking, human beings have the need to be made to feel secure in their everyday lives.

Indeed, here human beings are the subjects of security. Furthermore, human security is a widened concept of security understood as freedom 
from fear, freedom from want and can be interpreted to address categories of security, such as economic, health, food, personal, political, community, and environmental (e.g., Hoogensen et al. 2009). Due to the fact that human security has also influenced discourse in Arctic research for example in the context of climate change, or with regards to oil and gas drilling - it has been interpreted by many as a component of Northern security. In the early1990s the idea of the good polity of citizens meaning some sort of "community" and the concept of "civil security" as per Griffiths (1993) emerged to emphasise human beings as citizens with their intrinsic rights and duties.

Broad concepts of security are not just theoretical or academic as these concepts are now widely accepted both in national and international contexts and used by many political actors. For example, this approach was adopted by the Canadian Government in the 1990s (Dwivedi et al. 2001), while the concept of "human security" was popularised through the United Nations Human Development Report (UNHDR) again, in the 1990s. In general the UN has provided an important international platform for the discourse on human security. The work undertaken to define human security by the UNHDR was continued by the UN in its Human Security Resolution 1325 (UN Security Council 2000) on gender equality, among other things the resolution declares the need "to protect women and girls from gender-based violence [...] in situations of armed conflict." Further, it is already practice in several, though not all, parts of the globe.

One aspect of human security is, as noted previously, "food security", which can entail a scarcity of traditional dietary and food staples. It has been documented by many studies (e.g., Paci et al. 2004) that climatic changes in the Arctic have a direct impact on the availability of food staples and thus affect the traditional dietary arrangements of indigenous peoples. This in turn has raised concerns over food security - safety, primarily relating to potential access to traditional means of subsistence such as hunting and fishing in some Arctic areas (e.g., Canada's Arctic) and the ability of indigenous peoples to maintain their traditional livelihood and practices. This also led to uncertainty regarding the future of these practices. Each of these issues precipitated changes with regards to adaptation to climate change, as it may be too late to mitigate its consequences in most instances. Those adaptation measures are currently manifested in 
various strategies based on resilience and the usage of traditional and local knowledge.

The questions raised by climate change thus not only concern the environment and environmental security but also the impacts of high rates of anticipated warming on natural systems and human communities (e.g., IPCC 2007). Moreover, the uncertainty associated with climate change is, as Gleditsch (2008) puts it, one of the most serious effects people(s) and society(s) face, and all of this fundamentally impacts their everyday (human) security. As has already been noted, this has a direct impact on the Arctic. Furthermore, one can draw connections between human security and civil security which is intertwined with food safety and supply.

In sum, climate change already challenges and indeed threatens the security of many Northern peoples as well as the stability of Northern settlements. In specific terms it poses major risks to coastal communities (e.g., Shishmaref community in Alaska). Therefore, climate change with its physical impacts and the associated levels of uncertainty it produces, has become an important security issue and thus a significant day-to-day factor in the lives of Northern peoples, and thus of the Arctic States.

\subsection{Energy Security in the Arctic}

"Energy security" is an important and developing issue in the Arctic. In terms of general comprehensive definitions, energy security includes not only security of supply, but also security of investment, as well as of the environment, and energy cooperation or dialogue. In the Arctic, energy security has a growing strategic importance for the national interests of a state in ensuring its access to energy resources; it also plays a key role in foreign policy as well as in the economics of a state.

Arctic energy security has become a highly political and strategic issue as, according to rough estimations, a significant share of the world's undiscovered oil and natural gas are located north of the Arctic Circle, mainly in the shelf of the Arctic Ocean. The potential for new found riches of the High North is then the major driving force in the littoral states' desire to seek extensions to their continental shelves. Although this is totally in accordance with UNCLOS rules, as the Russian expedition to the bottom of 
the North Pole in August 2007 confirmed, in the media, it has been editorialised as constituting a "race" for energy resources and thus the potential incubator of emerging conflicts (e.g., Beary 2008).

This alone does not justify the strategic position given to energy security in the Arctic. One additional factor is required to confirm the importance of energy security in the region and this is what is generally termed, the "Arctic paradox" (e.g., Palosaari 2012). Accordingly, climate change has acted here like a trigger to increase the utilisation of natural resources and made the potential energy resources of the shelves of the Arctic Ocean strategically important. Therefore, in relation to Arctic energy security climate change can be viewed as a more important factor than the scarcity of conventional oil.

All in all, energy security has become a significant new factor in the rising strategic importance of the Arctic in world politics and in the increasingly globalised world economy due to the rich energy resources of, or options to harvest them within, the region, particularly those of Norway, Russia and the United States. In addition to the routine defence of national security and state sovereignty, these Arctic States have taken on the responsibility to protect strategic energy resources, such as oil and natural gas deposits, and ensure their safe transportation. Furthermore, these states are ready to guarantee energy security by the military means, if necessary. This is in line with the traditional viewpoint of Realpolitik, and that of classical Geopolitics, emphasising state hegemony and national interests, such as state sovereignty, economic welfare and prosperity and traditional, national security. As such, we will now turn to a discussion of traditional security.

\subsection{Traditional Security in the Arctic}

"Traditional security" generally means weapon-oriented, unilateral and national military security (see: Newcombe 1986), where a state is the subject of security. This means that security, or peace, is guaranteed by the military, or by military deterrence. Further, the pursuit of national security is taken as a guarantee of state sovereignty and thus national security does not have a price. 
The military aspect of national security includes all aspects of normal national defence and routine patrolling (e.g., activities of strategic nuclear submarines, SSBNs and long-range strategic bombers), testing of weapons/weapon systems, deployment of weapon systems, radar stations and forces, the training of and military exercises performed by troops. It also includes the whole nuclear weapon system (e.g., permanent weapons such as testing, land-based deployment, bases for ships and aircraft, and storage; transit - ships, aircraft, port calls and staging by aircraft; weaponsrelated involvement - missile testing, surveillance/communication, and uranium; non-weapon involvement - dumping, storage, provision, and nuclear energy) and its implementations.

In the Arctic context, traditional security means several things. Currently, there is no military tension in the Arctic, however, the region continues to host important military structures and armies, especially the nuclear weapons system of the USA, and that of the Russian Federation. It is also a strategic area for the testing of new weapons and arms systems. As noted previously, NATO is still present in the High North and in addition to its traditional role as a transatlantic organisation for collective defence, it has recently expressed more interest in the Arctic region.

As such, a complex continuity of high military-political importance exists. While in some parts of the Arctic military bases and radar stations have been closed and activities concluded or decreased, in other parts military areas have been extended and new areas are being used by the military such as, for example, on land in Alaska, Northern Greenland and the Kola Peninsula and in marine areas in the Barents Sea and the Arctic Ocean. All in all, the military presence in the region, either for routine military defence, control of national borders and the enforcing of sovereignty or for global and strategic military hegemony through the deployment of nuclear weapon systems, consists of several kinds of military structures, functions and activities (Heininen 2010).

Based on SIPRI's detailed study of "Military Capabilities in the Arctic" (Wezeman 2012) the following military structures can be found in the Arctic:

- Military structures for defence, patrolling, guarding (e.g., Coast Guards, SSBNs); surveillance, monitoring (e.g., radars, satellites), for attack (e.g., combat aircraft, nuclear attack submarines, SSNs); 
- Military exercises (e.g., Northern Edge/ Alaska Shield Exercise, Norwegian-Russian joint exercises, etc.), weapon's and strategy testing, and military and cold weather training;

- The command, control, communications and intelligence, or C3I, systems including radars, satellites and other surveillance systems (e.g., the North-American Air Defence system - NORAD, The US radar base in Thule, Greenland; and the US National Missile Defence system NMD), and reconnaissance aircraft;

- The nuclear weapon systems of Russia and the USA, including strategic nuclear-powered submarines (e.g., older Russian SSBNs are being modernised and new ones already have this equipment and can operate under sea ice), attack submarines (e.g., most of US ones are able to operate under the sea ice).

The testing of new weapons, arms systems and military applications, military training and exercises in the Arctic has, in addition, become a vital function of the military. Arguably, this is a result of the political attitude which suggests that the conduct of such activities is technically more suitable in these sparsely-populated "empty" northern areas. Moreover, as noted previously, this occurs despite the fact that such activities have implications for the fragile Arctic ecosystem and may cause environmental pollution, thus, clearly, threatening both environmental and human security.

The Arctic States have, however, undertaken only a limited modernisation of their military equipment, and adjustments to their force levels and structures (Wezeman 2012). Despite a lack of real nuclear disarmament in the region, and the fact that the Arctic is becoming more accessible, these changes in military capabilities have little, if nothing, to do with any potential, or claimed, power projection into the Arctic. In reality they much more readily reflect a significant change of power in global balance. The defence of national security and sovereignty has, however, due to climate change become a sensitive issue to some Arctic States (e.g., Canada's Northwest Passage; Russia's Northern Sea Route).

Moreover, climate change has already been interpreted as a potential threat to national sovereignty, and thus become a relevant security factor from the point of view of traditional security, in sparsely-populated Arctic areas. Furthermore, in the traditional national security terms climate 
change plays a dualistic role because, on the one hand, it makes it easier to gain access to the icy northern seas thus helping to potentially increase the utilisation of natural resources and their transportation. While on the other, it acts like a trigger, or it is used as an excuse, for the militarisation of the area, or for new national claims to expand the right to utilise natural resources. Consequently, the littoral states of the Arctic Ocean, as well as NATO, have become more interested in non-military aspects of security of the Arctic. This is unlikely, however, to precipitate an armed race for Arctic riches. One consequence of this is that sometime in the future, the issue may become a traditional security issue demanding traditional answers, such as more military defence. Although it has been shown that climate change security is rooted in issues of both environmental and human security, it remains important to re-define the security dimension of climate change and to emphasise its global factor in the promotion of stability.

The military presence in the Arctic, which is primarily due to the legacy and "militarisation" of the Cold War period, thus remains in place. There are no imminent military security threats in the foreseeable future, but a "new" threat such as climate change has been taken into consideration in the theoretical discourse, and new points of view and premises added to that of traditional security. Interesting enough, the nuclear safety issue has already prompted a change in the definitions used in security discourse(s) and with climate change discourse having the potential to do the same.

\subsection{Conclusion}

Many global problems broadly relating to security issues can be witnessed in the Arctic (e.g., nuclear weapon systems, radar and missile defence systems, climate change, long-range pollution, ozone depletion, etc.). As has been shown above, despite the fact that the general definition of security can be employed in the Arctic region, Northern security nevertheless has its own specific additional features which are reflective of Northern particularities. The evolution of Northern security has been gradually developing and has witnessed major changes since the end of the Cold War seeing numerous new developments over the past two decades. As a result, the shift from "confrontation" to stability and institutionalised 
peaceful cooperation has also had a significant influence on the general state of security in the region. The Arctic, as of 2013, is then highly stable and is based on a well-established process of institutionalised international cooperation. No indications currently exist of rising tensions which are likely to be translated into armed conflict or other serious internal security issues. In conclusion, since the end of the Cold War Northern security has become more comprehensive and complex primarily through the inclusion of its aforementioned environmental and human aspects.

\section{References and further reading}

ACIA, Impacts of a warming Arctic: Arctic Climate Impact Assessment. (Cambridge: Cambridge University Press, 2004).

AMAP, Arctic Pollution. (Oslo: Arctic Monitoring and Assessment Program, 2002).

Bailes, Alyson J.K. \& Cottey, A. "Regional Security Cooperation in the Early 21st century." SIPRI Yearbook 2006: Armaments, Disarmament and International Security. (Solna: SIPRI, 2006).

Beary, B. "Race for the Arctic. Who Owns the Region's Undiscovered Oil and Gas?," Global Researcher. Exploring International Perspectives, (2008)2(8): 213-242. www.GLOBALRESEARCHER.COM

Buzan, Barry. People, States and Fear: An Agenda for International Security Studies in the Post-Cold War Era. (Hertfordshire: Harvester Wheatsheaf, 2nd ed., 1991).

Dalby, Simon. Environmental Security. Borderlines, (Minneapolis: University of Minnesota Press, 2002).

Deudney, D.H. “Environmental Security. A Critique." Deudney, D.H. \& R.A. Matthew (eds.), Contested Grounds. Security and Conflict in the New Environmental Politics. (Albany: State University of New York Press, 1999).

Dwivedi, O.P. et al. Sustainable Development and Canada- National \& International Perspectives,(Ottawa: Broadview Press, 2011).

Galtung, Johan. Environment, Development and Military Activity. Towards Alternative Security Doctrines. (Oslo-Bergen-Trondheim: Universitetsforlaget, 1982).

Gleditsch, Nils Peter. "The Liberal Moment Fifteen Years On." International Studies Quarterly (2008)52 (4): 691-712.

Griffiths, Franklyn. "Defence, Security and Civility in the Arctic Region." The Nordic Council's Arctic Conference, Reykjavik, 1993. (University of Toronto, 18 June 1993).

Heininen, Lassi. "Politicisation" of the Environment: Environmental Politics and Security in the Circumpolar North." Barry Zellen (ed.), Anthology on Arctic Security. (Calgary: University of Calgary Press, 2013).

Heininen, Lassi. "Globalisation and Security in the Circumpolar North." In Lassi Heininen \& Chris Southcott (eds.), Globalisation and the Circumpolar North. (Fairbanks: University of Alaska Press, 2010):227-252. 
Heininen, Lassi. "The Military and the Environment: An Arctic Case." In Jyrki Käkönen (ed.), Green Security or Militarised Environment. (Brookfield, VT: Dartmouth Publishing Company, 1994):153-165.

Heininen, Lassi \& Segerståhl, Boris. "International Negotiations Aiming at a Reduction of Nuclear Risks in the Barents Sea Region," Rudolf Avenhaus, Victor Kremenyuk \& Gunnar Sjöstedt (eds.), Containing the Atom. International Negotiations on Nuclear Security and Safety. (Lanham, MD: Lexington Books, 2002): 243-270.

Hoogensen, Gunhild., D. R. Bazely, et al. "Human Security in the Arctic - yes, it is relevant!" Journal of Human Security (2009) 5(2):1-10.

IPCC (2007). “Climate Change 2007” Synthesis Report. Summary for Policymakers. Intergovernmental Panel on Climate Change.

Newcombe, Hanna. "Collective Security. Common Security and Alternative Security: A Conceptual Comparison," Peace Research Reviews (1986)10(3), 1-8 \& 95-99.

Paci, James et al. "Food Security of Northern Indigenous Peoples in a Time of Uncertainly." The Resilient North - Human Responses to Global Change. Proceedings of the Third Northern Research Forum Open Meeting, Yellowknife, NWT, Canada, 15-18 September 2004. http://www.nrf.is/Publications/The\%20Resilient\%20North/Plenary\%204/3rd \%20NRF_Plenary\%204_PP_Paci\%20et\%20al.pdf, accessed 27 February 2013.

Palosaari, Teemu. “The Amazing Race.” Nordia Geographical Publications, Volume 40:4. NGP Yearbook 2011 "Sustainable Development in the Arctic Region though Peace and Stability." (Tornio: The Geographical Society of Northern Finland \& The Department of Geography, University of Oulu, 2012):13-29.

Poverty \& Environmental Times. A periodic publication by UNEP/GRID-Arendal, No. 2, March 2004.

United Nations Security Council. Resolution 1325 (2000) adopted by the Security Council at its $4213^{\text {th }}$ meeting, on 31 October 2000 .

Westing, Arthur. "The Environmental Component of Comprehensive Security." Bulletin of Peace Proposals, (1989)20(2):129-134.

Wezeman, Siemon T. Military Capabilities in the Arctic. (Solna: SIPRI Background Paper, March 2012).

\section{Questions}

- How do you see the future of Northern security developing, and are there any emerging issues or new challenges on the horizon?

- What types of security are relevant to the Arctic region, or can be considered for further studies?

- What is the role of a security institution, if any? 



\section{The Agreement on Cooperation on Aeronautical and Maritime Search and Rescue in the Arctic - A New Chapter in Polar Law}

Anton Vasiliev

\subsection{Introduction}

Recent political, technological and climatic changes have transformed the perception of the Arctic region, within its boundaries and beyond, from the traditional view - of an unreachable and almost unliveable corner of the world - to the new understanding - which sees it as an area of innovative progress and as a land of huge opportunities. Technological progress has allowed reaching out for something that was previously unthinkable while climate change and the continuous and rapid thawing of the Arctic sea ice are making Arctic mineral resources and shipping routes more accessible. The economic development of the Arctic is now occurring and presents enormous possibilities, attracting human, fiscal and business capital to the region. This development is focused essentially on the exploration and extraction of oil and gas. For example, industrial drilling on the Arctic continental shelf starts on the Prirazlomnoe and the Goliath oil rigs in the Russian and Norwegian parts of the Barents Sea in 2013. Substantial developments in Arctic tourism can also be seen (e.g., cross-polar air flights, cruise tours, and trips to the North Pole), as well as developments in navigation mainly in relation to the Northern Sea Route which has seen 
a significant increase in international transit shipping. The expansion of economic activity in the Arctic brings a greater human presence which entails growing risks to peoples and their livelihood in the still extremely harsh natural conditions of the High North with its low temperatures, periods of darkness, ice, permafrost, etc.

These newly emerging Arctic realities suggest an increasing need for collaboration between the various relevant stakeholders across a variety of issues. That is why, in parallel with the developments outlined above, we are also witnessing a substantial expansion of cooperation between the Arctic States and the increasing role of the Arctic institutions among which the Arctic Council plays a key and ever growing role since its inception in 1996. One of the primary dimensions of the Council's work focuses on issues of emergency prevention, preparedness and response (EPPR) in the Arctic. Thus, this chapter looks at the evolution of the Council's work, initiatives and outcomes in this area. More specifically, it looks at the development of the pioneering and first-ever binding agreement prepared under the aegis of the Arctic Council, namely, the Agreement on Cooperation on Aeronautical and Maritime Search and Rescue in the Arctic (SAR) which came into existence in May 2011. I served as a Co-chair of the Arctic Council Task Force on SAR from 2010-2011, however, the views expressed here do not necessarily reflect the position of the Arctic Council and, as such, should be viewed as personal based on my own experience and understanding of this issue.

\subsection{The Arctic Council and its Agenda on EPPR}

As ensuring the safety and security of its citizens is one of the basic functions of any state, cooperation in the prevention of and in combating emergencies has become, since its establishment, one of the highlights of the Arctic Council's agenda. It is no accident that one of the specialised working groups of the Arctic Council became the "EPPR"- a group responsible for the issues of emergency prevention, preparedness and response. This group was actually established even earlier than the Council, in 1991, within the framework of the Arctic Environmental Protection Strategy forum, which preceded the creation of the Arctic Council. From the outset, 
the EPPR was engaged in many projects, driven by justified expectations that increased international cooperation between the Arctic States could to a certain extent compensate for the deficiencies in the relevant national capabilities and that the sharing of relevant information could be beneficial for all. The EPPR succeeded in undertaking many projects and gained a lot of important and positive experience. Although the output of the EPPR was limited to scientific studies, the accumulation of best practices and producing non-binding recommendations, it was in this group where the idea of not only theoretical, but also practical and multilateral cooperation in search and rescue (SAR) and, more generally, in fighting emergencies in the Arctic, was first discussed.

\subsection{The Development of the SAR Instrument Proposal}

These Arctic Council discussions culminated in the emergence of several initiatives from the Arctic States and other interested stakeholders. For example, the Russian Federation was the first to formulate a concrete proposal to work out an agreement in this field, initially tabled within the Barents Euro-Arctic Council (BEAC) in 2003, and in 2004 in the Arctic Council. The negotiations within the BEAC ultimately resulted in the elaboration and signing in 2008 in Moscow of the Agreement between the governments in the Barents Euro-Arctic Region (Denmark, Finland, Iceland, Norway, the Russian Federation, Sweden and the European Commission) on Cooperation within the Field of Emergency Prevention, Preparedness and Response. ${ }^{2}$

Despite this positive development within the Arctic Council the proposal did not win immediate consensus support, although it did became "food for thought" in the capitals of the Council's Member States. Meanwhile, the Arctic Council began work on a more global framework project led by the Russian Federation and Norway - "Safety systems in implemen-

\footnotetext{
2 http://www.barentsinfo.fi/beac/docs/Agreement_Emergency_Prevention_Preparedness_and_ Response_English.pdf
} 
tation of economic and infrastructural projects in the Arctic." This project was adopted at the Council's Ministerial meeting in Tromsø in April 2009, which noted its comprehensive character and importance in minimising the risks of increased human activity. This project provided a general framework for movement towards the construction of a future regionwide collaborative safety system able to manage and counter all kinds of man-made catastrophes and other emergencies. Its discussion in an Arctic Council context stimulated further consideration in the national capitals, which resulted in a formal proposal by the USA in the Arctic Council to start negotiations on the SAR instrument. This proposal was also adopted by the Troms $\varnothing$ Ministerial meeting which approved the formation of a task force authorised to develop and finalise negotiations on an international instrument on collaboration on Arctic search and rescue operations by the 2011 Ministerial meeting of the Council.

\subsection{The SAR Instrument Task Force and its Work}

In conformity with its mandate, the Arctic Council SAR Instrument Task Force was initiated in December 2009. The group consisted of around 60 participants. The Russian Federation and the USA co-chaired the negotiations held within this Task Force. Being its Russian co-chair, I would like to pay tribute to the professionalism and dedication demonstrated throughout the negotiations by my distinguished Task Force co-chair, Ambassador David Balton from the US State Department. It is also evident that the negotiations would not have led to a meaningful conclusion without the interested and creative work undertaken by all of the Arctic Council member state delegations - Canada, Kingdom of Denmark, Finland, Iceland, Norway, the Russian Federation, Sweden, and the United States of America. The delegations were comprised of representatives from various relevant national ministries and agencies - defence, transport, national security, emergencies, coast guards and others. Representatives from the Arctic Council's "Permanent Participants" - associations of indigenous peoples of the North - were invited to all rounds of the talks; although they were not able to attend (the negotiators were the governmental delegations, representing the relevant institutions with direct responsibili- 
ties and capacities for SAR operations). The negotiations enjoyed the close attention of the Danish chairmanship of the Arctic Council 2009-2011, including the Chair of Senior Arctic Officials, Ambassador Lars Møller. Cochairs have also regularly briefed the Council on the intermediary outcomes of the Task Force's endeavours.

The negotiations required five full Task Force sessions. These meetings were held in 2009-2010 in Washington, Moscow, Oslo, Helsinki and Reykjavik respectively with the kind sponsorship of the governments of the host countries. In order to facilitate the final "polishing" of the agreed text teleconferences were organised. In accordance with the principles of the Arctic Council, all issues arising in the context of the negotiations were resolved by consensus. The negotiations represented a process of very intensive and detailed discussion. The working atmosphere was businesslike, friendly and constructive. All were united by a common task and in the end it was fulfilled right on time. In my judgment, this inaugural negotiation process between all the Arctic States per se will be conducive to the further strengthening of mutual understanding, trust and cooperation in the Arctic. It was a significant and a useful experience.

\subsection{Key Features of the SAR Agreement}

The issue of the legal nature of the instrument was actively debated at the first three sessions. The reasoning of those who advocated a legally binding instrument, rather than a politically binding memorandum of understanding or declaration, ultimately prevailed, which immediately added importance to the negotiation process. Its product became an Agreement on Cooperation on Aeronautical and Maritime Search and Rescue in the Arctic, signed in Nuuk, Greenland, 12 May 2011.

As has been emphasised in its Article 2, "The objective of this Agreement is to strengthen aeronautical and maritime search and rescue co-operation and coordination in the Arctic." In essence, the Agreement is about better regional cooperation and coordination in extending free help to people in distress in the Arctic, irrespective of who they are, how they got there and what they were doing. The Agreement does not however deal with the issue of salvage in relation to ships, aircraft or other hardware - though this could 
become an area of cooperation and the subject of subsequent agreements. The focus of the SAR Agreement is thus placed firmly on saving people caught in distress in the Arctic.

The Agreement is based on the existing and valid universal international documents, namely, the 1979 International Convention on Maritime Search and Rescue (SAR Convention), the 1944 Convention on International Civil Aviation (Chicago Convention), and the International Aeronautical and Maritime Search and Rescue Manual (IAMSAR Manual, published by IMO and the International Civil Aviation Organisation), which the Arctic States will continue to comply with. All principles, mechanisms, rights and obligations provided in these documents shall be fully respected and implemented.

The same understanding applies to the existing bilateral and multilateral agreements and memorandums (e.g., Agreement between the Government of the Russian Federation and the Government of the Kingdom of Sweden on cooperation in maritime and aeronautical search and rescue in the Baltic Sea; Agreement between the Government of the Kingdom of Norway and the Government of the Russian Federation concerning cooperation on searches for missing persons and the rescue of persons in distress in the Barents Sea; Memorandum of Understanding for Cooperation between Canada, the United States and the United Kingdom concerning search and rescue; Agreement by and between the Government of the Finnish Republic and the Government of the Russian Federation about cooperation to avert disasters and to prevent their consequences; Agreement between the Government of the republic of Finland and the Government of the Russian Federation regarding cooperation in respect of maritime and aeronautical search and rescue; Agreement between the Government of the Republic of Finland and the Government of the Kingdom of Sweden regarding cooperation in respect of maritime and aeronautical search and rescue; Search and Rescue Agreement between Commander, Canadian Maritime Forces Pacific, and Commander, Seventeenth Coast Guard District United States Coast Guard, Juneau, Alaska; Agreement between Denmark, Finland, Norway and Sweden on cross-border collaboration with the aim of preventing or limiting personal injury and damage to property or the environment; Operational Agreement between the Swedish and the Danish aeronautical and maritime search and rescue services; Operational Agreement between the Swedish and Norwegian authorities, responsible for aeronautical and maritime search and rescue; Agreement between the 
Government of the United States of America and the Government of the Union of Soviet Socialist Republics on maritime search and rescue; Agreement between the Government of the Kingdom of Denmark and the Government of the Kingdom of Sweden concerning cooperation in respect of aeronautical and maritime search and rescue; Agreement between the Government of the Kingdom of Sweden and the Government of the Kingdom of Norway concerning cooperation in respect of aeronautical and maritime search and rescue; Agreement between the Governments in the Barents Euro-Arctic region on cooperation within the field of emergency prevention, preparedness and response, and others), although the 2011 pan-Arctic SAR Agreement will take precedence over them.

The text of the Agreement incorporates a preamble, 20 articles and one annex. The Agreement also has three appendices attached to it. While the Agreement builds on the existing international instruments, it does not simply reproduce their contents as applied to the Arctic, but rather has significant added value.

\subsection{Key Provisions of the SAR Agreement}

First, as a result of long negotiations, the parties to the Agreement (i.e., the governments of the 8 Arctic States) have established their distinct zones of responsibility as per this Agreement, named "search and rescue regions." The description of the geographical scope of the Agreement for each party is provided in the Annex to the Agreement, which is an integral part of the agreement and is thus legally binding. The flight information zone borders of the Chicago Convention were taken as a basis for the relevant division lines between the SAR zones of responsibility. However, some division lines were adjusted and agreed bilaterally during separate consultations in the Task Force and were subsequently corrected by the International Civil Aviation Organization (ICAO) as the new flight information zone borders. Experts from ICAO took part in several rounds of negotiations and were instrumental in providing the Task Force with updated technical information. As regards the southern limits of the zones of responsibility, each country took its own decision. The Agreement clearly states that the delimitation of search and rescue regions is not related to 
and shall not prejudice the delimitation of any boundary between States or their sovereignty, sovereign rights or jurisdiction. Such delimitations are made and applied exclusively for the purposes of this Agreement.

The clarification of the SAR regions (responsibility zones) of the parties has practical significance, eliminating grounds for possible misjudgements on whose responsibility it is to initiate and coordinate the SAR operation. This also takes away any grounds for possible misinterpretation of the situation, the division of labour or the distribution of roles between the states and their relevant agencies thus also facilitating quicker search and rescue. These provisions are of the utmost importance as when you are saving people's lives time is everything. An illustrative map of the geographical zone of application of the Agreement was prepared, but it was not made a part of the agreement and serves only for explicative purposes.

Secondly, the parties have clarified which specific agencies in their own countries are responsible for different aspects of SAR operations and other activities, proceeding from the premise that a three-layered command system is in place everywhere. This command system includes:

- Competent authorities;

- Agencies responsible for SAR operations;

- Rescue coordination centres.

These specific agencies are listed in the appendices to the agreement which are of an informative nature only and thus are not legally binding. Any party can unilaterally adjust/update this information on its relevant agencies and inform the other parties about the changes in the appendices through the depositary of the Agreement.

The "competent authorities" denote the political level in the SAR decision-making hierarchy, "agencies" are the governing units with either a territorial or a functional sphere of competence, and "rescue coordination centres" are the units which undertake the practical SAR work and possess the necessary equipment and personnel.

Such clarification is important in a practical sense because it reduces the need to engage in length inter-state communications at the onset of any new incident and clearly allocates responsibility to specifically named actors for all imaginable phases of the SAR activities, including SAR opera- 
tions. In practical terms this helps to identify all the addresses of the participants in respect of SAR activities and - where an incident does occur ensures that they can be reached immediately just by pressing one computer button, as everything is now pre-programmed.

Importantly, this clarification also had a positive feedback impact on the clarification of the division of labour in respect of SAR activities in the Arctic within some states because the existence of a large number of participating ministries, agencies and units did not generally allow for the creation of a streamlined and coherent SAR management system in countries where multiple agencies had emerged in this field.

Thirdly, the parties have introduced simplified regime for entry into each other's territory for search and rescue purposes, including for refuelling. Indeed, it has now become a legally binding obligation to use the most expeditious border crossing procedure possible for the SAR personnel and equipment of the other parties to the agreement for these ends. These provisions will also help to speed up the arrival of international assistance thus making SAR operations more efficient.

Fourthly, the parties have also reached agreement on a whole series of cooperation measures in relation to the implementation of the Agreement. They include, inter alia, the exchange of information (such as: communication details; information about search and rescue facilities; lists of available airfields and ports and their refuelling and resupply capabilities; knowledge of fuelling, supply and medical facilities; information useful for training search and rescue personnel); the exchange of experience; arranging exchange visits between search and rescue personnel; joint review of actual SAR operations; implementation of joint research and development initiatives; conducting regular communications checks and exercises, etc.). These measures enhance the level of preparedness of the personnel involved in possible SAR operations, simplify people-to-people contacts, raise the level of awareness of partner capacities and reinforce predictability in respect of practical actions in the course of SAR operations.

The Agreement provides for a mechanism to oversee its own implementation. All the relevant decisions shall be taken at the regular meeting of the parties. Possible disagreements on the application and/or interpretation of the Agreement are to be resolved through direct negotiations. 
These are the major areas where the Agreement constitutes a significant regional step forward compared to the established global legal regime on maritime and aeronautical search and rescue. But it also stipulates that the parties shall cooperate with non-Arctic States if they are able to contribute to the conduct of search and rescue operations. These nonparties shall be obliged to help in accordance with the basic international SAR conventions, although they will not enjoy those extra benefits which the Arctic States will provide to each other according to the Agreement.

\subsection{Importance of the SAR Agreement}

\subsubsection{Practical Significance}

The Agreement has both practical and political importance. In practical terms, it is supposed to decrease reaction times thus increase operational effectiveness. In so doing it also provides additional incentives for the further exploration and development of the Arctic.

The Agreement shall be implemented upon its entry into force; the agreement has come into force in January 2013. Importantly, even before the formal entry of the Agreement into force the member states began to implement it de facto. In September 2011, Canada - the depository of the Agreement - initiated the first table-top exercise, held in Whitehorse (Yukon), within the framework of the Agreement. All the Arctic States sent their SAR representatives to the exercise which explored a number of scenarios relating to vessel and airplane accidents in the Russian Arctic and the consequent multinational SAR operation. According to both organisers and participants these were very successful and useful exercises.

In September 2012 Denmark initiated the first field exercises within the framework of the Agreement, its scenario being a cruise ship accident in the Greenland Sea. This was also a really useful event. Both Canada's and Denmark's exercises have confirmed the strong interest of the Arctic States in SAR cooperation and the high practical value of the Agreement.

It should also be noted that from the outset of the process all of the participants exchanged information about their available SAR capacities in the Arctic and their actual use. The general picture in the region however remains 
patchy with national capacities remaining very limited and modest for the most part, although there are some exceptions. The implementation of the Agreement will undoubtedly encourage the more effective use of all available SAR resources through cooperation, but in reality this cannot substitute for efforts to enhance national SAR capabilities in the Arctic which should take priority. The Agreement itself does not contain any direct obligations on this issue, indeed, Article 12 states in this regard that "Implementation of this Agreement shall be subject to the availability of relevant resources."

Nevertheless, the discussion of the new Arctic realities and of the inevitable growth of risks in the Arctic that took place throughout the negotiation process will, hopefully, be conducive to the re-invigoration of national efforts in this regard. For example, after the signature of the Agreement in 2011 the Russian Federation took a domestic decision to establish, by 2015, ten new and well-equipped SAR monitoring and coordination stations (run by EMERCOM, the Russian Ministry of Emergencies) in various Arctic towns and ports spread evenly along the Northern Sea Route.

Interestingly, the limited SAR capabilities of the Arctic States could be enhanced by the military vessels, airplanes and other infrastructures located in the Arctic or in close proximity to it. But this was not discussed at the negotiations or reflected in the Agreement. Nevertheless, the possibility of military assistance to ensure the implementation of the Agreement and in relation to other emergency operations in the Arctic was one of the main topics of discussion at the first ever meeting of the Chiefs of Defence and senior military officials of the 8 Arctic States, held by Canada at Goose Bay Air Base (Labrador) in April 2012. No doubt, possible cooperation between the military will be a major additional asset in the practical implementation of the Agreement. In addition, SAR cooperation in the Arctic clearly also provided the impetus for multilateral cooperation between the region's militaries and highlights one of the important political implications of the Agreement.

\subsubsection{Political Importance of the SAR Agreement}

In addition to the points highlighted above, the main political value of the Agreement comes from the fact that this is the first ever legally binding document elaborated under the aegis of the Arctic Council and the first 
truly pan-Arctic legally binding document (the only other multilateral Arctic binding document, the 1973 Polar Bear Agreement, was signed by only five of the eight Arctic States - Canada, Denmark, Norway, the USA, and the USSR).

The signing of the SAR Agreement is a manifestation of the new level of trust and cooperation in the Arctic and further illustrates the ability of all Arctic States to agree among themselves and bear responsibility for the state of affairs in the Arctic. It is, of course, a major contribution to the Polar/Arctic law.

The Agreement lays out the ground-breaking precedent of a legally binding decision taken by the Arctic Council. Previously, all "products" of the Council were limited to declarations - political recommendations which, although they were agreed upon by the member states, were not legally binding. This Agreement is thus a clear step forward in the process of the gradual strengthening of the Arctic Council, the key multilateral institution in the Arctic.

\subsection{Conclusion}

The SAR Agreement opens up a new chapter in terms of Polar/Arctic law and charts the ongoing evolution of the Arctic Council. At the 2011 Ministerial Meeting of the Council in Nuuk, Greenland, important decisions on its strengthening were taken, including making more binding decisions, along with the establishment of its standing secretariat with its own budget, and the streamlining of the relationship between the Council and observers. In my mind, this is a step forward in the gradual transformation of the Arctic Council, which is currently only a "forum," albeit a high-level intergovernmental forum, into a full-fledged international organisation. However, as the Council's decisions are taken by consensus, this transformation may still require some time.

The signing of the Agreement has raised the level of expectations of the Arctic Council. As always, one success brings about the taste for more. Building on this successful experience, the Arctic Council has taken the decision to establish for the period of the Swedish chairmanship, in the period 2011-2013, a new Task Force to develop an international instru- 
ment on Arctic marine oil pollution preparedness and response, a no less important issue in respect of Arctic cooperation. Negotiations were apparently highly productive in this regard and it is expected that a new legally binding pan-Arctic agreement will be prepared and signed at the next Arctic Council ministerial meeting in May 2013. In this sense, the SAR Agreement has paved the way for other legally binding pan-Arctic instruments, which will build on it while using it as a precedent and as an intellectual and political foundation. In a broader sense, being itself a product of the "warming" of the political climate in the Arctic, it significantly raises the level of collaboration between all of the Arctic States.

The significance of the SAR Agreement goes far beyond its practical contents. In short, this is history made today. It will always be remembered as such, as a major step on a way to a new, peaceful, prosperous and safe Arctic.

\section{Further reading}

The Agreement on Cooperation on Aeronautical and Maritime Search and Rescue in the Arctic, 12 May 2011: www.arctic-council.org

\section{Questions}

- What are the key factors that contributed to the evolution of the Arctic Council and its willingness to move from traditional soft-law instruments towards legally-binding ones, e.g., the SAR Agreement?

- Does the SAR Agreement have a significant impact on general cooperation and the wider state of affairs in the Arctic?

- What are the other areas in which the Arctic Council could show further leadership and affirm itself as the primary institution for multilateral cooperation in the Arctic? 



\section{Polar Regimes Tackling Climate Change}

Timo Koivurova

\subsection{General Framework of Climate Regime in the Polar Regions}

Climate change as a global problem was first addressed in the context of the UN climate regime, which commenced with the adoption in 1992 and entry into force, in 1994, of the United Nations Framework Convention on Climate Change (UNFCCC). Given that this treaty, which commands almost universal support, lays out only very general climate change mitigation and adaptation duties for states, it was only natural that states negotiated a Protocol (Kyoto Protocol) to lay down binding emission reduction targets for the industrialised states in 1997 (entry into force in 2005). The first commitment period, within which industrialised states were expected to cut their greenhouse gas emissions, ran from 2008 to 2012.

It is still the UNFCCC and its Kyoto Protocol (including a vast number of conferences and meetings between the parties and where the decisions are taken detailing these rules) - the so called climate regime - that provides the framework under which any mitigation measures to tackle the problem of climate change are sought. The December 2012 climate regime meeting in Doha was able to agree on a second commitment period for some industrialised states, led by the European Union and Australia, but many others dropped out. Of the Arctic States, Russia did not join the second commitment period and Canada had already withdrawn from the Kyoto Protocol in 2011 while the United States had never been a party to it. Yet, perhaps the most important future decision achieved in the context of the climate regime was at the 2011 Durban Climate Conference where 
the states agreed to negotiate "a protocol, another legal instrument or an agreed outcome with legal force under the Convention applicable to all Parties." The formulation does not however make it clear what kind of a legal outcome the parties actually committed themselves to. The goal of this negotiation process is nevertheless to set binding emission reductions after 2020 for all parties - even industrialising countries and the United States. The principle of common but differentiated responsibilities thus seems to be gradually releasing its grip in the climate regime.

There is however no reason to celebrate this achievement as it seems likely that the world community will not be able to keep the rise in global temperature below two degrees, the figure which constitutes the accepted threshold that cannot be exceeded if the objective recorded in the UNFCCC, namely, the stabilisation of greenhouse gas concentrations in the atmosphere at a level that would prevent dangerous anthropogenic interference with the climate system (Article 2), is to be observed. Most scientific evaluations state that if we intend to keep the temperature rise below two degrees above pre-industrial levels, global emissions should be at their highest in 2015 decreasing steadily thereafter with the legal treaty entering into force as late as 2020.

Even if the Inter-governmental Panel on Climate Change (IPCC) is not formally a part of the climate regime, it has been the scientific data that the IPCC collects and synthesises that has influenced the course of the climate regime. In the most recent 2007 Inter-Governmental Panel assessment on Climate Change, both Polar Regions were deemed to be experiencing the ongoing impacts of climate change (as they were in the 2001 IPPC Assessment). The impacts on the Arctic are, however, much more pronounced. As numerous scientific studies have shown, climate in the region is an indicator of climate change worldwide. Moreover, climate change in the Arctic has been recognised for some time. Average temperature has risen twice as fast in the Arctic as those in the rest of the world. Of particular interest however is the rapidly receding and thinning Arctic Ocean sea ice, which demonstrates how quickly climate change is progressing - 2012 marked the lowest summer sea ice extent since satellite measurements began in 1979. The rise in temperature will moreover have overwhelming repercussions for the region's ecosystems though it will also render its economic potential more accessible. The retreat of the sea 
ice among other changes has however brought about opportunities for economic development and, in turn, prompted numerous studies on how the region's oil and other natural resources could be exploited, its tourism potential increased, and its navigational waterways utilised. The impacts of climate change to the Antarctic are less pronounced, even if there is clear evidence that Antarctica (especially the Antarctic Peninsula) and the Southern Ocean faces various impacts. Yet, as the IPCC 2007 report points out, changes in Antarctica are difficult to predict though they are likely to be of significant importance, given that in the long-term these processes have the potential to have an irreversible impact on ice sheets, global ocean circulation and sea-level rise, each of which potentially have both regional and global impacts.

This difference in the impact of climate change in respect of the Polar Regions is reflected in the way the two polar regimes have responded to the challenge of climate change. For example, the Arctic Council has come up with innovative ways of tackling climate change regionally while the Antarctic Treaty System (ATS) has seen less ambitious policy responses.

As Chaturvedi shows, there was a definite reluctance in Antarctic Treaty Consultative Meetings (ATCMs) to deal with climate change until the middle 2000s (starting gradually from 2004 onwards), even if IPCC Reports highlighted Antarctica as an area of special concern as early as 2001; climate change was dealt with under various agenda items, for instance, in the most recent ATCM in Hobart Australia 2012 it was addressed in the context of "Climate Change Implications for the Environment: Strategic approach." It was however the 2009 Climate Change and Environment Report prepared by the Scientific Committee on Antarctic Research (SCAR) that was instrumental in raising the profile of climate change at the ATCM's. The Antarctic Treaty Meeting of Experts on the impacts of climate change for the management and governance of the Antarctic region was held in Norway in April 2010 producing 30 recommendations for adoption by the XXXIII ATCM in Uruguay in May 2010; most of these recommendations were based on the SCAR report and had the effect of raising the profile of climate change in the ATS. Chaturvedi (2012:279) estimates that "climate change will be somewhere near the top of the agenda of future ATCMs", even if its current position is still fairly weak. 
Both polar regimes have, however, acknowledged the challenges climate change poses, in particular in the future. Moreover, they affirmed in their joint 2009 Washington Declaration that scientific information from the Polar Regions should feed into our overall understanding of climate science, with the findings produced in the context of the IPCC seen as particularly relevant. As the Arctic Council has already made a real effort to address climate change, it will be useful in the remainder of this chapter to focus on its efforts to influence the mitigation of climate change and the adaptation efforts undertaken to combat its impacts. It will, moreover, be important here to examine the ways in which this soft-law based and inter-governmental regional body has been able to function in a policy area that needs, primarily, to be tackled globally.

\subsection{Arctic Council and Climate Change}

Climate change presents a policy problem that requires concerted action across the whole of international society. All states and other stakeholders need to come up with a series of joint actions to reduce the emission of greenhouse gases, given that all of them contribute their production (even if to varying degrees), and climate change will impact us all. This does not mean that the biggest greenhouse gas emitters should not shoulder most of the reduction measures. It is the principle of common but differentiated responsibilities that underlies the climate change regime (1992 UNFCCC, its 1997 Kyoto Protocol and all decisions and measures taken under the climate meetings), which functions as the main mechanism by which the international community tries to both curb greenhouse gas emissions and adapt to their inevitable consequences. This principle means that the industrialised states are obligated to take the lead in tackling climate change, while developing states need only take lesser measures (for instance, they do not have to commit to any binding emission reductions).

Moreover, even if climate change is a global problem, it does not mean that no one is legally responsible for its impacts, even if this may be difficult to establish. For example, the international Inuit Circumpolar Council - an indigenous NGO representing these Arctic peoples - in its 2005 petition to the Inter-American Commission on Human Rights tried to demon- 
strate that the United States has violated several of the human rights of the Inuit via its irresponsible climate policy. In a similar vein, Small Island states whose land is expected to inundate because of rising sea levels, have pondered various ways of litigating against the biggest greenhouse gas emitter states but none of this has, as yet, led to any action.

What then can an intergovernmental regional soft-law forum - such as the Arctic Council - do to contribute to the mitigation of climate change globally and to help in adapting to its consequences locally?

\subsubsection{Scientific Influence}

The scientific results of research on climate change will form the basis of the way in which it is tackled even if it is also true that the current climate regime has not been taking scientific results as seriously as it perhaps should have. It is science that has established that our globe is warming, and therefore that its climate has changed in numerous ways, it is therefore also science that we have to rely on (in large part) when deciding measures on climate change.

The Arctic Council has made its strongest impact on mitigation measures via sponsoring large-scale scientific assessments, starting with the 2004 Arctic Climate Impact Assessment (ACIA). It was the ACIA - an assessment conducted by 300 scientists and indigenous traditional knowledge experts - that established the Arctic as a barometer of climate change, a region where the average surface temperatures change (both past and in the future) twice as fast as in the rest of the world. ACIA also established climate change as a cross-cutting policy issue within the Council and was followed by many other relevant scientific assessments, such as the 2009 Arctic Marine Shipping Assessment (AMSA). From the viewpoint of climate change adaptation, the most important project so far is the Council's 2007 project on Vulnerability and Adaptation to Climate Change in the Arctic (VACCA), which focused on collecting and disseminating information on various adaptation measures taken in the Arctic.

More importantly, ACIA led also to specific projects highlighting the importance of the Arctic as part of the global climate system. The 2011 Snow, Water, Ice and Permafrost in the Arctic (SWIPA) project highlighted the importance of Arctic surfaces, the melting of which will further accelerate 
climate change, both regionally and globally. The taskforce on short-lived climate forcers (such as black carbon) increased knowledge on the pathways transferring black carbon to the Arctic and what policy measures are available to counter this. Nevertheless, what is important here is that the Arctic Council taskforce has not only taken up the issue (as well as others, such as methane) of reduction measures in larger international policymaking fora (such as in International Maritime Organisation - IMO) but also demonstrated that the Arctic States can do a lot themselves.

There have been numerous ways in which these Arctic Council sponsored scientific endeavours have influenced policy. For instance, the 2004 ACIA was the first regional climate change assessment to demonstrate the importance of the Arctic's place in the functioning of the global climate system. The influence of the ACIA can be seen not only via the research results themselves but also in the fact that many of the same scientists that were implementing ACIA also took part in the 2007 IPCC assessments. Hence, given that IPCC assessments have, and continue to be, important for the development of the global climate regime, the Arctic Council has done its part in contributing to the global science of climate change. It can also be argued that by placing a considerable importance on climate change impacts in the Arctic the Council has also increased awareness of

the consequences of climate change and thereby induced awareness of the need for both mitigation and adaptation measures in particular.

\subsubsection{Direct Policy Influence}

As argued above, the main way in which the Arctic Council has been able to influence policy is via sponsoring climate science. Has the Arctic Council then been making decisions that have exerted influence on climate policy and law? ACIA did contain policy recommendations albeit very weak, mainly encouraging the dissemination of the results of the assessment, and how climate change should become a cross-cutting issue in the Council. The main question evidently is whether the Council has been able to act as a platform for its member states to act in a global climate regime. After all, the Council member states and permanent participants were able to influence the negotiations of the global 2001 Stockholm persistent organic pollutants convention and were able to agree in AMSA that they 
would support the negotiations in IMO to transform the non-binding Polar Code into a legally binding one. The Council has thus shown that it can be used as a vehicle for strong international environmental policy by Arctic actors, if they so desire.

The Arctic States have indeed issued joint statements in the climate regime annual conferences of parties, e.g., in conferences of the parties in Cancun, Mexico (2010) and in Doha, Qatar (2012). The most recent statement, made by all the Arctic Council member states in 2012 in Doha, expresses particularly strongly the concerns these states have over developments in the Arctic:

"Arctic sea ice is rapidly diminishing. September 2012 saw the lowest sea ice extent observed in modern times. Summer sea ice extent in 2012 was only half of the (1980-2000) average summer sea-ice extent [...] Re-cord high temperatures and surface ice melt were recorded over the Greenland Ice Sheet in the summer of 2012. We are now witnessing feedbacks from changes in Arctic snow and ice conditions to the global climate system and there is justified concern that Arctic warming will spur further melting and global warming."

They also urge the international community to "implement additional measures to address short lived climate forcers, including through cuts in emissions, which can help to slow Arctic near-term warming" and affirm that "Arctic States will continue to spearhead these efforts." They also signal that they are committed to strong efforts to avert climate change and "to limit the rise of global temperature to below 2 degrees Celsius, thereby avoiding potentially irreversible changes to the Arctic and global climate." These are very strong words especially from countries like the United States, Russia and Canada.

Evidently, these joint statements by the Arctic Council member states do not reflect the realities of the climate policies of the very same states. As mentioned above, Canada withdrew from the Kyoto Protocol (with effect from 14 December 2012) a protocol to which the United States never even become a party. Even Russia did not commit to a second commitment period target under the Kyoto Protocol. It is thus quite clear that climate policy is such a big policy area for these states that it is not Arctic considerations alone that dictate the way they conduct their climate policy, but rather other more broad-based considerations. 


\subsection{Conclusion}

It is fair to say that the Arctic Council has been able to find itself something of a niche here, where it can fulfil an important function in the struggle against climate change. By sponsoring major scientific assessments, it can help deepen our knowledge in relation to the importance of Arctic climate change impacts on the world as a whole and in so doing, at least in its own way, contribute to the design of better climate mitigation policies. It is likely however that the most important function these Council assessments have had is to raise the level of awareness among the residents in the Arctic of the changes they will face, which, in turn, has arguably induced greater awareness of the need for adaptation to climate change in the region.

Even if the Arctic Council member countries, together with the region's indigenous peoples, have been able to act in concert in some global policymaking processes, tackling climate change is just too high-level a policy area for Arctic considerations alone to play a role in the way the Arctic States conduct their mitigation policies. Even in the field of adaptation, the national strategies of the Arctic States do not greatly flag up the Arctic as a special place of concern. Although the Arctic does play an important symbolic role in the fight against climate change in general, it does not figure prominently in the climate policies of the Arctic Council member states.

Both Polar regimes do have the opportunity to raise the profile of their climate change policies. With the ongoing increase in the level of scientific knowledge, the ATS has gradually taken up climate change as an issue of concern, and there are signs that climate change issues will play a more prominent role in the ATS in the future. It seems that the Antarctic Treaty Consultative Parties are now increasingly ready to take action in the context of the global climate change regime. This is important, given that the Polar Regions play a very significant role in how climate change evolves, and in very concrete terms: e.g., the more the ice sheets of Greenland and the Antarctic melt, the quicker the sea level rises. It is nevertheless important for the two Polar regimes to go beyond what they are doing already by providing their climate science results to the IPCC while also undertaking joint actions in global climate change conferences. 


\section{Further reading}

Antarctic Treaty-Arctic Council Joint Meeting Washington Ministerial Declaration on the International Polar Year and Polar Science, see at http://www.state.gov/e/oes/rls/other/2009/121340.htm

Sanjay Chaturvedi. "The Antarctic "Climate Security" Dilemma and the Future of Antarctic Governance," in Alan D. Hemmings, Donald R. Rothwell \& Karen N. Scott (eds.), Antarctic Security in Twenty First Century. (London: Routledge, 2012): 257-283.Timo Koivurova, Eva Carina H. Keskitalo \& Nigel Bankes (eds.), Climate Governance in the Arctic. (USA: Springer, 2009).

Doha Statement (Canada, Kingdom of Denmark, Finland, Iceland, Norway, Russian Federation, Sweden, United States of America. Statement to Unfccc Cop XVIII), 2012. http://www.arctic-council.org/index.php/en/about/press-room/653arctic-states-release-unfccc-cop-18-statement

Final Report of the Thirty-fifth Antarctic Treaty Consultative Meeting (Hobart, Australia), 11-20 June 2012, Volume I, at http://www.ats.aq/documents/ATCM35/fr/ATCM35_fr001_e.pdfIPCC - Climate Change 2007: Working Group II: Impacts, Adaptation and vulnerability (executive summary, chapter 15 Polar Regions, Arctic and Antarctic), at http://www.ipcc.ch/publications_and_data/ar4/wg2/en/ch15s15-es.html

\section{Questions}

- Why do you think it is difficult to take up climate change as a policy problem to be addressed in the Antarctic Treaty Consultative Meetings?

- How would you suggest the Arctic Council could function more effectively in the global climate regime?

- How can the Polar Regimes co-operate together to strengthen the measures used to combat climate change globally? 



\section{The International Legal Regime of the Continental Shelf with Special Reference to the Polar Regions ${ }^{3}$}

Ted L. McDorman

\subsection{History and Basic Legal Features}

Lawyers and scientists have differing understandings of the term continental shelf. In straight-forward terms, the physical continental shelf is one component of the continental margin that involves the shelf, slope and rise. These are described as distinct physical features. The legal understanding of the continental shelf is premised on the physical but is one of legal definition, as will become clear below, is not necessarily related to the physical features. An obvious situation of the physical-legal distinction concerns Antarctica, where, as explained below, there is a physical continental shelf adjacent to the continent, but debate whether there is or can be a legal continental shelf.

\footnotetext{
${ }^{3}$ Much of this chapter has come from papers written by the author over the years with appropriate modification. Also, Professor McDorman is currently on secondment to the Bureau of Legal Affairs of the Canadian Department of Foreign Affairs and International Trade working on Canada's submission on the outer limits of its continental shelf. The contents of and views contained in this chapter are personal and do not reflect the views or opinions of the Bureau of Legal Affairs, the Department of Foreign Affairs and International Trade, or the Government of Canada.
} 
The history of the international legal regime of the continental shelf is closely linked to hydrocarbon resources. The first international instrument dealing with the continental shelf, albeit using the phrase submarine areas and "sea-bed and sub-soil" outside territorial waters rather than continental shelf, was the 1942 Treaty between the United Kingdom and Venezuela in respect of the Gulf of Paria, which involved the division of oil fields. In order to deal with the increasing level of offshore oil activity in the Gulf of Mexico, the United States through the 1945 Truman Proclamation on the Continental Shelf asserted exclusive U.S. authority over the resources in the continental shelf adjacent to the United States. Many States, in particular Latin American States, made similar continental shelf claims in the immediate post-Truman Proclamation period.

The principal features of the international legal regime of the continental shelf were solidified in the 1950s in the preparatory work undertaken leading up to the First U.N. Conference on the Law of Sea in 1958. The principal features, set out in the 1958 Geneva Convention on the Continental Shelf and repeated in the 1982 Law of the Sea Convention, largely reflect the economic and geopolitical importance, for coastal states, of controlling offshore hydrocarbon exploration and exploitation in their adjacent seafloor areas.

- The international legal basis of a coastal State's authority over a continental shelf is adjacency. The International Court of Justice in the 1969 North Sea Continental Shelf Cases introduced the concept of "natural prolongation" in the context that a coastal State has rights over the area of the continental shelf "that constitutes a natural prolongation of its land territory."

- The nature of coastal State's rights over the continental shelf is "sovereign rights for the purpose of exploring it and exploiting its natural resources" and these rights are exclusive to that State. Thus, the international legal right is not ownership per se and is focused on natural resources (mineral resources and sedentary fish species).

- Coastal States are legally able and have the exclusive authority to construct and maintain installations and other structures for the purposes of exploring and exploiting the natural resources of the continental shelf. 
- Coastal State rights over the continental shelf do not depend upon occupation or an express proclamation. The International Court in the North Sea Continental Shelf Cases commented "that the rights of the coastal State in respect of the area of continental shelf [...] exist ipso facto and ab initio, by virtue of its sovereignty over the land. In short, there is [...] an inherent right" (para. 19). The basic importance of this is that every coastal State has an adjacent continental shelf without the necessity of making a public claim.

- The rights of a coastal State over the continental shelf "do not affect the legal status of the superjacent waters" or the airspace above those waters. In the 1958 wording, the waters were referred to as high seas, while in the 1982 wording no reference is made to high seas.

The legal regime of the continental shelf is functionally based in that the adjacent coastal State has exclusive authority over exploration and exploitation of the natural resources of the shelf but other uses of the shelf, for example the laying of submarine cables and pipelines, are subject to reasonable measures, open to all States.

\subsection{Outer Limit of the Shelf}

\subsubsection{Overview}

What the 1958 Continental Shelf Convention did not accomplish was the establishment of a definable outer limit of the continental shelf. Article 1 of the 1958 Convention provided two criteria for the outer limit of the shelf - the seabed and subsoil within the envelope of waters to a depth of 200-metres "or, beyond that limit, to where the depth of the superjacent waters admits of the exploitation of the natural resources." The term "exploitability" was seen as being tied to hydrocarbon exploration and development possibilities and the unwillingness of coastal States to forego access to these resources in their adjacent offshore areas. Moreover, as a matter of law, "exploitability" was flexible and ambiguous. 
Unlike in 1958, during the negotiation of the LOS Convention (the Third U.N. Conference on the Law of the Sea, 1973-1982) there was a necessity to provide for a definitive outer limit of the continental shelf because of the "Common Heritage of Mankind" and the International Seabed Authority (ISBA), since the ISBA and the Common Heritage were to apply to the mineral resources of the seafloor beyond national jurisdiction, in other words beyond the outer limits of coastal States' continental shelves.

The first step respecting the location of the outer limit of the continental shelf was the acceptance that all coastal States could apply the legal regime of the continental shelf to the seafloor out to 200 nautical miles regardless of whether the physical continental margin reaches that far. While the continental shelf regime is legally distinct from the 200-n. mile Exclusive Economic Zone (EEZ) and predates the emergence of the EEZ in international law and practice, it is generally accepted that a coastal State within its EEZ has exclusive rights as regards respecting all the resources therein and this includes the resources of the seafloor of the EEZ.

The second outer limit step involved the situation where the physical continental margin extended beyond 200-n. miles. Here compromise was necessary between those States which took the view that international law already acknowledged exclusive coastal State authority over the shelf beyond 200-n. miles based on inherent rights and "exploitability" and those States seeking to limit coastal State continental shelf authority at 200-n. miles. The negotiated compromise involved three new and distinctive features of the legal continental shelf regime:

- A complex formula for determining the outer limit of a State's continental shelf beyond 200-n. miles;

- The establishment of the Commission on the Limits of the Continental Shelf (Commission), a body composed of science specialists, designed to interact with States in applying the above complex formula; and

- Coastal State sharing of revenues with the international community respecting mineral resources exploited by a coastal State from the shelf area beyond 200-n. miles. 


\subsubsection{The Criteria}

The criteria agreed upon in the LOS Convention to be applied by a coastal State in determining its outer limit in respect of the continental margin beyond 200-n. miles is succinctly set out below.

- Pursuant to Article 76(4), an envelope for the outer limit of the margin is first created by determining the foot of the continental slope and then constructing:

- A line connecting the outermost points where "the thickness of sedimentary rocks is at least one $\%$ of the shortest distance from such point to the foot of the continental slope."

- A line connecting points "not more than 60 nautical miles from the foot of the continental slope."

- The envelope created by Article 76(4) is subject to two constraints. The lines created pursuant to 76(4) are not to extend beyond:

- 350-n. miles from a State's baselines.

- 100-n. miles from the 2,500 metre isobath.

- For submarine ridges, the 350-n. mile constraint applies. However, for "submarine elevations that are natural components of the continental margin, such as its plateaux, rises, caps, banks and spurs," either 350-n. miles or 100-n. miles from the 2,500 metre isobath is the constraint.

- There is a general limitation that the continental margin does not include the oceanic floor with its oceanic ridges.

The criteria are not easily applicable in any given situation because of the technical and definitional difficulties of determining the thickness of sedimentary rocks, the foot of the continental slope, the 2,500 metre isobath, and distinguishing among submarine ridges, oceanic ridges, and submarine elevations that are natural components of the continental margin. 


\subsubsection{Process}

The LOS Convention provides that a coastal State is to submit information supporting its proposed outer limit of its "legal" continental shelf to the Commission. The Commission is to consider the submitted material and make recommendations to the submitting State regarding the information received and the relevant Article 76 criteria. There are two points to note here. First, the authority of the Commission is solely as regards the outer limit of the continental shelf. Second, it is the coastal State not the Commission that determines the outer limit of its continental shelf beyond 200-n. miles. This is consistent with the reality that the determination and delineation of a maritime boundary is a political act of a coastal State. It is also worth noting the practice that is developing in respect of the relationship between submitting States and the Commission is that submitting States are treating the Commission, while not as a court, nevertheless as a body whose opinion (recommendations) matter and, as result, as a body which needs to be satisfied. The outcome of the application of the outer limit criteria and process is described in Article 76(8) of the LOS Convention - the "limits of the shelf established by a coastal State on the basis of these recommendations shall be final and binding." There is debate about upon whom the limits established by a coastal State are "final and binding" - the State establishing its outer limits; all State Parties to the LOS Convention; all States.

In the 2012 Bay of Bengal Case (Bangladesh/Myanmar), the International Tribunal for the Law of the Sea (ITLOS) was confronted with the question of the relationship between the continental shelf outer limit criteria and procedures (the Commission) in the LOS Convention and the international legal right of a State to its adjacent continental shelf. Put differently, can a coastal State only exercise jurisdiction over the resources of the continental shelf beyond 200-n. miles after the Commission has dealt with the outer limit of the coastal State's shelf? The ITLOS answered no, stating that: "A coastal State's entitlement to the continental shelf exists by the sole fact that the basis of entitlement, namely sovereignty over the land territory, is present. It does not require the establishment of outer limits" (para. 409). In the preceding paragraph, the Judgment provides that entitlement to the continental shelf does not depend "on any procedural requirements" (para. 408). Thus, as was also 
already noted a State has an inherent right to a shelf beyond 200-n. miles (where it physically exists) and the LOS Convention provides a procedural opportunity to establish the outer limits of that shelf that will enhance the opposability of those limits vis-à-vis other States or, as it has been described, the Commission process provides legitimacy to a coastal State's outer limits.

\subsubsection{Submissions to the Commission and Submission "Politics"}

The most significant unforeseen development in respecting the continental shelf in the first thirty years of the LOS Convention has been the number of States of the view that they have a legal continental shelf beyond 200-n. miles adjacent to their coasts. During the negotiation of Art. 76 it was projected that 30 or so States had adjacent continental margins beyond 200-n. miles that would result in the employment of the outer limit criteria and procedures of Art. 76. What has occurred, however, has far exceeded that number.

The first submission to the Commission was from Russia in 2001. Since then, the Commission had received 60 submissions of information respecting the outer limits of a continental shelf and an additional 45 notices of intent by States to make future submissions. These numbers involve a degree of double-counting since some States, for example Ireland, have made two separate submissions, one for its proposed outer limit of shelf area adjacent to Ireland on the Porcupine Abyssal Plain and another as part of a Joint Submission with France, Spain and the United Kingdom regarding the Celtic Sea and Bay of Biscay. Double-counting also arises, for example, regarding Cuba, which submitted a notice of intention to submit and shortly thereafter made its Submission to the Commission. The number of States having made either a submission or indicated an intention to submit is approximately 80 with Canada, the last of the original 30 States that are party to the Convention, to join the list in 2013.While the LOS Convention is clear that the work and recommendations of the Commission are "without prejudice" to the question of delimitation of the continental shelf between States with opposite or adjacent coasts, nevertheless, the Rules of Procedure of the Commission provide States with the opportunity to "block" the Commission 
from proceeding to consider submissions where a "dispute in the delimitation of the continental shelf between opposite or adjacent States or in other cases of unresolved land or maritime disputes" exists. This has occurred, for example, between Argentina and the United Kingdom as regards the shelf area adjacent to Malvinas/the Falkland Islands. Regarding Iceland's blocking of a submission made by Denmark, see below.

In many situations, submission "politics" have been neutral or even positive. Many States in the preparations for their submissions have communicated with neighbouring States that may be affected in order to obtain a "no objection" from that State for the Commission to proceed to consider the submission, subject to the "without prejudice" understanding. One recent such example is Canada's "no objection" note verbale to Denmark's submission concerning the shelf area beyond 200-n. miles within the Labrador Sea (over which Canada will also be making a submission), that was the product of the close cooperation between the two States. In the case of Australia and New Zealand, the 2004 boundary agreement that applies to the EEZ and continental shelf beyond 200-n. miles appears to have been motivated by the desire of the two States to resolve their boundaries before proceeding to the Commission. The 2010 Norway-Russia Maritime Boundary Agreement, which deals with only a small area of continental shelf beyond 200-n. miles, but a much larger area within 200-n. miles, may have been facilitated by the discussions between the States on their respective submissions to the Commission. Innovatively, Denmark, Iceland and Norway through the 2006 Agreed Minutes have essentially agreed on the delimitation of the "southern banana hole" in the Northeast Atlantic pending their submissions to the Commission and re-commendations supporting their individually proposed outer limits in the "banana hole".

\subsubsection{Revenue-Sharing}

Thus, far there has been no production of mineral resources beyond 200-n. miles to which the revenue-sharing (Art. 82) provision would apply. It is difficult to predict when and to whom the Art. 82 obligation will first apply with there being no obvious situation on the horizon. Moreover, the provision is not without interpretative complexities that the coastal States with the potential for resource production beyond 200-n. miles will need to face. 


\subsection{The Continental Shelf in the Arctic}

\subsubsection{Overview}

The five States that border the central Arctic Ocean basin, Canada, Denmark/Greenland, Norway, Russia and the United States, in word and deed, apply the international law of the sea to the Arctic Ocean in much the same manner as all coastal States deal with their adjacent ocean areas by reference to the law of the sea. This is the case even though the Arctic Ocean, especially the central Arctic Ocean basin, is a unique, sensitive and relatively pristine marine environment and this includes the "special" nature of the impact that developments in the Arctic environment (global climate change) may have on global weather, sea-levels, ocean currents, etc. While during the negotiation of the 1982 LOS Convention little attention was paid to the Arctic Ocean, it was not totally absent from consideration. It has been observed that: "The fact that the Arctic rarely received specific mention (at the negotiations) - by virtue of an unspoken "gentleman's agreement" among Arctic and non-Arctic nations - took little away from the general applicability of the Convention to the Arctic" (Johnston ed., 1982:12).

While the Arctic Ocean was not at the forefront of State considerations during the negotiation of the continental shelf beyond 200-n. miles, the Arctic Ocean was not entirely absent from their thinking. During the negotiations on the criteria to be adopted in respect of the outer limit beyond 200-n. miles, the United States, for example, had concerns about the possible misuse by Russia of Arctic ridges as a means of claiming large areas of the Arctic Ocean. Moreover, in 1980 the United States made it clear that it viewed the Chukchi Plateau in the central Arctic Ocean basin as being a "submarine elevation" and thus the feature was not to be understood to be a submarine ridge, one of the key factors in the outer limit criteria. In the May 2008 Ilulissat Declaration, the five Arctic Ocean States endorsed that: "the law of the sea provides important rights and obligations concerning the delineation of the outer limits of the continental shelf" and that the States were committed to "this legal framework and to the orderly settlement of any possible overlapping claims." Further, in reference to the continental shelf, protection of the marine environment, freedom of navi- 
gation, marine scientific research and other uses of the sea, the five Arctic Ocean States made it clear that they saw "no need to develop a new comprehensive international legal regime to govern the Arctic Ocean." This does not preclude, however, the development of international treaties and other instruments dealing with specific matters.

Despite the above, as noted at the beginning of the chapter, the media story respecting the seafloor in the Arctic Ocean is often that the bordering States are desperately "scrambling" to assert claims in order to eventually reap the anticipated bonanza of hydrocarbon and other potential mineral wealth in the seafloor. The depositing of a Russian flag on the seafloor at the North Pole in early August 2007 was an exceptional publicity event which encouraged the media narrative of conflict and sovereignty assertion respecting untold energy riches in the Arctic Ocean. While over-hyped there is the possibility of hydrocarbon and other energy and mineral resources in the seafloor of the Arctic Ocean. At present, however, most of the known resources are within the 200-n. mile zones of the Arctic States.

\subsubsection{Outer Limits}

What "scramble" has been taking in the Arctic Ocean amongst the bordering States has been one of acquiring scientific data respecting the geological and morphological features and other physical properties of the continental margin in the Arctic Ocean. In December 2001, the Russian Federation submitted to the Commission information respecting its proposed outer limit of the continental margin beyond 200-n. miles. The Executive Summary contained coordinates and maps which indicated that the Russian-claimed area covered a large wedged-shaped portion having as its endpoint the North Pole. The Commission has requested that additional information be provided respecting the continental shelf outer limit proposed by Russia in the Arctic Ocean. Russia has indicated that it will provide such information in due course. It is anticipated that Canada will be submitting information to the Commission on its proposed continental shelf outer limit in the Arctic Ocean in 2013 and Denmark/Greenland is expected to follow suit in 2014. Both Canada and the Denmark/Greenland have "unofficial" charts and maps on websites and elsewhere, which provide pictorial guidance in respect of possible shelf areas beyond 200-n. 
miles that may be enclosed by proposed outer limits. The United States is not a party to the LOS Convention and thus is under no obligation to submit information to the Commission. The United States has, however, indicated its intentions to act in a manner consistent with the wording of Art. 76 and, like Canada and Denmark/Greenland, has made public charts and maps on websites and elsewhere indicating areas of the continental shelf beyond 200-n. miles in the Arctic Ocean.

Only Norway has submitted information to the Commission, received recommendations and announced that it will proceed with outer continental shelf delineation on the basis of the its recommendations. The area involved is a small slice beyond 200-n. miles northwest of Svalbard.

Iceland, Denmark and Norway have coordinated their submissions to the Commission in respect of the Norwegian and Greenland Seas within the socalled "banana hole" as a result of the above-noted 2006 Agreed Minutes. Norway has received recommendations in respect of that part of its submission that dealt with the "banana hole", the Commission has however yet to deal with the submissions of Iceland and Denmark. Iceland's 2009 submission to the Commission also deals with an area to the southwest of Iceland and southeast of Greenland on the Rekyjanes Ridge. To the southeast of Iceland and south of the Faroe Islands is the Hatton-Rockall area. In December 2010, Denmark made a submission to the Commission respecting this area and in 2011 Iceland responded by blocking the Commission from dealing with the Danish submission noting that the area "is part of the Icelandic continental shelf but is subject to overlapping claims by Denmark on behalf of the Faroe Islands and the United Kingdom." (Iceland, Note Verbale, 5 April 2011, http://www.un.org/Depts/los/clcs_new/submissions_files/dnk54_10/ isl_5apr11.pdf.) 


\subsubsection{Bilateral Agreements}

There are three maritime boundary agreements that deal with shelf areas within the central Arctic Ocean basin. The 1990 United States - Soviet Union (now Russian Federation) Agreement, which also deals with the Bering Sea, establishes the boundary for the territorial sea and the 200-n. mile zones of the two States in the Arctic Ocean and indicates, in Art. 2, that the line extends into the Chukchi Sea should the continental margin of both States extend beyond 200-n. miles. The 1990 Agreement is, therefore, a complete boundary for the two States in the Arctic.

In 2006, Denmark/Greenland and Norway (Svalbard) completed a continental shelf and fisheries zone maritime boundary agreement. The line appears to follow an equidistance line utilising the coasts of both Greenland and Svalbard. This Agreement supports the view of Norway that Svalbard is capable of generating offshore zones and is to be taken into account in maritime boundary delimitation.

The 1957 Norwegian - Soviet Union (now Russian Federation) Agreement, delineates the maritime boundary between Norway and the Russian Federation for a distance of 24.35-n. miles within the Varanger Fjord. The exciting new agreement is that between Norway and the Russian Federation entered into in 2010. The Agreement is the result of nearly 40 years of negotiation and creates a single line for the EEZ and continental shelf area beyond 200-n. miles through the Barents Sea and into the central Arctic Ocean basin.

Canada and Denmark have a continental shelf boundary from Davis Strait to the Lincoln Sea. The boundary terminates in the Robeson Channel before entering the Lincoln Sea that is part of the Arctic Ocean and, thus, is incomplete. There is also a small gap in this maritime boundary as a result of the sovereignty dispute over Hans Island.

The Jan Mayen Case between Denmark and Norway before the International Court of Justice resulted in 1995 in a maritime boundary agreement between the two States. This was followed in 1997 with a maritime boundary accord between Iceland and Denmark/Greenland and a subsequent one between Greenland and Iceland. The 1990s flurry of activity followed two agreements in the early 1980s between Iceland and Norway delimiting their respective fishery zones and continental shelf and ended with agreement on a tri-junction point between the three States. 


\subsubsection{Overlapping Claims Disputes}

There are only two cases in the central Arctic Ocean basin where there are clear situations of overlapping claim disputes. One is between Canada and the United States in the Beaufort Sea and the other is between Canada and Denmark/Greenland in the Lincoln Sea. Both involve overlapping 200-n. mile zone claims. As regards the continental shelf beyond 200-n. miles in the central Arctic Ocean basin, there are as yet no overlapping claim disputes as none of the States have officially indicated the extent of their continental shelves beyond 200-n. miles.

It is however quite likely that there is an area of continental shelf beyond 200-n. miles adjacent to the Beaufort Sea that may be subject to overlapping Canadian and U.S. claims. It has been noted that beyond 200-n. miles strict equidistance, favoured by the United States within 200-n. miles, rather than an extension of the $141^{\text {st }}$ meridian, favoured by Canada within 200-n. miles, becomes more favourable to Canada and less favourable to the United States. The two States are cooperating in the collection of data and mapping respecting the seafloor area (possible continental shelf) adjacent to the Beaufort Sea. It is reported that Canada and the United States are in the early stages of discussions about the Beaufort Sea dispute.

As already noted, the 1973 Canada - Denmark/Greenland Continental Shelf Agreement does not extend into the Lincoln Sea. It is however reported that both States accept that equidistance should be used to delineate their overlapping territorial sea and 200-n. mile zone claims in the Lincoln Sea. It is likely that the continental shelf in the Lincoln Sea area extends beyond 200-n. miles from each State. It is reported that Canada and Denmark/Greenland are engaged in negotiations on some of the above matters.

The possible dispute between Norway (Svalbard) and Denmark/Greenland regarding claimed continental shelf areas beyond the 200-n. mile limits in the Arctic basin is referred to in their 2006 bilateral Agreement and the 2006 Norwegian submission to the Commission. In Norway's submission to the Commission it was indicated that Denmark/Greenland did not object to the Commission considering the Norwegian proposed outer limit in this area and that a maritime boundary will be negotiated between the two States. 
It may be the case that Russia will have a continental margin area beyond 200-n. miles in the Arctic Basin that overlaps with shelf areas of both Denmark/Greenland and Canada. In response to the 2001 Russian submission to the Commission, both Denmark and Canada explicitly noted that the Russian submission and any recommendations by the Commission were "without prejudice to the delimitation of the continental shelf" between the States. In the case of Denmark/Greenland, the seafloor area in question is most likely to be related to the Lomonosov Ridge. The seafloor area in question between Canada and Russia may also involve the Lomonosov Ridge as well as the Alpha-Mendeleev Ridge. Until Canada and Denmark/Greenland indicate the extent of their continental shelf in the central Arctic Ocean basin, it is unclear whether or not there exist overlapping claims. This should become clearer when Canada and Denmark/Greenland submit their information to the Commission on their proposed continental shelf outer limits.

\subsection{The Continental Shelf in the Antarctic?}

As noted in the first paragraph of this Chapter, there is little doubt that there is a physical continental shelf adjacent to the Antarctic land mass. The question is whether, pursuant to the LOS Convention, there exists a legal continental shelf. More generally, the reality of the continental shelf and Antarctica is that a series of questions remain to be answered.

Argentina, Australia, Chile, France, New Zealand, Norway and the United Kingdom - the Antarctic 7 - have territorial claims in Antarctica and, of course, there is part of Antarctica that is unclaimed by any State. States such as - India, Japan, the Netherlands, Russia and the United States, among others - do not recognise the territorial claims of any of the "Antarctic 7" and ipso facto, that any of the "Antarctic 7" States are capable of having an adjacent legal continental shelf.

Further complicating the situation is Article IV(2), seen as the critical provision of the Antarctic Treaty respecting potential continental shelf jurisdiction both within and beyond 200-n. miles. Article IV(2) provides: 
"No acts or activities taking place while the present Treaty is in force shall constitute a basis for asserting, supporting or denying a claim to territorial sovereignty in Antarctica or create any rights of sovereignty in Antarctica. No new claim, or enlargement of an existing claim, to territorial sovereignty in Antarctica shall be asserted while the present Treaty is in force."

Does an Antarctic State's assertion of authority over an area of continental shelf adjacent to its claimed territory constitute a "new claim" or an "enlargement of an existing claim"? If yes, then the assertion of authority by the Antarctic State is inconsistent with Article IV(2); if no, then the assertion of authority is not captured by Article IV(2). ${ }^{4}$

Australia, Argentina and Norway have submitted information on their proposed outer limits of shelf areas adjacent to their claimed territory in Antarctica to the Commission understanding that, because of the obvious legal and political uncertainty, the Commission will not be able to deal with the submitted material.

Beyond the reach of the Antarctic Treaty, are sub-Antarctic islands under the authority of Australia, France and Norway and the islands of disputed authority between Argentina and the United Kingdom. Submissions of information respecting proposed outer limits have been made to the Commission in respect of these islands.

\subsection{Conclusion}

The international legal regime of the continental shelf has a distinguished history and is largely set out in the LOS Convention. The core parameters of the regime are well understood and applied in a consistent manner by States. On bilateral matters, States have been involved

\footnotetext{
${ }^{4}$ These questions of interpretation are however more complex than perhaps they first appear. See, for example, Stuart B. Kaye, "The Outer Continental Shelf in the Antarctic" in Alex G. Oude Elferink and Donald R. Roth well, eds., The Law of the Sea and Polar Maritime Delimitation and Jurisdiction (The Hague: Martinus Nijhoff, 2001), at 133-136. Another question worthy of consideration here is whether the unclaimed land area on the Antarctic continent is legally capable of having an adjacent continental shelf. Again, see Kaye, at 131-133 for arguments.
} 
with continental shelf overlaps and related issues for decades. What has been new in the last decade is the application of the criteria in Art. 76 respecting the outer limits of the legal continental shelf by States and the engagement of States with the Commission.

Issues regarding the continental shelf in Antarctica have been largely ignored as compared to those pertaining to the continental shelf in the Arctic Ocean. An entire industry has been created raising deeply-felt concerns over a "race for the resources" on the ocean floor. The frenzy was undoubtedly ignited by the flag planting "photo opportunity" conducted by the Russians at the North Pole. This has been coupled with:

- The reduction both in the presence and thickness of ice attributed to global climate change;

- Reports of oil and gas riches in the Arctic, with the overlooked fine print that most of these resources are most likely to be on land areas and ocean areas within $200 \mathrm{n}$. miles; and

- The activities of Arctic coastal nations in gathering scientific evidence for submissions of proposed shelf outer limits to the Commission as required by the LOS Convention.

\section{Further reading}

Baker, Betsy. "Law, Science, and the Continental Shelf: The Russian Federation and the Promise of Arctic Cooperation" (2010), 25 American University Law Review: 251-281.

Churchill, Robin and Vaughn Lowe, The Law of the Sea, 3rd ed., (Manchester: Manchester University Press, 1999).

Elferink, Alex G. Oude. "Arctic Marine Delimitations: The Preponderance of Similarities with Other Regions," in Alex G. Oude Elferink and Donald R. Rothwell, eds., The Law of the Sea and Polar Maritime Delimitation and Jurisdiction (The Hague: Martinus Nijhoff, 2001): 179-199.

Elferink, Alex G. Oude. "The Outer Continental Shelf in the Arctic: The Application of Article 76 to the LOS Convention in a Regional Context," in Alex G. Oude Elferink and Donald R. Rothwell, eds., The Law of the Sea and Polar Maritime Delimitation and Jurisdiction (The Hague: Martinus Nijhoff, 2001):139-156.

Elferink, Alex G. Oude and Donald R. Rothwell, eds., The Law of the Sea and Polar Maritime Delimitation and Jurisdiction (The Hague: Martinus Nijhoff, 2001).

Johnston, Douglas M. (ed.) Arctic Ocean Issues in the 1980's (Honolulu: The Law of the Sea Institute, 1982). 
Kaye, Stuart B. "The Outer Continental Shelf in the Antarctic," in Alex G. Oude Elferink and Donald R. Rothwell, eds., The Law of the Sea and Polar Maritime Delimitation and Jurisdiction (The Hague: Martinus Nijhoff, 2001):125-137.

Macnab, Ron. "The Outer Limit of the Continental Shelf in the Arctic Ocean," in Myron H. Nordquist, John Norton Moore and Tomas H. Heidar, (eds.), Legal and Scientific Aspects of Continental Shelf Limits (Leiden: Martinus Nijhoff, 2004): 301-311.

McDorman, Ted L. "The Continental Shelf beyond $200 \mathrm{~nm}$ : Law and Politics in the Arctic Ocean" (2009), 18 Journal of Transnational Law and Policy (Florida State University): 155-193.

Rothwell, Donald R. and Tim Stephens, The International Law of the Sea (Hart Publishing: Oxford, 2010).

Tanaka, Yoshifumi, "Reflections on Arctic Delimitations: A Comparative Analysis between Case Law and Practice" (2011), 80 Nordic Journal of International Law: 459-484.

United Nations, Division for Ocean Affairs and the Law of the Sea, The Law of the Sea: Definition of the Continental Shelf (New York: 1993).

Weber, Mel. "Defining the Outer Limits of the Continental Shelf across the Arctic Basin: The Russian Submission, States' Rights, Boundary Delimitation and Arctic Regional Cooperation" (2009), 24 International Journal of Marine and Coastal Law: 653-681.

\section{Questions}

- What explanation can be given for the complexity of the Article 76 criteria for determining the outer limit of a State's legal continental shelf?

- For the Arctic coastal States, what is the current balance that exists between cooperation and conflict/competition in respect of the continental shelf? What factors could lead to changes in the existing balance? What do you think the balance will be in 20 years?

- Many aspects of the continental shelf regime set out in the 1982 LOS Convention are part of customary international law. Which, if any, parts of the continental regime in the LOS Convention are not part of customary international law?

- There is no doubt that the continental shelf regime in the LOS Convention applies as regards the Arctic Ocean. If the LOS Convention regime was not applicable, (a) what regime might the States have agreed upon for the continental shelf in the Arctic Ocean; and (b) what regime might the world have agreed upon for the continental shelf in the Arctic Ocean? 



\section{Arctic Biodiversity and Marine Wildlife}

Malgosia Fitzmaurice

\subsection{Introduction: Arctic Biodiversity}

The subject-matter of Arctic biodiversity is an issue of great concern. In 2008 the United Nations Environment Programme (UNEP) passed a resolution expressing "extreme concern" over the impacts of climate change and other multiple stressors on Arctic indigenous peoples, other communities, and biodiversity. The Arctic Biodiversity Selected Indicators of Change 2010 report provides evidence that some of those anticipated impacts on Arctic biodiversity are already occurring. Although climate change is a pervasive stressor, negative effects on Arctic biodiversity can also be observed deriving from long range transport of contaminants, harvesting of wild species, and resource development.

This chapter will outline some general issues relating to Arctic biodiversity. Apart from numerous publications on this subject-matter, anyone interested in this area should follow the work of the Conservation of Arctic Flora and Fauna (CAFF) working group of the Arctic Council. CAFF's mandate is to address the conservation of Arctic biodiversity, and to communicate its findings to the governments and residents of the Arctic, helping to promote practices which ensure the sustainability of the Arctic's living resources. The CAFF's projects provide data for informed decision-making in resolving the challenges which are now arising in trying to both conserve the natural environment and permit regional growth in the Arctic.

This work is based upon cooperation between all Arctic countries, indigenous peoples, international conventions, and organisations. Thus, CAFF serves as a vehicle of cooperation on species and habitat manage- 
ment and utilisation; sharing information on management techniques and regulatory regimes, and ensures the facilitation of more knowledgeable decision-making. It also provides a mechanism to develop common responses on issues of importance for the Arctic ecosystem such as: development and economic pressures, conservation opportunities, and political commitments. In order to successfully conserve the natural environment and allow for economic development, comprehensive baseline data is required, including the status and trends of Arctic biodiversity, habitats, and ecosystem health. CAFF is developing the framework and tools necessary to create a baseline of current knowledge, and to provide dynamic assessments over time. It is expected that this evolving, sustainable, and responsive approach will produce more regular, timely, and flexible analyses on topical issues of Arctic biodiversity.

Biodiversity is defined in the Convention on Biological Diversity (CBD)(see below) in the following manner: "Biological diversity means the variability among living organisms from all sources including, inter alia, terrestrial, marine and other aquatic ecosystems and the ecological complexes of which they are part; this includes diversity within species, between species and of ecosystems" (Art. 2). There are several different definitions of biological diversity (none are however official,) for scien-

tific definitions of biodiversiy (see: <http://biodiversity.ca.gov/ Biodiversity/biodiv_def2.html >).

\subsubsection{Arctic Biodiversity - Threats for Fauna and Flora}

The key findings by UNEP indicate that Arctic biodiversity is threatened. For example, tundra ecosystems are being replaced by evergreen shrubs. Furthermore, due to climatic changes, permafrost is decreasing in the Northern peatlands.

As noted above, of all the stressors influencing Arctic biodiversity detrimentally, climate change is the most significant. However, other stressors such as contaminants are also negatively impacting Arctic biodiversity. For example, a high level of PCBs was found in polar bears; we are currently also witnessing habitat fragmentation; there are linkages between industrial development and unsustainable harvest levels. It is also observed that warming climate results in increased shipping and resource 
development (oil and gas exploration) with potential for increased pollution which will adversely affect biodiversity. In addition, full knowledge of the current state of marine resources in the Arctic, especially in the areas beyond state jurisdiction, is currently lacking due, in part, to ongoing and rapid climatic challenges (Rayfuse, 2008:3).

According to various estimates, the majority of Arctic species are currently stable. For instance, populations of very abundant seabirds remain generally at good levels. Freshwater Arctic char populations are healthy in comparison to those in southern locations (Reist \& Sawatzky, 2010:43). However, some of the most important species to Arctic indigenous peoples, such as caribou and wild reindeer, are declining. As to vertebrae, the Arctic Species Trend Index (ASTI) shows a 10\% overall decline in terrestrial population. ASTI is an index that tracks trends in over 300 Arctic vertebrate species; it describes overall trends across species, taxonomy, ecosystems, regions and other categories. Currently, information on the size of Arctic species is deemed inadequate (Hohn \&Jaakkola, 2010:10). For example, the information on polar bears - one of the most charismatic Arctic species - is only known for 12 out of 19 sub-populations, 8 of these are declining (Lunn et al., 2010:27). Out of 6 sub-species of red knot three are declining while the other three are either suspected of being in decline or their status is unknown (Sitters et al., 2010:34). Marine fish show a trend towards a northward shift in the distribution of some species in both exploited and unexploited stocks. It is possible that such a shift is the result of climate change in addition to other pressures such as overfishing.

\subsubsection{Protected Areas}

Protected areas play a fundamental role in maintaining and conserving Arctic and global biodiversity and habitats, as they are central to the policy of protecting migrating species. The lack of programmes which specifically relate to the Arctic in international environmental instruments effectively highlights the importance of developing a "circumpolar protected areas strategy" for the Arctic, with the participation of indigenous and local peoples (Barry \& McLennan, 2010:98). The first protected areas in the Arctic were established in Sweden and Alaska at the beginning of the 20th century. In the 1970s the establishment of protected areas began to 
increase significantly with the establishment of the Greenland National Park. By 1980, 5.6\% of the Arctic was classified under some degree of protection. At present $11 \%$ of the Arctic (about 3.5 million $\mathrm{km}^{2}$, has protected status in 1127 protected areas). The level of protection however differs somewhat across these areas. In addition, over $40 \%$ of Arctic protected areas have a coastal component but for the majority of these areas it is not possible at present to determine the extent to which they incorporate the adjacent marine environment (Barry \& McLennan, 2010:97).

Climate change has undoubtedly influenced the way in which protected areas have been established. Traditionally, they have been based on either the protection of unique habitats or the concept of ecological representivity. Under this system important areas that are sufficiently large and contain targeted components of ecological biomes are selected for protection. The changes caused by climate change in Arctic ecosystems complicate this approach to protected areas. It may be that what is singled out for protection at present has been altered or lost through climate change (e.g., due to the northward shift of species, greening of the Arctic, the growth of invasive species, and so on). Therefore it is of the utmost importance for environmental conservation not only to apply measures within protected areas but also beyond their boundaries as currently unprotected areas often become crucial corridors connecting species migrations (Ibid. 96).

Marine ecosystems in the Arctic enjoy lesser protection than terrestrial ones. This is now a serious issue because of the more rapid than anticipated melting of Arctic sea ice. This melting will have a detrimental effect on the population levels of Arctic marine mammals, fish, benthic communities, and seabirds. This effect is, moreover, still not fully understood.

The 2008 Convention on Biological Diversity (CBD) recognised the importance of the conservation and sustainable use of wetland biodiversity and peatlands in particular - in addressing climate change. The most important factor for the effective protection of Arctic ecology is the cooperation of all Arctic States and establishment of an efficient network between these states (Barry \& McLennan 2010, 98). Such a network has emerged in the context of the Circumpolar Biodiversity Monitoring Program (CBMP), which constitutes the main element of the CAFF working group. It received official endorsement from the Group on Earth Observations Biodiversity Observation Network (GEO BON) in January 2012. CBMP now 
belongs to the GEO BON regional network Arctic-BON. It is the biodiversity component of the Sustaining Arctic Observing Networks (SAON) and the official Arctic Biodiversity Observation Network of the Global Earth Observations Biodiversity Observation Network (GEO BON). The Group on Earth Observations Biodiversity Observation Network - GEO BON - coordinates activities relating to the Societal Benefit Area (SBA) on Biodiversity of the Global Earth Observation System of Systems (GEOSS). Some 100 governmental, inter-governmental and non-governmental organisations are collaborating through GEO BON to organise and improve terrestrial, freshwater and marine biodiversity observations globally. Its other goal is to make their biodiversity data, information and forecasts more readily accessible to policy-makers, managers, experts and other users. Moreover, GEO BON has also been recognised by the Parties to the CBD.

The CBMP is an international network of scientists, government agencies, indigenous organisations and conservation groups working together to harmonise and integrate efforts to monitor the Arctic's living resources. The CBMP includes over 80 organisations and 700 individuals. The CBMP's goal is to facilitate more rapid detection, communication, and response with respect to the significant biodiversity-related trends and pressures affecting the Circumpolar world.

\subsubsection{Main Underlying Principles of Biodiversity Management}

A number of key principles can be identified as crucial in Arctic biodiversity management. The first is the precautionary approach/principle. This principle states that in order to protect the environment, where threats of serious or irreversible damage to it arise, the lack of full scientific certainty shall not be used as a reason for postponing cost-effective measures to prevent environmental degradation.

The precautionary approach (principle) is one of the underlying principles of the conservation of fish stocks, as it was expressly introduced in the Fish Stocks Agreement (FSA) (see below). The FSA is probably the most important global international instrument in achieving the sustainable use of fish stocks. The precautionary principle is also featured in some of the regional fisheries treaties. It is widely known that the precautionary principle has generated an 
extensive body of literature and has been the subject of continuing discussion as to its legal nature, effectiveness and implementation.

The concept of sovereignty raises complex questions with many attached elements. For the purposes of this chapter, I will only look at the issue of permanent sovereignty over natural resources, i.e., fish stocks or transboundary natural resources. The principle of Permanent Sovereignty over Natural Resources is the primary general principle underlying the exploitation of fish stocks. This implies permanent sovereignty over natural resources (which is connected to the flag state jurisdiction on the high seas) in areas under the jurisdiction of the coastal state. For example, the relevant convention here, the $\mathrm{CBD}$, introduces provisions on the national regulation of biological diversity, i.e., diversity here is a state sovereignty issue. However, other principles of international law, such as common concern in relation to biodiversity (included in the preamble of this convention) impose certain limitations on the sovereign rights of states.

These rights have to be distinguished according to the zones in which the fish stocks are found (i.e., the high seas; the territorial sea; or the Exclusive Economic Zone - EEZ) and whether they are confined to one zone or are transboundary. The rights constituting sovereignty over natural resources comprise a nexus of rights and, accordingly, they include the right to possess, to use and to manage. From these rights follows the right of a state to the exploration and exploitation of its natural resources and also the right to profits obtained from these resources. Permanent sovereignty over natural resources is not currently absolute but rather is limited by several legal and economic factors. These factors are:

- The principle that permanent sovereignty must be exercised for the benefit of national development as well as the well-being of people;

- The state has a duty to compensate foreign investors whose property has been expropriated following legal proceedings;

- The state has the duty to protect the interests of indigenous peoples;

- And, lastly that the state has the duty to cooperate (by way of notification and consultation) in relation to shared natural resources. 
There are several limitations on state sovereignty in relation to shared resources deriving from customary international law and treaties, such as: the prohibition on causing transboundary environmental damage, a rule of customary international law which has been enshrined in Principle 21 of the 1972 Stockholm Declaration on Human Environment and Principle 2 of the 1992 Rio Declaration on the Environment and Development. Cooperation between states in respect of transboundary resources is very important in relation to fish stocks, which are, for instance, found in different EEZs. The United Nations Convention on the Law of the Sea (LOS) has several provisions concerning such fishery resources (see below).

\subsection{Indigenous Peoples and Biodiversity}

Special mention must also be made here of the situation of indigenous peoples and the protection of biodiversity. The Arctic is, for example, home to both the Inuit (Canada, Greenland, Chukotka and Alaska) and Sami peoples (Norway, Finland, Sweden and Russia). The indigenous peoples of the Arctic have a special relationship with nature and therefore with biological diversity. This special relationship is acknowledged by the ILO's 169 convention on Indigenous and Tribal Peoples in Independent Countries in Article 15 (this 1989 convention entered into force in 1991, Denmark and Norway are the Arctic States who are parties to it).

The 2007 United Nations Declaration on the Rights of Indigenous Peoples also contains several provisions which relate to the special relationship of indigenous peoples with nature and natural resources (see: Arts. 25-27). Another aspect of biodiversity and indigenous peoples relates to the store of "traditional knowledge" associated with genetic resources (see below).

The human rights aspect of the indigenous rights and biodiversity issue, generally relating to cultural heritage protection based on the common Article 1 of the 1966 UN Covenant on Civil and Political Rights ("ICCPR") and the 1966 UN Covenant on Social, Economic and Cultural Rights (ICSECR) which grants to all peoples the right to "freely dispose of their natural wealth and resources" is also an important consideration here. Article 27 of the ICCPR is of fundamental relevance to the relationship between indigenous peoples and nature (biodiversity). 
The importance of biodiversity in relation to indigenous peoples is documented by the relevant clauses in terms of the state's international obligations in respect of cooperative conservation in certain treaties concluded, for example, between indigenous peoples and Canada. Thus, the Yukon Final Agreement calls for Canada to make reasonable efforts to ensure that Yukon First Nation interests are represented when issues involving fish and wildlife management arise in international negotiations. The Labrador Inuit Final Agreement includes similar provisions concerning aquatic plants, fish habitat, management and stocks. Agreements with Yukon First Nation and the Sahtu Dene and Métis confirm that amendments to international treaties should not diminish indigenous peoples' rights (see: Penikett, 2010:15).

\subsection{International Instruments Relevant to the Protection of Arctic Biodiversity and Marine Wildlife}

\subsubsection{Introduction}

No one treaty, concluded among the Arctic States, currently exists covering the protection of Arctic biodiversity in its entirety. The Arctic is however addressed by several global, and regional as well as other specific treaties pertaining to particular marine species (e.g., polar bears). There are also a number of declarations dealing with Arctic biodiversity, which are, unlike treaties, of a non-binding nature, and, as such, are referred to as "soft law" documents.

\subsubsection{General Multilateral Environmental Agreements (MEAs) Relevant to the Arctic}

Several existing global MEAs currently play a role in the preservation of Arctic biodiversity. These are the following: the Convention on Biological Diversity (CBD); the World Heritage Convention; the Convention on Wetlands of International Importance (Ramsar Convention); the Convention 
on the Conservation of Migratory Species; and the Convention on International Trade in Endangered Species of Wild Fauna and Flora (CITES).

\section{The CBD and the Cartagena Protocol on Biosafety}

The CBD was signed in 1992 and entered into force in 1994; it currently has 193 state signatories. All Arctic States (with the exception of the United States) ratified this Convention. The CBD was signed, along with the Framework Convention on Climate Change, at the Rio United Nations meeting. The CBD is the first treaty to adopt a holistic approach to biodiversity, i.e., to address all aspects, from conservation to access and biotechnology (Art. 1). It is a framework Convention, which, while laying down general principles can also be supplemented by Protocols (Bowman et al., 597). The Preamble and Articles 3, and 15 recognise states' sovereign rights over the exploitation of their natural resources pursuant to their own environmental policies. The Convention further states in its Preamble that the conservation of biological diversity is the "common concern of mankind," which has given it, to a certain extent, an international dimension. It may be noted, however, that the CBD does not recognise the internationalisation of biological resources, either in terms of their ownership or their control (Bowman et al., 598). The jurisdictional scope of the CBD is set out in Art. 4 which reads:

\footnotetext{
"subject to the rights of other States, and except as otherwise expressly provided in this Convention, the provisions of this Convention apply, in relation to each Contracting Party: (a) In the case of components of biological diversity, in areas within the limits of its national jurisdiction; and (b) In the case of processes and activities, regardless of where their effects occur, carried out under its jurisdiction or control, within the area of its national jurisdiction or beyond the limits of national jurisdiction."
}

The CBD does not, however, define what is meant by "conservation." Sustainable use is defined in Art. 2 as meaning "the use of components of biological diversity in a way and at a rate that does not lead to the long-term decline of biological diversity, thereby maintaining its potential to meet the needs and aspirations of present and future generations."

The key provision of the Convention relates to "in situ" conservation which is defined in Art.2 as: "...conditions where genetic resources exist within ecosystems and natural habitats, and, in the case of domesticated 
or cultivated species, in the surroundings where they have developed their distinctive properties." It is further described in Art. 8.

Also of relevance here is the notion of "ex situ" conservation by which is understood "the conservation of components of biological diversity outside their natural habitats" (Art. 2), further described in Art. 9. The CBD is also based on the eco-system approach, which means "a dynamic complex of plant, animal and micro-organism communities and their nonliving environment interacting as a functional unit" (Art. 2).

The fair and equitable sharing of the benefits arising out of the utilisation of genetic resources is one of the fundamental objectives of the CBD, set out in Art. 1. This issue is elaborated further in Art. 15 and specified in even greater detail by the Nagoya Protocol on Access to Genetic Resources and the Fair and Equitable Sharing of Benefits Arising from their Utilisation to the Convention on Biological Diversity. This protocol was adopted by the Conference of the Parties to the CBD at its tenth meeting on 29 October 2010 in Nagoya, Japan and shall enter into force 90 days after the date of deposit of the $50^{\text {th }}$ instrument of ratification (see: www.cbd.int).

The CBD and the Nagoya Protocol are very important in relation to the traditional knowledge of indigenous peoples (Art. 8(j) of the CBD). Article 8(j) refers to the promotion of the wider application of knowledge, innovations and practices of indigenous and local communities with their approval and involvement, and to encouraging the equitable sharing of the benefits of utilisation arising therefrom. This Article also deals with intellectual property rights obtained over subject matter arising from the use of traditional knowledge.

In its Preamble the Nagoya Protocol acknowledges the 2007 UNDRIP (see above) and obliges state parties, inter alia, to take measures to ensure that "traditional knowledge associated with genetic resources that is held by indigenous and local communities is accessed with the prior and informed consent or approval and involvement of these indigenous and local communities" (Art. 7, see on this subject: International Law Association, Final Report on the Rights of Indigenous Peoples, Sofia Conference 2012, http://www.ila-hq.org, 22-23).

The Protocol is an international agreement which promotes sharing the benefits arising from the utilisation of genetic resources in a fair and equitable manner, including the maintenance of appropriate access to 
genetic resources and the appropriate transfer of relevant technologies, taking into account all rights over those resources and to technologies, and appropriate funding, thereby contributing to the conservation of biological diversity and the sustainable use of its components.

The Cartagena Protocol to the CBD on Biosafety was adopted on 29 January 2000 and entered into force on 11 September 2003. Of the Arctic States only Denmark, Finland, Norway and Sweden are party to it. Pursuant to Art. 19, para 3, of the CBD, the Conference of the Parties, by its decision II/5, established an Open-ended Ad Hoc Working Group on Biosafety to develop a draft protocol on biosafety. Their objective was specifically to focus on the transboundary movement of any living modified organism resulting from modern biotechnology that may have an adverse effect on the conservation and sustainable use of biological diversity. This Protocol is an international treaty governing the movement of living modified organisms (LMOs) resulting from modern biotechnology from one country to another. Article 1 of the Protocol sets out the main objective which notes that:

\footnotetext{
"In accordance with the precautionary approach contained in Principle 15 of the Rio Declaration on Environment and Development, the objective of this Protocol is to contribute to ensuring an adequate level of protection in the field of the safe transfer, handling and use of living modified organisms resulting from modern biotechnology that may have adverse effects on the conservation and sustainable use of biological diversity, taking also into account risks to human health, and specifically focusing on transboundary movements."
}

Article 3(g) defines LMOs as follows: "[...] living organism[s] that possesses a novel combination of genetic material obtained through the use of modern biotechnology." The main regulatory technique is included in Art. 7, i.e., the advanced informed agreement (AIA) procedure which is aimed at ensuring that contracting parties are provided with the information necessary to make informed decisions prior to agreeing to import LMOs into their territory. 


\section{The UNESCO Convention Concerning the Protection of the World Cultural and Natural Heritage (the WHC)}

This convention was signed in 1972 and entered into force in 1975. It has 189 state signatories; all of the Arctic States have ratified this convention. The key point is contained in Art. 4 which imposes a duty on state parties to ensure the identification, protection, conservation, presentation and transmission to future generations of cultural and natural heritage of outstanding universal value situated on their territory and belonging primarily to these states. The treaty obligations included all cultural and natural heritage of outstanding value and not only objects that are inscribed on the World Heritage List (WHL). There is also a duty of cooperation in respect of the international community as a whole not to deliberately adopt any measures which might damage directly or indirectly world heritage located on the territory of other state parties (Article 16 (1) and (3)). Articles 2 and 3 of the WHC contain definitions of cultural and natural heritage.

The protection of designated cultural and natural heritage is bestowed by inscription on the WHL. There are 936 properties listed (these include: 725 cultural, 183 natural and 28 mixed properties) in 153 state parties. Listing on the WHL is not a unilateral state decision: rather the decision to list is bestowed upon the Convention's organs. It is not necessary to become a party to the WHC to have properties listed. A special procedure exists in relation to the listing of cultural and natural properties. There is also a List of World Heritage objects in Danger ("Danger List"), Art. 11 of the WHC. Properties may also, under certain circumstances, be removed from the list (de-listed). The natural heritage to be protected, conserved and transmitted to future generations must be of "outstanding, universal value" (the Operational Guidelines provide the procedures for the nomination of such sites). One of the most important features of the WHC is the existence of a World Heritage Fund. In the Arctic, objects/areas which fall under WHL include, for example, Ilulissat Icefjord (Greenland/Denmark).

\section{The Convention on Wetlands of International Importance (The Ramsar Convention)}

The Convention on Wetlands of International Importance Especially as Waterfowl Habitat (Ramsar Convention on Wetlands) was signed in 1971 and entered into force in 1975 (see: www.ramsar.org). There are 162 state parties to the convention including all of the Arctic States. The objective of the 
Convention is stated in Art.1 (1) as: "to stem the progressive encroachment on and loss of wetlands now and in the future," as "a resource of great economic, cultural, scientific and recreational value."

In 1982 the Paris Protocol amending this Convention was signed relating primarily to the amendment procedure of the Ramsar Convention. The definition of wetlands is as follows: "areas of marsh, fen, peatland or water whether natural or artificial, permanent or temporary, with water which static or flowing fresh, brackish or salt, including areas of marine water in depth of which low tide does not exceed six metres" (Art. 1 (1)).

At the centre of the Ramsar philosophy is the "wise use" concept. The wise use of wetlands was defined by the Conference of the Parties at its 3rd meeting in Regina, Canada, in 1987 as "the maintenance of their ecological character, achieved through the implementation of ecosystem approaches, within the context of sustainable development." "Wise use" therefore has at its heart the conservation and sustainable use of wetlands and their resources, for the benefit of humankind. Each party designates "suitable wetlands within its territory" for inclusion in the list. Article 2(2) enlists the criteria for the inclusion of sites. The Ramsar Convention permits the deletion and restriction of listed sites. Wetlands are widely distributed across the Arctic (e.g., in Russia), covering about 70\% of the region. Of the 6 Ramsar wetland types represented the most extensive are forested and non-forested peatlands.

\section{The Convention on the Conservation of Migratory Species of Wild Animals (CMS Convention)}

The CMS was signed in 1979 and entered into force in 1983. There are 116 state parties to the convention, including the following Arctic States: Denmark, Finland, Norway, and Sweden (see: www.cms.int). The Convention's aim is to conserve terrestrial, aquatic and avian migratory species throughout their range. Migratory species are defined in Art. 1(1)(a) as "the entire population or any geographically separate part of the population of any species or lower taxon of wild animals, a significant proportion of whose members cyclically and periodically cross one or more national jurisdictional boundaries." The fundamental principles of the Convention are set out in Art. 2 -"The parties acknowledge the importance of migratory species being conserved and of Range States agreeing to take action to this end whenever possible and appropriate." They also acknowledge that 
such states should pay "special attention to migratory species the conservation status of which is unfavourable and tak[e] individually or in cooperation appropriate and necessary steps to conserve such species and their habitat." In Art. 2(2) the Parties acknowledge "the need to take action to avoid any migratory species becoming endangered."

In Article 2(3) the Convention states that "the Parties: (a) should promote, cooperate in and support research relating to migratory species; (b) shall endeavour to provide immediate protection for migratory species included in Appendix I; and (c) shall endeavour to conclude agreements covering the conservation and management of migratory species included in Appendix II."

Migratory species threatened with extinction are listed in Appendix I of the Convention. The parties to the CMS aim to protect these animals, conserving or restoring the places where they live, mitigating obstacles to migration and controlling other factors that might endanger them. Besides establishing obligations for each state that joins, the CMS also promotes concerted action among the so-called "Range States" of many of these species. Migratory species that need, or would significantly benefit from, international co-operation are listed in Appendix II of the Convention. For this reason, the convention encourages the Range States to conclude global or regional agreements. In this respect the CMS acts as a framework convention. One such example of an applicable Arctic species here is the narwhal.

\section{The Convention on International Trade in Endangered Species of Wild Fauna and Flora (CITES)}

CITES was signed in 1973 and entered into force in 1975. It has 175 state signatories with all of the Arctic States being parties to it (see: www.cites.org). Its aim is to ensure that international trade in specimens of wild animals and plants does not threaten their survival. As such, CITES is in effect a trade rather than an environmental Convention. CITES works by subjecting the international trade in specimens of selected species to certain controls. All import, export, re-export and introduction from the sea of species covered by the Convention has to be authorised through a licensing system. Each party to the Convention must designate one or more management authorities to be in charge of administering that licensing system and one or more scientific authorities to advise them on the effects of trade on the status of the species. The species covered by CITES 
are listed in 3 Appendices, in accordance with the degree of protection they require. Thus, Appendix I includes species threatened with extinction. Trade in specimens of these species is permitted only in exceptional circumstances. Arctic species on this list include, for example, all types of Arctic whales. Appendix II includes species not necessarily threatened with extinction, but in which trade must be controlled in order to avoid utilisation incompatible with their survival (e.g., polar bears). Appendix III contains species that are protected in at least one country, which has asked other CITES signatories for assistance in controlling the trade (e.g., the walrus is listed by Canada). Changes to Appendix III follow a distinct procedure in relation to changes to Appendices I and II, as each Party is entitled to make unilateral amendments to it.

Roughly 5,000 species of animals and 29,000 species of plants are protected by CITES against over-exploitation through international trade, covered by the 3 Appendices. CITES is recognised as a one of the most successful MEAs. Its drawback is, however, its numerous exceptions in relation to the level of protection offered.

\subsection{Marine Wildlife}

\subsubsection{Introduction}

The conventions described above are also relevant to Arctic marine wildlife. There are, however, a number of global conventions which are specially aimed at the protection of marine wildlife. The most interesting are those aimed at marine mammals (e.g., whales). This chapter shall therefore focus on the following global conventions in the context of Arctic marine wildlife: the 1982 Law of the Sea Convention (LOS); the 1995 Straddling Fish Agreement (SFA) and the 1946 Whaling Convention (ICRW).

\subsubsection{The Law of the Sea Convention (LOS Convention)}

The LOS Convention entered into force in 1994. It has 164 state signatories. All of the Arctic States, with the exception of the United States, are parties to it (see: www.un.org). The LOS Convention has a complex set of provisions 
regulating fisheries both on the high seas and in the EEZs which extend out to 200 nautical miles from baselines measuring territorial seas, where $90 \%$ of the oceans' fish stocks are located. The nature and control of the jurisdiction of states depends on the zone in which the fish stock in question is found. In their EEZs coastal states determine allowable catches and promote optimal resource use. Article 61 uses the term "maximum sustainable yield" while Art. 62 employs the term "optimum utilisation." Arguably, the LOS Convention's use of terms is intentionally ambiguous in an attempt to make it more acceptable and open to broad interpretation. The ambiguity in relation to terms is undoubtedly however a contributory factor to the failure of uniform principles to emerge in respect of the exploitation and conservation of marine living resources worldwide.

Part V of the Convention regulates fishing in the EEZs. The Convention takes a holistic view of the conservation of species, and its regulation therein is based on their interdependence (see Buck). In addition, there are a host of provisions regulating the following issues:

- Conservation (Art. 61).

- Exploitation (Art. 62).

- Transboundary and straddling stocks (Art. 63).

- Highly migratory stocks (Art. 64).

- Marine mammals (Art. 65).

- Anadromous stocks (Art.66).

- Catadromous stocks (Art.67).

- Sedentary species (Art. 68).

- And the continental shelf regime (Art. 77(4)).

Living resources in the high seas are regulated in Articles 116-120 with marine habitat protection provided by Articles 192-196. With the exception of Art. 65, the Convention exhibits a preference for the optimal exploitation of resources. As noted, the relevant provisions of the Convention are rather vague in setting standards for the exploitation of natural resources.

As regards jurisdiction over straddling, transboundary and highly migratory fish resources, they are to be managed cooperatively through bilateral or multilateral international agreements between coastal states through whose waters these fish stocks range, as well as any states which 
fish these stocks on the high seas. If a coastal state is unable to harvest its entire allowable catch it is obliged to grant access to its resources to other nations, subject to appropriate terms and conditions. The Convention also provides special rights of access to surpluses of living marine resources within coastal nation EEZs for nearby developing nations that are landlocked or geographically disadvantaged (Art.63).

Regional, sub-regional or bilateral agreements are negotiated to indicate the provision of an equitable allocation to any such disadvantaged nation. It is the right of the coastal state to determine whether any harvestable surplus exists within its EEZ. Articles 65 (EEZ) and 120 (the high seas) regulate the protection of marine mammals, which calls for international cooperation through "appropriate international organisations" (by which is understood the International Whaling Commission (IWC)).

Anadromous species (e.g., salmon) spend most of their lives in the ocean, but spawn in freshwater. Primary interest in, and responsibility for, anadromous fish stocks is given to those states in whose rivers such stocks originate. Fishing for anadromous stocks is prohibited in the high seas, except in cases where economic dislocation might result. Coastal states through whose waters anadromous fish migrate are required to cooperate with the nations in whose territory the anadromous stocks originated. Catadromous species (e.g., eel) spend most of their lives in freshwater, but enter the ocean to spawn. The coastal states where these species spend most of their lives have a responsibility to manage them. International cooperation is required where these species migrate through more than one EEZ. Sedentary species are defined as “[...] organisms which, at the harvestable stage, either are immobile, on or under the seabed or are unable to move except in physical contact with the seabed or the subsoil" (Art. 77 (4) of the LOS Convention). It is accepted that sedentary species are sponges, corals, and clams. However, sedentary status is disputed in relations to crabs, lobsters and scallops, as during some periods they move unattached to the bottom. 


\subsubsection{The United Nations Agreement for the Implemen- tation of the Provisions of the UN Convention on the Law of the Sea of 10 December 1982 relating to the Conservation and Management of Straddling Fish Stocks and Highly Migratory Fish Stocks (The Fish Stocks Agreement FSA)}

The FSA was signed in 1995 and entered into force in 2001. There are 78 state signatories to the agreement. All of the Arctic States, with the exception of the United States, are parties to FSA (see: www.un.org). As noted previously, straddling fish stocks are regulated by Art. 63 of the LOS Convention, which imposes an obligation of cooperation on coastal states and on states fishing in the high seas. Again, as outlined above, the formulation of this Article is generally acknowledged to lack precision. Therefore the aim of the FSA was to complement the Convention in this respect (and also concerning highly migratory species). Article 4 states that "nothing in this Agreement shall prejudice the rights, jurisdiction and duties of states under the Convention. This Agreement shall be interpreted and applied in the context of and in a manner consistent with the Convention." The jurisdictional issues under the FSA Agreement are however rather complex, as they deal with all types of jurisdiction over fisheries: flag state jurisdiction; coastal state jurisdiction; and port state jurisdiction.

The FSA is a framework treaty. The implementation of the Convention is entrusted to regional fisheries management organisations at regional (and sub-regional) levels. The FSA favours the interests of coastal states over those of those involved primarily in high seas fishing. Article 6 of the FSA introduces the precautionary principle in relation to stocks regulated by it. The FSA is not however a global treaty, and thus cannot command the same legal status as, the LOS Convention. 


\subsubsection{The International Convention for the Regulation of Whaling (ICRW)}

The ICRW was signed in 1946 and entered into force in 1948. All of the Arctic States, with the exception of Canada, are parties to this Convention (see: www.iwcoffice.org). The main duty of the IWC (which is a body of the Convention) is to keep under review and revise as necessary the measures laid down in the Schedule to the Convention which governs the conduct of whaling throughout the world.

In addition, the Commission encourages, co-ordinates and funds whale research, publishes the results of scientific research and promotes studies into related matters such as the "humaneness" of the killing operations. There are three ways in which whales can be captured: commercial whaling (from 1986 there has been a moratorium on commercial whaling, i.e., zero quotas); indigenous whaling, and scientific whaling. Norway and Iceland subsequently however opted out of the moratorium. The IWC sets quotas for commercial and indigenous whaling but permits for scientific whaling are granted by the states themselves. The continuous moratorium on commercial whaling is very controversial and several states (e.g., Iceland, Norway and Japan) oppose to it, which makes the work of the IWC very difficult.

\subsection{Regional Treaties}

\subsubsection{Introduction}

A number of regional treaties exist which can be viewed as relevant to the conservation of Arctic biodiversity. Within the scope of this chapter however only some will be mentioned. The regional treaty which is clearly of fundamental importance in this regard is the Convention on the Conservation of European Wildlife and Natural Habitats. Arctic regional cooperation in this area is manifested by agreements on the protection of polar bears and on Cooperation in the Research, Conservation and Management of Marine Mammals in the North Atlantic (NAMMCO). 


\subsubsection{The Convention on the Conservation of European Wildlife and Natural Habitats (the Bern Convention)}

The Bern convention was signed in 1979 and entered into force in 1982. It has 50 signatories. Denmark, Finland, Norway and Sweden are parties to it (see: www.coe.int). This Convention is one of the Conventions of the Council of Europe, but it also has signatories which are non-members of the Council, such as Belarus, Burkina Faso, Tunisia, Morocco and Senegal. The Bern Convention's aim is to conserve wild flora and fauna and their natural habitats and to promote European co-operation in this field. The Convention places particular emphasis on the need to protect endangered natural habitats and endangered and vulnerable species, including migratory species. All signatories to the Bern Convention must take action to: promote national policies for the conservation of wild flora and fauna, and their natural habitats; have regard to the conservation of wild flora and fauna in their planning and development policies, and in their measures against pollution; promote education and disseminate general information on the need to conserve species of wild flora and fauna and their habitats; encourage and co-ordinate research related to the purposes of this Convention and also co-operate to enhance the effectiveness of these measures through the co-ordination of efforts to protect migratory species and the exchange of information and the sharing of experience and expertise. The Convention has 3 Appendices: Appendix I (plants); Appendix II (animals); Appendix III (lists of animals not included in Appendix II).

\subsubsection{Agreement on Cooperation in Research, Conservation and Management of Marine Mammals in the North Atlantic (the NAMMCO Agreement)}

This agreement was signed in 1992 and entered into force in the same year. Iceland, Norway, Greenland and the Faroe Islands (Denmark) are all parties to it (see: www.nammco.no). The main organ of the NAMMCO agreement is the North Atlantic Marine Mammal Commission. The primary focus of the agreement is on modern approaches to the study of the marine ecosystem as a whole, and to gaining a better understanding of the role of marine mammals in this system. NAMMCO provides a mechanism for cooperation on conservation and management for all species of cetaceans (whales and 
dolphins) and pinnipeds (seals and walruses) in the region. The parties to NAMMCO aim to strengthen and further develop effective conservation and management measures for marine mammals. Such measures should be based on the best available scientific evidence; should take into account both the complexity and vulnerability of the marine ecosystem and the rights and needs of coastal communities to make a sustainable living from what the sea can provide.

\subsubsection{The Convention on the Future of Multilateral Cooperation in North-East Atlantic Fisheries}

This Convention established a North-East Atlantic Fisheries Commission (NEAFC). The parties to the Convention are as follows: Faroe Islands and Greenland, the EU, Iceland, Norway and the Russian Federation. In addition, there are also a number of so-called Cooperating Non-Contracting Parties to the Convention: Canada, New Zealand and St Kitts and Nevis.

This 1980 Convention covers the North-East Atlantic located between longitudes 42 degrees west and 51 degrees east and which includes the Barents Sea and the Norwegian Sea and a large portion of the central Arctic Ocean, reaching all the way to the North Pole. It applies to all fishery resources (sedentary species, molluscs and crustaceans, according to its 2006 amendment). It does however exclude from its scope marine mammals, highly migratory species and anadromous stocks.

The objective of this Convention is to ensure the long-term conservation and optimum utilisation of the fishery resources in the Convention Area, providing sustainable economic, environmental and social benefits (Art. 2(4)).

Within the NEAFC two schemes are currently operated in relation to control measures, namely: the Control and Enforcement Scheme (an electronic surveillance scheme to control the fishing activities of vessels in the Regulatory Area - outside the fishing zones of the coastal states) and the non-contracting party scheme to address the problem of non-contracting party fishing activity in the NEAFC Regulatory Area. The NEAFC works closely with its sister organisations in the North Atlantic Ocean (NAFO Northwest Atlantic Fisheries Organisation) as well as the International Council for the Exploration of the Sea (ICES). NEAFC was updated in 2004 
(adding dispute settlement procedures) and in 2006 (bringing the 1980 Convention into line with developments in international law and instruments). The Parties have agreed, voluntarily, to use these as the basis for the measures taken until the amendments are ratified by all the parties.

\subsubsection{The Convention for the Conservation of Salmon in the North Atlantic Ocean (NASCO)}

Only states can be members of NASCO, which was signed in 1982 and currently has 6 signatories: Canada, Denmark (in respect of the Faroe Islands \& Greenland), the EU, Norway, the Russian Federation and the USA, (see: www.nasco.int). Iceland withdrew from NASCO as of 31 December 2009 because of financial considerations, but may re-accede to the Convention when the economic situation improves. The Convention applies to all anadromous stocks that migrate beyond the areas of national jurisdiction of the coastal states of the North Atlantic throughout their migratory range.

\subsubsection{Agreement Between the Government of Iceland, the Government of Norway and the Government of the Russian Federation Concerning Certain Aspects of Co-operation in the Area of Fisheries}

This 1999 Agreement concerns fisheries in the Barents Sea "loophole" with a view to enhancing co-operation in the field of fisheries. Thus, for this purpose it establishes principles and procedures for such cooperation based on a precautionary approach and in accordance with international law (Art.1) (see: www.eelink.net). Article 7 introduced an important provision that the parties agree to take measures to prevent the landing in their ports of catches if it has been established that such catches have been taken in a manner which undermines the effectiveness of this Agreement and the conservation and management measures referred and, subject to obligations according to established international law, to deny access to ports to vessels that engage in such activities, except in cases of distress or force majeure. 


\subsubsection{Cooperation Regarding Polar Bears (Ursus Maritimus)}

The 1973 Agreement on the Conservation of Polar Bears (ACPB) which was signed by: Canada, Denmark, Norway, the USSR, and the United States, (see: animallaw.info) is the primary agreement in this regard. The main objectives of the Agreement are as follows: to encourage cooperation in research programmes; to restrict the killing and capture of polar bears; prohibit certain hunting methods; and to protect ecosystems of which polar bears are a part. In 2000, the United States and the Russian Federation concluded a Bilateral Agreement on the Conservation and Management of the Alaskan/Chukotka Polar Bear Populations. This Agreement is linked to ACPB through its enforcement provisions. For more details see Bankes in this textbook.

\subsection{Relevant Conventions not Directly Aimed at the Protection of Biodiversity}

A cluster of treaties, both global and regional, exists where the protection of the marine environment is the general goal thus contributing also to the maintenance of biodiversity. These Conventions include the 1972 International Convention for the Prevention of Pollution from Ships (MARPOL 73/78) and the 1972 Convention on the Prevention of Pollution from Dumping of Wastes and Other Matter (the London Convention) and the 1996 Protocol to this Convention.

MARPOL has over the years been updated with numerous amendments. All of the Arctic States are parties to this agreement (see: www.austli.ed) which consists of an umbrella Convention and six Annexes (Annex I Regulations for the Prevention of Pollution by Oil; Annex II Regulations for the Control of Pollution by Noxious Liquid Substances in Bulk; Annex III Prevention of Pollution by Harmful Substances Carried by Sea in Packaged Form; Annex IV Prevention of Pollution by Sewage from Ships; Annex V Prevention of Pollution by Garbage from Ships; Annex VI Prevention of Air Pollution from Ships).

All of the Arctic States are parties to the London Convention which is based on the drawing up of "grey" and "black" lists (black lists contain 
substances the dumping of which is prohibited). The Protocol additionally prohibits all dumping at sea though with certain exceptions. Denmark, Canada, Iceland and Sweden are parties to the Protocol (see: www.admiraltylawguide.com).

The 1992 Convention on the Protection of the Marine Environment of the North-East Atlantic (OSPAR) and its 5 Annexes and 3 Appendices is a regional treaty which is also relevant here (see:www.ospar.org). OSPAR's annexes focus on the pollution from land-based sources (Annex I); Prevention and elimination of pollution by dumping or incineration (Annex II); Prevention and elimination of pollution from offshore sources (Annex III); Assessment of the quality of the marine environment (Annex IV); protection and conservation of ecosystems and biological diversity (Annex V). Despite some success however issues remain in respect of OSPAR's implementation (see: Rayfuse 2008).

\subsection{Non-Binding ("soft law") Instruments}

One example of such a non-binding instrument is the 1991 Rovaniemi Declaration on the Protection of the Arctic Environment (see: www.libraryarcticportal.org). The governments of Denmark, Finland, Iceland, Norway, Sweden, the USSR and the USA committed themselves to the joint Action Plan of the Arctic Environmental Protection Strategy (AEPS). The aims of AEPS were as follows: protection of the Arctic ecosystems, including humans; restoration of environmental quality and the introduction of sustainable utilisation for the local population including indigenous peoples; accommodation of the traditional values and practices of indigenous peoples as determined by themselves; the evaluation of the state of the Arctic environment and, as a final goal, the elimination of pollution. In 1996 the AEPS was embraced by the working groups of the Arctic Council and included, inter alia, conservation of Arctic flora and fauna, and facilitating the exchange of information and the coordination of research on species and habitats of flora and fauna. For example, the Arctic Monitoring and Assessment Programme (AMAP) was established under the aegis of the AEPS. 


\subsection{Conclusion}

Arctic biodiversity (terrestrial and marine) is covered by a very large number of global and regional instruments. It is also under constant review by the CAFF and the Arctic Council in general. There has undoubtedly been an improvement in the number of viable species of plant and animal life in this region but there are numerous factors, such as climate change and high pollution levels, which adversely influence the recovery of population levels.

Despite the sheer volume of work being done in this area it is clear that increasing the already extensive number of international treaties covering the issue of Arctic biodiversity alone may not in itself necessarily be the best way to protect threatened Arctic populations of plants, animals or fish. On occasions they compete with each other (e.g., the IWC and the NAMMCO Commission do not always pursue the same policy regarding whaling) while it is also frequently, the case that the listing of "endangered" species differs across various agreements. Sperm whales are a good example of this as they are listed under Appendices 1 and 2 of the Bonn Convention on Migratory Species, Appendix 3 of the Bern Convention, and Appendix 1 of CITES. States can also opt out of certain conservation decisions adopted by bodies which are established by these agreements or submit reservations. In some cases conventions are not fully implemented. Another emerging issue is the protection of indigenous peoples' right to nature and to securing access to (biodiversity) which is not always satisfactory and/or sufficient.

Recent years have undoubtedly seen a growing level of awareness in respect of biodiversity protection as well as an increase in inter-state cooperation. In particular, at the global level, CITES must be mentioned as an uplifting example of the MEA which actually works. At the regional level, one excellent example of a successful collaborative venture between states is cooperation over the protection of species, including migratory species, in the Arctic. The CAFF is a very active body, indispensable both in the provision of data and in providing leadership on international projects. Moreover, the work done within the Arctic Council, particularly with regard to biodiversity and marine wildlife in the Arctic, shows that it is not always necessary for an organisation to have far-reaching powers to achieve ground-breaking results. 


\section{Further reading}

Arctic Biodiversity Trends 2010-Selected Indicators of Change. CAFF: Akureyri, Iceland, May 2010. www.arcticbiodiversity.is

The Arctic Biodiversity Assessment, Work Plan and Financial Strategy, 2008, CAFF http://arcticportal.org/uploads/LI/Br/LIBrPLbS58h27UbqNvAScA/ABAWorkplan-and-Financial-Strategy.pdf

Barry Tom \& Donald McLennan. "Changes in Protected Areas," in Arctic Biodiversity Trends 2010: 96-98.

Bowman, Michael, Peter Davis \& Catherine Redgwell. Lyster's International Wildlife Law (Cambridge: Cambridge University Press, 2 ${ }^{\text {nd }}$ ed., 2010).

Buck, E.H.,"U.N. Convention on the Law of the Sea: Living Resources Provisions,:" http://www.fas.org/sgp/crs/row/RL32185.pdf.

Fitzmaurice, Malgosia. "Indigenous Whaling, Protection of the Environment, Intergenerational Rights and Environmental Ethics," in Natalia Loukacheva Special editor, The Yearbook of Polar Law, Vol.2, (Leiden: Martinus Nijhoff Publishers, 2010): 253-279.

Fitzmaurice, Malgosia. Contemporary Issues in International Environmental Law, ( (The Lypiatts, UK\& Northampton, MA, USA, Edward Elgar Publishing, 2009) in particular Ch. I On the precautionary principle, 1-67.

Hohn, Janet and Esko Jaakkola." Introduction," in Arctic Biodiversity Trends 2010:8-11.

Lunn, Nick et al, Polar Bears, in Arctic Biodiversity Trends 2010:26-28.

Penikett, Tony. "At the Intersection of Indigenous and International Treaties," 2010 at www.arcticgovernance.org

Ong, David M. "International Environmental Law Governing Threats to Biological Diversity," in Malgosia Fitzmaurice et al. eds., Research Handbook on International Environmental Law (The Lypiatts, UK\& Northampton, MA, USA, Edward Elgar Publishing, 2010), 519-542.

Rayfuse, Rosemary. "Protecting Marine Biodiversity in Polar Areas beyond National Jurisdiction," Review of European Community and International Environmental Law, Vol. 17 (2008): 3-13.

Reist, James D. \& Chantelle D. Sawatzky, "Arctic Char," in Arctic Biodiversity Trends 2010:41-44.

Sitters, Humphrey P. \& Pavel S. Tomkovich, "Shore Birds-Redknot," in Arctic Biodiversity Trends, 2010:32-34. 


\section{Websites}

The Conservation of Arctic Flora and Fauna (CAFF) working group of the Arctic Council, www.caff.is

Convention on Biological Diversity, www.cbd.int

The UNESCO Convention Concerning the Protection of the World Cultural and Natural Heritage (the WHC), http://whc.unesco.org/en/convention

Convention on International Trade in Endangered Species of Wild Fauna and

Flora (CITES), www.cites.org

\section{Questions}

- Compare the legal nature of the CBD and the CITES? Which one is more effective in the protection of Arctic biodiversity?

- Explain the World Heritage Convention's listing procedure with reference to sites listed in the territories of Iceland and Norway.

- Explain the differences between NAMMCO and the International Whaling Commission in respect of whaling protection. 



\section{Polar Bears and International Law}

Nigel Bankes

\subsection{Agreement on the Conservation of Polar Bears}

Concluded in 1973, the Agreement on the Conservation of Polar Bears and their Habitat (ACPB) was primarily developed as a response to commercial over-hunting of bears in some polar bear states, in particular the United States (Alaska) and Norway (Svalbard)(1). The ACPB principally sought to address this problem by banning hunting (Article 1(1)) and, in particular, banning hunting using large motorised vessels and aircraft (Art. IV). Under the Agreement, harvesting may still occur for scientific purposes, conservation purposes and in connection with the management of other species (Art. III(1)). In addition, and most importantly, the ACPB contemplated the continuation of harvesting by indigenous peoples where this was already occurring (Alaska, Russia, Canada and Greenland) (2).

The Agreement did not provide for any institutional mechanism such as a conference of the parties although, as matter of practice, the Polar Bear Specialist Group (PBSG), a sub-group of the Species Survival Commission of IUCN $\backslash$ World Conservation Union, monitors the implementation of the Agreement and in effect serves as a scientific advisory committee for the Agreement. In recent years the range states to the Agreement have taken measures to create a more formal institutional structure by convening meetings of the states party to the ACPB. The first such meeting was held in Tromsø, Norway in March 2009, and the second in Iqaluit, Canada in October 2011(3). The Tromsø meeting dealt with a number of topics including: climate change, habitat protection, contaminants, shipping related activities etc., and harvest management. 
Most commentators regard the Agreement as a success. According to Prestrud and Stirling (at 120-121) the agreement has been successful in limiting hunting to sustainable levels but less successful in promoting habitat protection. Populations of polar bear have recovered as a result of the restrictions on harvesting.

The Agreement has been less successful in responding to two challenges: climate change, and the overharvest of shared populations of polar bears. As to the first, there is a mismatch of both scale and subject matter between the global problem of atmospheric climate change, and the ACPB as a regional wildlife agreement (4). The ACPB has proven to be either unwilling or unable to deal with this problem. Thus, while the Tromsø meeting of the parties in 2009 recognised that climate change (at 1) "has a negative impact on polar bears and their habitat and is the most important long term threat facing polar bears" the parties went on to state that "Action to mitigate this threat is beyond the scope of the Polar Bear Agreement. Climate change affects every nation on the earth and reaches well beyond the five parties to the Agreement so the parties look to other fora and national and international mechanisms to take appropriate action to address climate change" (Ibid.) \& (5)( Bankes 2009 \& 2009a).

The second issue arises in those cases in which one of the 19 subpopulations of polar bear is shared between two jurisdictions, both of which allow harvesting. For example, Russia and the United States share the Chukchi Sea population, while the United States and Canada share the Southern Beaufort Sea (SB) population. Similarly, Canada (principally Nunavut) and Greenland share the Kane Basin, Baffin Bay and Davis Strait populations. The ACPB had very little to say about the challenges posed by the existence of shared populations, and while PBSG reports have frequently commented on the issues associated with shared populations, its advisory responsibilities limit it to drawing attention to actual or potential problems of overharvest and exhorting the range states of these subpopulations to reach agreements to address these issues. For the most part that has happened in a timely way, either as between the user groups themselves (as in the case of the Inuvialuit and Inupiat (6)), or at the state to state level (as in the case of the Russia/US agreement with respect to the Chukchi Sea population) (7). On the other hand, an agreement between Greenland and Canada (8) was very slow in coming and was only 
successfully negotiated after some years of unacceptably high harvests, criticism from the PBSG, and the issuance of negative "no detriment" conclusions by both Canada and Greenland within the context of Convention on International Trade in Endangered Species (CITES)(9). Implementation of this bilateral agreement is only just beginning.

\subsection{Discussion of Polar Bear in other International Fora}

The ACPB is undoubtedly the leading international agreement dealing with the conservation of polar bears in the same way as the International Convention on the Regulation of Whaling (ICRW) is the leading international instrument dealing with whales. But just as the ICRW faces "competition" from other instruments including the Bonn Convention on Migratory Species, NAMMCO and CITES (10) the conservation of polar bears is also on the agenda of other multilateral environmental agreements. For example, polar bear has long been listed on Appendix II of CITES (i.e., threatened rather than endangered) but at the last CITES CoP in Doha (2009), the United States, following the domestic listing (2008) of polar bears as threatened under its Endangered Species Act (11), proposed uplisting polar bear from Appendix I to Appendix II. Although the up-listing proposal failed to get the necessary support, the United Sates has indicated that it will renew its up-listing proposal at the upcoming CITES CoP in Thailand in March 2013 (12). One of the implications of Appendix II listing is that range states must make a no-detriment finding (NDF) before authoring export of a specimen (e.g., a polar bear hide) (i.e., a finding that export will not be detrimental to the survival of the species). As noted above, both Greenland (with respect to all of its polar bear populations) and subsequently Canada (with respect to the shared Baffin Bay population) were forced to issue negative NDF findings for some sub-populations of bears (Bankes 2012 \& Icon on Ice).

More recently, the Working Group on Aquatic Mammals of the Scientific Council of the Bonn Convention considered a proposal to list polar bear on appendix II of the Convention (13 at 3). In the inconclusive discussion that followed it was "emphasised that a CMS listing should complement the im- 
portant work already being carried out by Range States, in particular through the Polar Bear Agreement and the Arctic Council Circumpolar Biodiversity Monitoring Programme. The listing would not have the purpose of triggering another agreement for the Arctic but to both complement existing CMS Arctic priorities and to facilitate the discussion and possible mitigation of climate change impacts by CMS Parties beyond the Arctic"(Ibid.).

One final development worthy of note is the effort of the Center for Biological Diversity (a US based ENGO) to use the petition procedure available under the North American Agreement on Environmental Cooperation (14) to argue that Canada is failing to effectively enforce its domestic environmental law by failing to list polar bear as threatened or endangered under Canada's Species at Risk Act. On this point the Commission on Environmental Cooperation has ruled that the submission is admissible and has asked Canada for its views on the petition (15).

\section{Further reading/notes}

1. The text of the Agreement is available on the website of Polar Bear Specialist Group (PBSG) under the heading "agreements and conventions" http://pbsg.npolar.no/en/ For the background to the ACPB see in particular Pal Prestrud and Ian Stirling, "The International Polar Bear Agreement and the Current Status of Polar Bear Conservation" (1994) 20 Aquatic Mammals:113-124, Fikkan et al, "Polar Bears: The Importance of Simplicity" in Oran Young \& Gail Osherenko (eds.), Polar Politics: Creating International Environmental Regimes (Ithaca: Cornell University Press, 1993): 96151 and Donald C. Baur, "Reconciling Polar Bear Protection Under United States Laws and the International Agreement for the Conservation of Polar Bears" (1996) 2 Animal Law:9-99.

2. On indigenous harvesting of polar bears see: Milton M.R. Freeman \& Lee Foote (eds.), Inuit, Polar Bears, and Sustainable Use: Local, National and International Perspectives (Edmonton: University of Alberta, CCI Press, 2009). 
3. Meeting of the parties to the 1973 Agreement on the Conservation of Polar Bears, Iqaluit, Nunavut, Canada, 24-26 October 2011. The "Outcome of Meeting" document for both this and the earlier Troms $\varnothing$ meeting is available at <http://www.polarbearmeeting.org/ content.ap?thisId=500038172 $>$ (accessed 15 October 2012).

4. For an argument that the parties to the Agreement do have a duty to take steps to protect the ecosystem of which the bear is a part, and that this should include measures to mitigate climate change see: Nigel Bankes, "Climate Change and the Regime for the Conservation of Polar Bears," in Timo Koivurova, E. Carina H. Keskitalo \& Nigel Bankes (eds.), Climate Governance in the Arctic (Hanover: Springer Verlag, 2009):351-382.

5. Nigel Bankes, "The Tromsø meeting of the parties to the 1973 Agreement on the Conservation of Polar Bears: a comment on three aspects of the meeting report" http://ablawg.ca/wpcontent/uploads/2009/10/blog_nb_polarbears_april-2009.pdf (2009a), and 2009 note 4 .

6. Agreement between the Inuvialuit (Canada) and Inupiat (Alaska) for the management of the Southern Beaufort Sea population, March 2000, at http://pbsg.npolar.no/en/agreements/USA-Canada.html. See also Memorandum of Understanding (2008) between Environment Canada and the United States Department of the Interior for the Conservation and Management of Shared Polar Bear Populations at http://graphics8.nytimes.com/packages/pdf/national /20080515polar_memo.pdf

7. Agreement between the Government of the United States of America and the Government of the Russian Federation on the conservation and management of the Alaska-Chukotka polar bear population. Washington DC, 16 October 2000 (entered into force 2008), http://pbsg.npolar.no/en/agreements/US-Russia.html

8. Memorandum of Understanding (2009) between the Government of Canada, the Government of Nunavut and the Government of Greenland for the Conservation and Management of Polar Bear Populations, A signed text of the MOU is available at http://pbsg.npolar.no/export/sites/pbsg/en/docs/GN-MOU-PB.pdf The text is undated but press reports suggest that the text was 
signed on 30 October 2009: CanWest News Service "Canada, Nunavut sign polar bear agreement" http://www.canada.com/ news/Canada+Nunavut+Greenland+sign+polar+bear+agreement $/ 2$ 164805/story.html

9. For the CITES text and other related documents visit the CITES website here: http://www.cites.org/ For more details see: Nigel Bankes, "An Arctic Governance Issue: The management of shared populations of polar bear," in Øyvind Ravna \& Tore Henriksen (eds.), in Juss i nord: Hav, fisk og urfolk: En hyllest til Det juridiske fakultet ved Universitetet i Tromsøs 25-årsjubileum, (Oslo: Gyldendahl Juridisk, 2012):40-70. See also Tanya Shadbolt et al, Icon on Ice: International Trade and Management of Polar Bears, Traffic, 2012, http://www.traffic.org/species-reports/traffic_species_ mammals69.pdf

10. There is a significant body of literature on this competition in the context of the IRWC. See in particular Alexander Gillespie, "Forum Shopping in International Environmental Law: The IWC, CITES, and the Management of Cetaceans" (2002) 3 Ocean Development and International Law: 17-56. On NAMMCO see: David Caron, "The International Whaling Commission and the North Atlantic Marine Mammal Commission: The Institutional Risks of Coercion in Consensual Structures" (1995) 89 American Journal of International Law: 154-174.

11. The listing decision and related information is available at http://alaska.fws.gov/fisheries/mmm/polarbear/esa.htm

12. For the listing proposal see:

http://www.cites.org/eng/cop/15/prop/

E-15-Prop-03.pdf and for the position of the Government of Canada on the proposal see: http://www.cites.org/common/cop/16/Inf/ E-CoP16i-10.pdf

13. 17th Meeting of the Scientific Council, Bonn Convention, Bergen, 1718 November 2011, Report of the Working Group on Aquatic Mammals.

14. 14 September 1993, 32 ILM 1480. This is the so-called environmental side agreement to the North American Free Trade Agreement. 
15. CEC Determination on Petition, 29 November 2012. The Determination, the petition and other relevant documents are available on the CEC's website at: http://cec.org/Page.asp?PageID= 2001\&ContentID $=25143 \&$ SiteNodeID $=250 \&$ BL_ExpandID $=\& A A_{-}$ SiteLanguageID $=1$

\section{Questions}

1. Most MEAs provide for a conference/meeting of the parties (C/MoP) which brings governments together at the political and diplomatic levels on a regular basis. As noted above this has not happened until very recently in the case of the ACPB. What do you think are some of the implications of this? Has the PBSG served as an adequate substitute for a $\mathrm{C} / \mathrm{MoP}$ ?

2. The ACPB is one of the very few international agreements, if not the only such agreement, between the five littoral states (as opposed to the Arctic 8 of the Arctic Council). The 2008 Ilulissat Declaration, while not a treaty, was similarly signed by the littoral states. Do you see any parallels between the Declaration and the ACPB?

3. The PBSG has been very influential in developing a science based approach to managing polar bear populations. Visit the PBSG's website and take a look at some of the Group's recommendations arising from its regular meetings. The PBSG emphasises the importance of western science. What can you discern of its attitude to the traditional knowledge of Inuit and Inupiat harvesters of polar bears?

4. What is the NDF status of sub-populations of bears in Canada and Greenland? Where can you find that information? What types of information must a national scientific authority have in order to be able to make NDF determinations?

5. What are the criteria for Appendix I listing under CITES? What are the arguments for and against up-listing? See the US proposal and Canada's rebuttal (references/notes above).

6. What is the position of the EU in relation to the conservation status of polar bear? With respect to CITES listing decisions? And with respect to the import of polar bear hides etc.? For a discussion on this issue see the Icon on Ice 2012:72 report. 



\section{The Antarctic Treaty System and the Regulation of Antarctic Tourism}

Kees Bastmeijer

\subsection{Introduction}

Antarctic tourism has grown rapidly since the early 1990s. While in 1992 about 2,000 tourists made landings in Antarctica, this number had increased to more than 16 times that number by $2007-08$. During that season, the total number of Antarctic tourists, including those involved in cruise only activities, airborne tourism and land-based activities, exceeded 46,000 while the total number of persons visiting the Antarctic for tourism purposes, including staff and crew, was estimated at more than 73,000 . In the last few years however, the numbers have dropped significantly, in season 2010-11 to around 34,000 tourists and in season 201112 to about 26,000 (see: www.iaato.org). This decline in numbers has undoubtedly been caused by the economic crisis. The situation was exacerbated further by a regulation recently introduced by the International Maritime Organization (IMO) that prohibits the use of heavy oil as ship fuel in the Antarctic region. It is however estimated that in the 2012-13 season numbers will begin to rise again and that further sustained growth in the Antarctic tourism sector can be expected over time. In a world where the number of people will increase towards 9 billion in just a few decades, a "holiday on ice" in one of the last true wildernesses on this globe represents a dream for many. 
Parallel to the numbers of tourists the diversity of tourist activities has also increased over the last twenty years. For many decades Antarctic tourism was primarily ship-based; however, since the 2003-04 season socalled "fly-sail" or "fly-cruise" operations began where tourists are taken to the Antarctic peninsula by aircraft and then make excursions on yachts or cruising vessels. Other activities in Antarctica include scuba diving, camping, kayaking, cross country skiing, mountaineering, long distance swimming, excursions by helicopter, sky diving, marathons and the use of a hovercraft.

These developments in Antarctic tourism raise various international management questions relating to the safety of tourists, the interaction between science and tourism and the direct, indirect or cumulative effects on the Antarctic environment. This chapter aims to undertake a comprehensive overview of how the states involved in the Antarctic Treaty System (ATS) and the tourism sector itself have responded to these developments and related concerns. It also provides a gap analysis.

At the outset, the ATS and the relevance of existing legal instruments for tourism activities in Antarctica will be briefly discussed. Next, an overview of international Antarctic tourism management over the period of 1990 to 2012 is provided. Based on this overview, the chapter's final section discusses the main "outstanding questions" in relation to the strategic management of Antarctic tourism.

\subsection{The Antarctic Treaty System and Tourism}

\subsubsection{The Antarctic Treaty System (ATS): A Brief Introduction}

Antarctica, politically defined as the continent, all islands and surrounding oceans below the 60 degrees south latitude, is the subject of a unique international management system: 28 states, each with a substantial scientific interest in the area, manage the area collectively through a consensus-based decision-making system. This system derives from historic international discussions on territorial claims. During the first half of the $20^{\text {th }}$ Century, 7 states (Argentina, Australia, Chile, France, New Zealand, Norway and the 
United Kingdom) claimed parts of the continent, but the legitimacy of these claims was internationally disputed. In 1959, the 7 claimant states and 5 other states involved in Antarctic research (conducted during the International Geophysical Year of 1957-58) signed the Antarctic Treaty in Washington. This treaty entered into force in 1961. A central element of the treaty is the "agreement to disagree" of Art. IV regarding the legitimacy of the sovereignty claims: the positions of all states regarding the legal status of Antarctica are reserved and the contracting parties agree to manage Antarctica collectively. Since 1961, other states succeeded in showing a substantial scientific interest in Antarctica and received the "consultative status" ("right to vote-status") in accordance with Art. IX of the Antarctic Treaty. Today 28 consultative parties are involved in the Antarctic decision-making process, which is based on consensus, while 22 other states are contracting parties to the Treaty (non-consultative parties). The most recent new members of the "Antarctic family" are Malaysia (accession to the Treaty on 31 October 2011) and Pakistan (accession to the Treaty on 1 March 2012 and to the Protocol on 31 March 2012). These accessions are important for the international legitimacy of the ATS as in the past these 2 states put much effort into the international advocacy campaign for the management of Antarctica in the framework of the United Nations.

Since the Treaty was promulgated, several other conventions and many recommendations have been adopted (for an overview, see: http:// www.ats.aq). Some of these agreements are in various ways linked to the Antarctic Treaty but are in fact independent international agreements. An important example here is the Convention on the Conservation of Antarctic Marine Living Resources (CCAMLR), signed in 1980. For tou-rism, the most important legal instrument is the Protocol on Environmental Protection to the Antarctic Treaty (the Protocol). The Protocol, which entered into force on 15 January 1998, establishes a comprehensive system of obligations and prohibitions, addressing most types of activities (including tourism) in the region below the 60 degrees south latitude and designates this region as a nature reserve, devoted to peace and science (Art. 2). In addition to these more comprehensive legal instruments, the Antarctic consultative parties also regularly adopt additional measures (legally binding instruments) and resolutions (non-binding instruments) at their annual meetings: the Antarctic Treaty Consultative Meetings ("ATCMs"). 
This set of international instruments for the governance of the Antarctic is often referred to as the "ATS." From the start, safeguarding peace and ensuring the freedom of scientific research constituted the two main pillars of the ATS, but with the adoption of the Protocol in 1991, the protection of the Antarctic environment emerged as a third pillar. At the ATCM, the consultative parties discuss the implementation of the Treaty, the Protocol and measures and resolutions, as well as the need to adopt additional management measures.

\subsubsection{The Protocol's Relevance for Tourist Activities}

One of the consequences of the Protocol for tourist activities is that a prior environmental impact assessment (EIA) must be prepared. Depending on the possible impacts of an activity on the Antarctic environment (including, e.g., the intrinsic values, such as wilderness values), the proposal for the activity must be subjected to a preliminary assessment (PA), an initial environmental evaluation (IEE) or a comprehensive environmental evaluation (CEE). The details of this EIA-obligation are laid down in Art. 8 and Annex I to the Protocol. Annex II includes general provisions on the protection of flora and fauna, which are also relevant for tourist activities. For instance, taking or harmful interference with flora and fauna must be avoided and precautionary measures must be taken to prevent the introduction of non-native species and diseases. Tourist expeditions should also take into account the waste management provisions of Annex III (on land) and Annex IV (at sea). Annex V constitutes the bases for designating Antarctic Specially Protected Areas (ASPAs), Antarctic Specially Managed Areas (ASMAs) and historic sites and monuments. Tourist activities in ASPAs are allowed only if the internationally agreed management plan allows for such activities and if a permit for entering the ASPA has been issued by one of the contracting parties to the Protocol. Tourist activities in ASMAs may be conducted in accordance with the code of conduct for the area. In general, historic sites and monuments may be visited, but damage to the sites or monuments must be avoided.

The state parties to the Protocol must ensure that these provisions and all other provisions of the Protocol have been implemented in the domestic legal and administrative systems and are applied in practice to all Antarctic activi- 
ties under their jurisdiction. Many of the state parties deve-loped detailed implementation legislation and most of these states (e.g., Germany, Sweden, New Zealand, and the Netherlands) connected the EIA obligations to a domestic permit or authorisation system for the conduct of activities in the Antarctic. This enables these governments to deny access to the Antarctic Treaty area if it is determined that the activity would be in violation with the domestic legislation. However, not all consultative parties adopted this approach. For instance, the United States implemented the Protocol without a general authorisation system. Consequently, tourist activities are the subject of EIA provisions and other specific provisions implementing the Annexes to the Protocol, but the US government has limited means to prevent a tour operator from going to the Antarctic.

The general practice under the domestic implementation systems is that tourist expeditions are subjected to preliminary assessments or initial environmental evaluations (not to CEEs) and that authorisations or permits for tourist activities are seldom refused. One of the very rare court decisions with respect to refusing a permit for an Antarctic nongovernmental activity relates to an art project that planned to leave a permanent bronze sculpture in the Antarctic (Final Report ATCM XXIX, para. 172). In 2006, the German court decided that the German competent authority had the legal competence to refuse a permit for this activity on the basis of the German Antarctica legislation.

\section{3 "Phases" of Tourism Management in the Antarctic between 1990 and 2012}

\subsubsection{0-1992: A Tourism Annex to the Protocol?}

Already during the negotiations on the Protocol (1990-91), concerns were expressed about the development of tourism and other nongovernmental activities in Antarctica. For example, the report of the negotiations working group II of the Chile session of the XIth Special ATCM $(1990,108)$ states: 
"Consideration was also given to the convenience of carrying out tourist activities by maritime means. This would avoid the proliferation of terrestrial support infrastructure in Antarctica. It also considered the possibility of establishing duly monitored special tourist interest areas, in order to determine the impact of human presence on the environment and its feasibility as a management scheme."

These considerations did not however result in specific provisions on tourism in the text of the Protocol. In view of the concerns expressed by certain states over the development of tourism in Antarctica, the Final Report of the XIth Special ATCM $(1991,102)$, states: “[...] the meeting proceeded to initiate a study on tourism, and the representatives agreed that their study of this subject would be carried out in the XVI Consultative Meeting" (see also p. 23).

Accordingly, the issue of tourism received substantial attention during the XVIth ATCM in 1991. Five working papers and eleven information papers on the issue were tabled. Some of the working papers included proposals for a 6th Annex to the Protocol on tourism and non-governmental expeditions. A special sub-working group on tourism was established, that also discussed the proposals for a separate annex (Ibid., 29-30). However, no consensus could be reached on the desirability of specific regulations on tourism activities that would go beyond the general provisions of the Protocol. Therefore, the discussions resulted in a procedural agreement, laid down in Recommendation XVI-13. With this recommendation, the representatives expressed their concerns "about the possible effect of increased tourism and non-governmental activities in Antarctica" and recommended to their governments (Ibid., 131-132):

\footnotetext{
"that an informal meeting of the Parties be convened with a view to making proposals to the XVIIth Consultative Meeting on the question of a comprehensive regulation of tourist and non-governmental activities in Antarctica in accordance with the Protocol and taking into account the proposals made at the present XVIth Consultative Meeting, including proposals for a future Annex to the Protocol on environmental protection."
}

Furthermore, the recommendation listed a number of issues that were not addressed in the Protocol and should receive further attention, including the "number of tourist/carrying capacity, permanent infrastructure for tourists, concentration/dispersal of tourist activities and access to unexplored areas." 
Several of these issues were dealt with in a draft annex to the Protocol on tourism, tabled at the XVII th ATCM by Chile, France, Germany, Italy and Spain (Doc. XVII ATCM/WP 1); however, the informal meeting prior to the $\mathrm{XVII}^{\text {th }}$ ATCM (9 and 10 November 1992) as well as the formal discussions at that ATCM made it clear that again no consensus could be reached among the consultative parties. One of the arguments against a separate annex on tourism at that stage was that the Protocol already applies to all human activities, including tourist activities, and that a separate annex on tourism would adversely affect the adequate implementation and ratification of the Protocol. Nonetheless, several states "maintained that more precise regulation having legally binding force was required for such activities" (Final Report of the XVII th ATCM, 1992: para. 112).

\subsubsection{2-2003: Little Decision-making and Reliance on Self-regulation}

At the XVIIIth ATCM (1994), consensus was reached on the desirability of non-binding guidelines as a compromise between "no action" and "additional legal regulation" in respect of tourism (Final Report of the XVIIIth ATCM, 1994, para. 59):

\footnotetext{
"There was agreement that the objective at this Meeting was not to create new rules and regulations but to provide guidance to those visiting Antarctica and those organising and conducting tourism and non-governmental activities there."
}

The meeting adopted Recommendation XVIII-1 which included a set of guidelines for visitors to the Antarctic as well as a set of guidelines for the organisers of non-governmental expeditions (Ibid., 35-45).

Between 1994 and 2000, the item of tourism was discussed at each ATCM. Issues that were discussed include requirements on and formats for advance notification and post-visit reporting, compliance enforcement from gateway ports, concerns related to cumulative impacts, the visitation of new (previously unvisited) sites, monitoring, education and training, selfregulation and tourism activities from non-contracting states.

These discussions clearly show that several consultative parties were concerned about the development of tourism in Antarctica, in particular 
because of the possible adverse impacts of these activities on science and the Antarctic environment. However, these concerns did not result in a substantial number of additional measures. Only a limited number of additional measures were adopted with regard to the issue of advanced notice and post-visit reporting (see: Resolution 3(1995) and the Final Report of the XIX ${ }^{\text {th }}$ ATCM, 1995, paras 55-58; Final Report of the XX ${ }^{\text {th }}$ ATCM, 1996, para. 76). The rather more fundamental issues concerning Antarctic tourism however received relatively little attention. For instance, the issues reflected in Recommendation XVI-13 (1991, see above) were still not discussed.

At the XXIVth ATCM (2001; para. 106) the meeting "noted that there is an increase in the diversity of tourism activities, which may present new management challenges." The consultative parties agreed on the importance of the appropriate management of Antarctic tourism and agreed further "that the issue of tourism should be the subject of detailed discussion at XXV ATCM" (para. 112). At that ATCM in 2002, certain contracting parties argued that additional legally binding rules should be adopted to manage Antarctic tourism. France once again proposed the development of a separate Annex to the Protocol on tourism (Doc. XXV ATCM/WP 02). Although the issue was discussed intensively, no consensus was reached on the need to take any measures that go beyond the Protocol or that specify the consequences of the Protocol for Antarctic tourism. According to the Final Report of the XXVth ATCM (2002; para. 116):

"A number of Delegations considered that a new Annex to the Environmental Protocol concerning regulation of tourism and non-governmental activities [...] is not required. They considered that the Protocol deals effectively with the environmental aspects of tourism."

During the period 1992-2003, this reluctance to adopt additional legal instruments may also be related to a growing recognition of the work of the International Association of Antarctica Tour Operators (IAATO, see: http://iaato.org). In 1991, the year in which the Protocol was adopted, this association was founded by 7 tour operators with the objective being in part " $(\mathrm{t}) \mathrm{o}$ advocate, promote and practice safe and environmentally responsible travel to Antarctica." Currently, more than 100 tourism companies are (associated or full) members of IAATO. IAATO has taken many 
initiatives to increase the environmental awareness of its members. Most important here are the objectives and bylaws that must be respected by all members. These objectives and bylaws include the requirement for members to ensure compliance with the requirements of the Protocol (e.g., in respect of EIA), additional measures outlined by the ATCM and the guidelines for tour operators and for visitors.

IAATO has however, in addition, adopted bylaws that clearly go beyond the requirements of the governmental system. Examples here include: guidelines on watching sea mammals, guidelines on the prevention of the introduction of alien species and diseases, and a wilderness guideline. Furthermore, the association undertakes various practical coordinating activities, for instance, to increase safety and to prevent the visit of more than one ship to any Antarctic site at the same time. IAATO's work has thus clearly developed into a comprehensive and robust selfregulatory system for Antarctic tourism.

Since its foundation, IAATO has been very successful in showing the value of its work to the Antarctic consultative parties. At each ATCM, IAATO tables a comprehensive annual report and a paper that provides an overview of Antarctic tourism. The report includes the number of tourists that have visited the Antarctic during the previous season, the type of tourist activities that have been conducted and the incidents that have occurred. Furthermore, in its papers IAATO predicts the number of tourists for the next season and discusses the trends in Antarctic tourism (e.g., increasing diversity of activities, growth of land-based activities). IAATO also plays an active role in political and legal discussions, both at the domestic level and the international level. At the domestic level, one example from the USA is the involvement of IAATO in the process of drafting the "Proposed Rule on the Environmental Impact Assessment of Nongovernmental Activities in Antarctica." At the international level, IAATO is actively involved in discussions held within the Commission for Environmental Protection (CEP) and the ATCM's Working Group on Tourism and Non-Governmental Activities.

Many contracting parties clearly attach high value to IAATO and its work. This is perhaps best illustrated by the opportunity they provide for it to participate in ATCM-discussions as an expert organisation. In addi- 
tion, it has also been explicitly noted in ATCM reports. For example, the Final Report of the XX ${ }^{\text {th }}$ ATCM (1996, para. 84) states.

"the Meeting stressed the importance of effective self-regulation by the tourist industry. To this end, the Meeting urged IAATO to:

- Ensure that its members conform fully to the provisions of the Protocol;

- Disseminate ATCM recommendations and other texts relevant to tourism;

- Produce further guidelines and codes of conduct where appropriate;

- Encourage all tour companies operating in Antarctica to become members of the Association."

As stated above, for this time period, this recognition is probably one of the reasons why several consultative parties did not support additional legal measures in respect of Antarctic tourism.

\subsubsection{4-2007: Growing Awareness of the ATCM's Responsibility for Tourism but Still Little Decision- making}

With the continuing expansion of Antarctic tourism, in term of both numbers and in diversity, the question of whether the existing regulations (particularly the Protocol), paralleled by the IAATO self-regulation regime, should be considered sufficient to address the various concerns, became more prominent. In 2004, Norway hosted an Antarctic Treaty Meeting of Experts on Tourism to promote informal discussions. This was a particularly valuable meeting because some of the more strategic issues were tabled and seriously discussed for the first time since the beginning of the 1990s (e.g., the allowance of permanent facilities for tourism in Antarctica; options for improving supervision of tourist activities in Antarctica through the development of an international observer scheme).

At the ATCMs of 2004-08, issues related to Antarctic tourism were intensively debated in the Working Group on Tourism and Non-Governmental Activities. Important issues of debate included the following: 
- Safety risks related to adventure tourism and the risk of disturbing scientific research posed by such activities;

- Safety and environmental risks related to the increase in large passenger ships sailing in Antarctic waters (ships with a capacity of more than 500 passengers);

- The (increased) use of third country flagged vessels for tourism activities in the Antarctic;

- The potential increase of non-IAATO tour operators in Antarctica;

- Monitoring and addressing the (potential) cumulative impacts of visitors in the Antarctic;

- The possible development of an accreditation system for Antarctic tour operators;

- The question of whether (new) permanent facilities for tourism in Antarctica should be prohibited.

Debate on most of these issues has been lengthy and based on well prepared papers. Unlike the period 1992-2003, the argument that tourism was sufficiently regulated by the Protocol and IAATO received less emphasis. Although consultative parties continued to support cooperation with IAATO, the "responsibility" of the ATCM to address tourism-related concerns was stressed more explicitly and more often.

To exercise this responsibility the ATCM adopted various resolutions on Antarctic tourism issues. Resolutions (not legally binding) and even a measure (Measure 2004(4)), which will become legally binding after formal approval by all consultative parties, were adopted to promote self-sufficiency and safety in relation to tourist expeditions, for instance by requiring search and rescue (SAR)-arrangements and financial security (e.g., insurance) to cover SAR-related costs. Other resolutions aimed at preventing visitorbased cumulative impacts at landing sites. Two approaches are particularly important here. First, for a growing number of landing sites, "Site Specific Guidelines" have been developed and adopted in the form of resolutions. These resolutions urge the governments of consultative parties to encourage tour operators to take these guidelines into account during visits to the relevant landing sites. Secondly, Resolution 4(2007) "codified" some important IAATO bylaws relating to landing in Antarctica. For instance, according to the resolution, governments should discourage tour operators 
that use ships with a capacity of 500 or more passengers from making landings in Antarctica. Finally, in 2007 the ATCM adopted Resolution 5(2007) through which the parties are recommended to "discourage any tourism activities which may substantially contribute to the long-term degradation of the Antarctic environment and its dependent and associated ecosystems."

Thus, by the end of this period (ten years after the Protocol entered into force in 1998), only a limited number of additional measures have been taken to address concerns related to the ongoing increase in Antarctic tourism. Moreover, almost all of the recommendations adopted are not legally binding, having instead "resolution status" and, as such, are often based on work established by IAATO's self-regulation system. Only one measure specifically related to tourism has been adopted (Measure 2004(4)). This measure primarily aims to ensure the self-sufficiency of tourist expeditions to prevent human safety incidents and to avoid disturbing scientific programmes if and when rescue operations take place. Furthermore, the ATCM did not reach consensus on any of the more strategic policy questions, including certain questions that were already raised in the early 1990s. For instance, suggestions by France to develop an area-regime for tourist visitation (e.g., areas closed and opened for tourism) again received very little attention by the ATCM. Particularly in response to certain incidents (e.g., the sinking of the $M / S$ Explorer in 2007) ship safety issues have received significant attention at the ATCM; however, partly due to the existence of different views on the relationship between the IMO and the ATCM, the ATCM were not able to adopt any resolution in this time period. After 4 years of debate, no consensus could be reached in respect of the question whether permanent facilities for tourism in Antarctica should be prohibited or regulated in some other way. It could be argued that the above-mentioned general policy statement of Resolution 5(2007) is important here but its wording remains extremely weak and rather vague (a resolution that recommends the parties to discourage). 


\subsubsection{8-2012: Careful Steps Towards a More Strategic Approach}

At ATCM XXXI (2008) the United Kingdom tabled a paper that included the proposal "that the ATCM should develop a Strategic Vision for the development of Antarctic tourism over the next decade" (UK, Doc. ATCMXXXI/wp051, 2008: 3, at www.ats.aq). The need for a more strategic approach regarding Antarctic tourism management by the ATCM had been advocated in the literature as well as during several ATCMs, but the UK paper signalled the start of the first serious debates at the ATCM on this issue. The UK proposal received support from many of the consultative parties, which gave the UK reason to table a more comprehensive paper at the XXXIInd ATCM (2009), entitled: "Strategic vision of Antarctic tourism for the next decade." Building partly on inter-sessional contributions from 7 other consultative parties and 2 observers, the UK "developed an outline Strategic Vision for consideration by the ATCM" that "aims to establish the broad principles by which the Antarctic Treaty parties will manage tourism in Antarctica" (UK, Doc. ATCMXXXII/wp10, 2009, 3, at www.ats.aq). The proposed vision included a number of "general principles" as well as more concrete policy statements on issues such as: "growth of tourism," "protecting the Antarctic environment," "safety of tourism activities," and "monitoring and information exchange."

Discussion in respect of this paper made clear that the consultative parties had divergent views on several of these more concrete issues. Furthermore, some consultative parties had problems with the prescriptive character of (parts of) the document.

"There was some discussion as to whether a strategic vision document for tourism should be aspirational, focusing on general themes and goals for the future of tourism, or prescriptive, and thereby include a more detailed list of tasks that might be required as part of the implementation of such a strategy" (Final Report ATCM XXXII, para. 184).

Given these different views, the meeting's attention focused on the part of the paper that contained a number of "general principles." This resulted in the adoption of Resolution 7(2009) (Final Report ATCM XXXII, para. 185). With this Resolution, the representatives of the consultative parties recall their commitment to the comprehensive protection of the Antarctic environment 
and recommend "that the following general principles be used to inform and guide further work in managing Antarctic tourism activities:"

\section{General Principles (Resolution 7(2009))}

- All tourism activities undertaken in Antarctica will be conducted in accordance with the Antarctic Treaty, its Protocol on Environmental Protection, and relevant ATCM Measures and Resolutions;

- Tourism should not be allowed to contribute to the long-term degradation of the Antarctic environment and its dependent and associated ecosystems, or the intrinsic natural wilderness and historical values of Antarctica. In the absence of adequate information about potential impacts, decisions on tourism should be based on a pragmatic and precautionary approach, that also incorporates an evaluation of risks;

- Scientific research should be accorded priority in relation to all tourism activities in Antarctica;

- Antarctic Treaty Parties should implement all existing instruments relating to tourism and non-Governmental activities in Antarctica and aim to ensure, as far as practicable, that they continue to proactively develop regulations relating to tourism activities that should provide for a consistent framework for the management of tourism;

- All operators conducting tourism activities in Antarctica should be encouraged to cooper-ate with each other and with the Antarctic Treaty Parties to coordinate tourism activities and share best practice on environmental and safety management issues;

- All tourism organisations should be encouraged to provide a focus on the enrichment and education of visitors about the Antarctic environment and its protection.

Several consultative parties were clearly disappointed with this outcome, probably because of the general nature of the wording of these principles and the lack of consensus on more concrete issues that have been the subject of ATCM discussions for so many years: "Germany, supported by other Parties, thanked the UK for the effort to draft a strategic vision. It underlined however that the Resolution in its current form does not meet the expectations for a "vision". (Final Report ATCM XXXII, para. 186). 
However, it should be noted that at the same meeting agreement was reached on a number of concrete steps towards the more comprehensive management of Antarctic tourism. Particularly relevant here is Measure 15(2009). With this measure, initiated by the US, Resolution 4(2007) (landing prohibition for ships carrying 500 or more passengers, see above) was "upgraded" to a measure that will become legally binding after official approval by all consultative parties.

Being aware of their responsibility for shipping safety issues in the Antarctic, the consultative parties met in 2009 for the Antarctic Treaty Meeting of Experts (ATME) on the management of ship-borne tourism in Antarctica (Wellington, New Zealand, 9-11 December 2009). The aim of the ATME was "to accelerate consideration of the issues associated with ship-borne tourism." The ATME resulted in 17 recommendations which received substantial attention during the ATCM in 2010. Although most recommendations were explicitly endorsed by the ATCM, decision-making (resulting in measures or resolutions) was limited. Resolution 6(2010) was adopted to improve "the co-ordination of maritime search and rescue in the Antarctic Treaty area." The resolution relates to information exchange in respect of available SAR-facilities, the exchange of vessel schedules, and the desire to have vessels report their geographic position regularly. Resolution 5(2010) aims to improve the "co-ordination among Antarctic Treaty Parties on Antarctic proposals under consideration in the IMO" and Resolution 7(2010) requests that "the Parties proactively apply, through their national maritime authorities, the existing regime of port State control to passenger vessels bound for the Antarctic Treaty area." These are all relevant tools but the most important step towards the more comprehensive regulation of ship safety in the Antarctic would be the adoption of a mandatory "code for polar shipping" within the IMO.

With Resolution 8(2009) the ATCM had already expressed "the desire [...] that the IMO would commence work as soon as practicable to develop mandatory requirements for ships operating in Antarctic waters, which would include inter alia matters relating to vessel design, construction, manning and equipment, including survival craft and lifesaving equipment, taking particular note of the types of vessels, especially passenger vessels, operating in Antarctica." This mandatory polar code is being developed by IMO's "Sub-Committee on Ship Design and Equipment" and 
although the aim was to finalise this work in 2012, at its 56th Session on 28 February 2012 the Sub-Committee "agreed to extend the target completion year for the finalization of Step 1 (SOLAS passenger and cargo ships) to 2014 [...]" (DE \56\25.doc, http://www.uscg.mil/imo/de/ docs/de56-report.pdf, para. 10.33/p. 30).

The adoption of general principles in 2009 could not prevent the ATCM from "falling back" into ad hoc discussions in 2010; no papers with the aim of continuing the strategic and pro-active debate on the basis of the general principles were tabled. A substantial part of the Working Group's available discussion time was given over to the issue of yachts in Antarctica and, indeed, to one incident in particular relating to a yacht at "Wordie House" (a historic site). To strengthen the strategic character of the debates, in 2011 the ATCM agreed to convene an open-ended Intersessional Contact Group (ICG). One of the aims of this ICG, which was convened by the Netherlands and supported by the Antarctic Treaty Secretariat through an electronic discussion forum, was to identify the policy questions relating to Antarctic tourism that had not yet been adequately addressed by the ATCM ("outstanding questions"). Furthermore, the ICG discussed whether the development of new regulatory instruments was desirable. It also looked at the question of which issues should be considered a priority. At the ATCM in 2012, the Netherlands tabled a report on the ICG's work as well as an information paper summing up and briefly discussing the identified "outstanding questions." In the following section these outstanding questions are listed with the ATCM 2012 discussions on each briefly summarised.

\subsection{Regulating Tourism in Antarctica: Outstanding Questions for the ATCM}

To emphasise the strategic character of the ICG's work, and the resulting list of outstanding issues, the questions were structured on the basis of the "General Principles" adopted by the ATCM in 2009 (see above): 


\section{Outstanding Questions Related to Principles I \& IV}

Note: these questions are transposed from the original text.

a) Would there be benefit in clearly defining the use of the term tourism and/or visitor within the ATCM context, e.g., to avoid either confusion, or misinterpretation of requirements in the future?

b) Should the ATCM take (further) action (in addition to Resolution 7 (2010) on Port State Control) in view of the possible future increase of vessels (including yachts), used for tourism purposes, sailing the flag of states that are not a Contracting Party to the Treaty and/or the Protocol?

c) Should the ATCM take action to improve the supervision of whether tourist activities comply with the regulations of the Environmental Protocol and the measures/resolutions? For instance: should the ATCM develop a joint observation scheme? (See the discussions of the ICG 2010-2011 and ICG 2011-2012, chaired by Argentina).

d) Should the ATCM take action (in addition to Resolution 3(2004)) to improve the information exchange and cooperation between competent authorities of Contracting Parties to the Protocol? For example, should the forum of competent authorities, initiated by Germany and the Netherlands at CEP VIII (2005) and CEP IX (2006), have a more structured role in the future? Or should the efforts primarily be focused on the continued development and refinement of the EIES to facilitate information exchange?

e) Should the ATCM take action to ensure greater consistency of interpretation and implementation of the Protocol's provisions and Measures relevant for Antarctic Tourism? For instance, is it desirable that the ATCM studies and discusses existing differences among the domestic legal and administrative arrangements that are being applied to Antarctic tourist activities and the possible consequences of these differences (e.g., forum shopping)?

f) In view of the delays in entering into force of the instruments that are meant to be legally binding (e.g., Annex VI, various Measures), should the ATCM consider some form of fast tracking procedures? 


\section{Outstanding questions related to Principle II}

g) How should cumulative impacts by visitation (e.g., at popular tourist sites) be measured and managed? For instance:

i. $\quad$ Should (joint) action be taken to improve long-term monitoring? And if so, who should be responsible (e.g., National Antarctic Programs/the science community, the tourism industry, jointly)?

ii. Should the issue of cumulative impacts be reflected more explicitly in EIA procedures?

iii. Should - in addition to existing instruments such as Site Specific Guidelines - more strategic instruments be considered (e.g., opening and closure of areas, maximizing numbers of visitors per regions/site)?

h) Should the ATCM adopt regulatory instruments to prevent or regulate the further expansion of tourist activities in Antarctica?

i. How can Annex I of the Protocol be effectively applied for the establishment of new tourism destinations?

ii. Should the ATCM further regulate the expansion of tourist activities into the Antarctic interior?

iii. Should pristine areas be closed for any type of human visitation in the future, including all tourism activities, even where none currently take place, e.g., to preserve these areas as reference areas for future scientific research or because of the intrinsic values of these sites?

i) Do the (possible) interrelationships between Antarctic tourism management and climate change require the attention of the ATCM?

j) Currently, Antarctica is, in principle, open for any type and form of tourism and other non-governmental activities, provided they are conducted in accordance with the Environmental Protocol. Would further policy guidance from the ATCM on this issue be desirable in view of the continuing increase of the diversity of activities in Antarctica? More specifically, should Antarctica be open to all types of activities or should "priority [...] be given to tourism focusing on educational enrichment and respect for the environment" (Final Report of ATCM XXXII, 2009, para. 208)? 
k) Should additional regulations be adopted in respect of permanent facilities for tourism in Antarctica (such as hotels), for instance, to prevent further degradation of Antarctica's wilderness values or to limit the risk of legal debates on ownership?

l) Should the potentially increasing use by tourists of infrastructure, established with the principal aim of supporting scientific activities (e.g., air connections, bases, etc.), be considered as a concern, and if so, how should the ATCM respond to this concern?

m) Related to several of the previous questions, how can precautionary action be taken, given the dynamic character of the tourism industry and the absence of effective monitoring mechanisms at most sites used for tourism purposes?

n) As lead responsibility for many "safety" issues fall largely to others such as the International Maritime Organisation, should the ATCM engage more actively with such bodies and, if so, how?

\section{Outstanding Questions Related to Principle III}

o) Are current tourism activities interfering with scientific research at frequently visited sites and is further ATCM action needed to prevent such interference?

\section{Outstanding Questions Related to Principle IV}

p) Should the ATCM take action in view of a possible increase of tour operators operating outside of the self-regulatory system of IAATO ("free riders")?

q) Are there any bylaws, guidelines or best practices of the tourism sector that require codification in a recommendation or measure of the ATCM?

\section{Outstanding Questions Related to Principle V}

r) Should ATCM and/or individual Contracting Parties to the Protocol take additional initiatives to encourage tourism organizations to provide a greater focus on the enrichment and education of visitors about the Antarctic environment and its protection (in line with Resolution 7 (2009))? For instance: 
i. Should the ATCM develop a trainer's manual for tourism operators with the relevant existing regulations (e.g., measures/resolutions on tourism including the general and specific site guidelines for visitors, tourism relevant regulations of the Environmental Protocol)?

ii. Should the ATCM establish a system of obligatory or voluntary payments by individual tourists or tourist organizations (as a payment for "ecosystem services")? What would be the purpose of levying such charges? (e.g., financing long-term monitoring, financing educational programs)?

Of all the questions raised d), g), h), j) and k) were those most often mentioned by the 12 consultative parties that participated in the ICG as being priority issues for the ATCM. In structuring and leading the discussions, the chairman of the Tourism Working Group ensured that these 5 questions received special attention. This list was not however adopted by the ATCM as its priority list for the coming years. The ICG's report and other papers tabled at the ATCM nevertheless resulted in comprehensive discussions on issues that are of great relevance for the long-term management of the Antarctic. The final report of the ATCM states that " $[t]$ here was a broad view that there were gaps in the current framework of regulation for land-based activities, in particular the expansion of tourism activities into the Antarctic interior" (para. 222) and that the "Parties recognised that this required consideration of how to regulate use of pristine areas, as interior areas are less likely to have been exposed to human impacts" (para. 222). Discussions also related to the increasing diversity of types of activities in Antarctica as well as the question of what criteria should be used to determine the allowance of activities: "Several Parties stated that the determinant of environmental impact assessments should be the impact of the activity and not its purpose, while others were of the view that the purpose of the activity was relevant to the application of the Protocol" (para. 218). On this issue of diversification in respect of Antarctic tourism and in particular the experiences of, and challenges faced, in relation to the application of domestic law in respect of those activities, an informal contact group will be convened to prepare further discussions at 
the ATCM in Brussels in 2013 (para. 233). In relation to the issue of the allowance of (new) permanent facilities for tourism (e.g., hotels), "[t]here was substantial support for the view that tourism activities likely to have more than a minor or transitory impact should not be authorised" (paras 225 and 226). For the purpose of limiting cumulative impacts various possible instruments were discussed, including "reviewing site guidelines, the possibility of making some guidelines mandatory, closing sites for a season or more, and setting precautionary limits on the number of visitors" (para. 216).

\subsection{Conclusion}

It is clear that in 2012 tourism in Antarctica is certainly not unregulated. The provisions of the Protocol apply also to tourist activities; IAATO has developed quite an impressive system of self-regulation; several important resolutions and measures have been adopted by the ATCM; and a number of international maritime instruments also apply to Antarctic shipping. However, taking into account the rapid ongoing developments in Antarctic tourism since the adoption of the Protocol and the clear objectives of the Protocol on environmental protection (e.g., comprehensive protection), ever greater concerns have been raised about the relatively limited attention given by the ATCM to strategic policy questions and the difficulties that are clearly being experienced in reaching consensus on the need to adopt additional regulatory instruments.

The list of outstanding questions outlined above makes clear that many issues remain open and these questions clearly include issues that are of crucial importance for the timely and adequate protection of the values identified as important in this respect (see Art. 3 of the Protocol). Should the ATCM close and open areas to tourism in order to better address the issue of cumulative impacts? Should Antarctic tourists be allowed to use infrastructure that was basically build to aid scientific research? Should hotels and other permanent tourist facilities in Antarctica be prohibited in order to ensure the long term protection of the region's wilderness values?

Many of these questions directly relate to the issue of how the consultative parties want Antarctica to look in 10 or 20 years and what the in- 
ternational management of Antarctica - for the benefit of all mankind (a central objective of the ATS) - means for the "tourism dossier." The ATS has often been praised for its proactive approach in addressing possible future policy concerns (e.g., regulating mining activities before they began, prohibiting dogs because of possible disease risks, etc). Nevertheless, it remains uncertain whether the ATCM will be able to adopt this approach in respect of the joint regulation of Antarctic tourist activities. The discussions held at the ATCM in 2012 do however constitute a reason to be hopeful in this respect, as they clearly indicate a willingness among the consultative parties to discuss the outstanding questions in detail. It has also been announced that these discussions will be continued at the ATCM in Brussels in 2013, although this remains heavily dependent on the consultative parties preparing well for the debates by engaging in intersessional discussions and by producing well developed working papers.

\section{Further reading}

Antarctic Treaty, Washington, 1 December 1959. www.ats.aq/.

Bastmeijer, Kees, \& Roura, Ricardo. "Regulating Antarctic Tourism and the Precautionary Principle." American Journal of International Law, (2004) 98(4):763-781.

Bastmeijer, Kees, Lamers, Machiel, \& Harcha, Juan. "Permanent Land-based Facilities for Tourism in Antarctica: The Need for Regulation." Review of European Community and International Environmental Law, (2008) 17(1):84-99 (also available at www.ssrn.com).

Blay, Samuel. "Current Developments, New Trends in the Protection of the Antarctic Environment: The 1991 Madrid Protocol." The American Journal of International Law, 86 (1992):377-399.

Maher, Patrick, Stewart, Emma \& Lück Michael (eds.). Polar Tourism: Human, Environmental and Governance Dimensions. (Elmsford, NY: Cognizant Communication Corporation, 2011).

Haase, Daniela, Lamers, Machiel \& Amelung, Bas. "Heading into Uncharted Territory? Exploring the Institutional Robustness of Self-regulation in the Antarctic Tourism Sector." Journal of Sustainable Tourism 17(4) (2009):411-430.

Hemmings, Alan D. “Considerable Values in Antarctica." The Polar Journal 2(1) (2012): 139-156.

Lamers, Machiel. The Future of Tourism in Antarctica: Challenges for Sustainability. (Maastricht: Maastricht University, 2010).

Neumann, Antje \& Bunge, Thomas. "New Challenges Pose New Management Problems, The Permanent Installation of a Bronze Sculpture." Environmental Policy \& Law 36(3-4) (2006):158-163.

Protocol on Environmental Protection to the Antarctic Treaty, Madrid, 4 October 1991. See: www.ats.aq/. 
Tin, Tina, Hemmings, Alan D. \& Roura, Ricardo. International Journal of Wilderness, 14(3) (2011):7-12,

http://www.wilderness.net/library/documents/IJWDec08_Tin.pdf

Vidas, Davor (Ed.). Implementing the Environmental Protection Regime for the Antarctic. (Dordrecht: Kluwer Academic Publishers, 2000).

\section{Websites}

Antarctic Treaty Secretariat: www.ats.aq

Map of the Antarctic: http://www.ats.aq/imagenes/info/antarctica_e.pdf

International Association of Antarctica Tour Operators (IAATO): www.iaato.org

Antarctic and Southern Ocean Coalition (ASOC): www.asoc.org

Free downloads of academic publications on Antarctic law and policy on the Social Science Research Network (with search function for the Antarctic): www.ssrn.com

Scientific Committee for Antarctic Research (SCAR): www.scar.org

National Geographic, discover Antarctica:

http://ngm.nationalgeographic.com/ngm/

antarctica/index.html

Polar News: http://polarnews.com

\section{Questions}

- The consultative parties to the Antarctic Treaty have regularly stated that they manage the Antarctic for the benefit of all mankind (preamble Antarctic Treaty, various recommendations, the 30th anniversary of the entry into force of the Antarctic Treaty and the preamble of the Protocol). Looking at this statement from a legal perspective, what could or should this more concretely mean for the management of Antarctic tourism?

- To what extent and in what way have international agreements between states, containing standards for Antarctic tourism, been made legally binding for individual tourists and/or tour operators?

- What are the consequences of the obligation to conduct an Environmental Impact Assessment (Protocol, Art. 8 \& Annex I) for tourist activities and what are the strong and weak characteristics of the Antarctic EIA-system in comparison with the EIA-system in your own country? 



\section{Renewable Energy in the Arctic: Regulatory Frameworks}

Maria Pettersson

\subsection{Introduction}

The adoption of renewable energy is seen as one of the main ways to improve living conditions in some parts of the Arctic especially in areas that are particularly exposed to the effects of climate change. Thus, the provision of domestic carbon-free electricity in some Arctic locations can enhance energy security, minimise environmental impacts and mitigate climate change. Many renewable energy sources are also available for offgrid applications, which make them an attractive option for energy supply in inaccessible Arctic areas.

This chapter highlights the potential for renewable energy development in the Arctic and the role of law in this development. While, to date, many renewable energy technologies have emerged that are technically and in many cases also economically feasible to use (e.g., wind power and hydropower), there are many other factors that can hinder this development and, therefore, they must be considered in the context of the implementation and dissemination of renewable energy technologies. Notwithstanding national and global incentives for renewable energy development, the actual implementation of the energy policy objectives will, at least in part, be down to the legal conditions for the planning, installation and operation of these facilities. 
The main focus of this chapter is therefore on the impact of the regulatory framework on the development and implementation of renewable energy technologies in the Arctic. The chapter is structured as follows: in the first part, the concept of renewable energy is outlined while the various renewable energy sources are described, with reference also made to the particular situation regarding availability, power generation and future potential in the Arctic States. In the second part, general legal functions vis-à-vis the extraction and utilisation of renewable energy resources are examined, for example, rules regarding land use, environmental consideration and concession etc., followed by a number of national examples. Lastly, the challenges and possibilities for future renewable energy development in the Arctic are discussed, such as they relate for example, to climate change.

\subsection{Renewable Energy in the Arctic}

Renewable energy is defined as energy sprung from natural processes, like sunshine and wind, which are replenished at a faster rate than they are consumed. Among the more common sources of renewable energy we find solar, wind, hydro and biothermal sources. Numerically, for example, in 2010 renewable energy supplied about $16 \%$ of the global final energy consumed and represented close to $20 \%$ of the global supply of electricity (REN21, 2011:11). These numbers are expected to grow significantly over the coming decades with the primary policy drivers here being climate change and security of supply (energy security).

The energy sector accounts for a large proportion of all global greenhouse gas emissions; the combustion of fossil fuels, such as coal and oil, is assumed to have increased the concentrations of greenhouse gases in the atmosphere, causing a warming of the global climate that exceeds its natural variability (climate change). Renewable energy sources have the potential to provide energy with zero emissions of greenhouse gases and an increased use of renewable energy is therefore a very important strategy in mitigating the adverse effects of climate change. An increased proportion of renewables in the energy mix also contributes to energy diversification, and thus to security of supply, by expanding the technology portfolio, increasing 
the geographical diffusion of the energy sources, reducing energy imports, and by offering some protection against the geopolitical shocks which generally produce the ups and downs in the price of fossil fuels.

The potential for renewable energy is generally very high in the Arctic region. Although the source of the energy varies with respect to the differrent countries' geographical location, climate, topography etc., vast reserves of e.g., hydropower and wind power are located across the region. Renewable energy sources can therefore play an important role in creating a more sustainable future in the Arctic by providing clean energy to territories that have hitherto been dependent on fossil fuels.

Next, different types of renewable energy sources and their relative importance for the Arctic States are briefly described.

\subsubsection{Hydropower}

Hydropower, or hydroelectric power, is produced by converting the energy in flowing water into electricity. The most common approach for the large scale extraction of electricity from flowing water is to build a dam in a river to store water. The water is then released through a turbine that activates a generator and produces electricity. For small scale applications, a smaller dam or a canal can be used to channel the river water through the turbine.

Hydroelectric power is the largest of the traditional renewable energy sources and one that is extensively utilised all across the Arctic. Five of the Arctic States are in the top ten list of the world's largest hydropower producers: Canada (10.9\%), the United States (9\%), Russia (5\%), Norway (3.8\%) and Sweden (2\%) (IEA, 2011:19). Expressed as a percentage of total domestic electricity generation Norway leads with $95.7 \%$, followed by Canada (60.3\%), Sweden (48.3\%), Russia (17.8\%) and the US (7.1\%). In Iceland, Finland and in Greenland hydropower also represents a significant share of the country's total electricity supply (IEA, 2011:19).

Despite the already extensive development of hydroelectric power in the Arctic, the feasible potential for further expansion remains significant. While hydroelectric development in the United States decelerated in the late 2000s as a result of the economic recession, installed capacity in Canada, Russia and Greenland has continued to increase. In addition, in Swe- 
den and Norway some expansion has occurred recently, although only on a relatively moderate scale, and has in the main consisted of the construction of small-scale facilities and capacity increases in existing plants. In Sweden, further expansion in relation to the major national rivers is also prohibited by law.

\subsubsection{Wind Power}

Like most renewable energy forms, wind energy is derived from the sun; 3$5 \%$ of the solar radiation that reaches the Earth is converted into the kinetic energy which constitutes the basis for the world's wind energy resources. In terms of global installed renewable energy capacity, wind power ranks second to hydropower and is expected to play a key role in the future of renewable energy development and climate change mitigation.

Until recently, the development of wind power in the Arctic region had been modest. Except for Denmark (although not in Greenland or the Faroe Islands) and in the United States (although not in Alaska) the installed capacity in most Arctic countries was insignificant. Since the beginning of the $21^{\text {st }}$ century however wind power generation has taken off, driven primarily by the need to ensure security of supply and by general environmental concerns, with climate change to the fore. As a result, most Arctic countries now have in place various policy instruments to support the development of both onshore and offshore wind power, while installed capacity across the region is increasing year on year.

The further potential for wind power generation in the Arctic is huge; estimates show that wind could account for $10-20 \%$ of the total power capacity in the region, and it can also be utilised off-grid. Great wind resources are found in, for example, the mountain areas of Norway and Sweden, the Northwest of Russia, the Northeast of Canada, as well as in Greenland and Alaska.

\subsubsection{Geothermal Energy}

Geothermal energy derives from the interior of the Earth. The energy can be utilised in two ways: directly as a heat source, or indirectly to produce electricity by using steam to rotate a turbine generator. The direct use of 
geothermal energy, primarily for bathing and swimming applications together with heating, is widespread in the Arctic. Measured in installed capacity, the United States and Sweden lead in this field, with Iceland, Sweden, Norway and Denmark (not Greenland or the Faroe Islands) in the forefront in terms of average annual use per person. The United States is the world leader also in terms of geothermal electricity generation with more than $3000 \mathrm{MW}$ installed capacity (although not in Alaska), followed by Iceland where more than a quarter of the country's total electricity generation comes from geothermal resources. In 2010, the installed capacity in Iceland was 575 MW (Energy statistics database www.nationmaster.com). In addition there are several more geothermal power development projects already underway in Iceland. In Greenland the potential for geothermal energy for small-scale applications is being tested while in Alaska geothermal energy for both energy production and heating is currently under consideration. In both Greenland and Alaska the major challenge is the remote location of most geothermal resources.

\subsubsection{Solar Energy}

From a global perspective, solar energy is the most abundant source of energy. It is available in many applications, both directly as solar radiation, and indirectly in the form of e.g., wind power, hydropower and ocean energy. To take advantage of this direct solar energy, two basic types of devices are used: (a) photovoltaic collectors (solar pv), which convert sunlight directly into electricity and (b) solar thermal collectors, which are used to heat e.g., air or water. Solar photovoltaic is one of today's fastest growing power generation technologies and is in use in all Arctic States except Iceland, where the preconditions for the extensive use of solar power are modest due to relatively low insolation. The potential for solar power use in Russia is great but thus far, in terms of utilisation at least, progress has been slow. The largest installed capacity among the Arctic States is found in the United States (although not in Alaska) and Canada (which has one of the world's largest operational photovoltaic facilities, located in Sarnia, Ontario). The contribution made by solar photovoltaic systems in terms of electricity supply in the other Nordic countries, including Greenland, remains, however, minimal. 


\subsubsection{Ocean Energy}

The ocean can produce two types of energy: (a) thermal energy as a result of heat from the sun (not discussed further here) and (b) mechanical energy generated by tidal and wave movements. Tidal power is produced by converting the highly predictable fall and rise of the water level that occurs as a result of the tides into electricity, while wave power is exploited mechanically via a wave energy converter. Neither tidal nor wave power are widely utilised anywhere in the world, although there is a future potential for electricity generation. In the Arctic areas, potential for the development of tidal power is primarily to be found in Russia (e.g., in the Kola Bay and in the Sea of Okhotsk), Norway (e.g., Hammerfest) and Alaska (in the Yukon, Eagle and Nenana rivers). Tidal power plants (mostly small-scale) are already installed in some of these areas. The potential for wave power in the Arctic States is more modest; only the west coasts of Norway and Canada and a few sites in Alaska are suitable.

\subsubsection{Summary}

The development of renewable energy is key to a sustainable future and a necessary component in the fight against environmental degradation and climate change. Increasing the proportion of domestic renewable energy also enhances overall supply security. From a resource availability perspective, the potential for renewable energy development in the Arctic is very significant. Almost all renewable energy sources are represented in abundance, especially hydroelectric power and wind power, while, for various reasons, such as, the lack of economic attractiveness (e.g., high construction costs or low relative prices on other energy sources), grid and system integration issues, institutional constraints, etc., only a fraction of the potential is currently being utilised. 


\subsection{Legal Functions in Relation to the Extraction and Exploitation of Renewable Energy}

Many factors are of importance for the development of renewable energy. These include:

- Natural conditions, for instance, resource quality and availability;

- Technological development;

- Economic and financial conditions, i.e., costs;

- Social aspects, such as attitudes;

- Institutional factors; like customs, norms and legal rules.

Hence, despite the relative overall benefits of using renewable energy sources, in terms of e.g., reduced emissions and pollution, there are many factors that interact and affect the potential to effectively disseminate renewable energy technologies, and to implement renewable energy policy objectives, especially at a local level. In addition, the terms "renewable" and "sustainable" are also not always synonymous; the utilisation of a renewable energy resource may be in direct contradiction to sustainable development. One such example here might be large hydro developments which typically involve enormous environmental consequences for both the water and the surrounding ecosystems, and may cause the area to become uninhabitable. One additional very important factor in the context of renewable energy development is therefore the particular energy project's sustainability. A very important function of the legal system is however to solve conflicts and to weight different interests against each other. In this context environmental law aims at balancing the use of natural resources in a way that best promotes sustainable development. This implies that the law, as such, has both a facilitating and a hindering function in relation to the extraction and exploitation of renewable energy resources (it can also be neutral).

The regulatory framework for renewable energy can be expressed in terms of legal functions, in other words, in the way in which a certain issue is addressed in law. The starting point for the identification of the relevant legal functions for the extraction and exploitation of renewable energy is the characteristics of the particular energy source. To find out 
what laws and regulations arise, for example, in relation to the development of wind power, we have to determine what resources are necessary to harness wind and what other impacts, for instance, in relation to human health and the environment, such a development would bring.

The utilisation of natural resources to generate energy thus raises a number of legal issues. In the following, some of the primary legal functions in this respect are examined.

\subsubsection{Rights of Use}

The right to develop resources is typically a right of ownership. The main rule in most countries is that the ownership of land carries with it a right to harvest renewable resources such as forest and wind. If resources cannot be individualised the right is often defined as a right of disposition rather than a right of ownership.

Ownership is, however, not the only factor to consider in terms of resource rights. Whether the ownership or user right belongs to the state or private entities, or a mixture of the two, the right to develop them is normally also subject to some sort of legal control. The regulations are usually aimed at controlling utilisation and steering allocation with respect to e.g., the environment, public interest and social structure, and reducing/solving/ or otherwise handling conflicts. Although some renewable resources are abundant in the sense that they cannot be considered as scarce in the traditional sense, such as sunlight and, to some extent, wind, the use of the resources to produce energy nevertheless involves competition, primarily due to the fact that energy installations in addition to the actual resource also require access to land (or water) areas.

\subsubsection{Land Use Planning}

Even in the relatively scarcely populated Arctic, land can be perceived a scarce resource. Despite relatively low population density, land-use conflicts are not uncommon, in the northern parts of Sweden, Norway and Finland where the different interests of, for instance, reindeer herding, forestry, energy production (like wind and hydropower), and outdoor recreation etc., often are at loggerheads. In the Arctic, land use planning is 
a fundamental prerequisite for the development of many renewable energy sources such as: wind, solar and geothermal energy. The use of land is typically controlled via physical (spatial) planning laws that regulate (or give direction) to what and how land and water areas may be utilised. Physical planning thus effectively sets out the ways in which the public sector influences the allocation of activities and resource use in areas on different levels. It constitutes a fundamentally important instrument in controlling the use and management of natural resources. For plans or programmes whose implementation is likely to have significant environmental effects, a Strategic Environmental Assessment (SEA) should usually be produced (the SEA instrument is used in all Arctic countries). The purpose of the SEA is to integrate environmental aspects into the plan, or programme, to promote sustainable development. Planning instruments can thus have both promotive and a counteractive functions in relation to the development of renewable energy.

The starting point for the physical planning in the Nordic Arctic countries is basically the same: multi-level planning where the legal effect of the plans increases with the level of decentralisation, i.e., legally binding plans are primarily made at the local (municipal) level.

\subsubsection{Management of Environmental Concerns}

Although an increased share of renewable sources in the energy mix generally entails environmental as well as climatic benefits there are, as previously indicated, various additional environmental aspects to consider, including human health issues. For example: the noise created by wind turbines is a kind of pollution that affects both wildlife and human health. Wind power may also cause bird and bat mortality if the location of the turbines is not carefully considered, while the turbines may also affect the landscape. This is something which is viewed as a significant negative externality. Geothermal energy development for instance also involves aesthetic concerns as well as extensive land and water use questions. The negatives in respect of tidal energy include e.g., adverse impacts on mudflats as well as on fish, marine mammals and birds. The most extensive environmental impacts of renewable energy, however, probably derive from the production of hydroelectric power. The construction of dams 
often involves irreversible adverse impacts on ecosystems and strongly affects the living conditions of both humans and animals.

Thus, the production of renewable energy involves not only benefits but also costs. One way of controlling the negative impacts on human health and the environment is through environmental legislation. The greater the potential of the environmental impacts of an activity, the more restrictive typically are the rules; the overall purpose of environmental legislation is to prevent or arrest damage or detriment to human health and the environment. On an overarching level, environmental law is expressed as principles, such as, for example: the precautionary principle, the principle of best available technology and the polluter pays principle. These principles are then - in varying degrees - translated into substantive national law becoming applicable in e.g., the licensing of various types of activities affecting the environment.

The precautionary requirement under the Swedish Environmental Code, for example, means that the operator - to obtain a permit - must take the precautions necessary to prevent damage from the activity to human health and the environment, such as noise reduction measures, compensatory measures, etc. The operator then receives a permit on the condition that these requirements are upheld. Also the location of the activity requires careful consideration. The site must be "the best possible" from the point of view of the environment, which means that it is not primarily the operator's access to the site that is crucial for the decision, but rather an objective assessment of the suitability of the site from an environmental perspective.

Noise and other pollution (e.g., emissions) can also be controlled by the use of legal standards and environmental quality norms determining general permissible emission or noise levels. Denmark uses legal standards e.g., to control noise pollution from wind power farms, thus avoiding an individual examination of permissible noise levels for each installation.

\subsubsection{Licensing}

In addition to access to the actual resources, the utilisation of renewable energy like wind, sun and water also includes the construction of various types of facilities. This means, as discussed above, that there are potential 
effects on human health and the environment, thus giving rise to licensing requirements. An application for a permit shall, in most countries, include an environmental impact assessment (EIA) where the direct and indirect environmental impacts - in the broadest sense - of the planned activity are described. To exemplify, the construction of an offshore wind farm in Sweden will, depending on the size and location, require at least three permits (e.g., a permit for environmentally hazardous activity, a water operation permit, and building permission), including, in some cases, permission from the government.

\subsubsection{Summary}

A number of legal functions affect the development of renewable energy. Since the law aims at protecting a great variety of interests, private, as well as public, the legal functions may promote but also counteract such development. The starting point for determining applicable law for a particular renewable energy activity is the specific features of that development. Most renewable energy installations are however subject to laws and legal rules governing land use, environmental impacts and permits.

\subsection{The Future of Renewable Energy Development in the Arctic - Challenges and Opportunities}

The development of renewable energy in the Arctic faces both challenges and opportunities, not least considering the issue of climate change. A warmer climate involving among other things melting sea ice, thawing permafrost and more extreme weather conditions has implications for both the access to and exploitation of renewable energy resources. Renewable energy development is also affected by climate policy. In general, climate change mitigation strategies involve the diffusion of carbon-free energy technologies. Together with the resource potential for wind and hydroelectric power for example, the development potential for renewable energy should in general be high or very high throughout the whole of the Arctic region. There are, however, other potential barriers to renewable energy technology 
dissemination, as well as other aspects to consider in this context. In the following section some of the most common implementation issues are considered.

\subsubsection{Costs}

The development of many renewable energy technologies, such as solar photovoltaic systems, tidal and wave power, and, to some extent, geothermal energy is hindered by e.g., high construction costs. Since new energy technologies must compete with existing energy sources at today's price, appropriate economic and regulatory measures like taxes, subsidies and Research \& Development (R\&D) support are crucial for the development and dissemination of renewable energy technologies to significantly lower their relatively high costs. Policy support for renewable energy investments has increased significantly since the end of the 1990s. Today, regulatory policies and/or fiscal incentives and public grants, such as capital subsidies and renewable energy credits, to support the dissemination and development of different renewable energy technologies are in place in all Arctic States.

\subsubsection{Opposite Interests}

The development of renewable energy in the Arctic may also be at odds with other activities and interests connected to the use of land and water resources. This includes both activities that are linked to indigenous peoples, such as: reindeer herding, fishing etc., and other activities such as forestry, as well as recreational (outdoor) interests in general and also nature preservation interests, including the protection of biological diversity. All of these are typically subject to some kind of legal protection and must be considered in the context of renewable energy development. The potential complexity involved in decision-making relating to land use requires well thought out rules and processes that uphold the overall principles on which the system is based.

Balancing rules are rules that are intended to handle conflicts and provide guidance for the assessment of various conflicting activities or measures, in order to - in each case - make a decision that best serves the 
aims of the particular legislation. At the overarching level, the main (environmental) goal in most Arctic countries is sustainable development. Thus, for instance, in Sweden, Finland and Canada this goal is also expressed in legislation (i.e., the Canadian Environmental Protection Act, the Finnish Environmental Protection Act and the Swedish Environmental Code). The purpose of the Swedish Environmental Code is, for example, to promote sustainable development. With reference to balancing rules in general and the Swedish provisions on resource management in particular, this means that, in a situation where two interests collide, and if there is no further guidance for the choice, the one that is most conducive to sustainable development should take precedence. This is, however, rather too general as a way of providing concrete guidance in individual cases, not least since two conflicting interests can, potentially, each promote sustainable development. Therefore, the balancing rules also entail more substantive guidance; for example, such that areas that are particularly suitable for energy production should be protected from activities that can significantly hamper, e.g., the extraction of wind power. Still, the rules are fairly general in design and provide significant discretion in each individual case.

In other Arctic countries, for example Russia, the balancing of interests is in practice often based on negotiations, where developers voluntarily or for example, in relation to the Forestry Stewardship Council (FSC) certification principles or the like, negotiate solutions with landowners and indigenous peoples. This may also lead to very different outcomes depending on e.g., the parties' bargaining position. To be applicable, overarching principles thus need to be accompanied by careful planning and substantive rules that are clear and predictable enough to reduce uncertainties regarding both content and application.

\subsubsection{Licensing and Appeals}

Another factor of importance in the context of renewable energy development is the legal procedure for licensing, including the system for appeals. It is often the case that, for example, the installation of a wind farm or hydroelectric power plant raises several permit requirements for which EIAs need to be prepared. In Sweden and Norway, for example, the extensive permitting requirements have had a clear inhibitive effect on 
the installed capacity of wind power in particular. In general, cumbersome licensing processes, especially in combination with a high degree of uncertainty regarding the outcome, increase the rate of return requirements and thereby reduce the incentives to invest.

The extent of the licensing process is also affected by the opportunity to appeal against decisions. It is also a fact that the more permits that must be applied for; the more decisions there are to appeal. One way to reduce the time between application and final authorisation without compromising environmental concerns is to introduce legal standards for the control of environmental impacts where suitable. Legal standards, that set limits for noise pollution, distance to residential or conservation areas etc., can reduce the incentive to appeal by clearly establishing the limits that apply, thereby reducing the chances of a successful appeal.

\subsubsection{Public Participation}

In the context of any development, public participation is an issue that has to be considered. In the short term, and from a one-sided development perspective, the requirement for public participation in the process can be perceived as a barrier to implementation; the consultation process with citizens, stakeholders and authorities is often time-consuming. However, in the long term, the public participation process is usually a facilitating factor that helps to generate legitimacy for the project. It is important that the deliberations take place as early as possible, preferably already at the planning stage, for several reasons: (a) to detect potential obstacles regarding location, user rights etc., early; (b) for the deliberation to be perceived as meaningful and constructive; it is difficult for people to feel involved if decisions about e.g., size and location have already been made, (c) the sooner people are involved, the greater the potential benefits of their participation, for example, in terms of local knowledge.

\subsubsection{Local Self-governance}

Another important question concerns local municipal self-government and decentralised decision-making. On the one hand, strong local selfgovernance implies a bottom-up approach where decisions are made by 
those affected, and where local knowledge can be applied and local concerns are taken into account, etc. On the other hand, strong local selfgovernance may imply that local interests are given priority over national (or even global) interests to increase the share of renewable energy. Municipal self-government is indeed a potential barrier to development in, for example, Sweden, where e.g., issues relating to spatial planning are a municipal matter. As a consequence, the municipality can hinder development simply by avoiding to plan for it, or by using its veto. The overall system is similar in Denmark and Norway, with the important difference being that it is possible to ensure that national planning objectives are considered on a local level.

\subsubsection{Grid-connection}

Finally, the ability to increase the share of renewable energy in the Arctic is also affected by the potential for grid-connection. On the one hand, large scale developments in particular may be constrained by an inability to connect into the power grid, for example, in parts of Siberia or Greenland. In Greenland the primary obstacle to the development of solar and wind power is the problem of power distribution. On the other hand, many renewable energy sources have great potential for off-grid applications, for example, wind and solar power, which make them favoured options especially in the Arctic context where many remote settlements still rely on diesel generators.

\subsection{Conclusion}

The key reason for developing renewable energy in the Arctic (and elsewhere!) is probably the imminent threat of climate change and the necessity to hasten the transition from fossil fuels to low-carbon energy sources. Increased use of renewable energy is, however, also important in reducing the local environmental impacts of fossil fuel use, as well as in satisfying the need for security of supply, not least in the remote areas of the Arctic. 
When talking about renewable energy in the Arctic it must, however, be kept in mind that the Arctic is far from being a homogeneous region. There are significant differences both within and between the Arctic States, for example, in terms of resource endowments, demographic structure, climate conditions, and economic and technological development etc. Thus, there are no simple "solutions" (legal or otherwise) as regards increasing the use of renewable energy in the Arctic region as a whole. It rather becomes a question of identifying individual and area-specific difficulties, based on the general factors that are assumed to influence the possibilities for diffusing and developing renewable energy, for example, the design of the regulatory framework.

To approach the potential for renewable energy in the Arctic quite a few obstacles must therefore be overcome. Among the major challenges in terms of adapting the institutional and regulatory framework are (in no particular order):

- Conflicting rights and interests may lead to powerful lobbying against renewables. Even though the Arctic areas are often sparsely populated and the rivalry in use of natural resources is perhaps less explicit than in more urban areas, there are other potential conflicts to consider. For example, the rights of indigenous peoples. This may collide with other land-use, or other conflicting interests, such as the exploitation and transportation of, say, natural gas or oil. One way to deal with such conflicts legally is to ensure that the process of developing renewable energy includes extensive public and stakeholder participation and consultation, as well as thoughtful balancing rules that provide clear guidance in the direction of sustainable development. This can, for example, be achieved through the EIA and SEA, but also by other legal means, such as rights to compensation, or via the licensing process.

- The licensing of renewable energy installations is often singled out as an important institutional barrier to penetration. This is true in many cases. To facilitate the development and diffusion of renewable energy technology it is therefore important to streamline the licensing procedures. For example, by clarifying the purpose of the licensing process (e.g., ensure the operator's capability and financial strength and avoid damage and nuisance to people's health and the 
environment), and adapting the process (and assessment) to the specific requirements that - given the purpose - is deemed reasonable for the particular activity.

- The lack of power grid access poses a major challenge for the development of renewable energy in remote Arctic areas. Although this issue cannot be solved by legal rules per se, it is still a matter of the design of the institutional framework. Reinforcement of the grid requires large investments that are not normally funded by the company interested in investing in renewable energy, but by the state.

- Construction costs. In order to make investments in renewable energy economically viable it is often necessary to introduce various incentives to reduce the large investment and construction costs. Importantly, economic policy instruments are also based on legal rules. Furthermore, taxes, certification schemes or feed-in tariffs do not exist independently of the law. Hence, to realise financial incentives, a functioning legal system must already be in place.

In conclusion then, in addition to resource availability and favourable economic conditions, a key precondition for the efficient and timely development and diffusion of renewable energy in the Arctic is that the institutional and regulatory frameworks are well adapted to the specific conditions that apply in the Arctic regions. For instance, they are adapted in terms of local environmental impact and vulnerability, including the impact of such developments on indigenous communities.

\section{Further reading}

Ellerman, A. Denny. "Mitigation Options - Energy Supply." Paper form the Sustainable Development and Global Climate Change Conference, Governed by U.S. Global Change Research Information Office 1995. Accessed 6 September 2012, see: http://www.gcrio.org/USGCRP/sustain/ellerman.html

Holm, Alison et al. Geothermal Energy: International Market Update. (Geothermal Energy Association: 2010). Accessed 2 October 2012, see: http://www.geoenergy.org/pdf/reports/gea_international_market_report_final_may_2010.pdf

International Energy Agency. 2011 Key World Energy Statistics. Accessed 2 October 2012, see:

http://www.iea.org/textbase/nppdf/free/2011/key_world_energy_stats.pdf

Kagel, Alyssa. A Handbook on the Externalities, Employment, and Economics of Geothermal Energy. (Washington DC: Geothermal Energy Association, 2006). 
Keskitalo, E. Carina H. et al. "Local Consequences of Applying International Norms: Differences in the Application of Forest Certification in Northern Sweden, Northern Finland, and Northwest Russia." Ecology and Science 14(2):1-14.

Panwar, N.L., S.C. Kaushik, and Surendra Kothari. "Role of Renewable Energy in Environmental Protection: A review." Renewable and Sustainable Energy Reviews, 15 (2011):1513-1524.

Painuly, Jyoti Parikh. "Barriers to Renewable Energy Penetration; A Framework for Analysis.” Renewable Energy 24 (2001):73-89.

Pettersson, Maria. "Mitigation Possibilities in the Energy Sector - An Arctic Perspective." In Koivurova, Timo, Keskitalo, E. Carina. H. and Nigel Bankes (Eds.), Climate Governance in the Arctic. (United Kingdom: Environment \& Policy vol. 50, Springer, 2009):303-326.

Pettersson, Maria. Renewable Energy Development and the Function of Law. A Comparative Study of Legal Rules Related to the Planning, Installation and Operation of Windmills. Doctoral Dissertation, (Luleå: Luleå University of Technology, Sweden, 2008).

REN21. 2011. Renewables 2011 Global Status Report (Paris: REN21 Secretariat)

Richards, Garret, Bram Noble and Ken Belcher. "Barriers to Renewable Energy Development: A Case Study of Large-Scale Wind Energy in Saskatchewan, Canada." Energy Policy 42 (2012):691-698.

Screening report Iceland (chapter 15 - Energy). Accessed 2 October 2012 see: http://ec.europa.eu/enlargement/pdf/iceland/key-documents/screening report_15_is_internet_en.pdf

Söderholm, Patrik, Kristina Ek and Maria Pettersson. "Wind Power Development in Sweden: Global Policies and Local Obstacles." Renewable and Sustainable Energy Reviews, 11(3)2007:365-400.

Tupy, Tatjana. "The Importance of the Legal and Regulatory Framework for the Development of Renewable Energy." Paper accompanying a keynote presentation held at the 10th Baku International Congress - "Energy, Ecology, Economy," Baku, 23 September 2009 on behalf of the OSCE office in Baku. Accessed 2 October 2012 see: http://www.osce.org/baku/41263

Tysiatchniouk, Maria and Olga Maletz. "The Effect of Expertise on the Quality of Forest Standards Implementation: The Case of FSC Forest Certification as a Form of Forest Governance in Russia (extended abstract)." In Böcher, Mikael, Lukas Giessen and Daniela Kleinschmit (Eds.), Environmental and Forest Governance. The Role of Discourses and Expertise. Proceedings of the International Conference, Göttingen 2007:133-136.

World Energy Council. 2010 Survey of Energy Resources. Executive Summary.

\section{Websites}

Energy statistics database www.nationmaster.com.

Renewable energy information www.renewableenergyworld.com.

International Energy Agency www.iea.org. REAP Renewable Energy Alaska Project http://alaskarenewableenergy.org. 


\section{Questions}

- Why is renewable energy diffusion and development considered important, in general, and in the Arctic in particular?

- What are the conditions for the development of renewable energy in the Arctic? Provide examples.

- What are the main barriers to the development of renewable energy, in general, and in the Arctic in particular? How can these barriers be eliminated or mitigated to increase the share of renewable energy in the Arctic? 



\title{
10. Oil and Gas Regulation in the United States Arctic Offshore
}

Betsy Baker

\subsection{Geography and Recent History}

The United States is an Arctic nation because of the State of Alaska. The U.S. Arctic Research and Policy Act of 1984 (ARPA) defines the U.S. Arctic without expressly naming Alaska but by referencing geographic features that are either in or border on the state:

\begin{abstract}
"All United States territory north of the Arctic Circle and all United States territory north and west of the boundary formed by the Porcupine, Yukon and Kuskokwim Rivers; all contiguous seas, including the Arctic Ocean and the Beaufort, Bering and Chukchi Seas; and the Aleutian chain" (15 U.S.C. § 4111 section 112).
\end{abstract}

By including the Bering Sea and the Aleutian Chain, the ARPA definition extends the U.S. Arctic well south of the Arctic Circle (latitude 66 33'44" $\mathrm{N}$ ); for example, the Aleutian Island of Amatignak is at 51 $11^{\prime} 44^{\prime \prime} \mathrm{N}$. To the North, Barrow, at $71^{\circ} 76^{\prime} 26^{\prime \prime} \mathrm{N}$, is well above the Arctic Circle and the largest community in the North Slope Borough, where - at Prudhoe Bay (Sagavanirktok) - the history of hydrocarbon exploration in Alaska is rooted. The U.S. Arctic Research Commission provides a map of the area defined under ARPA at http://www.arctic.gov/maps/ARPA_Alaska_only_ 150dpi.jpg (O'Rourke 2013).

Inuit have lived and hunted on the North Slope of Alaska, its ice, and its waters for thousands of years (Dorough 2010). By contrast, hydrocarbon 
exploration and production have occurred sporadically for just under a century in Arctic North America, beginning with the discovery of the Norman Wells in Canada's Northwest Territories in 1920. The high cost of production and transport limited that first oil rush but, with the 1968 discovery of abundant reservoirs in Prudhoe Bay, oil boomed again in the Canadian and U.S. Beaufort Sea (Emmerson 2010). Development of the Prudhoe fields led to construction of the Trans-Alaska Pipeline, which delivered the first North Slope oil to the port of Valdez, Alaska, on Prince William Sound, in 1977. Oil has been a mainstay of the Alaska economy ever since, the state collecting $\$ 170$ billion in state petroleum revenues through 2012 in today's dollars (Goldsmith 2012). Those revenues soared in 1980-1985, declined in the 1990s with the collapse in oil prices, and have risen again since 2006, peaking in 2008, through a combination of record oil prices and a change in Alaska's production tax (Ibid.; Leask 1990).

The history of hydrocarbon development in Alaska is intertwined with the negotiation and passage of the Alaska Native Claims Settlement Act of 1971, which was followed by the Alaska National Interest Lands Conservation Act of 1980 (Sambo Dorough 2010, Mitchell 2001). The history is also inseparable from economic development and the transition to a mixed subsistence-cash economy in northern Alaska, with its positive and negative effects (Berman 1998). Finally, the history of oil in Alaska critically influenced development of marine oil pollution legislation in the United States. The 1989 Exxon Valdez disaster, which resulted in 11 million gallons (2.91 million litres) of crude oil spilling into Prince William Sound, led quickly to the federal Oil Pollution Act of 1990 (OPA). The OPA was a landmark piece of U.S. legislation that provided more rigorous protections than the regime for civil liability for marine oil pollution then developing globally. In 2010 the Exxon Valdez was replaced as the largest marine oil spill in U.S. history by the fatal Deepwater Horizon disaster, in which 11 men died and more than 158 million gallons (600 million litres) of oil spilled into the Gulf of Mexico. As discussed in Part II, below, the legislative response to the Deepwater Horizon disaster has been almost non-existent and the regulatory response modest. 


\subsection{Jurisdiction, Legal and Regulatory Framework}

\subsubsection{Overview}

This chapter mainly focuses on developments since 2010. In the three years since the April 2010 Deepwater Horizon accident, Congress has still not enacted any new laws for offshore operations or liability in response to this watershed environmental catastrophe. This inaction stands in stark contrast to the 1990 enactment of the Oil Pollution Act in the wake of the Exxon Valdez spill. The responsible federal regulatory agencies, however, have begun to make structural and substantive changes.

\subsubsection{State and Federal Jurisdiction}

Jurisdiction over offshore oil and gas activity in the U.S. Arctic depends on where that activity occurs. The State of Alaska owns and regulates oil and gas resources within three miles $(5 \mathrm{~km})$ from shore, see, e.g., the federal Submerged Lands Act of 1953: "Within their offshore boundaries, coastal states have "(1) title to and ownership of the lands beneath navigable waters within the boundaries of the respective states, and (2) the right and power to manage, administer, lease, develop and use the said lands and natural resources" (43 U.S.C. § 1311, Vann 2011). The federal government exercises jurisdiction over the Territorial Sea beyond three miles, the Contiguous Zone, the Exclusive Economic Zone, and the Continental Shelf, see e.g., the Outer Continental Shelf (OCS) Lands Act (OCSLA), 43 USC §§ $1331 \mathrm{ff}$.

\subsubsection{State of Alaska Legal Framework}

Several state agencies and statutes are relevant to Alaska's jurisdiction over offshore activity in the three miles $(5 \mathrm{~km})$ seaward of its coast. Relevant state entities include the Alaska Oil and Gas Conservation Commission, and three Alaska Departments: Environmental Conservation; Fish and Game; and Natural Resources, within which two Divisions - Oil and Gas, and Mining, Land and Water - and the Office of Habitat Management and Permitting, play a role. Finally, the Alaska Coastal Management Pro- 
gram (ACMP), authorised by the federal Coastal Zone Management Act of 1972, was established in 1977. In its early years the ACMP, a voluntary programme, was generally considered a success as municipalities produced coastal zone management programmes with enforceable policies to balance conservation with development of natural resources. In 2011, the State legislature adjourned without passing the legislation necessary to extend the ACMP (ACMP 2011). Other state laws relevant to offshore hydrocarbon activity and still in force include: the Alaska Public Land Act, the Alaska Fishway Act, and the Alaska Anadromous Fish Act, which require permitting for certain activities.

\subsubsection{Federal Legal and Regulatory Framework}

\section{Outer Continental Shelf (OCS) Lands Act}

The OCS Lands Act (OCSLA), which governs oil and gas development in federal waters, states as Congressional policy in 43 USC §1332(3), that the outer Continental Shelf is a vital national resource reserve held by the Federal Government for the public, which should be made available for expeditious and orderly development, subject to environmental safeguards, in a manner which is consistent with the maintenance of competition and other national needs.

The Department of the Interior (DOI) is responsible for implementing OCSLA in all U.S. waters, including the U.S. Arctic. There are no special provisions in OCSLA statute relevant only to the Arctic.

In response to the Deepwater Horizon disaster, from 2010 to 2011, DOI replaced the Minerals Management Service, which had combined all of these functions in one entity, with three new agencies. The Bureau of Ocean Energy Management (BOEM), oversees the leasing process, environmental and economic analysis of plans to develop the OCS; the Bureau of Safety and Environmental Enforcement (BSEE) handles permitting, inspections, oil spill response and other safety and environmental matters; and the Office of Natural Resources Revenue collects revenues from OCS activity (BOEM 2011). This separation of resource management from safety oversight, and those two functions from revenue collection, was a structural as opposed to a regulatory or legal response to Deepwater Horizon. 
OCSLA divides the process that underlies federal offshore oil and gas activity into four potentially overlapping stages: "(1) development of a nationwide five-year leasing program by the U.S. Secretary of the Interior; (2) auction of offshore lease tracts by the federal government to the highest responsible bidder; (3) exploration of those tracts by successful bidders, and (4) development and production of oil and gas resources" (Huntington et al. 2012, at 12; BOEM, undated). DOI implements OCSLA through the regulations entitled Oil and Gas and Sulphur Operations in the Outer Continental Shelf, 30 CFR Part 250. The regulations often require federal decision makers to solicit and review public comment on five-year lease plans as well as on proposed lease sales. The burden to respond to public comment and other information requests under OCSLA and related legislation falls disproportionately on Alaska Native communities (Huntington et al. 2012).

The DOI has put forth two changes to the OCSLA implementing regulations since the Deepwater Horizon event, and implemented one. Both deal with Safety and Environmental Management Systems (SEMS). The first SEMS regulations, SEMS-I, had been under preparation well before the DWH, and were promulgated 15 October 2010. They require operators to implement SEMS, rather than doing so on a voluntary basis as had previously been allowed (DOI 2010). The SEMS-I regulations incorporate by reference American Petroleum Institute Recommended Practice 75 (API RP75) and require risk analysis at the operational and job level, and stricter record keeping requirements (DOI 2010, Hastings 2012). The SEMS-II rule, proposed in September 2011, strengthens SEMS by addressing stop-work provisions, reporting of unsafe conditions, definition of authority and the use of independent third-party auditors (DOI 2011). Finalisation of the rule is expected in 2013.

\section{Other U.S. Federal Agencies and Statutes}

In addition to BOEM and BSEE, other federal actors are also potentially involved in permitting or otherwise regulating offshore activity in the U.S. Arctic. The Fish and Wildlife Service (FWS), also in the DOI, splits oversight of Marine Mammal Protection Act authorisations and Endangered Species Act (ESA) requirements with the National Marine Fisheries Service, which is in the Department of Commerce under the National Atmospheric and Oceanic Administration (NOAA). The Environmental Protection Agency (EPA) reports directly to the President and oversees permit- 
ting under the Clean Air Act (CAA) and the Clean Water Act (CWA) the U.S. Coast Guard typically becomes involved in reviewing and implementing contingency and discharge prevention plans and takes the lead in implementing the U.S. Canada Joint Marine Pollution Contingency Plan, which has a Beaufort Sea annex. The U.S. Army Corps of Engineers is also involved under the CWA.

The National Environmental Protection Act (NEPA), 42 U.S.C. $\S 4321$ et seq., requires that federal agencies prepare environmental analyses for major federal actions. In Alaska those actions include OCS oil and gas fiveyear lease programmes, and individual OCS lease sales, as well as Exploration Plans and Development and Production Plans. The three levels of analysis possible under NEPA are a determination of categorical exclusion (no further analysis required); preparation of an environmental assessment/finding of no significant impact (EA/FONSI); and preparation of an environmental impact statement (EIS). As with OCSLA public participation requirements discussed in 10.2.4.1 above, similar requirements for the ESA, CWA and CAA under NEPA's implementing regulations, as well as federal consultation requirements, can place great demands on Alaska Native communities and groups that want to provide input on federally regulated offshore activity (Huntington et al. 2012).

To expand only briefly on the other federal statutes mentioned above that are potentially relevant to offshore oil and gas activity in the U.S. Arctic, the Clean Air Act applies to emissions from offshore operations. Notably, a rider to an omnibus appropriations bill signed into law in December 2011 transferred CAA permitting authority on the Arctic OCS from the Environmental Protection Agency to the Department of the Interior (U.S. 2011). The Clean Water Act relates to waste water discharges from offshore operations, and the Endangered Species Act to potential harm to species or habitat from such operations. The Marine Mammal Protection Act deals with possible disturbance ("harassment") to whales, polar bear, and other marine mammals, and the Oil Pollution Act applies, e.g., to Facility Response Plans for potential discharge of oil to navigable waters. 


\section{Executive Actions}

Following the 2010 Deepwater Horizon blowout and spill President Obama appointed the "National Commission on the BP Deepwater Horizon Oil Spill and Offshore Drilling" (National Commission 2011). The Commission Recommendations discuss many aspects of Arctic offshore activity, identifying as one specific action that the United States should "[l]ead in the development and adoption of shared international standards, particularly in the Gulf of Mexico and the Arctic." A Commission staff working paper on offshore activity in the Arctic provides further important background information (Ibid.).

In 2011, the president established an Interagency Working Group on the Coordination of Domestic Energy Development and Permitting in Alaska (Ex. Order 2011). The Working Group is to coordinate federal agencies involved in those processes, with an emphasis on efficiency, safety, and responsible development of on and offshore energy in the state.

\subsection{Conclusion}

This chapter aimed to introduce a basic outline of laws, regulations and recent history relevant to offshore oil and gas activity in the United States Arctic. The following list of references is therefore intentionally broader than works cited above and is designed to provide resources for readers interested in a deeper discussion of the individual topics raised here.

\section{Further reading}

Alaska Coastal Management Program http://www.alaskacoast.state.ak.us/ (website is static as of 1 July 2011).

Arctic Human Development Report (Akureyri, Iceland: Stefansson Arctic Institute, 2004).

AMAP 2007. Arctic Monitoring and Assessment Programme, Arctic Oil and Gas 2007. Arctic Oil and Gas Assessment, Overview Report, at http://www.amap.no/oga/

AMAP undated. Arctic Monitoring and Assessment Programme Arctic Oil and Gas Assessment, Background Reports for the United States (unpublished, on file with author). 
BOEM, Bureau of Ocean Energy Management, The OCS Leasing, Exploration, and Development Process (undated), <http://boem.gov/uploadedFiles/BOEM/Oil_ and_Gas_Energy_Program/Leasing/OCS\%20Leasing\%20Exploration\%20Develo pment\%20Process\%200verview.pdf>

BOEM, Fact Sheet: THE BSEE and BOEM Separation, 19 January 2011, An Independent Safety, Enforcement and Oversight Mission, at http://www.boem.gov/ About-BOEM/Reorganization/Reorganization.aspx

Thomas R. Berger, Village Journey: The Report of the Alaska Native Review Commission (1985).

Matthew Berman, Sustainability and Subsistence in Arctic Communities, Paper prepared for presentation to the Western Regional Science Association annual meeting, Monterey, California, February 1998.

Jennifer Dagg et al., Comparing the Offshore Drilling Regulatory Regimes of the Canadian Arctic, the U.S., the U.K., Greenland and Norway (Pembina Institute) June 2011.

Doug Hastings et al., Recommendations for Improved Oversight of Off-shore Drilling Based on a Review of 40 Regulatory Regimes (Cambridge, Mass.: Harvard Law School, Emmett Environmental Law \& Policy Clinic, June 2012).

DOI 2010. U.S. Department of the Interior, Oil and Gas and Sulphur Operations in the Outer Continental Shelf-Safety and Environmental Management Systems, 75 Fed. Reg. 63,610 (15 October 2010); 30 C.F.R. § 250.1900.

DOI 2011. U.S. Department of the Interior, Oil and Gas and Sulphur Operations in the Outer Continental Shelf-Revisions to Safety and Environmental Management Systems, 76 Fed. Reg. 56,683 (proposed by BOEMRE on 14 September 2011).

EPA undated, U.S. Environmental Protection Agency, Basic Information: National Environmental Policy Act, at http://www.epa.gov/compliance/basics/nepa.html

Charles Emmerson, The Future History of the Arctic (New York: Public Affairs/ Perseus 2010).

Executive Order No. 13,580, 76 Fed. Reg. 41,989 (12 July 2011).

Scott Goldsmith, TAPS at 35: Accounting for the Oil Revenues, Institute of Social and Economic Research, University of Alaska Anchorage, Web Note No. 12, July 2012, at http://www.iser.uaa.alaska.edu/news/?p=342

Inuit Circumpolar Council, A Circumpolar Inuit Declaration on Resource Development Principles in Inuit Nunaat (2011).

Linda Leask et al., Trends in Alaska's People and Economy, Prepared for the Alaska 20/20 Partnership, Institute of Social and Economic Research, University of Alaska Anchorage, (Alaska Humanities Forum 2001).

Donald Craig Mitchell, Take My Land, Take My Life, The Story of Congress's Historic Settlement of Alaska Native Land Claims 1960-1971 (Fairbanks: University of Alaska Press, 2001).

National Commission on the BP Deepwater Horizon Oil Spill and Offshore Drilling, Deep Water: The Gulf Oil Disaster and the Future of Offshore Drilling, Report to the President (2011). See also Macondo, The Gulf Oil Disaster, Chief Counsel's 
Report (2011) and Staff Working Papers. All are available at http://www.oilspillcommission.gov/

Mark Nuttall and Terry Callaghan, Arctic: Environment, People, Policy (Amsterdam: Harwood, 2004).

Henry P. Huntington et al., Less Ice, More Talk: The Benefits and Burdens for Arctic Communities of Consultations Concerning Development Activities, Carbon and Climate Law Review, Vol.1 (2012): 33-46.

Ronald O'Rourke, Changes in the Arctic: Background and Issues for Congress, Congressional Research Service R41153, 2 January 2013.

Dalee Sambo Dorough, "Inuit of Alaska: Current Issues" in Natalia Loukacheva ed., Polar Law Textbook (Copenhagen: NCM TemaNord 538: 2010):199-217.

Mark Schrope, Dirty blizzard buried Deepwater Horizon oil; One-third of oil from 2010 spill may be mixed with sea-floor sediments, 26 January 2013, at http:// www.nature.com/news/dirty-blizzard-buried-deepwater-horizon-oil-1.12304.

U.S. 2011. Consolidated Omnibus Appropriations Act of 2012, P.L. 112-74 § 432 (2011).

United States, Oil Pollution Act of 1980, 101 H.R.1465, P.L. 101-38033, codified at U.S.C. §2701 et seq. (1990).

Adam Vann, Offshore Oil and Gas Development: Legal Framework, Congressional Research Service, RL33404, 2 May 2011.

Alex Williams et al., The Future of Arctic Enterprise: Long-term Outlook and Implications, Smith School of Enterprise and the Environment University of Oxford, November 2011, with Royal Dutch Shell and IUCN.

\section{Questions}

Note: These questions are designed to require some basic research beyond the information provided in the text.

- Why might the United States' definition of the U.S. Arctic include areas below the Arctic Circle? How have other Arctic States defined the Arctic?

- What are Safety and Environmental Management Systems (SEMS) and what potential do they have to strengthen regulation of offshore oil and gas activity?

- In what ways do oil and gas activities within and beyond three miles from the Alaska shoreline differ? 



\section{Good Governance in the Arctic}

Gudmundur Alfredsson

\subsection{Introduction}

This chapter has two purposes. Firstly, it examines the main contents and characteristics of available international standards and monitoring activities relating to good governance and, secondly, it looks at the relevance, applicability and application of good governance in the Arctic. In addition, commonalities in terms of human rights and democracy will be identified, with a focus on indigenous peoples.

At the international level, good governance has been introduced to ensure sustainable human development. The origins of the notion of good governance emerged from within the development agencies and global financial institutions, like the World Bank (www.worldbank.org), the International Monetary Fund (www.imf.org) and the Organisation for Economic Co-Operation and Development (www.oecd.org). More recently the United Nations (www.un.org) has become involved through, in the main, the United Nations Development Programme (www.undp.org and ww.undp.org/content/undp/en/home/ourwork/democraticgovernance/ oslo_governance_centre/), the Human Rights Council and the Office of the High Commissioner for Human Rights (www.ohchr.org). Nongovernmental organisations, such as Transparency International (www.transparency.org), are also actively engaged in promoting good governance and monitoring compliance. 


\subsection{Links to Human Rights and Democracy}

Multiple links exist between the themes of good governance, human rights and democracy. In the 2007 UN Declaration on the Rights of Indigenous Peoples, in paragraph 3 of article 46 it says: "The provisions set forth in this Declaration shall be interpreted in accordance with the principles of justice, democracy, respect for human rights, equality, non-discrimination, good governance and good faith." These connections will be further explored in this chapter by the highlighting of parallels or overlaps between the three themes. All are mutually reinforcing and share the goal of improving quality of life in our societies.

A series of human rights instruments overlap with many of the components of good governance and democracy. The freedom of expression covers political speech, while the freedom of association covers the right to form and participate in political parties, the freedom of assembly covers political demonstrations, and the freedom of information and the right to education enable the public to make informed choices. Under article 21 of the Universal Declaration of Human Rights and article 25 of the International Covenant on Civil and Political Rights, the will of the people is the foundation of government, and it is to be achieved through free and periodic elections with secret ballots. There are multiple overlaps here with good governance components, like transparency, accountability, equal participation and the rule of law. International standards on good governance, human rights and democracy rely to a considerable degree on different academic disciplines and originate with a variety of intergovernmental organisations. While the three themes share the purpose of improving our societies and the quality of life therein, and, while they have much in common, they are also different. One can say that they are travelling on parallel but sometimes distinct tracks and use different terms and approaches while addressing the same or similar issues. 


\subsection{The Good Governance Guidelines}

While some good governance guidelines are of a general character, the majority is set out in hundreds of reports and documents addressing specific country conditions or particular resource situations. The goal, as mentioned above, is to ensure sustainable development by enhancing the integrity, effectiveness and efficiency of a country's public and private sectors. When one types "good governance" into the search engines of the websites of the international organisations concerned, thousands of hits come up.

The good governance guidelines may concern national and local administration and politics, development, the environment, food security, natural and revenue resources, good financial governance, good corporate governance, and good international governance. Not surprisingly, considering the originating organisations and the contents, economists are the leading drafters. For the most part, the guidelines are not intended to be legally binding unless and until they emerge as customary law or can be based on treaty law as with the anti-corruption treaties.

The guidelines are mainly directed to governments. Private sector entities are however also targeted, and it is for governments to regulate them. The emphasis is on developing countries, on the basis that development will not be successful and sustainable unless and until the various good governance components prevail. For many years, governments did not tolerate reference to good governance within the UN human rights programme, but recently the importance of good governance for human rights has been acknowledged in resolutions of the UN Human Rights Council (www.ohchr.org/EN/HRBodies/HRC/Pages/HRCIndex.aspx).

\subsubsection{Contents}

The main content components of the good governance guidelines are noncorruption, transparency, accountability, equal participation and inclusiveness, decentralisation, law reform and the rule of law. Additional components include the responsiveness of institutions within a reasonable time, effectiveness and efficiency, and the achievement of consensus in democratic processes. It can however be said that the anti-corruption efforts have become a cornerstone of good governance activities. 


\section{Non-Corruption}

Corruption has been defined as "the abuse of entrusted power for private gain" (www.transparency.org/whatwedo). The obvious opposite is bad governance and nobody wants that.

Anti-corruption efforts crucially call for the ability of a free press to identify, report on and evaluate the performance and proper behaviour of elected and appointed officials. Anti-corruption efforts also require competent police and independent and impartial prosecutors and judges; the roles of the police and prosecutors in fighting corruption are acknowledged in the 1979 UN Code of Conduct for Law Enforcement Officials (article 7 and the attached commentary) and the 1990 UN Guidelines on the Role of Prosecutors (paragraph 15).

The UN Convention against Corruption, adopted in 2003 and ratified by all of the Arctic States addresses, across several chapters, anti-corruption efforts through prevention, criminalisation, law enforcement, international cooperation, asset recovery, technical assistance, and mechanisms for implementation. Principle 10 of the UN Global Compact, a policy instrument for businesses, reads: "Businesses should work against corruption in all its forms, including extortion and bribery" (available at "www.unglobalcompact.org /aboutthegc/thetenprinciples/principle10.html").

The OECD Convention on Combating Bribery of Foreign Public Officials in International Business Transactions, adopted in 1997 and ratified by all the Arctic States, requires each State Party to make foreign bribery a crime holding their companies to account for their behaviour abroad. The Convention has 39 parties and is overseen by the OECD Working Group on Bribery (www.oecd.org/daf/briberyininternationalbusiness/anti-briberyconvention/oecdconventiononcombatingbriberyofforeignpublicofficialsininternationalbusinesstransactions.htm").

The website of Transparency International is rich in information and ideas about anti-corruption efforts in both the public and private sectors. For prevention purposes, the website presents Integrity Pacts, which are agreements between government agencies offering contracts and the companies bidding for them, where the parties commit to abstaining from bribery, collusion and other corrupt practices for the extent of the contract. The Integrity Pacts also suggest the need for a monitoring system to be put in place and led by civil society groups (www.transparency.org/whatwedo/tools/integrity_pacts/3/). 
Witness accounts and whistleblowers are encouraged (www.transparency. org/topic/detail/whistleblowing). GATEWAY is offered as a tool for collecting, sharing and expanding knowledge on corruption assessments (www.transparency.org/whatwedo/tools/gateway_corruption_assessment_ toolbox/0/). E-learning tools on corruption are available at (www.thefightagainstcorruption.unodc.org/). Corruption inevitably brings about human rights problems. Where there is corruption, equal rights will have been violated inasmuch as persons who unfairly make use of family or political connections or have the ability and willingness to pay bribes get more than their fair share of the public goods available. In addition to personal injustices, funding is siphoned away from economic and social development, and justice is denied when corruption extends to prosecutors and the judiciary. Some of the other good governance components mentioned below, such as transparency, accountability and the rule of law, are also essential in the combating of corruption.

\section{Transparency}

Transparency is about public authorities operating in the light of full public scrutiny with individuals, NGOs and the press able to access full information on the records and activities of the authorities. Officials are more likely to be honest when they know that the public is entitled to know about what they are doing. It is thanks, in part, to Transparency International that transparency has become a household word around the world.

Transparency is applicable to all branches of government. As an example, the 2007 Guide on Resource Revenue Transparency (www.imf.org/external/np/fad/trans/guide.htm) applies the principles of the IMF Code of Good Practices on Fiscal Transparency (www.imf.org/external/np/fad/trans/code.htm) to problems faced by countries that derive a significant share of their revenues from oil or mineral resources. Countries known for transparency and proud of their records are Canada, Estonia and Sweden. For example, on the website of the Swedish Government, there is an informative page called "Why public access to official documents?" (www.regeringen.se/sb/d/9395/a/86408). For transparency under the heading of good governance, obvious human rights and democracy parallels here include freedom of information and expression, includ- 
ing political debate. For transparency to be successful, the freedoms of the media and the internet, without external or internal censorship, must prevail as must a free civil society and vigorous NGOs.

\section{Accountability}

Public officials, both elected and appointed, should be accountable for their conduct. Moreover, elected officials must at regular intervals face the public in elections. The private sector and civil society organisations should however also be accountable to the public. Accountability cannot be properly enforced without transparency and the rule of law, coinciding with the demand for checks and balances and the independence and impartiality of the judiciary and of prosecutors.

On the website of Transparency International, social accountability is "defined as a citizen-centred approach to building state accountability," covering a range of actions that can be employed to hold government officials accountable, "including but not limited to participatory budgeting, independent budget analysis, public expenditure tracking, citizen report cards, community scorecards, social audits, citizen's charters, public hearings, e-governance and e-procurement, citizens" juries and community radio" (gateway.transparency.org/guides/intro/social_accountability).

\section{Law Reform and the Rule of Law}

Fair, stable and equitable laws, predictability and legitimacy, equal protection under the law and non-discrimination, these are all parts of the rule of law. Enforcement of the law requires an independent and impartial judiciary and impartial and incorruptible police and prosecutors. This includes appropriate legal frameworks as well as political, managerial and administrative processes responsible for responding to the rights and needs of the population. The United Nations is able to support Member States in ensuring domestic implementation of international standards and strengthening the institutions, processes and conditions that ensure an effective and just national order (www.unrol.org/). 


\section{Equal Participation}

The motivation for including equal participation and inclusiveness in good governance is to maximise the number of participants in economic development. Equal participation by both men and women is a cornerstone of good governance, but the same is true for minorities and disabled persons, to mention just some categories that are often victims of discrimination in education and employment and whose participation will increase the number of people contributing to the economy.

All human rights and their equal enjoyment across society are thus important for good governance. This is true in relation to securing equal opportunities and equal treatment in the enjoyment of standards on, for example, education, culture, employment, labour unions, collective bargaining, social security and health. As to politics, one must bear in mind that representative democracy does not necessarily mean that the majority understands or meets the concerns of the most vulnerable in society (www.unescap.org /pdd/prs/ProjectActivities/Ongoing/gg/governance.asp). International human rights instruments are explicit in requiring special measures or positive discrimination in the combating of discrimination, like, for example, article 2 of the International Convention on the Elimination of All Forms of Racial discrimination (/www2.ohchr.org/english/bodies/cerd/).

\section{Decentralisation}

Along with facilitating local democracy and public participation in local development, good governance is about the delegation of powers to institutions that are closer to the people concerned. For minorities and indigenous peoples, this is about self-government, autonomy, traditional government, self-management or devolution.

Article 4 of the 2007 UN Declaration on the Rights of Indigenous Peoples provides: "Indigenous peoples, in exercising their right to selfdetermination, have the right to autonomy or self-government in matters relating to their internal and local affairs, as well as ways and means for financing their autonomous functions." Article 5 moreover states: "Indigenous peoples have the right to maintain and strengthen their distinct political, legal, economic, social and cultural institutions, while retaining their right to participate fully, if they so choose, in the political, economic, social and cultural life of the State." And article 34 talks about the mainte- 
nance of distinctive indigenous customs, traditions, practices and juridical systems or customs.

The 1999 Lund Recommendations on the Effective Participation of National Minorities in Public Life (available at www.osce.org/hcnm/32240), adopted under the auspices of the OSCE High Commissioner on National Minorities, also address the representation of minorities in local politics. A separate chapter on minority self-governance spells out that such institutions, based on democratic principles, whether non-territorial or territorial, should have certain legislative and administrative powers. The basis for the Lund Recommendations is to be found in paragraph 35 of the 1990 Document of the OSCE Copenhagen Meeting on the Human Dimension (available at www.osce.org/odihr/elections/14304) as well as in paragraph 7, part IV of the 1991 Report of the CSCE Geneva Expert Meeting on National Minorities. Notably all the Arctic States are members of the OSCE.

The Lund Recommendations also call for special measures to be taken, where necessary, to compensate for the existence of groups with small numbers of members, in respect of their national or local representation. IGOs and other international fora are moving in this direction. Half the membership of the UN Permanent Forum on Indigenous Issues (PFII), the UN Special Rapporteur on the Rights of Indigenous Peoples and the UN Expert on Minority Issues are indigenous or minority persons. The decision to grant indigenous representatives the status of permanent participants in the Arctic Council is another example of such a measure being put into practice.

Both the 2007 UN Declaration and the 1989 ILO Convention concerning Indigenous and Tribal Peoples in Independent Countries (ILO Convention No. 169) foresee a range of special rights and special measures concerning rights to land and natural resources as tools for maintaining and developing indigenous ways of life and self-management or self-rule. Based on article 27 of the International Covenant on Civil and Political Rights, the Human Rights Committee has confirmed the land rights of indigenous peoples. Two such cases are illustrative: Communication No. 167/1984 (Bernard Ominayak, Chief of the Lubicon Lake Band v. Canada), views adopted on 26 March 1990, and Communication No. 197/1985 (Kitok v. Sweden), views adopted on 27 July 1988 (/www2.ohchr.org/english/bodies/hrc/ HRCommitteeCaseLaw.htm). 


\subsubsection{National Implementation}

The domestic implementation of the good governance standards rests with governments. States thus carry the primary responsibility for the implementation of human rights in law and in fact, but international organisations, particularly in relation to developing countries, are available for technical cooperation. Just as with the national implementation of human rights, the various components of good governance should be consistently incorporated into constitutional law and/or legislative acts. Independent and impartial courts and national human rights institutions must be available for addressing grievances and providing relief. States are now increasingly adopting legislation on good governance or the components thereof. Numerous such examples can be found by searching for good governance on the websites of the Council of Europe (www.coe.int) and the Organisation for Security and Cooperation in Europe (www.osce.org).

\subsubsection{International Monitoring}

Monitoring of compliance in relation to the good governance guidelines is in the hands of the above-mentioned intergovernmental organisations, with, and this oversight is generally viewed as light touch. The significance of the guidelines rests mainly on the weight of the adopting financial institutions with the developing countries concerned. As is the case with human rights, political and economic elites frequently oppose the guidelines as they threaten their power and privileges. The Inspection Panel of the World Bank is authorised to receive complaints about projects supported by the Bank from individuals, groups and NGOs, but its jurisdiction is necessarily limited to countries with World Bank sponsored programmes while, in addition, the panel's conclusions are non-binding on the Bank (enter Inspection Panel into the search engine at www.worldbank.org).

Drawing on the naming and shaming tactics of human rights NGOs, Transparency International (TI) does an excellent job of monitoring and publicising national practices as they relate to transparency and corruption. The place of human rights in the work of TI serves as further evidence of this relationship. National TI chapters exist in every Arctic country including Greenland (see www.transparency.gl). TI also monitors progress in relation to the implementation of the above-mentioned Conventions; annual reports on the OECD 
Convention place countries in enforcement categories (see www. transparency.org/whatwedo/pub/progress_report_2011_enforcement_of_the_oecd _anti_bribery_convention).

Global and regional organisations actively monitor State compliance with international human rights standards, and many of them allow individuals, and sometimes even groups, to file complaints against States. Regional organisations, including the Council of Europe and the Organisation of American States, have set up human rights courts, and several organisations have established quasi-judicial expert procedures that are authorised to deal with complaints. In addition, it is clear that the human rights performance of States is increasingly being monitored, even when such States are not party to specific treaty obligations. The good governance community is also increasingly drawing directly upon human rights law as a tool. Human rights standards and monitoring reports can help to clarify the meaning of the governance guidelines, for example on political freedoms and political participation, while experience of the human rights issues can provide guidance as to how to proceed in respect of monitoring mechanisms and methods.

Likewise, good governance and democracy do, in practice, generally contribute to the promotion of greater respect for human rights. Governments which are accountable to the people and represent the will of the people as expressed in regular, fair and free elections are more likely to care about human rights. One possible exception here is respect for minority and indigenous rights when the members of the groups often carry insufficient electoral weight, further underlining the importance of the special rights and special measures available under human rights law.

\subsection{Relevance to the Arctic}

Good governance in the Arctic as a matter of international regulation gives rise to interesting questions. If good governance guidelines are drafted for developing countries, do they also apply to the rich countries of the north? If the guidelines are to maintain their credibility as international instruments, the answer must be in the affirmative. Their credibility would be seriously diminished if they were seen to apply only to developing coun- 
tries. It is unimaginable in this day and age to come to a different conclusion and, as such, the Arctic should be no exception here. On top of this the guidelines are emanating from organisations that are often dominated by the rich countries of the north; it would thus be major hypocritical if such guidelines were marked "for export only". Good governance must then be seen as not only relevant but also applicable to the Arctic. It is noteworthy then in this context that the Arctic Council discusses indigenous peoples' and human rights issues in a Working Group on Sustainable Development.

Do the Arctic States live up to international standards on good governance? Remarkably and rather unfortunately, the Arctic States can often be seem to be lagging behind the worldwide trend when it comes to endorsing the international human rights standards that concern the indigenous peoples who live in their northernmost areas. Six of the eight Arctic countries have not ratified ILO Convention No. 169, and much of the opposition to the adoption of the 2007 UN Declaration came from countries in the north. Furthermore, the Arctic Council which claims to be the primary intergovernmental forum dealing with the Arctic has shown only a passing interest in directly addressing good governance and human rights. It is thus, for many, a matter of some regret that the rich and supposedly democratic countries of the north are not doing much better in this regard.

The indigenous peoples of the Arctic are governed from far-away capitals where the groups concerned are likely to be underrepresented or not represented at all and where official attention is most likely to focus on the exploitation of resources and strategic interests. When discussing law reform as a matter of good governance, human rights standards should be employed to improve national laws, for example by means of the consistent incorporation of international standards into national law. For countries rich in natural resources, transparency in relation to both their exploration and exploitation is key to the successful management of accumulated wealth and the maximization of long-term benefits to society. Indeed, many of the "hits" on good governance concern the governance of natural resources (see above under Transparency).

Some of the Arctic States such as Finland in relation to the Åland Islands maintain successful autonomy practices, although the ethnic Swedish minority enjoys much broader level of autonomy than the Sami. For the Inuit of $\mathrm{Nu}$ navut in Canada and the Sami in Scandinavia varying degrees of self- 
government have been introduced, but it is doubtful that these arrangements fulfil the said international standards. The approaches used are often uneven and inconsistent both inside the various countries and in particular when comparisons are made between countries. International standards on indigenous self-government as well as land and resources rights are fully applicable to the Arctic. Furthermore, with distant capitals and culturally distinct population groups, ensuring representation in national institutions and local selfgovernment are especially relevant.

\subsection{Concluding Remarks}

There is much to be gained from building bridges between good governance, human rights and democracy. These themes should not be kept in separate boxes or structures. The three communities of good governance, human rights and democracy have much to learn from each other in relation to contents and methods available for achieving their goals. The good governance people can learn about standard-setting and monitoring from human rights proponents. And the human rights people should enlist support from the governance guidelines as well as the democracy movement and the relevant argumentation, that is to say, the lawyers learning from the economists and political scientists. Economic explanations, for example on equal rights, effective participation and the freedom of information, will help explain the benefits of the broader realisation of human rights. With so many things in common, the opportunities for bringing about cross-fertilisation and mutually supportive arguments should be much more actively used.

International standards on human rights, good governance and democracy may amount to a limitation of sovereignty. That is, in part, the result of consent in the form of accepting treaty obligations. It may also be the result of the emergence of international customary law. Governments trying to defend their conduct on the basis of non-interference in a state's internal affairs or on the primacy of domestic jurisdiction can no longer credibly do so; human rights have been acknowledged as matters of international concern. For the governments of the Arctic States, most of whom claim to respect good governance, human rights and democracy in their foreign poli- 
cies and are outspoken on the governance, rights and democracy performances of other countries, their credibility is thus now certainly at stake.

\section{Further reading}

Sam Agere, Promoting Good Governance: Principles, Practices and Perspectives,

(Commonwealth Secretariat, 2000).

Gudmundur Alfredsson, "Human Rights and Indigenous Peoples," in Natalia Loukacheva (Ed.), Polar Law Textbook, (Copenhagen: Nordic Council of Ministers, TemaNord 2010/538):147-170.

Asbjörn Eide, "Good Governance, Human Rights, and the Rights of Minorities and Indigenous Peoples," in Hans-Otto Sano, Gudmundur Alfredsson \& Robin Clapp (Eds.), Human Rights and Good Governance. Building Bridges, (The Hague: Martinus Nijhoff Publishers, 2002): 47-72.

Factsheet, The IMF and Good Governance, at www.imf.org/external/np/exr/facts/ gov.htm

Factsheet, Transparency at the IMF, at www.imf.org/external/np/exr/facts/ trans.htm

"Good Governance" at http://en.wikipedia.org/wiki/Good_governance

"Good Governance Practices for the Protection of Human Rights", Office of the UN High Commissioner for Human Rights, Geneva 2007, HR/PUB/07/4, UN Publication Sales No. E.07.XIV.10.

Report from the UN Seminar on Good Governance Practices for the Promotion of Human Rights, held in Seoul on 15-16 September 2004, in UN document E/CN.4/2005/97 of 14 December 2004.

"What is Good Governance?" at www.unescap.org/pdd/prs/ProjectActivities/ Ongoing/gg/governance.asp

Working Paper No. 5/2008 of Transparency International, entitled Human Rights and Corruption, available at hyperlink http://www.transparency.org/publications/ publications/working_papers/wp_5_2008_human_rights_corruption www.transparency.org/publications/publications/working_papers/wp_5_2008_ human_rights_corruption. 


\section{Questions}

- What are the main components of good governance?

- How does good governance relate to human rights?

- Should the international good governance guidelines apply to the Arctic States?

- Can you identify good governance problems in the Arctic?

- How does one overcome the opposition to the introduction of good governance?

- Should the Arctic Council devote more attention to good governance issues? 


\section{Destiny or Dream Sharing Resources, Revenues and Political Power in Nunavut Devolution}

Tony Penikett

\subsection{General Framework}

\subsubsection{What is Devolution?}

Devolution involves the transfer of powers from Canada to the northern territories. Devolution can involve the transfer of administrative or financial powers as well as jurisdictional or legislative powers. The culmination of a series of transfers of Province-like powers from the federal government to the northern Territories is the acquisition of distinctive and precious jurisdiction over lands and mineral resources. In Nunavut, however, little progress has been made in devolution negotiations since 2008.

\subsubsection{The Constitution}

Canada's Constitution, which divides law-making powers between the provinces and the federal government, provides the backdrop for devolution negotiations. Section 91 of the Constitution lists matters under federal jurisdiction and section 92 lists matters of provincial jurisdiction, including non-renewable natural resources. When Alberta and Saskatchewan joined the confederation in 1905, they were junior partners. These 
Prairie provinces did not take control of their lands, minerals and energy resources until Parliament passed the Natural Resources Acts in 1930.

\subsubsection{The Meech Lake Accord}

In 1987, northern politicians lobbied long and hard against the Meech Lake accord, because sections $41(\mathrm{~h})$ and (i) of the proposed constitutional amendment, gave the provinces, for the first time, a veto over the creation of new northern provinces. The accord was not ratified. Nonetheless, the provincial veto seems to have become the rule, if not the law. Nowadays, nobody believes that provincial status is on the horizon for Yukon, NWT or Nunavut. Yet Yukon's devolution accord grants jurisdiction over natural resources without it becoming a province. Like Hamlet's ghost, Meech is dead, but influential. So, for Canada's northern territories, devolution may be all there is.

\subsubsection{Treaties}

Once the West was won, Indian treaties were considered a closed chapter in American history. Then geologists found oil in Alaska and Congress quickly passed the 1971 Alaska Native Claims Settlement Act, which gave native peoples there almost a billion dollars and title to 178,000 square kilometres of land.

The 1970s also saw Denmark grant Home Rule to Greenland and, in Canada, the beginning of treaty negotiations with 20 northern indigenous groups. These northern treaties negotiated with the Dene, Inuit and others to transfer title to huge tracts of land and re-establish aboriginal governance of those lands. Unlike the Victorian-era treaties that consigned First Nations to tiny reserves on marginal land, these northern treaties exist on a larger scale. For seven thousand Dene and Tlingit, the Yukon treaty provides 41,000 square kilometres - more land than is contained in all of the First Nations reserves in all of southern Canada.

Unlike the 19th-century treaties, which were drafted ahead of negotiations and which were brief and to the point, the northern treaties run to hundreds of pages. Yukon treaty negotiations produced a document longer than the New Testament, but that document contains many important poli- 
cy innovations, including those that promote conservation, such as indigenous and non-indigenous co-management of wildlife resources.

Under the devolution accord signed by its sister territory, Yukon manages federal lands. This means that the territory can authorise the transfer of ownership of these lands to private (third party) hands, lease these lands and license resource extraction on them. It can use and dispose of federal lands as though it were the owner.

\subsection{The Nunavut Story}

In the Eastern Arctic, negotiators completed the Nunavut land claims treaty in 1993. The Nunavut treaty had the dramatic result of making the Inuit there the largest private landowners in the world, with collective title to 350,000 square kilometres of land. In 1999, based on a commitment in the treaty, Parliament also created a new jurisdiction, the Nunavut Territory, a region where the Inuit constitute $84 \%$ of the population. A region and a government with a sustainable indigenous majority is something quite new in the Canadian Federation.

Confident of a continuing majority in the new territory, the Inuit of Nunavut opted for a territorial public government rather than the tribal governance alternative. Despite the 1993 land claims settlement and the creation of Nunavut in 1999, today, Ottawa still controls $80 \%$ of the territory's lands and, as energy developments and climate change jointly threaten the Arctic environment, these three facts create great uncertainty - an outcome anticipated by nobody in Nunavut.

Consequently, Nunavummiut, the residents of the new territory, have usually seen devolution as the logical third step in their journey towards autonomy. Because the federal government still has the final say over Nunavut's lands and mineral development policy, Nunavut has, for almost 10 years, been calling on Canada to devolve this power to Nunavummiut. In 2005, the northern affairs minister of the day promised to seek a federal negotiating mandate from cabinet and the appointment of a chief federal negotiator. 
Based on this promise, the Government of Nunavut (GN) Cabinet approved a devolution negotiation mandate. Devolution negotiations would be a three-party process involving the GN, the Government of Canada and Nunavut Tunngavik Incorporated (NTI) - the Inuit land claims organisation. In a 2007 letter to GN and NTI negotiators, the special ministerial representative for Indian and Northern Affairs Canada said that it was time to move forward on devolution and indicated that the three chief negotiators should attempt to co-author a Negotiations Protocol.

\subsubsection{The Protocol}

Most of Nunavut's communities are coastal settlements. Uniquely among the peoples of the world, indigenous Nunavummiut lived on the sea ice - and this fact will significantly influence negotiations. Nunavut's first premier, Paul Okalik, repeatedly stated that devolution negotiations must include such topics as net fiscal benefit, adequate staffing and Nunavut's "internal waters." However, the premier conceded that internal-waters or seabed-resource matters could be deferred to a later phase of negotiations.

Consequently, the Nunavut Lands and Resources Devolution Negotiation Protocol stipulated that the parties would proceed to negotiate an agreement-in-principle for lands and minerals, including a firm commitment to commence second-stage negotiations for an integrated onshore and seabed oil and gas management regime. The genius of the protocol is that it marries territorial and federal agendas. The territory seeks a jurisdictional transfer of province-like powers of its lands and waters, while the federal government focuses more on administrative capacity building. The protocol therefore proposes that these two processes proceed on parallel tracks.

The two governments and NTI signed the protocol on 5 September 2008. In the four years since the signing, the federal government engaged in no serious negotiations over sharing jurisdiction or resource revenues. Why has there been no progress? 


\subsubsection{Federal Response}

In January 2010, the federal health minister told the Aboriginal Peoples' Television Network that the reason Canada had not appointed a devolution negotiator was NTI's lawsuit. What is the NTI lawsuit?

The Nunavut land claims agreement anticipated stepped-up funding as the parties implemented each stage of the treaty, but Canada's Department of Finance proposed to "flat-line" the funding. Inuit representatives expressed pride (Penikett 2006:177-180) over having negotiated an arbitration provision in the Dispute Resolution chapter of the Nunavut treaty, but when they tried to proceed to arbitration, the federal finance ministry refused to participate.

Seventeen times the NTI tried to invoke their arbitration right and seventeen times the finance ministry refused. In the end, the Inuit probably had no choice but to take Canada to court. The NTI sued for $\$ 1$ billion for breach of contract. While there is no connection between this lawsuit and the devolution file, at least one federal minister saw it as reason to stall devolution negotiations.

On 27 January 2011, another cabinet member, Canada's minister of aboriginal affairs and northern development, said that Nunavut Territory and its Inuit population were "not at the stage of readiness" to assume responsibility for managing their lands - lands they had occupied for centuries.

\subsubsection{Administrative Capacity}

When the aboriginal affairs and northern development minister said $\mathrm{Nu}$ navut wasn't "ready", was he making a general comment about the community's intellectual or moral capacity to exercise jurisdiction over lands for which they were stewards long before Canada existed? With Nunavut's Inuk MP, sitting at the cabinet table with him, surely this was not the case. Was he then passing judgment on the administrative capacities of the Nunavut government?

The minister's officials have frequently questioned Nunavut's capacity to not only manage its current responsibilities but also to administrate its lands and resources. They sometimes point to the dearth of Inuit exploration geologists, mining engineers and chartered accountants in its territorial government ranks. However, Nunavut Territory is only 14 years old, and in 
the many decades of the department's federal government's absolute authority over the northern territories, how many Inuit geologists, mining engineers or chartered accountants has it trained and hired?

The answer is none. One federal official recently mentioned low graduation rates and high suicide numbers as two reasons to doubt Nunavut's capacity for managing its territorial lands and resources. Indeed, the statistics for both high-school graduation and suicide in aboriginal communities across Canada are alarming. Half of all aboriginal learners drop out of high school. Shawn Atleo, national chief of the Assembly of First Nations, said recently that "aboriginal children are more likely to go to jail than to graduate from high school" (Everett-Green: F5).

For young aboriginals, the suicide rate is six times the rate for nonaboriginal youth (Kennedy). So who in government has responsibility for this great Canadian tragedy of shameful aboriginal dropout and suicide rates? Given the general absence of aboriginal self-government in Canada, surely it is the department of aboriginal and northern affairs and, ultimately, its minister.

\subsubsection{Jurisdiction}

In his Conciliator's Report on Nunavut land claims implementation, Thomas Berger quotes Ejetsiak Peter, chairman of the Cape Dorset District Education Authority: "The children who drop out have not developed the skills to live off the land, neither do they have employment skills. So they are caught between two worlds" (Berger 2006). Berger recommended federal funding for a more culturally appropriate education system to improve Nunavut's graduation rates, but Ottawa refused.

A major study on suicide by two University of British Columbia scholars, M.J. Chandler and C.E. Lalonde, shows that aboriginal communities with higher levels of "cultural continuity" or self-government have lower suicide rates. By "continuity," the authors include community efforts "...to preserve, rebuild or reconstruct their culture by wrenching its remnants out of the control of federal and provincial government agencies"(Chandler\&Lalonde:13).

Stephen Cornell, America's leading expert on indigenous government, argues that, when it comes to cultural survival, it is jurisdiction that 
counts. Cornell argues that in Canada, as in the United States, federal government bureaucracies tend to approach aboriginal self-government with a focus on administrative activities, "while the big decisions still get made elsewhere" (Cornell 2003).

Indigenous people want "government", Ottawa offers them the "state". Administrative capacity can be built but this would require substantial federal and territorial investment over time. In democracies, jurisdiction rules administration; in a colonial relationship administrative incapacity may be used to justify a federal refusal to negotiate lands and minerals jurisdiction.

In Yukon's devolution deal, the territory assumed jurisdiction over oil and gas, then contracted back the management to the National Energy Board. This innovation gives the territory time to build administrative capacity while allowing it to exercise jurisdiction in a strategically vital field.

\subsection{Indigenous Government}

Since $84 \%$ of Nunavummiut are Inuit, the historical arc of indigenous government debates in North America might be illustrative.

In August 1521, (one Serpent in the year Three House of the Aztec calendar) Hernán Cortés, the Spanish conquistador, beheaded Cuauhtémoc, the last Aztec chieftain. Niccolò Machiavelli, a contemporary of Cortés, observed in The Prince that where city-states have a strong history of selfgovernment, the best thing is to destroy them completely. Consistent with Machiavelli's teachings, Cortés burned the Aztec capital, Tenochtitlán, to the ground, thus destroying the largest city in the world and the most powerful indigenous American government.

Ever since, for all indigenous Americans, restoring self-government has been a long and painful struggle.

In 1550, Bartolomé de las Casas, the first Catholic priest ordained in the New World, persuaded the Spanish crown to summon a council of 14 jurists and theologians to Valladolid to inquire into the legitimacy of the Spanish conquest and the treatment of the "Indians." Juan Ginés de Sepúlveda, a theologian, told the council the "Indians" were an inferior race and the Spanish, according to natural law, had every right to colonise and convert them by 
force. In a five-day response, Bartolomé de las Casas argued that indigenous American nations had great cities, kings, judges and laws, that they were selfgoverning peoples long before the Spanish invasion.

After the conquest of Mexico, the European powers fought for control of the rest of North America. All actively sought allies among Indian nations too weak to fight off the invaders but too strong to be ignored. As United States Chief Justice John Marshall later wrote, "The English, the French and the Spaniards were equally competitors for their friends and their aid" (Norgren:174).

After British and Iroquois forces defeated the French army at the Plains of Abraham in 1759, France signed the 1763 Treaty of Paris, the British took over the French forts and British settlers quickly occupied Indian lands. Pontiac, the Ottawa Nation's warrior chief, began to organise an army of resistance. On 7 May 1763, Pontiac's armies stormed British forts and took all but Detroit.

With Pontiac in mind, the British issued the Royal Proclamation of 1763, which promised that the Crown would only obtain lands required for settlement through publicly negotiated treaties with Indian nations. In effect, Britain had recognised Indian governments and aboriginal title to ancestral lands. The Proclamation eventually led to the negotiation of almost 400 Indian treaties in the United States and Canada, and the creation of Indian reservations or reserves everywhere except on the West Coast and in the Far North.

In 1831, as the signatory of international treaties with Britain and the United States, the Cherokee Nation petitioned the United States Supreme Court to recognise it as a "foreign state" but the court ruled that Indian nations were dependents or wards of the United States (Cherokee Nation v. Georgia, 30 U.S. 1 (1831)). However, a few months later, the court found that a state government had no authority on Indian lands (Worcester v. Georgia, 31 U.S. (6 Pet.) 515 (1832)). Chief Justice John Marshall wrote: "[T]he settled doctrine of the law of nations is that a weaker power does not surrender its independence - its right to self-government, by associating with a stronger, and taking its protection." Marshall's doctrine established that the national government of the United States, and not individual states, had authority in American Indian affairs. The same rule applies in Canada. 
When in 1971, Congress passed the Alaska Native Claims Settlement Act, the Act deliberately forbade "tribal" government. After considering a municipal option for Alaskan native peoples, Congress finally replaced tribal governments with state-regulated native corporations, in direct contravention of the Marshall doctrine.

The 1999 Nisga'a treaty negotiated with Canada and British Columbia reversed the tide of history by recognising significant province-like selfgovernment powers. As Chief Joseph Gosnell told the B.C. legislature, "...the Nisga'a is an old nation, as old as any in Europe... We governed ourselves according to Ayuukhl Nisga'a, the code of our own strict and ancient laws of property ownership, succession, and civil order..." (Gosnell: 6). The treaty made Nisga'a laws on Nisga'a lands paramount in the following areas: Nisga'a citizenship; structure, administration, management and operations of Nisga'a government; Nisga'a lands and assets; regulation, licensing and prohibition of businesses, professions and trades; preservation, promotion and development of Nisga'a language and culture; direct taxation of Nisga'a citizens; adoption; child and family services; pre-school to grade 12 education; advanced education; organisation and structure of health care delivery; authorisation of "aboriginal healers;" annual fishing plans for the harvest and sale of fish and aquatic plants; and Nisga'a wildlife and migratory birds entitlements.

Provincial Opposition Leader Gordon Campbell saw the Nisga'a selfgovernment agreement as "unconstitutional." However, the B.C. Supreme Court ruled otherwise, stating that self-government rights cannot be extinguished, but they may be defined or given content in a treaty. "The Nisga'a Final Agreement does just that" (Campbell et al. v. British Columbia, 4 c.n. L. R. 1. (2000)).

On becoming Premier in 2001, Campbell appealed the Campbell decision in the court of public opinion with a province-wide referendum. Campbell's 2002 referendum proposed that: "Aboriginal self-government should have the characteristics of local government, with powers delegated from Canada and British Columbia" (Elections BC). The Campbell Government won the referendum but was unable to maintain its position in self-government negotiations at British Columbia treaty tables after 2002.

For centuries, First Nations' vital interests resided in the lands and waters of their traditional territories - not in the dirt roads and water trucks 
of their villages (Penikett 2002). In the land-claim and self-government agreements negotiated by indigenous communities across northern Canada after 1973, these villagers retained title to some of these lands, mineral rights and significant governmental powers, among them taxation. Their treaties also guaranteed them co-management of fish and game resources and a voice in land planning decisions throughout their territory. Canadians have learned to think of these kinds of powers as "provincial," meaning within provincial jurisdiction - and that's the problem, particularly for the provinces that are even less willing to share jurisdiction than federal ministers (Courchene \& Powell).

As noted, in both Canada and the United States, Indians and Indian lands are federal responsibilities. Treaties are negotiated with First Nations, not Indian municipalities. Unlike municipalities, Indian governments have rarely been the creatures of provincial law.

Progress in negotiations for indigenous self-government has been painfully slow. At the current rate, British Columbia will still be negotiating treaties in the 23rd century. Twenty years after Yukon's First Nations negotia-ted Canada's first tribal self-government agreements with the territorial and federal governments, they still represent the majority of all such agreements in the country. The Supreme Court of Canada has yet to declare itself on indigenous government. Also, for indigenous peoples in the Arctic there remain serious unresolved issues, among them devolution.

The downgrading of indigenous governments from nations and allies to corporations and municipalities has been a long and painful process. The restoration of province-like powers to indigenous governments marks but one step on the long road to recovery.

\subsection{Right?}

The world is much changed since Cold War days when southern capitals enjoyed absolute power over northern communities. In 2005, the Government of Norway adopted the Finnmark Act, a law transferring $96 \%$ of a northern area to a new authority with equal representation from the indigenous Saami Parliament and the Finnmark County Council, a Nordic version of the co-management regimes in Canadian land claims treaties. 
On 21 June 2009, Greenlanders achieved self-government and a generous resource-revenue sharing package with Denmark.

Given what has been happening in Norway and Greenland, as well as in Yukon (which renewed accords with Ottawa in 2012) and in NWT (which negotiated lands and resources transfers in 2011), could devolution or local control of lands and resources be considered as something of a right - a right now enjoyed by all Canadians except the Nunavummiut and those First Nations trapped in the logjam of endless treaty and self-government negotiations? The United Nation's Declaration on the Rights of Indigenous Peoples, Article 26, clause 1, reads: "Indigenous peoples have the rights to the lands, territories and resources which they traditionally owned, occupied or otherwise used or acquired."

But what kind of a right can be trumped by an undefined bureaucratic test of administrative capacity? Canadian ministers might reply that the Declaration is not legally binding and therefore the "right" is no right at all. Aboriginal Affairs and Northern Development Canada seems to see jurisdiction as a reward for good administration, somewhat like a driver's exam, which gives one "jurisdiction" over a vehicle only after passing a government-administered test. With a driver's test the applicant may study the exam questions and answers in advance, but the Aboriginal Affairs and Northern Development has shared neither the questions nor the answers with Nunavummiut.

If "administrative assimilation" into a federal bureaucratic culture is Ottawa's objective, what are the benchmarks for success? The Minister has not said. In any event, no indigenous or northern government can ever reasonably be expected to reach Ottawa's unknown threshold. To some, this all seems far too much like the literacy tests once used in the southern United States, which were aimed at preventing American blacks from exercising their right to vote.

Obviously, Nunavut's government faces enormous administrative challenges in delivering economic development, education, health and housing to about 33,500 people spread over 2,093,190 square kilometres. With so few people in such a large area, population size is often raised as an issue particularly in discussions of indigenous government because, when it comes to administration, bigger is often assumed to be better. Is that also the case with jurisdiction? 
Many Canadians would agree that, for many years, our national government has suffered from the excesses of partisanship and patronage, bullying bureaucracy and the increasing centralisation of power in the prime minister's office. So, if northern and indigenous governments prefer consensus legislatures, co-management and decentralised administration, why would southern Canadians judge such approaches a failure? After all, the two regions, the North and the South, have different political cultures and different priorities. When the auditor general favours centralisation over decentralisation, as she did in her 2006 report, then indigenous and northern leaders may see that as evidence of a federal system that cares more about accounting than accountability.

Of course, compliance with universally accepted accounting principles is desirable, as is a commitment to training accountants and finance officers, but building administrative capacity in northern and indigenous governments will take huge investments of money and time. So also will Nunavut's land and resource devolution negotiations; northerners well remember that their land claim agreements typically took 20 years to complete. Obviously, a professional public service is essential to the effective operation of democratic government, but which comes first, democracy or bureaucracy? Most Canadians would choose democracy.

\subsection{Revenues and the Stakes}

Of course, successful devolution negotiations must produce a net fiscal benefit for the territory. Anthony Speca has questioned whether any of Canada's northern territories - Yukon or NWT or, eventually, Nunavut could achieve as good a resource-revenue sharing deal with Canada as Greenland received from Denmark. As Speca writes, "Denmark agreed to reduce the grant by just half of Greenland's resource income, and subjected the first DKK 75 million (\$14 million) collected annually to no corresponding reduction at all" (Speca:62).

What is at stake? The Geological Survey of Canada estimates that there may be a trillion dollars worth of oil and gas in the High Arctic (George). Development of these resources is no doubt decades away. Without devolution and a fair share of energy and mineral resource revenues from their 
lands, Nunavut will have little capacity to care for the health or the education of future generations. Indeed, devolution might be the only prospect the territory has for building a private sector and for providing prosperity, physical health and mental health for future generations.

When the world has extracted the last of the North's diamonds, oil and ice, what will be left for the people there? Will they have heritage or sovereign wealth funds or will they be left with holes in the ground? Why should Ottawa, rather than northerners, get to exercise "provincial" jurisdiction on Nunavut's lands? Is Ottawa ready to answer that question?

\subsection{Sovereignty}

Ironically, the current Prime Minister portrays his administration as the great defender of Canada's Arctic sovereignty but his government seems not to appreciate how solidly Canada bases its sovereignty claims in the Arctic on thousands of years of Inuit occupancy and continued use of Arctic lands, waters and sea ice. However, this fact is implicitly acknowledged in the preamble of the Nunavut Land Claims Agreement Act, which states "the Inuit of the Nunavut Settlement Area have asserted an aboriginal title to that Area based on their traditional and current use and occupation of the lands, waters and landfast ice therein in accordance with their own customs and usages."

\subsection{Conclusion}

Where are we now? What is the big picture? Arctic warming - caused by human hunger for scarce energy resources - is fuelling a new southern rush to tap the oil and gas buried beneath northern lands and waters. Climate change is opening up previously inaccessible areas for exploitation and at the same time exposing Arctic communities to greater risk of environmental degradation. Though they have contributed very little to global warming, Canada's Arctic residents will be among the earliest victims of climate change. As things now stand, they will pay the social and 
environmental costs but may receive little in the way of benefits from the extraction of energy riches from their homelands.

Devolution could provide a solution to this injustice but, it remains to be seen what progress Nunavut will make in negotiations with Canada. History has no plot, and sometimes time seems to stand still.

\section{Further reading}

Auditor General Fraser, Sheila. 2006 February Report of the Auditor General of Canada - Report of the Auditor General of Canada to the Legislative Assembly of Nunavut - 2005. Office of the Auditor General of Canada, 2006.

Berger, Thomas R. "Conciliation Letter to The Honourable Jim Prentice Minister of Indian Affairs and Northern Development." Conciliator's Final Report: Nunavut Land Claims Agreement Implementation Planning Contract Negotiations for the Second Planning Period. Ottawa: Aboriginal Affairs and Northern Development Canada, 2006.

Courchene, Thomas J., \& Lisa M. Powell. A First Nations Province. Queen's University: Institute of Intergovernmental Relations, 1992.

Cornell, Stephen. Panel discussion on "Brainstorming Governance." Morris J. Wosk Centre for Dialogue. Simon Fraser University, Vancouver, 2 July 2003.

Chandler, Michael J., \& Christopher Lalonde. Cultural Continuity as a Hedge against Suicide in Canada's First Nations. Vancouver: The University of British Columbia, 1998.

Elections BC. Report of the Chief Electoral Officer on the Treaty Negotiations Referendum. Victoria: Elections BC, 2002.

Everett-Green, Robert. “Law and disorder: What Bill C-10 could mean for Canada's native people." Globe and Mail, 18 February 2012.

George, Jane. "Rising natural gas prices may send U.S. corporations scurrying to the High Arctic's trillion dollar gas supply." Nunatsiaq News, 22 December 2000.

Ginés de Sepúlveda, Juan. Democrates Alter or On Just Causes for War against the Indians. Madrid, IEP, 1547.

Gosnell, Joseph. "Speech to the British Columbia Legislature, 2 December 1998," BC Studies: The British Columbia Quarterly 120: 5-10.

Hanke, Lewis. All Mankind is One: A Study of the Disputation Between Bartolomé de Las Casas and Juan Ginés de Sepúlveda in 1550 on the Intellectual and Religious Capacity of the American Indians. DeKalb, IL: Northern Illinois University Press, 1974.

Kennedy, Mark. "Former Prime Minister Paul Martin is 73 and wealthy, yet he intends to spend the rest of his life improving the lot of aboriginal Canadians." Ottawa Citizen, 23 December 2011.

Machiavelli, Nicolo. The Prince. Chicago: University of Chicago Press, 1998, ch. V. Mayer, Paul. Mayer Report on Nunavut Devolution. Montreal: Fasken Martineau DuMoulin LLP, 2007. 
Norgren, Jill. The Cherokee Cases: Two Landmark Federal Decisions in the Fight for Sovereignty. Norman: University of Oklahoma Press, 1996.

Penikett, Tony. Reconciliation: First Nations Treaty Making in British Columbia. Vancouver: Douglas \& McIntyre, 2006.

Penikett, Tony. “Treaty Questions Falsely Simplistic.” Vancouver Sun,6 March 2002.

Penikett, Tony, "Blessed are the Peacemakers: Modern Treaty Making with Aboriginal Nations," The Institute of Mathematics and Its Applications Conference on Modelling International Conflict. Oxford: Wadham College, 1997.

RCAP: Royal Commission on Aboriginal Peoples. Renewal: A Twenty-Year Commitment, Volume 5. Ottawa: Indian and Northern Affairs Canada, 1996.

Speca, Anthony. "Nunavut, Greenland and the Politics of Resource Revenues," Options Politiques (2012):62-67.

\section{Questions}

- Yukon's devolution accord with Ottawa allows it to manage lands and mineral resources in the Territory. How does this devolution agreement differ from provincial status?

- What is the difference between the devolution of jurisdiction or legislative powers over territorial lands and resources and the devolution of federal programmes for the administration or management of territorial lands and resources?

- Is there any basis for the Inuit of Nunavut to claim devolution as an aboriginal right? 



\section{Faroese Governance}

Kári á Rógvi

\subsection{Introduction}

The Faroe Islands are located in the North Atlantic midway between the north of the British Isles (the Shetland Islands) and Iceland. The Faroes fall thus just outside the Arctic Circle but they have much in common with entities that fall within it, notably Greenland, Iceland and Northern Norway, and can be an interesting case study on governance in the region. The Faroe Islands have achieved a very high level of autonomy, preserved their own language, a high level of education, a largely sustainable economy with public finances in order and a good credit rating. All this is achieved whilst being situated very far from neighbouring countries and markets; being dependant on ocean fisheries made difficult by unstable and sub-arctic climate; and, likewise, with travel and trade greatly impaired by distance and adverse climatic conditions, and inhabiting a number of steep and not very bountiful islands. For others trying to realise self-governance and move from under the shadow of metropolitan rule, the Faroes may offer a realistic (though perhaps not ideal) model for gradually creating a viable self-governance under marginal conditions and with somewhat hesitant approval from the metropolitan power.

The etymology of the name Faroe, Føroyar in the Faroese language, is a compound noun meaning "Sheep Islands," indicating both the marginal agricultural value of the land and the national character, the islanders being descendants of agrarian Norse settlers (Vikings) expanding West in the late second millennia A.D. Sheep-farming is still highly valued and practiced by thousands of people on very small plots and communal farms. Though still highly agrarian, the culture has been influenced by the explosive growth of fisheries in the $20^{\text {th }}$ century, leading to a more hun- 
ting-based culture. Added to this, and influenced by evangelical movements and later through the media, education and the influx of Danish popular culture, Faroese society is complexly interwoven with deep traditions and modern developments.

The language is a distinct West-Nordic tongue, derived from old Norse, not very far removed from Icelandic and Nynorsk (New or Western Norwegian) but with a certain infusion of Danish vocabulary and expressions. The Faroese language is the high-status language of administration and culture. Faroese-speakers number less than a hundred thousand globally, and around 48,000 people inhabit 16 of the 18 islands. Most to the inhabitants are native Faroese, with some Danes, other Scandinavians, Icelanders and Greenlanders and others scattered among them. A certain influx of Danes has occurred as a result of Danish administration and earlier domination of church and trade, and more recently as spouses of Faroese students return with them from Denmark. However, Danes and others tend to integrate into Faroese culture and no minority schools or other institutions indicate permanent communities with stronger ties to outside communities. Denmark, which claims sovereignty, is seen as another country linked through the "Community of the Realm" by Faroese consent. Studies indicate that the Faroese are largely bilingual (Faroese and Danish) with a very good understanding of other neighbouring languages (Norwegian, Swedish, English and Icelandic). Many of the immigrants are therefore able to continue to use their native language in the Faroes.

Most notable to foreigners is often how distinctive the islands are compared to other parts of the region. Visitors notice this distinctiveness in multi-coloured houses and sheep, numerous dialects and the abundance of local sports teams, of churches, political parties, trade unions, musicians and artists. This is not to say that the Faroese are more inclined than others to be tolerant but collectively they have such divergent identities and views that a dynamic society is inevitable.

The Faroese Løgting (Law-Thing or Parliament) and the Faroe Islands as a jurisdiction are among the oldest in the world. The geographical situation and association to the Kingdoms of Norway and later Denmark have ensured that the Faroes have never been colonised or conquered since the Norse settlement around 800 A.D. (save for a welcomed British intervention 
during World War II) but have been allowed to evolve largely on their own terms without being fully integrated into or subjugated by outside powers. This, however, has also meant a very high degree of regional and local diversity and a certain lack of coherently formulated policies, and both the autonomy issue and economic policy tends to move by accident and force rather than by reflection and choice. The political discourse is at times very abrasive and the lack of consensus on the achievements hitherto as well as on the future goals is often perplexing but the Faroese model of governance (though in need of refinement) has still accomplished quite a lot.

Perhaps the relative success of the Faroese can best be seen by the fact that the Faroese government has a high credit rating and pays very low interest on its loans; it is also not very far from balancing its books. Furthermore, unemployment is low, university enrolment at an all-time high and the Faroese own substantial and diverse investments abroad, including running banks in Denmark and other neighbouring countries, searching for oil in British waters and various construction business in Greenland. The Faroese also provide thousands of highly skilled workers, notably navigators, engineers and electricians for fisheries, sea transport and off-shore oil industries in Greenland, Norway and Denmark.

The Faroese have also recently achieved a functional infrastructure and profitable industrial base. Notably the main island of Streymoy has been connected to the second island of Eysturoy by bridge, the second city of Klaksvík linked to Eysturoy by sub-sea tunnel, and Vágar (with the main airport) also joined to Streymoy via tunnel. This means that $80 \%$ of the population is connected by road, no longer than an hour's ride from the capitol of Tórshavn. Most of the rest can use modern car ferry. This has revolutionised production and the labour market, integrating what was earlier a highly fragmented country, where each sub-region tried to build the same production pattern centred on a small fish factory. Now the factories are fewer but bigger, more specialised and people commute to where their skills are best put to use.

However, none of this can obscure the unrealised potential of the islands with enormous resources available within its Exclusive Economic Zone (EEZ). There is a patent failure to implement some obviously needed reforms. For example, coastal fishing which used to form the crux of the Faroese economy is currently hampered by the depletion of stock by an 
oversized local fleet, as thousands of people still expect it to be possible to live on unrestricted coastal fishing and related industries. These people are vocally opposed to fisheries regulations and hold great political clout. Biological and economic studies show that the main costal species of cod, haddock and saithe are not migratory and could easily be managed and harvested when reaching commercial maturity but are typically harvested 2-3 years too early, resulting in both smaller overall catches and relatively lower prices. However, the fishing communities usually oppose any restrictions claiming the scientists to be wrong; a commonly held view is that the last bountiful era (circa 1993 to 2000) was the result of cod immigration from outside waters and divine intervention as result of active prayer groups, and that current restrictions are just hindering a renewed upsurge in catches.

Furthermore, a very substantial proportion of every generation leaves the islands due to the lack of opportunity. Two-thirds of Faroese seeking further education go abroad and are unable to choose fully or in part to get their education in the Faroe Islands. Expansion of the existing University and Maritime Academy into fields such law, economics, management, accounting, business and various other trades and professions that are already practised in the Faroes and could be taught by Faroese as well as visiting scholars seems a straightforward policy choice. To this could be added other studies that would allow a natural development of alternative industries including those service industries that are often mentioned but never take off, like tourism and textile design. However, the combination of budget discipline, path dependence and political inertia means that the Faroese still choose the easy short term option of nudging the youth towards affordable and accessible education in Denmark. Alas, this in turn means that around half of the most ambitious and best educated do not return to the islands, as they find opportunities elsewhere. Even Faroese couples expressing an interest in returning do not do so, when they have bought a house, started a job or sent their children to school; the evergrowing Faroese Diaspora in Denmark adds to the easy integration of the Faroese emigrants.

The failures of the Faroese are often disguised by fortunate off-sets. Thus, a recent influx of mackerel into Faroese waters hides the collapse in haddock and cod; a high birth-rate conceals the ongoing process of emi- 
gration, and a vibrant sports environment and national celebrations like the St. Olaf's festivities (a week centred on 29 July) with their distinct display of common identity and good moods combine to mask the increasing lack of trust and capability in government and civic society.

Contemporary Faroese governance is probably the result of what selfdetermination entails namely both the insight and motivation to develop and improve but also the dysfunctional results of ingrained cultural beliefs and local politics that pressure the system to sub-optimise and avoid necessary but painful reforms and instead continue wasteful priorities. This is probably not uncommon to other small communities; the absence of a paternalistic metropolitan power does not guarantee good governance on its own. The Faroese have, however, largely achieved independence in the functional sense with the Faroese, holding almost all powers of government and financing it too through a largely sustainable economy. All that remains is to redirect the streams of migration back to the Faroes and to realise the potential of further education, properly regulated fisheries and otherwise even better governance before either the onset of decline that emptied the Shetlands and Orkneys (islands groups to our south, formerly Norse-identity and vibrant) or the destabilising effect of an oil industry too large for us to handle.

We shall now look more closely at some aspects of Faroese history, development and governance.

\subsection{History of the Faroes}

The Faroese were likely first inhabited by Celtic people. They have not left much in their wake and are only documented to have included monks that were taken to the islands for solace. The Norse came sometime before the year $800 \mathrm{AD}$, partly from settlements already established in the British Isles. The resulting population shows signs genetically of being overwhelmingly Norwegian on the male side with some element of Celts on the female side. Language and culture have developed mainly from Old Norse with some Celtic influence early on and with much Danish cultural infusion in the last few centuries. 
The Celtic form of Christianity was probably introduced to the Norse early on, and the (Icelandic) sagas tell of the battle between the more organised formal church of Norway trying to eradicate heathen and autonomous Christian beliefs in the Faroes. The advent of the Catholic Church coincided with the ambitions of the Norwegian Kings to rule all the Norse settlements out West. This resulted in skirmishes and contentions for power. The period from around AD 1000 until 1300 was marked by this strife that ended in the western lands recognising the power of the Kings but retaining substantial autonomy and assurances. We know the content of the Old Pact made between Icelandic Chiefs and the Norwegian King in 1262-64, a similar Pact was probably made with the Faroese but the exact content has not survived.

The Catholic Church in the Faroes also became very impressive in its own right, amassing close to half of all land and creating a powerful bishopric in the town of Kirkjubø, where it erected a cathedral and had a fully functioning synod and seminary until the reformation of 1538. Its crowning achievement (so to speak) was the education of a man called Sverre, whose mother claimed that he had been fathered by a Norwegian King. Sverre was educated at Kirkjubø and then went to Norway, where he claimed the throne and was successful in fighting for it. King Sverre was renowned as an administrator and is still remembered in the Norwegian National Anthem with the words: "from its heights Sverre spoke up against Rome," for his insistence on national autonomy also in religious matters. Sverre was the King until 1202 and his descendants ruled Norway when the pacts were formed with the western isles, including Magnus VI the Law-Mender. One might speculate that this has contributed to the respect for the Faroese jurisdiction's distinctness and effective autonomy.

In late $14^{\text {th }}$ century, however, the Norwegian crown was united briefly with the Swedish crown and then more permanently with the Danish crown. The Faroe Islands were still regarded as associated to the Norwegian Realm; the phrase often used was our land Faroe whilst both Norway and Denmark were considered realms. However, political control of all our realms and lands (as an Act of Christian VII in late $18^{\text {th }}$ century puts it) was slowly centralised in Copenhagen, somewhat obscuring and dissolving the distinctness of the various entities under ultimate Copenhagen rule. The relative weakening of Norway in this union, including the impact of 
foreign, notably hanseatic, traders also appear to have weakened the western Norse isles that became increasingly dependent on foreign agents and powers. The King in Copenhagen established a monopoly trade and from time to time made the Faroes a feudal fief ruled by absentee lords. The national economy and institutions seemed to decline for a long period of time, although they remained in place and the jurisdiction retained its own body of law.

Around 1538, the King of Denmark-Norway decreed a reformation of the church, resulting for the Faroe Islands in the vast church holding becoming crown land, the dissolving of the diocese and ecclesiastical control being taken away. The language of the Lutheran Church became Danish despite one object of the reformation being preaching the gospel in the vernacular. Likewise the administrative language of all institutions became Danish.

Despite this, Faroese identity survived as well as its practical autonomy. The things still operated as both law courts and parliamentary bodies representing and governing the locals. There was no democracy in the modern sense, rather an oligarchic-traditional system whereby powerful farmers were able to retain the distinct character of the land through development of case law and petitions to the King and his officials. The small number of Danes moving to the islands and the reliance on prominent locals and integrated Danish families as basis for recruitment of many of the officials needed probably added the respect for the traditions of the jurisdiction.

The loss of Norway proper in the Napoleonic wars and continued centralisation under absolutism, however, meant that the Løgting was not convened from 1814 until 1852. Instead, power was concentrated in the hands of the new governors of the Faroes but they continued the policy of practical autonomy rather than integration into Denmark proper. The Governors were often eminently qualified and were afforded wideranging powers, which they often used to initiate change and developments like encouraging ocean fisheries, establishing an equitable distribution of the pilot whale catch and the distribution of crown land to the poor, encouraging new settlements, improved infrastructure and established a savings bank. Thus, the paradox is that the concentration of power in the hands of well-educated governors staying for a long time on the islands helped introduce reforms based on particular Faroese circum- 
stances and needs, contributing to economic development and population growth and thus providing the practical basis for the ultimate movement towards democratic and national influence.

The mentioned reforms provided an opportunity for starting to realise the enormous potential of ocean fisheries from the end of the $19^{\text {th }}$ century; the Faroese bought sloops and schooners from Britain and started to fish all over the North Atlantic, notably around Iceland and Greenland.

\section{$13.320^{\text {th }}$ Century Developments and Home Rule}

By the beginning of the $20^{\text {th }}$ century, the Faroe Islands had a very good base for further development. Their local identity was strong compared to the formerly Norse-identity communities of the Shetlands and Orkneys. Faroese people stayed and developed their local communities rather than seeking their fortunes elsewhere. Significant economic potential existed in fisheries while the governance structure was becoming increasingly robust.

The Faroese had by this time formed several political organisations that sought to advance the development of the economy and culture of the islands. The Society of the Faroese a mass movement for cultural and political autonomy formed in 1888 was pushing for the development of the language and other cultural/heritage issues. This ultimately resulted in the development of a Faroese written language, media and education. The Faroes' Progressive Society, which was closer to a political party, formulated a programme in 1903 of development, democratisation, education, language and equal rights. Although elections were of individuals and parties originally were held to be undemocratic, the Progressives appear to have won a majority of the half of the Løgting seats then up for election, in 1905. However, this unity was lost in subsequent years with Faroese politics subsequently dominated by an ongoing tug-of-war between numerous parties. The original split between the Unionist and Independence parties came in 1906, with the Social Democrats forming in 1932, Popular Party in 1936, and the Republican Party in 1948, with several others forming since, the latest just before the 2012 elections. The majority of the parties and members of parliament have an allegiance to the broad independence cause, with the Unionists usually holding around $25 \%$, however 
the independence movement is divided both on how to govern the islands and on how far and fast to take autonomy.

The six to eight parties generally achieving electoral success do not form tight coalition blocks nor the long-term governing agreements that are the quintessential characteristics of Scandinavian politics, where usually a red and a blue block compete for control of the government but then reach across the aisle for broad agreements on various policies. By contrast, the Faroese parties can form coalitions of all permutations and very rarely create the kind of long-term broad policy agreements practiced in mainland Scandinavia.

The Second World War brought increased desire for self-government and the Danish attempt to stop the evolution of autonomy into outright calls for independence led to the forcing of an alternative referendum on increased municipal powers or outright secession. The Faroese chose the latter, and, suddenly, a Home Rule arrangement was possible, resulting in a gradual and dynamic development since 1948. This gradually led to the Faroe Islands pushing the Danes to recognise an increased Faroese fisheries zone, Faroese membership in international organisations, particularly dealing with marine resources, and the future possibility of entering into negotiations over a Faroese Constitution.

\subsection{Economic Development}

To understand modern Faroese governance it is also essential to look at the Faroese economy. The Faroese economy was for centuries based on village farming with particular emphasis on pasture production of milk, with barley, sheep, coastal fishing for cod, seabirds and pilot whaling and, later, the growth of potatoes. However, for centuries the main staple source of calorie intake was milk produced from the rich grasslands scattered around the islands. Other sources, notably, the protein sources of sheep, fish and whale fluctuated significantly in terms of production.

The Faroese had very much taken the Norwegian pastoral farmer lifestyle to the islands but had to adapt it to the harsher prevailing conditions, for instance using peat as fuel and placing the cowshed below the main dwellings to ensure heat from the cattle. The Faroese like the Norse of 
Greenland were not inclined to do much fishing and as late as the $19^{\text {th }}$ century the enormous quantities of marine resources were only of secondary economic importance. Even today, the cultural affinity for agriculture can be seen in the thousands of people participating in small holding and common farms. Furthermore, the debates on milk and wool production and self-sufficiency in agricultural produce form a part of the public discourse widely out of proportion to their actual significance in today's fishing, fish farming and service-based economy.

The Faroese were largely opposed to economic development well into the $19^{\text {th }}$ century. However, the liberal Danish regimes eventually succeeded in replacing the King's monopoly trade with free trade. This gave the landless peasants access to a share of the whale catch and the King's estates for some subsistence farming that made it possible for people without landholdings to be active in the developing fishing industry.

Economic development however really accelerated when the Faroese, after 1870, started buying small ships from Britain and began fishing for cod off the coasts of Iceland and Greenland. The catches of larger whales (the Faroese traditionally mainly catch pilot whale and other small types) contributed to furthering development. This new export-led growth increased the size of the economy and the population grew from about 5,000 at the beginning of the $18^{\text {th }}$ century to 30,000 by the middle of the $20^{\text {th }}$ century and rising to almost 50,000 in the last 20 years.

Currently the Faroese economy remains highly reliant on fishing, fish farming and other fishing-related industries. However, a service sector has now emerged it remains relatively underdeveloped while education and tourism, particularly when compared to Iceland and Northern Norway, are also in a similar position.

\subsection{Resources}

Faroese economic management of resources is undoubtedly viewed as an important aspect of governmental capacity. Thus, we shall look further at resources that form the heart of the Faroese economy and provide a basis for Faroese autonomy. 
Faroese fish stocks are, in this context, also very significant. Stocks of cod and haddock have been overfished recently, as has saithe, which had otherwise overtaken the other two as the most important stock for nearshore fisheries. Historically, the Faroese have fished around Iceland, Greenland and elsewhere in the Atlantic area, as well as for herring and blue whiting. The Atlantic-Scandic herring collapsed from overfishing in the late 1960s. Later other pelagic or deep water fisheries have expanded, some of them adequately managed by the Faroese today, e.g., the greater silver smelt.

The Faroese fisheries management regime has the problems with cod, haddock and saithe notwithstanding, some advantages over other regimes such as the EU common fisheries policy. Notably, the problem with discarded catch is very limited as most quotas to smaller vessels are given in fishing days (effort management rather than volume management) and all catches are allowed to be landed (though the landing of very small fish will lead to certain areas being temporarily closed). Also, the many spawning grounds are well protected and catches of pelagic species seem to be both sustainable and profitable as the quotas are sufficiently large and the industry has been able to consolidate to the point where many companies are commercially viable. Thus, the crux of the debate especially concerning the pelagic species such as herring, blue whiting and mackerel is what the government should charge for the resources, rather than how much to subsidise the fisheries industry. In fiscal year 2013, the budgeted direct resource payment is close to DKK 150 million. This is a dramatic improvement compared to 20 years ago when almost all fisheries were subsidised and politically micro-managed. The industry on land is even more consolidated; it used to be dominated by local producers in almost every village which went bust on a regular basis only to be reconstructed by political intervention.

The above-mentioned failure of the regime dealing with certain stocks has much to do with the government issuing too many fishing days and the indirect subsidies through the minimum payment scheme that effectively supports the wages for some unprofitable boats, notably very small boats and long-line boats. Thus, measured by the scientific standards of minimum spawning stock and fish death, the cod, haddock and saithe are biologically overfished. The economic output is even worse, as even a 
biologically viable regime is likely to be unprofitable. To become commercially viable, an effort needs to be made to oversee further reductions with catches delayed until, for instance, the cod are around 5 years of age. To move from the current situation of limited stock and catches of around 2 year old cods, means a virtual ban for three years or a substantial reduction for longer periods, unless primary sea growth increases. This is very difficult to achieve, although the number of fishing days has been reduced and many areas, especially close to the land, harbouring very small fish are now simply off-limits.

Recently, the fishing of mackerel has increased dramatically. This new development is likely to be a combined result of changing temperatures and currents with the absence of other species due to overfishing possibly contributing. In any event, the mackerel stock is widely thought to be feeding in Faroese waters during late summer before retreating into Norwegian waters in the fall. The EU, Norway and the Faroes had agreed on sharing the stock in annual agreements, the latest concerning the calendar year 2010, according to which the Faroese share was around 5\%, resulting in around 50,000 metric tonnes that were to a large extent traded for either cod in Norwegian waters or for mackerel to be fished in Norwegian waters in the late autumn when it is usually priciest. The new or previously undiscovered feeding pattern led the Faroese to claim around 15\% of the catch, increase its domestic quota to 150,000 metric tonnes for 2011 and slightly less for 2012. Iceland and Greenland have likewise issued their own quotas as the stock seems to drift ever westwards. The changing distribution of mackerel in the Atlantic area from around 2010 highlighted the fact that the Law of the Sea Convention is failing in terms of the regulation of "slightly shifting stock." The Convention has provisions on straddling stock and highly migratory stock but not on in-between stocks like mackerel that turn out to straddle the international boundaries but to varying degree. As such, there is now considerable need for an international regime which is able to allocate varying shares to the participating countries.

The earlier herring collapse and the near collapse of blue whiting which produces similar quantities but less revenue all point to the need for an effective regional regime that includes the Faroe Islands and will deal with the results of climate change and the effects of industry on fish stocks that are impervious to national borders and other man-made concepts. 
The greatest resent resource success, however, is probably salmon farming. Faroese waters seem to be ideal for farming as the sea temperature is stable year round and never freezes and is also rich in nutrients and is naturally cleaned by strong currents that sweep the fjords effectively. The early fish farming regimes failed to regulate the necessary distance between farms to avoid the spread of decease and parasites but since around 2000 the regime has been near optimal resulting in record yields and profitability with one producer being listed on the Norwegian stock exchange marking a particular milestone in attracting foreign direct investment.

With regards to non-renewable resources, the Faroe Islands have some potential for hydropower, wind power and thermal energy. Currently however all of these sources of energy remain underdeveloped. As such, the Faroe Islands remain highly dependent on oil, not only for industry, which is almost exclusively run on oil, but also for domestic heating and electricity which is more than $50 \%$ dependant on oil. The Faroese economy suffers greatly as a result of the regular oil price spikes. There is a small deposit of coal but not commercially viable.

Hydrocarbons exist in the Faroese continental shelf beneath very deep waters close to the British border. The Faroese have secured sub-soil minerals as a special matter, so both the regulatory regime and all income are exclusively Faroese. The Danish Realm states claim and concludes agreements on the continental shelf vis-à-vis other states (the remaining claims are to the south east and to the north of the islands) but the Faroese serve on the committees dealing with the claims, have to approve any deals reached and manage all internal aspects of the oil and gas regime. Currently, the UN body set up to consider continental shelf claims according to the Law of the Sea Convention is considering the Faroese/Danish claims but negotiations have been completed with neighbouring countries on the subsequent delimitation pending validation. This may dramatically increase the area under Faroese jurisdiction with potential for future mineral exploitation.

However, the question remains whether the amounts detected are commercially viable as the production areas will be very costly to develop at such depths. The regime is however in place for exploration and the subsequent production of oil and gas and several successful rounds of licensing have already been completed, the success being that exploration in the form of seismic shooting and drilling has occurred increasing the 
knowledge of hydrocarbon activity and potential exploitation. Notwithstanding this it is clear that the explorative phase in itself has been very useful to the Faroese as many individuals and companies have increased their qualifications and business volumes as well as benefiting from licence fees and other tangible payments, all of which have already had a significant impact on the economy.

As for other resources, while the agricultural potential is negligible it nevertheless remains very important to the Faroese culture, most notably, the small scale sheep farming that still inspires thousands to part time farming, often communally and with several generations participating. Similarly, bird catching, pilot whaling and potato farming are deeply communal in nature and maintain the country's agrarian cultural roots.

Recently, tourism has been heralded as a great new commercial opportunity. The lack of a service culture and often inadequate facilities, as well as strict licensing laws and other regulatory quirks which hindered its development in the past have now begun to be addressed. Tourist volumes now seem to be picking up with up to some 20,000 tourists per year now visiting. Numbers are nevertheless likely to remain restricted because of the unstable climate of the islands which makes the planning of fishing trips, hiking or even driving around very difficult.

\subsection{Faroese Law and Authorities}

\subsubsection{Faroese Law and the Administration of Justice}

The Faroese created their own system of law built primarily upon what they knew from home with thing being held both locally (now defunct) and nationally (now called Løgting), constituting a form of government where traditional law gradually altered through case-law and on occasion the passing of general legislative acts. We know, for instance, of a statute limiting and organising the use of dogs for shepherding and hunting from around 1350 and statute regulating the remuneration of members of the Thing from around 1450 - they were paid in woolly cloth depending on how far they had to travel. 
We know, however, of a letter from 1271 recognising that the Faroese would keep their own laws regarding certain matters "according to your own law-book." In 1298, these Faroese laws were codified so that we now know indirectly what had developed in Faroese law prior to that date. The 1298 Reform Code contains provisions on a number of issues which varied from court procedure, tenancy, libel, and whaling to agriculture. For some reason, however, the name "Sheep Letter" has stuck to this document, a title that belittles the considerable achievement of an island community of perhaps 4-5,000 people developing its distinct legal tradition and being able to insist on its continuance and respect from a powerful and much larger polity. However, law records from before the late $17^{\text {th }}$ century are patchy.

Historically the six "sýslur" - roughly translatable to counties - were the main units of legal administration, with the entire archipelago - the "land" - only deciding on a few overarching matters. The locals held a Thing that was a hybrid between legislature and court, with many general acts and principled decisions providing local law and practice. The emphasis was on Norse traditions, thus both sýslur and land (local Thing and Løgting) decided disputes and resolved general regulations with emphasis on the former, as this was a conservative society that moved incrementally and only appears to have legislated when the general codes or previous resolutions were irrelevant, inexplicable or clashing.

When the Norwegian Kings became overlords in the late $13^{\text {th }}$ century, they largely allowed the counties to function but added powers and procedures. The Kings' Bailiff, later a Governor headed a very small administration in the capital Tórshavn, and to a large extent allowed traditional local self-government to continue. Thus, in those instances where laws on property, farming and other matters needed to be administered according to general rules promulgated by the Norse and later Danish overlords but set in the particular Faroese context, the Things were allowed to form bodies of case law that seem very impressive but have so-far been inadequately studied from the legal governance perspective.

Until the middle of the $19^{\text {th }}$ century the county courts were manned by locals who were chosen from among the landed farmers and together preserved a body of local and legal insight. After that each county was administered by just one sýslumaður (county sheriff) but until the middle of the $20^{\text {th }}$ 
century, the person chosen was always, by tradition, a local man. Thus, much customary law was preserved up to current times. It is often either codified or still continued by the present day legal system, so that the law concerning such issues as sheep farming and pilot whaling will be governed by tradition, often differing substantially from place to place.

\subsubsection{Local Administration}

The counties have in most matters of local politics and administration now been eclipsed by the local municipalities, some of which even straddle the old county borders. The Faroese kommunur (municipalities) were formed in the middle of the $19^{\text {th }}$ century to administer the fledgling welfare system but have since been transformed into powerful entities with tax rising powers, taking about as much as the land in direct income tax, while disposing significant budgets and powers over planning, day care, school buildings, roads, harbours, and other local infrastructure. The municipalities often have greater room in their budgets for new initiatives and in practice now give rise to much of the national political class, as most politicians start out as municipal councillors.

The municipalities started out being aligned to the old counties with the capital Tórshavn having its own council but they have since fragmented. Although some consolidation has taken place, they still constitute over 30 entities with the smallest comprising of just 1 or 2 villages, and often with fewer than 300 people. Most have between 1,500 and 5,000 inhabitants with Tórshavn standing out with around 18,000. With inspiration from neighbouring countries and Denmark in particular, very strong municipal reform has been a constant theme for decades. However, the matter was settled by a referendum in 2012 which resoundingly favoured the status quo and no further consolidations are to be expected in the near future.

\subsubsection{The Parliament}

On the national level, the Løgting (Law-Thing or parliament) was traditionally held in the summer and functioned as a combined legislature, appeal court and national festival. The Kings were keen on dampening the potency of this body but it remained formidable up until the $18^{\text {th }}$ century. 
By then the monarchy had, through the office of the sorinskrivari (legal clerk), created a legal office that largely replaced the appointed locals as judges in appeal cases, and general enactments became rare.

As noted previously, from 1814 onwards, due to a general tendency within the absolutist government to dismantle democratic structures and the particular occasion of the loss of Norway proper, the Løgting was not convened. However, by that time it had in any case become a shadow of its former self.

As parliament was reconvened in 1852, it was revitalised and many of its members were among the most educated and visionary, adding to the reforms initiated by Danish governors at the time. With Christian Bærentsen as Governor in the early 20 $0^{\text {th }}$ century, a Faroese national for the first time held that office and encouraged the Faroese language to be used in administration at the same time as Faroese theologians began to function as priests.

\subsubsection{Faroese Jurisdiction}

The situation evolved very slowly however until after the Second World War when the Faroese finally got the powers they had craved. In 1948 the Home Rule compact created a mechanism for transferring policy matters from Danish to Faroese rule as "special matters" and branding all others as "common matters" stressing self-determination and influence in all issues.

The Home Rule compact - established by the Home Rule Act sanctioned by both the Løgting and the Danish Parliament - shifted constitutional law immensely. The words of the Danish Basic Law (constitution) that could be read to exclude Faroese legislation, government, taxation, budget powers, foreign affair powers and otherwise see Denmark as "unitary" were ignored. As history suggests the theory of Denmark as a unitary state was baseless anyway but the Home Rule compact expressly recognised the powers of the state to be vested in Faroese bodies. Furthermore, policy matters were categorised as either common or special, meaning that all policy areas were subject to Faroese authority, either together with Danes or exclusively held by the Faroese. Pursuant to this arrangement the Faroese right away took over a number of policy areas such as taxation, fisheries, labour law and 
internal constitutional matters, setting out immediately to both direct their own economy and set up their own institutions.

Because of economic difficulties in the 1950s and a certain conservative streak in the policies particularly of the Unionists and Social Democrats at the time, the process of transferring policy areas stalled for a number of years after the initial burst of autonomy. It took until the 1970s for most matters to be transferred. In particular the period from 1974 to 1980, with the Social Democrat Atli Dam as Law Man, saw a number of policy areas being transferred to Faroese control, with the many areas associated with the Danish welfare-state being financed by the Danish treasury. This meant a massive expansion in the Faroese public sector and the setting up of a Faroese administration and bureaucratic institutions, providing and deciding what was previously either not available or decided in Copenhagen or by the Danish High Representative's office.

The administration of the Faroe Islands is today almost exclusively in the hands of the Faroese, with the only exceptions being a handful of peo-

ple at the High Representative's office and courts, in addition to the police, who are employed by the Danish State to administer common matters. Most of those individuals are Faroese natives, so the effective level of selfadministration is very high. The Løgmaður elected by the Løgting, heads the central administration and appoints a number of ministers (eight as of 2012) who each head ministries with various powers over a number of lower agencies and offices. The general lay-out is very similar to the various Scandinavian models. Some differences do however exist such as the ministers not being members of the parliament (if elected, they decline their parliamentary seats whilst in executive office), and due to the size of the country, some amalgamations of offices can be seen, such as the coordination of administrative appeal tribunals.

\subsection{Modern Legal System and Developments}

During the last century the Faroese court system was gradually integrated into the Danish court system as institutions of the Kingdom, depriving the old institutions like county courts, county sheriffs, and lay people of their role. This worked against the otherwise prevailing trend of empowering Faroese 
institutions. Nevertheless a Faroese administration of justice statute remains as do some quirky remnants of the old Faroese legal system, like the agricultural commissions from which there is direct appeal to the Danish Supreme Court, circumventing the regular court system.

Lately, however, the Court of the Faroe Islands has been increasingly staffed by native Faroese or Danes thoroughly integrated, increasing the practical use of the Faroese language as the official language at a trial level, leaving Danish as the language of the appeal process. The appeal courts have, moreover, increasingly understood the distinct nature of the Faroese legal system. Likewise, the Faroese Labour Law Tribunal established in 2006 uses Faroese senior lawyers as presiding judges but the majority of the judges are chosen for their insight of Faroese labour relations. It also led to better reasoned decisions in a country that is more dependent on case law being gradually created due to the less heavy legislative activity and lack of preparatory works and other materials often used as contributory in Scandinavian law.

Apart from the formal court system, the Faroese legal system as a whole is becoming more Faroese. Statutes in all special matters are only promulgated in Faroese, most administrative decisions and many court decisions are in Faroese. Textbooks and further education is being developed in Faroese and both practice and case law, including most administrative appeal procedures, is becoming more distinct and more Faroese. The Appeal Court sits regularly in the Faroes and the Supreme Court sat for the first time in Tórshavn in 2012, a very rare and symbolic occasion that was designed to signal the increased awareness of the distinct nature of the Faroese jurisdiction. Crucially, Faroese nationals occupy most administrative posts and are more likely to be educated at least partially at the University of the Faroe Islands which, for example, offers a distinct law programme focusing on certain areas of Faroese Law.

Historically, the Faroes did not follow Denmark in 1973 and thus remained outside the EU; this also contributed to the setting of Faroese and Danish laws on different paths. On several occasions the courts (which are Danish institutions but are operating according to legislation approved by both parliaments as justice is a common matter) have held that Faroese legislation has primacy and must be interpreted according to their own content not for instance in compliance with EU case law that is otherwise binding on the practice of comparable Danish statutes. 


\subsection{Constitutional Perspectives}

It will be clear that the Faroese certainly accept the association with Denmark, albeit for very different reasons. However, there is an equally very strong consensus on effective autonomy, often resulting in further transfers of policy areas, Faroese international participation co-ordinated with Denmark, amendments to common legislation or otherwise. The strongest indication of this paradigm of autonomy is the unilateral enactment of a Form of Government and the internal debate over its revision.

The first unilateral Faroese constitutional document, the former Form of Government Act, was enacted in 1948. The revised latter version was enacted in 1992. Thus the Faroes have had their own internal constitution all along and have only referred to the Home Rule Act when transferring policy areas and in other external instances. The Home Rule Act - the metropolitan formal empowering - has thus not functioned as the internal constitution, as have the comparable documents in Greenland or in the Åland Islands. Rather, the relevant documents have been the exclusively internal Faroese documents. This development is then rather more similar to that of Norway and Iceland with their own strong constitutional documents whilst associated with Sweden (from 1814 to 1905) and Denmark (from 1874 to 1944 ) respectively. Their examples have prompted the current debate on the progression to an even more full-fledged constitution with provisions on rights provisions, as well as national identity, selfdetermination and procedures for secession. It is noteworthy moreover that the Faroese constitutional debate continues without anyone suggesting anything but an internal procedure without Danish participation.

The Faroes, probably because the Danes accepted autonomy so grudgingly, got no formal recognition in the form of a viceroy or procedures of royal assent of legislation (as Åland effectively has today in the form of an often-used presidential veto), or being named a Kingdom in its own right as Iceland was in 1918. The new high representative represents the Danish government not the monarch, probably to avoid the earlier Icelandic parallel and similar developments in the British dominions. However, this served only to increase the effective autonomy as it left the Danes no veto procedures or other ways of formally hindering effective self-government. The only formal procedure to rein-in the Faroese, by calling for a special 
court with members of the Supreme Court and politicians from both sides, has never been used.

The Faroese governing coalition from 1998 to 2004 sought to establish the Faroe Islands as a sovereign nation associated with Denmark along the lines that Iceland had been associated to it in the period after 1918 (though without a Faroese Kingdom being created). However, this met Danish resistance and the Danish government wanted a choice between secession and continuing what in Danish is referred to as "the Community of the Realm."

The Faroese government from 2004 to 2008 was of a more conciliatory persuasion and agreed to amendments to the Home Rule compact, the new list of policy areas and a new foreign affairs arrangement. The former has clarified the statues of the Faroes (defining only five areas as exclusively common matters with an ultimate Danish say). The latter has largely been accepted as a step backwards as it failed to codify the wide ranging powers of the Faroese government in foreign affairs. The Faroese have negotiated fisheries agreements since the late 1970s with only nominal Danish participation and have been founding members, members or associate members of several international organisations, such as the Nordic Taxation Regime (full member), the North Atlantic Marine Mammal Coordination Organisation (full member, founder), the International Maritime Organisation (associate member) in addition to Faroese sports and other organisations having full membership of organisations such as the Paralympics and FIFA. The extreme fixation on the notionally unitary character of Denmark resulted in a provision that insists on a clause that states that there can be only one member from the Danish Realm in any international organisation. Thus Danish membership necessarily excludes Faroese membership. Likewise, if both the Faroese and Greenland want membership of, say an international organisation dealing with maritime resources, this results in an absurd joint membership, even if the other members would accept full membership for both countries. This appears to negate the earlier successes, like the Nordic taxation regime and NAMMCO, and to preclude further developments. The Løgting has unanimously resolved to renegotiate this arrangement and has objected to the Greenland codification of this new foreign affairs regime in their self-government act. 
The supplementary legislation of 2005 drew up a negative list of policy areas not under Faroese control rather than the positive list of 1948. Thus, everything except the five policy areas, defined as the Danish constitution, Danish citizenship, the Supreme Court, foreign affairs, security, and defence policy, and currency, are now Faroese special matters, except for around 20 areas that by Faroese choice will also remain common matters for the foreseeable future. These include, for example, banks, aviation, family law, police, the lower courts, passports and immigration. In addition three further policy areas are administered by the Faroese but with the Danish treasury funding the administration through the block grant that in fiscal year 2012 is DKK 615.5 million (around US \$100 million). These three are: old age pensions, medical care, and special care.

Lately, the Prime Minister, who is himself a Unionist, has emphasised that he envisages a development towards a "Community of Realms," emphasising the plural, with both the Faroes and Greenland being recognised as sovereign nations will full international memberships where needed but closely aligned nevertheless in some sort of commonwealth arrangement. The Prime Minister has even mentioned UN membership but emphasises the monarchy and Supreme Court as points of continued alignment. The Faroes would thus evolve much like the former British dominions towards a gradual independence in real terms but with certain important linking institutions and possibly overlapping citizenship and other arrangements. This vision is definitely feasible in practical terms as both Scandinavian, including Danish history shows, and the evolution of the British Empire demonstrates. However, much resistance will probably come from Danish officials whose conceptually positivist education makes creative discussions very difficult, in addition to Danish political opposition as Denmark's geopolitical importance could dramatically decrease if the associated countries become to "uppity". The long-term interest of Denmark is probably evolution rather than obstruction followed by secession, and Denmark would probably gain clout if it joined in the UN and other organisations by two friendly associates.

The Faroe Islands are "not a state but a land with the qualities of a state" as the great Faroese lawyer and politician Edward Mitens once remarked. Less prosaically the Faroese author William Heinesen likened the Faroese place in the world to an insignificant grain of sand on the floor of 
a dance hall, however "seen beneath a magnifying glass, this grain of sand is nevertheless a whole world." Indeed a whole world that was described by John F. West as a social laboratory.

Herein lays much truth. The Faroe Islands are in their own way a rather complete and functioning polity of a higher order. The Faroese generally place little importance in formalities and would not accept a permanent arrangement like that of the Åland Islands in the Finnish Constitution or the current Greenland arrangement with an explicit Danish veto on secession. The Danish Queen remains very popular but only around 10\% participated in the 2010 referendum on female succession rights, as it appears to most people as a matter for Danes to figure out who their monarch is. Even the language of the Faroese Unionists time and time again stresses popular sovereignty and that the Faroese shall govern the Faroe Islands and that self-determination is a matter exclusively for the Faroese.

Thus, the Faroe Islands are likely to ask for further progress to be made, primarily in relation to the need for a more comprehensive Faroese constitution, the need for further representation in an international context, and in relation to the particular relationships with the EU and other trading partners etc., which strain the very formal and minimalistic approach to constitutional law which is very often adopted by the Danish Government. The block grant transfer of money from Denmark to the Faroe Islands is just 5\% of Faroese GDP and will be dwarfed by any oil and gas deposits that are equivalent to discoveries in neighbouring British and Norwegian waters. Therefore any move towards separation from Denmark is unlikely to be hindered on economic grounds; however, the Faroese will not secede just because they can, an eventual exit will likely be triggered by Danish inflexibility in other respects such as the crises over consulates and foreign affairs that led Norway to secede from Sweden or the banking scandal in 1992 that revealed that the Danish government greatly favoured Danish commercial interests over Faroese public interests. 


\subsection{Conclusion}

The Faroe Islands appear to be little studied by outsiders. Presumably, the reason why not much focus has been placed on the Faroese model is that it evades easy categorisation. Apparently, Greenland has achieved more autonomy through its self-government, or the Åland Islands through their special status enshrined in the Finnish constitution and the EU Treaties. However, in real terms the Faroe Islands have arguably achieved more than most comparable associated polities as the Faroese control almost all policy areas with institutions manned by the Faroese themselves, in addition to reaming outside the EU the metropolitan power has also, largely, lost the ambition to interfere in internal matters. An association where federal pre-eminence is only assumed in five enumerated policy areas with no ban on unilateral secession and little dependence on the metropolitan power for resources, personnel or services is quite remarkable. This under-the-radar and understated autonomy is not easily appreciated and disappoints both people inclined towards full independence and relative autonomy in an integrated arrangement. The Faroese themselves even largely dislike the arrangement seeing it as either too little or too much.

The governance created by the dynamics of society influenced by shifting and contradicting influences and ideologies is, however, exactly the reason for studying the Faroes and why they are much more likely to provide a workable paradigm for other polar or marginal polities than, say, either Iceland or Greenland. The better functioning aspects of Faroese governance such as fish-farming, employment services, taxation and pelagic fisheries are the results of trial and error and evolved law and structures and vigorous debate, not planning or legal transplants. The Faroe Islands were called "The Land of Maybe" by the British during the Second World War. This is an very fitting label, capturing the dynamic and unpredictable nature of the place but also what makes it exciting to live in and instructive to study. 


\section{Further reading}

á Rógvi, Kári. Except for some Action not provided in the Instrument itself. 2 Faroese Law Review (2002):193.

á Rógvi, Kári. The Land of Maybe. A Survey of Faroese Constitutional History, in Skaale Sigurđur (ed.), The Right to National Self-Determination: The Faroe Islands and Greenland. (Boston-Leiden: Martinus Nijhoff Publlishers, 2004).

á Rógvi, Kári \& Larsen, Bárður Fyrisitingarlóg (Tórshavn: Fróðskaparsetur Føroya, 2012).

Debes, Hans Jacob Færingenes Lands - Historien om den færøeske nutids oprindelse (Copenhagen: Multivers, 2001).

Debes, Hans Jacob Føroya Søga 1-3 (Tórshavn: Føroya Skúlabókagrunnur, 1990-2000).

Hansen, Jóhannus Egholm \& á Rógvi, Kári Faroese Business Law (Copenhagen: Dania Law, 1998).

Heinesen, William The lost musicians, translated by W. Glyn Jones (Sawtry: Dedalus, 2006).

Jacobsen, Jacob Diplomatarium Fæoense I (Tórshavn: Bókagarður, 1985).

Larsen, Bárður \& á Rógvi, Kári A New Faroese Constitution? - Faroe Islands between Parliamentary Sovereignty and Sub-Sovereign Constitutionalism, between Statutory Positivism and Pragmatic Reasoning. 4 The Yearbook of Polar Law (2012):341-363.

Mitens, Edward Færøernes Selvstyre (Ugeskrift for retsvæsen [1950] 89).

Norgate, Sydney "Kanska" or the land of maybe (Tórshavn: H. N. Jacobsens Bókahandil, 1943).

Reistrup, Høgni \&á Rógvi, Heri Exit Føroyar (Tórshavn: Sprotin, 2012).

Spiermann, Ole Danmarks Rige i forfatningsretlig belysning (Copenhagen: DJØF, 2007).

Spiermann, Ole Responsum om muligheder for Færøernes tilknytning til EFTA samt for Færøernes og Grønlands tilknytning til EU (Copenhagen: Den Nordatlandiske Gruppe i Folketinget, 2008).

Spiermann, Ole Vore grundlovstridige hjemmestyreordninger (Juristen, 2008).

West, John F. 1836: an encouragement to the Faroese to study their own history from the rich materials available to them (Nottingham: John F. West, 1977).

West, John F. Faroe: the emergence of a nation (London: Paul S. Erikson 1972. New York: Hurst, 1972).

West, John F. The history of the Faroe Islands, 1709-1816 (Copenhagen: C.A. Reitzels Boghande, 1985).

\section{Websites}

www.logting.fo - Parliament

www.tinganes.fo - Executive Government

www.mfa.fo - Ministry of Foreign Affairs

www.fo.domstol.dk/Faeroeerne - District Court 
www.visitfaroeislands.com - Tourist Information

www.setur.fo - University

www.hagstova.fo - Statistics

www.kringvarp.fo - Broadcasting

www.sprotin.fo - Dictionaries and other publications

www.flb.fo - National library

\section{Questions}

- What is the importance of history for present day Faroese aspirations?

- What are the strengths and weaknesses of Faroese fisheries management?

- What is the importance of education if the Faroese are to obtain autonomy in real terms?

- Compare the Faroese and Greenlandic approaches to autonomy.

- What are the downsides and dysfunctional side-effects associated with self-determination as seen in the case of the Faroe Islands and others?

- Compare the development of small polities with and without their own language and culture.

- What is the case for a Faroese constitution?

- What would be the effect of a Faroese appeal court?

- What are the strengths and weaknesses of politics in small communities?

- How can necessary reforms be achieved in small communities? 


\section{Greenland and the United Nations Declaration on the Rights of Indigenous Peoples}

Marianne Lykke Thomsen

\subsection{Introduction}

Since the early days of Home Rule (HR) in the late 1970s, Greenland has been actively involved in the promotion and protection of indigenous peoples rights, notably through the drafting and negotiation of the Declaration on the Rights of Indigenous Peoples within the UN system, starting with the independent expert Working Group on Indigenous Populations (WGIP) established under the Sub-Commission on Human Rights in 1982, through to the ad hoc open-ended working group under the Commission on Human Rights in the 1990s and to its adoption by the Human Rights Council and the General Assembly in 2007.

Parallel to this process and in a unique partnership with Denmark, Greenland also contributed substantially to the process leading to the establishment of the UN Permanent Forum on Indigenous Issues (UNPFII) under the Economic and Social Council (ECOSOC) in 2001. In addition to this, Greenland and Denmark helped promote the appointment of a Special Rapporteur on Indigenous Rights, also in 2001. The establishment of the Expert Mechanism on the Rights of Indigenous Peoples (EMRIP) under the Human Rights Council in 2007 as the successor to the former Working Group on Indigenous Populations is the latest mandate to be established within the UN System due to considerable effort and support from Denmark-Greenland and other like-minded countries in a constructive partnership with indigenous peoples (See also Polar Law Textbook 2010). 
The three above-mentioned mandates, which are distinct but complimentary, seek to cooperate in a coordinated manner to promote and protect the rights of indigenous peoples, including the implementation of the provisions set out in the UN Declaration on the Rights of Indigenous Peoples ( UNDRIP).

In 2009, when Greenland obtained Self-Government, the powers and responsibilities of the former HR were expanded considerably. Shortly after the inauguration of the Greenland Self-Government, the Premier addressed the UN EMRIP in Geneva to share information on the new arrangement and to reassure indigenous peoples of Greenland's continued support.

This chapter will seek to highlight the interest in, and awareness of, UNDRIP in Greenland and how the issue of the applicability and implementation of the UNDRIP in Greenland often finds its way into political debates, despite the fact that Greenland has twice - that is in both the joint Greenland-Danish Commission on HR and the joint Commission on SelfGovernment - opted for a public governance model as opposed to an indigenous self-government one. The government in this way is defined by territory and not ethnicity. In practice, however, the Government of Greenland in many instances both resembles and acts as if it is in fact an Inuit government. Something which is supported by the ethnic composition of the political leadership and the primary status and use of the Greenlandic language in Government and Parliament as well as in society at large - except perhaps in Nuuk, the capital of Greenland, in which the majority of the country's 11\% Danish and foreign residents live.

Even though political mobilisation took the shape and function of a party political structure resembling the Danish or Nordic party models, the government declarations made by newly elected governments have for many years made specific mention of indigenous rights and solidarity among indigenous peoples, and, more specifically, the close cooperation among Inuit in an Arctic world. In the current government declaration, the Government states its intention to strengthen the recognition of the UNDRIP and to seek its implementation (Coalition Agreement 2009-13, official draft translation on www.nanoq.gl). 


\subsection{From Provincial Council to Self-Government}

Up through the 1970s, and parallel to indigenous peoples' mobilisation worldwide, Greenland experienced a significant period of political mobilisation leading to the establishment of the Greenland HR Government in 1979 followed by the Greenland Self-Government in 2009 (see Kleist 2010).

Both of these major developments in the political history of Greenland involved similar two-step processes starting with an all Greenlandic commission laying out the groundwork and the vision from the Greenlandic point of view, followed by a joint Greenlandic - Danish parliamentary commission preparing the actual legal framework.

The reasons for the political mobilisation and demand for selfdetermination are multiple, but central to negotiations for considerable transfers of power from Denmark have been the fact that Greenland is geographically separate from Denmark and that its original inhabitants Kalaallit or Inuit - are a distinct people with their own culture and language and the inherent desire to regain control over their own affairs and over the land and resources - both renewable and non-renewable - within the territory of Greenland.

While the importance of language and culture in Greenland will be discussed later, it is important to illustrate the sometimes divergent views on the importance of the UNDRIP to Greenland and differences in the level of overall identification with indigenous peoples. Particularly among the younger generations, identification with indigenous peoples is sometimes not as strong as among those who have been involved in the global movement of indigenous mobilisation. In this regard, the Inuit Circumpolar Council (ICC) plays an important role in terms of "educating" the youth to understand its own background. From the middle 1970s to the middle 1980s the Aasiviit (summer gatherings) were instrumental in creating awareness of the Inuit heritage as was the Training Center of Indigenous Peoples (ITCIP) established in 1997 which helped to (re-)introduce youth to their cultural heritage while also promoting the issue of indigenous peoples' rights. Other educational venues for Greenlandic youth include the UN Indigenous Fellowship Programme and the member state sponsored Junior Professional Officers positions at UN bodies. 
When the UNDRIP was finally adopted by the UN General Assembly in 2007, the view was expressed by the then Head of the Self-Government Commission Secretariat, Mininnguaq Kleist in a radio comment to the Greenland Broadcasting Corporation (KNR), that the adoption came too late for the Commission to consider and thus would be of little significance in Greenland (KNR 18 September 2007). The President of ICC, Aqqaluk Lynge promptly spoke out against this assessment, urging M. Kleist to caution his statement and early dismissal of the Declaration while negotiations on self-government were still taking place between Greenland and Denmark. Lynge argued that the UNDRIP had played a major role in achieving the recognition of the Greenland people (as a people under international law and thereby the recognition of the right of selfdetermination) and that it would also play into negotiations on landownership and subsurface rights. Finally, he expressed the expectation that the Greenlanders would be able to build future rights on the Declaration (KNR 18 September 2007).

What was clearly missing in Kleist's assessment, despite its good intentions, was the fact that the Declaration process has been feeding into the Self-Government process all along, either explicitly - in discussions or reports - or via the experience and expertise of the Commission members with respect to international work on indigenous peoples' rights.

\subsection{Indigenous Peoples Coming Together}

Greenland has a long history of contact and cooperation with indigenous peoples, particularly in the Arctic, which is documented through archaeological and historical knowledge.

In terms of the relationship with fellow Inuit in Canada and Alaska, it is a matter of choice how far one wants to go back in history. For example, the Kivioq legend from Greenland, tells us about a man named Kivioq who crossed the Davis Strait in his kayak and landed on Akilineq - the land on the other side, meaning Baffin Island in Nunavut. In modern times, the Kivioq legend inspired the Greenland (provincial) Council to organise a visit by young intellectuals to Baffin Island and Pangnirtung in the early 1950s. A visit which was later reciprocated. The so-called H.J. Rink Expedi- 
tion to Baffin Island in 1956, named after the Governor's vessel used for the expedition, and the return visit by fellow Inuit from Pangnirtung in 1958, became an important point of departure for the political and ethnic mobilisation of indigenous peoples. As once stated by my former professor, Professor Emeritus Robert Petersen, who personally took part in both the expedition and the subsequent development, it became clear during the political movements of the 1970s - and even before, as Inuit in Canada and Greenland began to visit each other in the late 1950s - that Greenland had not forgotten its part of the common Inuit cultural heritage (Tip of the Iceberg 2002).

Following the initial exchanges between Inuit in Greenland and Canada, Greenland became very active in the political movement leading to the creation of Inuit Circumpolar Conference (now Council) (ICC), in 1977 at the initiative of Inupiat in Northern Alaska who were struggling for recognition of their land and resource rights in the Alaska Native Settlement Act of 1971 (See also Sambo Dorough 2010).

In 1973, a group of mostly young Greenlandic intellectuals living in Denmark and their friends organised the Arctic Peoples' Conference held at the Danish Parliament in Copenhagen with the participation of mostly Saami, Inuit and North American Indians. In 1975, the conference in Port Albany, Canada included representatives from Australia, New Zealand and South America thus making the indigenous peoples movement more global in scope. At this conference, the World Council of Indigenous Peoples came into being and was rapidly followed by other initiatives, which soon made indigenous peoples very well connected.

For the Inuit, however, the ICC continued to be the most important international indigenous peoples' organisation (IPO). Since 1983, the ICC has held non-governmental organisation (NGO) consultative status within the United Nations ECOSOC and formed, together with the Saami Council, the so-called Arctic Caucus, which is an important and very creative international lobby within the UN.

The Arctic Leaders' Summits (ALS) from time to time gathered Arctic indigenous peoples in conferences and joint statements, starting with the meeting in Denmark immediately following the signing of the Declaration on the Arctic Environmental Protection Strategy (AEPS) in Rovaniemi, Finland, in 1991. The objective of this first ALS meeting was to launch a 
cooperative effort among Arctic indigenous peoples to discuss and identify solutions to common problems and challenges. The meeting resulted in the signing of a declaration of cooperation by the three participating organisations - the ICC, which hosted the conference, the Nordic Saami Council and the USSR Association of Northern Small Peoples, which is today known as the Russian Association of Indigenous Peoples of the North and Far East (RAIPON). The declaration urged governments to take decisive action in partnership with indigenous peoples to face the challenges of rapid global change and to provide adequate resources for Arctic indigenous peoples to meet their social, health, economic and educational needs. The Arctic States were also urged to support the Arctic indigenous peoples' desire for self-determination (Fægteborg 1993).

The ALSs became instrumental in promoting what is now Permanent Participant (PP) status in the Arctic Council as the three IPO's at the meeting decided to lobby for seats at the table with States. This goal was subsequently achieved during the Danish-Greenlandic chairmanship of the AEPS (Thomsen 2006). Today the ALS seems to have been replaced by Inuit Leaders' Summits, which are targeted more specifically on the situation of Inuit in the Arctic and have the strong support of the governments in the Arctic, whereas cooperation between Saami and Inuit continues in the UN through the Arctic Caucus, constituted by the Saami Council and the ICC, and between Arctic indigenous peoples more generally within the Arctic Council, with the assistance of the Indigenous Peoples Secretariat (IPS) located at the Greenland Representation body in Copenhagen.

\subsection{Inuit Hospitality and Partnership with Denmark}

Over the years, Greenland has hosted quite a number of conferences and expert meetings concerning the promotion and protection of the rights of indigenous peoples. Many activities have been sponsored jointly by Greenland and Denmark, although Greenland has hosted a number of ICC General Assemblies on its own. The following examples are not exhaustive and do not include the many meetings and conferences held at Greenland's representation in Copenhagen and even in Brussels for easier access, but these examples do provide an indication of how much focus 
Greenland places on indigenous issues and on international solidarity with indigenous peoples.

In 1991, Greenland hosted the UN Meeting of Experts on SelfGovernment. The meeting, held in Nuuk, was the first expert meeting on indigenous peoples' rights ever to be held outside the UN. The meeting resulted in the Nuuk conclusions and recommendations on indigenous autonomy and self-government. The Nuuk conclusions predate the UNDRIP, but recommend that States consider the ratification of international instruments of relevance to indigenous peoples, including the International Covenant on Economic, Social and Cultural Rights, the International Covenant on Civil and Political Rights, and Convention No.169 of the International Labour Organisation (ILO) (See E/CN.4/1992/42). The Meeting of Experts further recommended to the commission on Human Rights the need to consider the possibility of establishing international monitoring mechanisms to deal with indigenous peoples (See also Loukacheva 2010).

In 1993, Greenland hosted the ministerial meeting of the AEPS and, as mentioned above, the three participating Arctic peoples' organisations the Saami Council, RAIPON, and the ICC were successful in getting seats at the negotiating table facilitated not least by the strong support of the Danish-Greenlandic Chairmanship. The foundation for the Permanent Participant (PP) status, which later became a centrepiece of AEPS' successor, the Arctic Council, was thereby laid. The Arctic Council is a unique high-level intergovernmental forum for cooperation in the Arctic. It functions as a consensus forum in which Arctic Indigenous Peoples' Organisations (IPO) are prominent and actively involved as PPs (Thomsen 2006). 
In 1997, the Greenland-based International Training Center of Indigenous Peoples, ITCIP was founded by former principal of the Greenland Teacher Training College and then Vice-President of ICC Greenland, Ingmar Egede with the participation and support of a number of international and indigenous experts. The idea was to provide indigenous peoples with an understanding of the international system and the tools needed to transform this knowledge into action at the community and international levels. A number of prominent international and indigenous experts and leaders have over the years been part of ITCIP, either as board members or as part of faculty and curriculum development, where the UNDRIP naturally has been one of the core documents. The UN Special Rapporteur on the Rights of Indigenous Peoples as well as current and former members of the UN Permanent Forum on Indigenous Issues and the Expert Mechanism on the Rights of Indigenous Peoples and many leaders of indigenous organisations is among those individuals who have contributed their time and expertise to the important cause. The Premier of Greenland, Kuupik V. Kleist was among the founding members.

From the beginning the ITCIP attracted significant political attention in Greenland and received both funding and in-kind support for a number of years until it was able to secure funding from other sources. Most sessions have been held in Greenland in either English or Spanish with indigenous participants - mainly youth - from Greenland and around the world. The political leadership of Greenland has always been willing to contribute their time and to share their experience of the HR and Self-Government processes for the benefit of both international and local students.

The initiative has always been regarded as very important because, while the political leadership in Greenland has typically expressed selfconfidence with respect to their Inuit identity, young people have sometimes express uncertainty about their status or identity. Participation in the ITCIP training sessions has generally been an eye opener for the young participants and has helped them formulate questions and answers in this regard. For example, in 2005, Sara Olsvig, Member of the Danish Parliament for Greenland, upon participating in an ITCIP training session as a university student, posed the question: "Who are the indigenous?" and set out to answer the question herself based on her experience from the ITCIP 
training session and the input from fellow indigenous participants and instructors. Her questions and answers were published as articles in the national newspaper Atuagagdliutit and were responded to by another ITCIP student who had doubts about the particular nature of ethnicity and cultural heritage in this case. Questions were raised such as - given the nature of modern lifestyles and the resultant overall decline in health due to changing diet etc., how indigenous are we really? Yet, in spite of the doubt, the conclusion was that being indigenous means a lot in identity terms while it was acknowledged that this feeling will likely persist.

While Greenland, together with Denmark, was instrumental in the establishment of the UN Permanent Forum on Indigenous Issues, it was also fortunate to be able to host the first pre-sessional meeting of the UNPFII in Nuuk in 2006. The pre-sessional meeting was a first of its kind with the initiative, perhaps surprisingly, picked up initially by China which was subsequently to be followed by others.

The pre-sessional meeting was held in conjunction with a technical workshop titled: "A Workshop of the Permanent Forum of Indigenous Issues on Partnership Visions for The Second International Decade of the World's Indigenous People," (E/C.19/2006/4/Add.2) which was cosponsored by DANIDA, Greenland HR Government and the ICC.

While in Greenland, the UNPFII members met with the Standing Committee on Foreign Affairs of the Parliament of Greenland. An important result of this meeting was the decision to allow indigenous parliamentarians to participate in the UNPFII meetings in a special category, so enabling them to participate outside their state delegations. This initiative now seems to have inspired, in a certain way, the preparatory process for the upcoming UN World Conference on Indigenous Peoples to be held in 2014.

In 2007, Greenland's National Museum and Archives (NKA) hosted a conference on the repatriation of cultural heritage. The conference title "Utimut (the Greenlandic Inuit word for returning): Past Heritage - Future Partnerships. Discussions on Repatriation in the 21 $1^{\text {st }}$ Century" - referred to the very good cooperation and partnership between Denmark and Greenland with respect to the repatriation of cultural heritage.

Successful partnerships of this nature are uncommon in most parts of the world where indigenous peoples have been deprived of their culture heritage. The UNDRIP therefore - for obvious reasons - includes key pro- 
visions on repatriation and cultural heritage, identity and identification. The conference proceedings were published jointly by NKA and IWGIA in 2008 (Gabriel \& Dahl eds. 2008). In 2010, Greenland once again hosted the ICC General Assembly (GA) when it was time for ICC Greenland to take over the position of international Chair, which so far has circulated between Alaska, Canada and Greenland. The ICC enjoys huge moral and financial support from the Government and the Parliament of Greenland, which appoints representatives to the Greenland delegation. It is not uncommon that the Premier and a number of Cabinet Ministers participate actively in the GA both as speakers and in caucus meetings. At the 2010 GA, the Premier of Greenland addressed the urgent need for economic development in Greenland, which would also entail large scale extractive and other industrial development.

The most recent example of Greenland's engagement in the ongoing implementation of the UNDRIP and indigenous peoples' rights is the hosting of the Arctic Indigenous Peoples' Regional Preparatory Meeting for the above-mentioned World Conference (WCIP) to be held at the UN headquarters, New York, in 2014. This meeting of the Arctic Caucus was held in Nuuk in October 2012 and was co-hosted by the Saami Council, the ICC, the Sami Parliament of Norway and the Sami Parliamentary Council, Nuuk Municipality and the Government of Greenland. The purpose of the meeting was to prepare and sign an Arctic declaration in preparation for the WCIP, which will have the overall goal of promoting further the full and effective implementation of the UNDRIP, in particular the right of selfdetermination, but which is also seen as a venue to promote the full and effective participation of indigenous peoples within the UN.

Prior to this meeting, the Government of Greenland had, together with the Sami Parliament of Norway and the International Work Group for Indigenous Affairs (IWGIA), co-hosted an international open-ended indigenous peoples' brainstorming meeting in Copenhagen where an indigenous Global Coordinating Group (GCG) was established to help coordinate indigenous peoples' contributions to and participation in the UN WCIP. The meeting also nominated an indigenous co-facilitator, John B. Henriksen, a Saami from Norway to assist the UN in coordinating and promoting the full and effective participation of indigenous peoples in all stages of the World Conference. The meeting was opened by the Premier of Greenland Kuupik V. 
Kleist, the Danish Minister of Foreign Affairs Villy Søvndal and the UN Special Rapporteur on the Rights of Indigenous Peoples James Anaya.

It is the responsibility of the GCG to ensure that preparatory meetings are held in all of the seven regions of the world with the objective of feeding into a global indigenous preparatory conference in Alta, Norway in June of 2013, which will be hosted by the Sami Parliament of Norway.

\subsection{Moving the Work to the United Nations}

Attempts by indigenous peoples to get their voices heard at the UN had been made much earlier, however it was only after indigenous peoples joined forces in the late 1970s that things began to happen. As noted previously, in 1982 the Commission on Human Rights (CHR) established the WGIP. Indigenous peoples were gradually given more space to participate in the meetings of the five WGIP experts, and in 1985 drafting of what eventually became the UNDRIP began. In 1986, the ILO began a parallel process of revising and updating ILO Convention No. 107 on Indigenous and Tribal Populations (1957) for the first time involving indigenous representatives as experts. This revision was concluded three years later by means of the adoption of ILO Convention No. 169 Concerning Indigenous and Tribal Peoples in Independent Countries (see www.leeswepston.net and ILO 2009).

Along the way, other measures, designed to keep the promotion and protection of indigenous peoples' rights on the agenda internationally and within the UN system, were applied. The first International Year for the Worlds Indigenous People (Resolution 45/164) was a proclamation by the UNGA to be followed by the proclamation of an International Day $(49 / 214)$ for the Worlds Indigenous People to be celebrated annually on 9 August in recognition of the first WGIP meeting in Geneva. In addition, two consecutive decades were dedicated to the world's indigenous peoples. The first decade from 1995 to 2004 under the theme - "Indigenous people: partnership in action" - was proclaimed in a resolution by the UNGA in 1993 (48/163 of 21 December 1993) and coordinated by the High Commissioner for Human Rights. The second and current decade, from 2005 to 2014, under the theme - "Partnership for action and dignity" - is being coordinated by the Under-Secretary-General of Economic and Social 
Affairs (resolution 59/174). The goals of the decades have been to further strengthen international cooperation with a view to solving the problems faced by indigenous peoples in areas such as culture, education, health, human rights, the environment, and social and economic development (See www.IWGIA.org). There is no doubt that all of these actions by the UN for the benefit of indigenous peoples, and the resulting diverse range of international bodies, mechanisms and experts have each served to progress the negotiations and the eventual adoption of the UNDRIP in the Human Rights Council (HRC) and the GA in 2007 after the more than 20 years hard work carried out by numerous indigenous and human rights experts and governments. As noted previously, in 2000, the CHR adopted a resolution to establish the UNPFII that was endorsed by the ECOSOC. UNPFII's mandate is to discuss indigenous issues related to culture, economic and social development, education, the environment, health and human rights. The UNPFII had a Danish member (Professor Ida Nicolaisen) from 2002 to 2007 and a Greenlandic member (President of ICC, Aqqaluk Lynge) from 2004 to 2007.

In 2001, the CHR decided to appoint a Special Rapporteur on the situation of the human rights and fundamental freedoms of indigenous people, as part of the system of thematic Special Procedures. The Special Rapporteur's mandate was renewed by the CHR in 2004 and again by the HRC in 2010, where the name was modernised to Special Rapporteur on the rights of indigenous peoples.

In 2008, the HRC established the Expert Mechanism on the Rights of Indigenous Peoples (EMRIP) as an advisory body to the HRC. The Expert Mechanism provides expert studies and thematic advice to the HRC and works closely together with the Permanent Forum and the Special Rapporteur, using the UNDRIP as the principle framework for promoting the implementation of the rights of indigenous peoples in conjunction with the other international human rights instruments. 


\subsection{The Role of Greenland}

Very soon after the introduction of Home Rule, Greenland became actively involved in the drafting of the UNDRIP as well as in the revision and update of 1957 ILO Convention No. 107. In 1996, at the request of Greenland, Denmark ratified the ILO Convention No. 169, while at the same time submitting a joint declaration, co-signed by Denmark and Greenland, stating that: "There is only one indigenous people in Denmark in the sense of the Convention 169, viz the original population of Greenland, the Inuit." (“Bekendtgørelse nr. 97 af 9. oktober 1997" - in English and Danish).

The proposal to ratify ILO Convention No. 169 was introduced to the Danish Parliament by the Greenland member, Hans Pavia Rosing (former President of the ICC). It very symbolically coincided with the UN inauguration, in New York, of the first International Decade of the World's Indigenous People which was attended by the Premier of Greenland. It was generally recognised at the time that Greenland had achieved a reasonable political status in the HR arrangement and therefore did not need the protection of ILO Convention No. 169, but was interested in creating a good example to the world by way of early ratification. Denmark and Greenland subsequently jointly promoted the implementation of ILO Convention No. 169 by providing funding and experts. When, in 2003, Greenland for the second time established an all Greenland Commission on Self-Governance to prepare a proposal for the transfer of more powers, it was decided to deal more specifically with indigenous peoples, among others, in a separate working group on foreign policy and security issues. Then in the Executive Summary it was stated that: "The majority of Greenland's population is part of the Arctic Inuit Culture. This gives Greenland a special obligation and a special starting point for the global discussion on how to secure the original inhabitants' human rights in relation to the national states in which they live" (Executive Summary 2003). The UN and the PFII, as well as the Inuit territories in Canada were also specifically mentioned in relation to assessing the possibility of a (new) Greenland Representation in North America. Greenland had a representation in Ottawa from 1998-2002.

During the two decades of drafting and negotiating of the UNDRIP, regular updates and progress rapports were given to the Greenland political leadership and the general public. The ICC, as well as the government, is- 
sued press releases on meeting results and when comprehensive reporting on foreign affairs to the Parliament of Greenland was introduced in 1993, reporting on the UNDRIP process became a standing item. The Committee on Foreign Affairs and Security Issues had been established by law in 1988.

Greenland had a strong voice and a message to share in this debate because of the extensive level of self-government it had already achieved within the context of HR and thus quickly became a "role model" or example of good practice. Over time the political leaders of Greenland actively supported the process of the Draft Declaration and other initiatives to promote indigenous rights by participating in UN meetings and by firmly addressing the issues at numerous venues and to various high-level audiences. Greenland has, in addition, contributed to the UN with the services of various experts over the years.

This good cooperation partnership between Denmark and Greenland was frequently showcased to the world in the form of information tools, development programmes and strategies of support to indigenous peoples worldwide. In 1994, Denmark launched the first "Strategy for Danish Support to Indigenous Peoples" in partnership with Greenland. This has been a great success and a source of inspiration for other UN member states (Danida 1994). The Strategy was revised in 2004 after a review by a team of indigenous experts (Danida 2004) and was again the object of further review in 2011 (Danida 2011), where the Premier of Greenland together with the Danish Minister for Development Cooperation hosted an international seminar at the Greenland Representation in Copenhagen to discuss - based on the review - the way forward in terms of ensuring that the right support reaches the right peoples. One of the main recommendations of the review report was to support the implementation of indigenous peoples' rights at the country level via the UN Indigenous Peoples' Partnership (UNIPP), a cooperation initiative between five UN agencies aimed at local and regional capacity building. UNIPP was launched in New York in 2011 on the margins of the $10^{\text {th }}$ session of the UNPFII (see www.ohchr.org).

The joint push for the establishment of various UN mandates for the promotion of indigenous peoples' rights, which took place in parallel with the UNDRIP negotiations, notably the Permanent Forum and the Special Rapporteur on the Rights of Indigenous Peoples, together with a number of initiatives 
concerning special programmes and development aid to indigenous peoples, are very much indicative of a successful partnership in action.

There are many other examples, such as the UN World Conferences on Sustainable Development, including the recent Rio+20, where Greenland and Denmark jointly played an important role in promoting indigenous peoples' rights. In Rio de Janeiro in 1992, the Agenda 21 conference acknowledged the rights of indigenous peoples, in Johannesburg in 2002, Denmark and Greenland, together with indigenous peoples, launched a "Partnership Initiative," and again in Rio in 2012, where support for indigenous peoples' rights and their role in sustainable development were issues, yet again, this was actively promoted. As recently stated by the Premier, Greenland's commitment to supporting indigenous rights internationally is, in respect of the support and constructive input from indigenous peoples and friends around the world, based on the clear belief that Greenland has benefitted from this in its own development. The Government is of the view that it is only possible to ensure sustainable development globally when indigenous peoples' rights are respected so that all the peoples of the world can work together as equal partners (Kleist 2012 - AG 20 June). As noted previously, one of the first actions of the Premier of Greenland following the inauguration of Self-Government was to travel to Geneva to address the EMRIP on the new developments in Greenland and on the relationship between Denmark and Greenland, which he hoped would be an inspiration to others (Kleist 2009). The message was well received and responded to both by EMRIP and others. At the press conference following the commemoration of the 5th anniversary of UNDRIP in 2012, the Chair of the Permanent Forum, Grand Chief Ed John took the opportunity to acknowledge the valuable contribution made by Denmark and Greenland and praised the Greenland Self-Government as a good example of the substantive implementation of self-determination. One of the central notions animating the recent Greenlandic Self-Government negotiations was that "rights come with responsibilities." This notion fits very well with the commitment to the UN shown by Greenland so far. Despite its limited resources Greenland has placed a high priority on fulfilling its obligations with respect to reporting to UN treaty bodies, and as regards the Universal Periodic Review (UPR) process. This can be explained by the fact that both at the political level and in the general public there is a 
strong sense of responsibility towards, but also confidence in, the UN. In Greenland's contribution to the Danish UPR report of 2011, it is stated that: "The Government strongly endorses the UNDRIP. While the establishment of the Self-Government arrangement is an illustration of Denmark's de facto implementation of the UNDRIP vis-á-vis Greenland, the Government strives to implement important provisions of the UNDRIP in its day to day work, although the government is categorised as a public rather than an indigenous government" (A/HRC/WG.6/11/DNK/1).

\subsection{Increasing Focus on Human Rights}

Greenland has a tradition of celebrating just about every UN-designated day and has a strong focus on human rights and international aid, which has inspired several initiatives, including the recent decision to establish a human rights council in Greenland.

On 15 November 2012, the Parliament of Greenland unanimously adopted a parliamentary act providing for the establishment of a human rights council in Greenland (Inatsisartutlov nr. 23 af 3. december 2012). The Greenland Human Rights Council will cooperate with the Danish Institute for Human Rights - Denmark's National Human Rights Institution (NHRI).

The initiative is based on a decision in principle from 2008, where the Parliament of Greenland had requested the Government to investigate the possibility of setting up a Centre for Human Rights and International Studies similar to the Institute in Denmark. The motivation for the request was clearly inspired by the ICC and the ongoing negotiations at the UN on the UNDRIP. However, owing to the change of government and the introduction of Greenland Self-Government in 2009, the decision had never been executed despite much support for the issue in the Cabinet. The establishment of a human rights council is a first step towards enhancing Greenland's capacity in this field throughout its society. Even though it has been the ICC in the main that had pushed for action in the human rights area and had begun to take steps to establish something of its own, inspiration also came from the preparations made for the first UPR of the Kingdom of Denmark by the Human Rights Council. Public hearings were held in Denmark, Greenland and the Faroe Islands, where it became clear that 
there was an overwhelming interest in contributing substantively to the report. In Greenland, a wide variety of civil society organisations and other interested parties provided input to the hearing organised jointly by the Danish Ministry of Foreign Affairs and the Department of Foreign Affairs of the Government of Greenland. Many references were made to the UNDRIP, which however were subsequently minimised due to the very limited format permitted for the UPR report.

The Act on the Greenland Human Rights Council does not specifically make reference to the UNDRIP, however, during the introduction of and subsequent debate on the legislation in the Parliament of Greenland, the rights of indigenous peoples played a significant role with frequent references made to the UNDRIP. (www.inatsisartut.gl)

\subsection{Framing the Issues}

The UNDRIP is thus gaining more and more support and recognition as the universal tool for the promotion and protection of indigenous peoples and now plays an increasingly important role in terms of identifying and addressing issues of concern, not only for indigenous peoples, but also for a wider range of interest groups including NGOs, (educational) institutions, agencies, and governments. Since its adoption six years ago, it has succeeded in attracting significant levels of attention and has been recognised as the international instrument or framework with which to define, explain and claim rights. Compared to ILO Convention No. 169, the UNDRIP quickly attracted much greater level of awareness and legitimacy in Greenland. This is probably due to the very substantial and decisive contribution of indigenous peoples to the drafting and negotiation of UNDRIP, which is now being fed into a multitude of international processes, even though setbacks and resistance among some states are still being experienced. In all of the activities in respect of the UN mandates on indigenous peoples rights, the UNDRIP constitutes the primary basis for action as regards implementation internationally and on the ground. Upon the adoption of the UNDRIP, the Arctic indigenous peoples, in a statement of the Arctic Region, noted that the UNDRIP goes much further than other similar human rights instruments - including the ILO Convention No. 169 
- in recognising indigenous peoples' rights, though they continue to call for states to ratify the ILO Convention.

It is then as if ILO Convention No. 169 has been placed on the back burner so as not to interfere with the UNDRIP process. In the joint Strategy for the Arctic 2011-2020 the UNDRIP is included as an action point for Greenland and Denmark, whereas ILO Convention No. 169 is not. This must however be seen as something of an omission, because Denmark and Greenland have both in fact invested substantially in its implementation on the ground through financial support and as regards expertise given to the ILO - primarily in support of the UNIPP. The ICC also makes frequent reference to state obligations in the convention, in particular with respect to assisting indigenous peoples in cooperating across borders, including activities in the economic, social, cultural, spiritual and environmental fields (Art.32).

In Greenland, the UNDRIP was translated into Greenlandic and Danish immediately after its adoption by the UNGA and distributed widely in both Greenland and Denmark. It was also posted on the official websites of the Government and the UNPFII. Where any mention of the UNDRIP was previously linked, in the main, with the notion of solidarity and of Greenland's responsibilities towards indigenous peoples elsewhere, it has now become a key instrument in the Parliament of Greenland with respect to raising critical (human) rights issues with the government and in parliamentary debates, in particular with respect to land and resource rights. At the same time, it also serves, in many situations, as a positive measure for progress and success in the realisation of indigenous peoples' rights.

\subsection{Debating UNDRIP in Parliament}

In 2006, a written question to the Cabinet ( $\$ 36,1$ of 13 December) concerned the possible implications of the delay in getting the draft UNDRIP adopted by the UNGA and what means and resources the government would contribute towards this goal. Implicit in the questions was the fear that further delay implied the risk that the text would be diluted. In 2008 ( $\S 36,1$ of 15 February), a written question to the Cabinet concerned what actions the government was prepared to take in order to try to make Australia endorse the UNDRIP. The questions were clearly inspired by the 
official apology by the Australian Prime Minister concerning the so-called stolen generation of Australian Aborigines.

In a parliamentary debate on oral questions in 2008 (FM2008/118 § 35 ), the overall question concerned what policy and goals the government and the political parties in the parliament had in terms of getting the best possible outcome in terms of the Declaration. A series of questions concerned issues such as the government's vision for continuing cooperation between Greenland and Denmark with respect to implementing the UNDRIP and its vision for the dissemination of information and educational material to educational facilities at all levels.

The key explanation for the above request in this case was twofold: Firstly, it was stated that it was important to make national identity, cultural heritage, and internationally protected rights the basis for the control of our resources. Secondly, the urgency of the matter was emphasised because the UNDRIP is important not only to Greenland but to the world as a whole and that it brings hope for peace and fundamental freedoms and justice to peoples globally.

Finally, questions were posed in relation to future plans to push for the elevation of UNDRIP to a convention so as to make it legally binding, plans for further deliberations on the implementation of UNDRIP and a request for an annual parliamentary debate on the issue.

In 2008, (EM2008/80) in response to a report by the Minister for Infrastructure entitled, The Environment and Mineral Resources regarding the socio-cultural aspects of exploration and the extraction of uranium, reference was made to UNDRIP with respect to free, prior and informed consent (FPIC) in terms of ensuring indigenous peoples access to information from experts. To emphasise the continued opposition to uranium mining it was proposed to invite representatives of indigenous peoples in North America and Australia to Greenland in order to share their experiences with the impact of uranium mining on human health and living conditions.

In a parliamentary debate in 2011 (EM2011/63 §36) the key message or question was whether the UNDRIP should be made legally binding (in Greenland), similar to an earlier question about converting it into a convention. The argument was that implementation of self-determination is still incomplete owing to the lack of funding in areas pertaining to three core provisions of the UNDRIP, which, it was argued, are not implemented in 
Greenland. The articles concerned are: numbers 19, 27 and 30 concerning FPIC, respect for ownership of land and resources and military presence on indigenous peoples' lands and territories.

The Government, in its reply, noted that even if the UNDRIP is not a legally binding convention, it nevertheless provides inspiration and guidance in respect of cooperation and partnership between states and indigenous peoples. In the context of Greenland, Self-Government is in itself an example of the implementation of the provisions and rights contained in the UNDRIP. The most important being the right to self-determination, the right to lands, territories and resources, and the right, as peoples and as individuals, to control one's own development.

In 2012, in a written question to the Cabinet (§37, 1 No. 010, 9 January) the issue raised was what actions were intended at governmental level in the Kingdom of Denmark with respect to the EU import ban on sealskin, which had - in an open letter to the Cabinet - been claimed to be in breach of Articles 3, 5, 8, 20, 32 and Art. 46 of the UNDRIP by the Greenland Hunter's and Fishermen's Association, (KNAPK).

The government in its reply referred back to an earlier reply (EM/2011/63) in which it was stated that both previous parliaments and governments have endorsed the UNDRIP and its good intensions concerning cooperation and partnership between states and indigenous peoples. With the recognition of Greenland's right to self-determination in the Act on Greenlandic Self-Government, the government finds that there is ample opportunity to actively apply the good principles for cooperation which the UNDRIP represents.

It was stressed that responsibility for the management of living resources in Greenland rests with the Self-Government and that this is exercised in close cooperation with hunters and fishermen through the KNAPK and based on scientific advice from the Greenland Institute of Natural Resources and regional and from other international management bodies.

Despite unsuccessful efforts to avoid the EU adopting an import and trade ban, Greenland has, in cooperation with Denmark, succeeded in achieving a so-called Inuit exemption, which also recognises indigenous peoples' right to hunt seals. The government therefore urged the parties to use the opportunity constructively to market and sell the unique seal- 
skin products both in the EU and globally and expressed its continued support for sustainable sealskin production in Greenland.

Although UNDRIP and its provisions are not at the forefront of every meeting or debate, it always seems to create a certain atmosphere of unity in the Parliament of Greenland. Questions and debates on the UNDRIP tend to be connected with certain issues or activities, including of course the foreign affairs reports, which regularly contain updates on the various indigenous peoples' rights processes.

Another item of huge importance is language and cultural identity, which is also often linked to key provisions of the UNDRIP.

\subsection{Language and Cultural Identity in Greenland}

In a statement to members of the Nordic Language Commission at a meeting held in Ilulissat, Greenland in 2011, the Minister for Family, Culture and the Church, (Mimi Karlsen) emphasised, not only the recognition of the Greenland people in a legal sense, referring to the fact that the Act on Greenland Self-Government specifically states the recognition of the Greenland people under international law and thereby confirms the right of self-determination, but also stressed the fact that Greenlandic has been recognised as the official language of Greenland. In Kleist's view the reason for this is, according to the explanatory notes to the Self-Government Act (2010), that language is part of the Greenlandic people's cultural identity. There are an estimated 50,000 speakers of Greenlandic in Greenland and Greenlandic is the primary language of Parliament with simultaneous interpretation to or from Danish.

In a very comprehensive statement, the minister addressed the UN adoption of the UNDRIP, including language rights, and related it to the former colonial situation, the historical development of language usage in Greenland, and the efforts required to retain Greenlandic, which is part of the Inuit languages family.

As one of its first actions following the inauguration of the Greenland Self-Government, the Parliament of Greenland adopted a new Act on Language Policy (Inatsisartutlov nr. 7 af 19. maj 2010), in which ethnicity is clearly outlined (in the explanatory notes to the Act) in connection with 
the mapping of the indigenous language and dialects of Greenland. Hence, the Act establishes that Greenlandic consists of three major Inuit dialects spoken in North Greenland (Avanersuaq), East Greenland (Tunu) and West Greenland (Kitaa). There is one written Greenlandic language, derived from but not identical to the Central West Greenlandic dialect, which has become the standard language. One of the objectives of the Act is to promote language integration and the strengthening of community and identity by providing the framework for language training, in order to eliminate various language barriers in the society, which are also perceived as barriers to cultural and social integration. The government is already preparing legislative changes to the Act in order to further strengthen public use of Greenlandic.

The emphasis on language and culture in Greenland is generally very strong. So when the Bishop of Greenland, Sofie Petersen was elected as a member of the central committee of the World Council of Churches in 2006, her mission was to fight for the retention of indigenous languages as bearers of culture and identity: "By speaking the indigenous peoples' cause, I express a sister-solidarity that can contribute to preserving local language and identity" (Schultz-Lorentzen 2006). The reasoning behind this initiative was that the church has an obligation to supplement the work in the UN in support of indigenous peoples' rights. In Greenland, the church is Greenlandic and has a long tradition of using the Inuit language, both orally and in writing.

Another illustration of the high regard held for the Greenlandic language and culture is the emotional commentary by Gerhard Petersen leader of the Atassut party, which has otherwise traditionally been the most pro-Denmark party, in response to a debate in Denmark with respect to the Self-Government arrangement on oil and mineral resources. Under the heading, "The objective is independence," he stated that: "Our task is to make our country Greenlandic - a society which puts the competencies of the citizens to use, where they exist. And not like today where the society does not even regard our language and our cultural identity a competency" (Petersen 2012). 


\subsection{Conclusion}

As has been shown, the many parallel and overlapping processes internationally, and in Greenland and Denmark, have contributed both positively and constructively to the adoption of the UNDRIP and to its implementation on the ground both at home and abroad. There is no doubt that the UNDRIP is increasingly becoming a source of inspiration in Greenland. The government strongly endorses the UNDRIP and the general public is becoming increasingly aware of the Declaration and its potential in relation to a variety of situations and issues. In some instances, growing awareness of the UNDRIP as well as a focus on its possible application has, as illustrated by the debate between the ICC and the Self-Government Commission Secretariat, sparked some discussion and highlighted existing differences of opinion, owing to the nature of the Greenland Self-Government. Generally, however, there is in the general public a widespread understanding and acknowledgement of its applicability, which is used with a certain amount of constructive ambiguity.

A pragmatic approach taken by the Government of Greenland to the fact that it is a public government rather than an indigenous government has frequently been to downplay or simply ignore the fact, both in the media and in Parliament, when it makes more sense to focus on indigenous peoples' rights. On the one hand, such an approach probably only works because a large majority of Greenland's population is of Inuit descent, which again is reflected in the composition of both the Cabinet and the Parliament. On the other hand, we also see examples of nonindigenous civil society organisations, which are becoming increasingly inspired by, and make numerous references to, specific provisions of the UNDRIP in order to underscore the legitimacy of their claims. The overall impression is that there is a genuine sympathy for indigenous peoples in the society and for promoting their rights, as expressed in international instruments such as the UNDRIP.

Overall, both Greenland and indigenous peoples in general have benefitted from the dedication shown to international cooperation and to the rights of indigenous peoples, as this approach has undoubtedly helped to contribute to the shaping and defining of some legitimate actions in terms of both domestic and foreign affairs. Indigenous peoples in general have 
also benefitted from the strong support that Denmark, together with Greenland, has channelled into the promotion of the rights of indigenous peoples internationally. It is no accident that Greenland has acceded to or endorsed a number of international human rights instruments and some of these have been published in Greenlandic, including: the UN Universal Declaration on Human Rights; the ICECSR; the ICCPR; the UN Convention on the Rights of the Child; ILO Convention No.169, and the UNDRIP.

It will, moreover, be interesting to follow how the UNDRIP will be perceived in Greenland in future if and when major changes occur in society owing to growing economic development based on extractive industries. For now, it has been noticeable how UNDRIP and indigenous peoples' rights have popped up more frequently during the debates on large scale industrial development related to the extractive industries. People from different walks of life clearly want decisions to be taken in democratic ways, which includes the opportunity to participate in decision-making based on self-determination and the principle of free, prior and informed consent.

\section{Further reading}

Gudmundur Alfredsson, "Human Rights and Indigenous Rights," in Natalia Loukacheva (ed.) Polar Law Textbook, (Copenhagen: NCM TemaNord 538:2010):147-170.

Vincent A. Böre, "Reinstating Indigenous Rights in International Law. The Right to Self-Determination as Codified and Developed in the UN Declaration on the Rights of Indigenous Peoples." Thesis at the University of Amsterdam 2007).

Dalee Sambo Dorough, Indigenous participatory mechanisms in the Arctic Council, the Circumpolar Inuit Declaration on Resource Development Principles in Inuit Nunaat and the Laponia management system. Report to the UNPFII (E/C.19/2012/10).

Dalee Sambo Dorough, "Inuit of Alaska: Current Issues," in Natalia Loukacheva (ed.) Polar Law Textbook, (Copenhagen: NCM TemaNord 538:2010):199-219.

Mads Fægteborg, "Towards and International Indigenous Arctic Policy (Arctic Leaders' Summit)," (Copenhagen: Arctic Information's Forlag, 1993).

Mille Gabriel and Jens Dahl (eds.), Utimut, Past Heritage - Future Partnerships. Discussions on Repatriation in the 21th Century, IWGIA Document No. 122 (IWGIA/KNA: Copenhagen 2008).

Steen Jeppson, "De oprindelige folks rettigheder," in Atuagagliutit 22 September 2005.

Kuupik Kleist, "Changes and challenges in Greenland," The Circle Magazine 2, WWF 2010.

Kuupik Kleist, "Statement by Mr. Kuupik Kleist, Premier of Greenland, 2nd Session of the Expert Mechanism on The Rights of Indigenous Peoples, Geneva, 10-14 
August, 2009," in Claire Charters and Rodolfo Stavenhagen (eds.), Making the Declaration Work: The United Nations Declaration on the Rights of Indigenous Peoples, IWGIA Document No. 127 (IWGIA: Copenhagen 2009):248-251.

Kuupik Kleist, "Verdenstopmødet "RIO+20" om bæredygtig udvikling”, in Atuagagdliutit 20 June 2012.

Mininnguaq Kleist, “Greenland's Self-Government," in Natalia Loukacheva (ed.) Polar Law Textbook, (Copenhagen: NCM TemaNord538, 2010):171-198.

Christian Schultz-Lorantzen, "Bishop Front-runner for Indigenous Peoples." in Suluk \#03, 2006, Produced for Air Greenland by AG, Nuuk 2006.

Natalia Loukacheva, "Arctic Governance," in Natalia Loukacheva (ed.) Polar Law Textbook, (Copenhagen, NCM, TemaNord538:2010):125-146.

Sara Olsvig, "Hvem er "De Oprindelige?, in Atuagagdliutit 26 July 2005.

Sara Olsvig, "Hvort fælles ansvar," in Atuagagdliutit 28 July 2005.

Gerhardt Petersen, "Målet er selvstændighed" in Atuagagdliutit 29 August 2012.

Lee Swepston (www.leeswepston.net)

Polar Law Textbook, Natalia Loukacheva (ed.), (Copenhagen, NCM, TemaNord 538:2010).

Marianne Lykke Thomsen, "Hvorfor Arktisk Råd? - Et grønlandsk perspektiv," in Hanne Petersen (ed.) Grønland i verdenssamfundet. Udvikling of forandring af normer og praksis. Forlaget Atuagkat/Ilisimatusarfik. Atuagkat 2006.

Marianne Lykke Thomsen, "Sustainable Development and Climate Change: Challenges and Opportunities in the Case of Greenland" in UNESCO 2009: Climate Change and Arctic Sustainable Development: scientific, social, cultural and educational challenges. UNESCO, Paris 2009.

\section{Documents}

Bekendtgørelse nr. 97 af 9. oktober 1997 - (Declaration related to the ratification of ILO Convention 169 Concerning Indigenous and Tribal Peoples Independent Countries).

Commission on Self-Governance Executive Summary April 2003, Report by the Commission on Self-Governance, Greenland Home Rule Government, Nuuk Offset, Nuuk 2003.

Government of Greenland's Coalition Agreement for 2009-2013 (official draft translation Nuuk 10 June 2009) http://uk.nanoq.gl/Emner/coalition_ agreement.aspx

Indigenous participatory mechanisms in the Arctic Council, the Circumpolar Inuit Declaration on Resource Development Principles in Inuit Nunaat and the Laponia management system (E/C.19/2012/10). Study conducted by Dalee Sambo Dorough for the UNPFII.

Indigenous and Tribal Peoples' Rights in Practice - A Guide to ILO Convention No. 169, Birgitte Feiring (ed.), Programme to Promote ILO Convention No. 169. ILO, ILO 2009. 
http://www.ilo.org/wcmsp5/groups/public/---ed_norm/-normes/documents/ publication/wcms_106474.pdf

Information received from Governments. The Government of Denmark and the Greenland Home Government (E/C.19/2006/4/Add.2).

National Report submitted in accordance with paragraph 15 (a) of the annex to Human Rights Council resolution 5/1. Denmark (A/HRC/WG.6/11/DNK/1).

Nuuk conclusions and recommendations on indigenous autonomy and selfgovernment - UN document (E/CN.4/1992/42).

Tip of the Iceberg. A Summary of Contacts, Cooperation, and Agreements between Greenland and Canada, Greenland Home Rule Government, Foreign Affairs Office, April 2002. http://dk.nanoq.gl/Emner/Landsstyre/Departementer/ Landsstyreformandens\%20Departement/Udenrigsdirektoratet/ Hvad_arbejder_vi_med/Arktisk_Samarbejde/ /media/BB5FCDB1116A4AF997FDB 23B546B7D43.ashx

Permanent Forum on Indigenous Issues, Report on the fifth session (15-26 May 2006) Economic and Social Council Official Records Supplement No. 23 (E/2006 /43 - E/C.19/2006/11). http://daccess-dds-ny.un.org/doc/UNDOC/GEN/N06/ 384/35/PDF/N0638435.pdf?OpenElement

Review Report Strategy for Danish support to indigenous peoples 2001-2010. Ministry of Foreign Affairs, Danida, (Copenhagen 2011).

Strategy for Danish Support to Indigenous Peoples, Ministry of Foreign Affairs, Danida, (Copenhagen 1994).

Strategy for Danish Support to Indigenous Peoples, Ministry of Foreign Affairs, Danida, (Copenhagen 2004).

United Nations Declaration on the Rights of Indigenous Peoples http://www. un.org/esa/socdev/unpfii/documents/DRIPS_en.pdf

United Nations Declaration on the Rights of Indigenous Peoples. What is the UN Declaration on the Rights of Indigenous Peoples? Fact sheet on Chiefs of Ontario website 2012 www.chiefs-of-ontario.org

\section{Websites}

www.arctic-council.org

www.docip.org Indigenous Peoples' Center for Documentation, Research and Information

www.inuit.org Inuit Circumpolar Council - Greenland

www.ilo.org

www.imr.dk Danish Institute for Human Rights (NHRI)

www.inatsisartut.gl Parliament of Greenland

www.iwgia.org

www.knr.gl Greenland Broadcasting Corporation

www.nanoq.gl Government of Greenland

www.ohchr.org 
www.sermitsiaq.ag National Newspaper of Greenland - Sermitsiaq

www.um.dk Danish Ministry of Foreign Affairs

www.un.org/esa/socdev/unpfii

\section{Questions}

- How important is it for Greenland whether or not the UNDRIP is legally binding?

- What are the most important provisions of the UNDRIP? Explain why this is.

- How is the UNDRIP being implemented in Greenland?

- Is the UNDRIP principle of Free, Prior, and Informed Consent - in your opinion - implemented with the (Act on) Greenland Self-Government?

- What would be the most relevant indicators for full and effective implementation?

- What does full and effective participation mean? 



\section{Sámi Rights and Sámi Law in Norway}

Øyvind Ravna

\subsection{Introduction}

\subsubsection{The Sámi People}

The Sámi people live in the northern and central parts of Norway, Sweden and Finland, and on the Kola Peninsula in the Russian Federation, which in Sámi language is named Sápmi (Sámi land).They number in total around 50,000-80,000 people who earn their income from both marine and terrestrial livelihoods such as reindeer husbandry, agriculture industries and coastal fishing.

The Sámi can trace their roots in Northern Scandinavia back more than two thousand years. The Sámi are currently recognised as an indigenous people in Norway and as one of the two nations the Norwegian State is grounded on. This means that Norway is obliged to protect the Sámi language, culture and way of life. Norway is also obliged to identify and recognise the traditional Sámi lands, which the country has acknowledged by giving the Sámi constitutional protection and by ratifying ILO No. 169 Convention concerning Indigenous and Tribal Peoples in Independent Countries (ILO-169).

In Finland, Sweden and Russia the Sámi have, to varying degrees, achieved the legal protection of their language, culture and livelihoods, but as an ethnic minority rather than as an indigenous people (none of these countries have ratified IL0-169). This chapter is limited, however, to the situation in Norway and explores the concept of Sámi law and Sámi legal status in that country. 


\subsubsection{The Concept of Sámi Law}

Sámi law can be understood as an academic or legal discipline which includes the rules of law aimed at the protection of the Sámi language and culture. The interpreting of culture shows that it also includes the rights to land and natural resources as well as the capacity to maintain traditional livelihoods. Sámi Law may also include those parts of Norwegian law where the cultural differences between the Sámi and the majority society implies that the law works differently (Skogvang 2009:25).

Another way to determine Sámi law as a legal discipline is to define it as rules of law that contribute to the definition of Sámi legal positions (Sámi Rights Committee in NOU 1984: 18), which can be understood as rules regulating and protecting Sámi rights.

Sámi law can also be understood as Sami internal lawgiving, e.g., unwritten rules rooted in Sámi culture. Those rules are Sámi customary law and practices, including legal opinions, aimed to regulate the relations and use of natural resources etc., between the members of Sámi societies, but also in relation to outsiders.

If we include customs, legal opinions, legal thinking and application of the law, both formal and informal, this concept can be referred to as Sámi legal culture (Ravna 2010:149).

There are three sets of norm structures or legal systems that form the framework of the Sámi Law (Skogvang 2009:45). Firstly, it is national legislation, which in turn can be divided into constitutional law, other areas of statutory law and case law. Secondly, it is international law, where the International (UN) Covenant on Civil and Political Rights of 1966 (ICCPR) and ILO-169 are the key instruments. Thirdly, it is the Sámi's law and legal culture. In the wake of international law, Sámi legal practices were afforded increased legal status in Norwegian law as a source of law to be used in courts.

The aim of this chapter is to review the rules concerning the legal protection of the Sámi as an indigenous people and minority in Norway. This will be undertaken with reference to the three legal systems mentioned above, including Sámi customary law and legal culture. The struggle by the Sámi for the recognition of their rights to their lands and waters has been central in the development of the Sámi legal position. This part of the Sámi law, both as an academic discipline and as internal Sami law, will naturally be given a central place in our analysis. 


\subsection{Legal Developments Regarding Sámi in Norway}

\subsubsection{Introduction}

The protection of Sámi culture and their legal rights has undergone significant change over the past three decades. If we go back to the 1970s, the matter of Sámi rights was centred on questions as to whether the so called Sámi-speaking Norwegian population should have the right to be educated in their own language. Even in the 1980s few people assumed that the Sámi were entitled to legal protection as an indigenous people while even the importance of their protected status as a minority in Norway was highly controversial (Gauslaa 2007:152).

A significant change in the legal situation was triggered by the controversy over the construction of the Alta-Kautokeino hydro power plant around 1980. This undoubtedly led to the emergence of a new perspective on the Sámi's legal status and position, which was reflected in the political changes in the state's Sámi Policy in the following years.

This ultimately resulted in the abolition of a doctrine which was an important part of existing land law, and confirming that the Norwegian State was the owner of the land in Finnmark County without consideration for private usage or commonage rights of any kind.

Subsequently, these major legal advances implied a policy in which the Norwegian Parliament acknowledged that the Sámi are an indigenous people. The Sámi are thus entitled to the legal protection of their language, culture and way of life. This acknowledgement has also resulted in the fact that Norway was the first country to ratify ILO Convention No. 169, in 1990, which posed an obligation on Norway to identify Sámi lands and recognise the rights of ownership and possession over the lands the Sámi have traditionally occupied. By adopting the 2005 Finnmark Act, state ownership of the outlying fields and mountainous areas in Finnmark County was transferred to local governance, overseen in part by the Sámi Parliament, as an element of that recognition process. 
Norway's minority policy and legal developments with respect to the Sámi in general, and in relation to the Finnmark Act in particular, are, moreover, considered to be pioneering by the UN special rapporteur on indigenous rights S. James Anaya in his 2011 report on the situation of the Sámi in the Nordic Countries, where it is stated:

\footnotetext{
"The Finnmark Act provides important protection for the development of Sámi rights to self-determination and control over natural resources at the local level, and thus forms an important example for the other Nordic countries" (para. 44).
}

Even if problems remain in respect of relations between the Sámi and the Norwegian State, e.g., over the right to fish in coastal areas (NOU 2008:5), and over the legal development and current legal status of Sámi (including consideration of their legal culture in Norway), the resolution of such issues in itself functions as an important learning process.

\subsubsection{National Legislation}

\section{Legal Developments during the Post-war Period}

Despite the fact that little focus was placed on the question of the Sámi as an indigenous people before the 1980s, it is clear that the political will to recognise Sámi language and culture dates as far back as the 1950s, as seen in the wider context of the general development of human rights internationally after the Second World War. Step by step the Sámi were gaining better protection for their language and culture. However, in 1978 the Norwegian parliament decided to construct the Alta-Kautokeino hydro power plant by damming one of the main rivers in the Sámi areas. This placed the ongoing debate over Sámi rights to lands and waters squarely at the centre of the national agenda and showed that post-war policy was, despite the rhetoric, worth little when it came to practical governance and the exploitation of valuable natural resources. After large-scale police actions to remove the Sámi and environmental activists, construction finally began in 1979 .

Although the protesters did not manage to stop the power plant construction, it was a turning point in Norway's acknowledgement of its legal commitments to the Sámi people. It was also a key point in the Sámi 
struggle for their rights to enjoy their culture and language, including rights to lands and waters. In the autumn of 1980 , as a consequence of the political tumult arising during the Alta Case, the Nordli Government had to establish the Sámi Rights Committee (SRC). The Committee was given a mandate in four points where the first two were to examine: 1) the question of the Sámi people's legal position as regards the right to land and water; and 2) to ensure the Sámi people's ability to develop natural resources in their areas of habitation, while also recognising the non-Sámi populations interests (NOU 1984:18 pp. 42-43).The appointment of the SRC proved to be the starting point for a legislative process that resulted in the legal protection of the Sámi language, culture and way of life through a constitutional clause (1988), the establishment of the Sámi Parliament (1989) and the ratification of ILO Convention No. 169 (1990). The second investigation report of the SRC, published in the NOU 1997:4, was the first major step in the process leading to the adoption of the landmark Finnmark Act in 2005 (see section 15.2.3 below). This development is particularly important in terms of gaining an understanding of the process that led to Sámi rights to land and natural resources being protected in Norway.

The Sámi's legal position has been strengthened through legislation and new policy, but it has also been further advanced by developments in case law. It has, for instance, led to the recognition of reindeer herders' grazing rights; rights that are rooted in the immemorial usage of lands by the Sámi (and not just based on legislation alone). Although it has its basis in law, the courts have also held that landowners have the burden of proof if they want to claim that there are no reindeer husbandry rights on their properties within the Sámi reindeer husbandry areas. This has had an impact on the legal protection of such rights as in the renowned Selbu Case (2001) to which I will return in section 15.2.4.

\section{Constitutional Law and Sámi Rights}

Article 110a of the Norwegian Constitution protects Sámi language, culture and livelihood, and reads as follows:

"It is the responsibility of the authorities of the State to create conditions enabling the Sami people to preserve and develop its language, culture and way of life." 
This article was adopted by Parliament on 21 April 1988 and followed by a constitutional amendment in May of the same year. The article is based on a 1984 proposal from the SRC with one of its main objectives being to overturn past assimilation and "Norwegianisation" policies. According to the SRC, it put in place a legal obligation saying that Sámi language, culture and way of life must be safeguarded and given further development:

"State authorities will therefore have no legal right to pursue a policy in conflict with this principle. The provision sets the requirements for both legislation and other government actions" (NOU 1984:18, p. 433).

It should also be noted here that the Parliamentary Standing Foreign and Constitutional Committee stated that with the adoption of the provision, the Parliament:

"In the most solemn and binding form our legal system knows, recognised and drawn the consequences of the fact that throughout the history of Norway, there has been a particular Sami ethnic group in our country (Innst. S. nr. 147 (1997-88), 2)."

The Constitutional provision is modelled on Art. 27 of the ICCPR. This means that the provision must be interpreted in accordance with the "requirements of international law to the Norwegian authorities" (SRC II in NOU 2007:13, p. 191). Thus, the provision creates a legal obligation for the Norwegian authorities in the formulation and implementation of the country's Sámi policy and other issues of importance to the Sámi.

There is little case law relating to Art. 110a. However, Norwegian Sámi politics show that this article has had repercussions beyond its political and moral significance alone, including, for instance, the impact it had in acting (in 2004) as the basis for the establishment of the Sis-Finnmárkku Diggigoddi/Inner Finnmark District Court, with Sámi-speaking judges and a special responsibility to safeguard Sámi customary law (NOU 1999:22, p. 72).

This commitment has not however been adhered to in all instances (Ravna 2009). Admission of this reality did however contribute to the establishment, by the Courts Administration in 2010, of a working group to study "The Sámi dimension of the judiciary." The report produced by this group suggested that, based on the obligation contained in Art.110a, "the Courts of 
law have a responsibility to safeguard the interests of the Sámi legal traditions and Sámi customary laws" (Domstoladministrasjonen 2010:21).

\subsubsection{Other National Legislation on Sámi Issues}

This section analyses some of the most important laws that specify and apply the notion of constitutional protection while highlighting Norway's international obligations to protect the Sámi culture, language and rights to lands and waters.

The Sámi Act (12 June 1987 no. 56) aims "to facilitate that the Sámi people in Norway can maintain and develop their language, culture and way of life" (s. 1-1). It is thus complementary to Art. 110a of the Constitution. Section 1-2 provides for the establishment of the Sámi Parliament, which is further regulated in Ch. 2. Chapter 3 deals with the Sámi languages. Among other things, it determines that "acts and regulations with particular interest for the Sámi population shall be translated into Sámi language" (s. 3-2). The chapter also contains rules on the extended right to use Sámi language in the courts (s. 3-4) and in the health and social services (s. 3-5). There are also rules on the right to have a paid leave of absence for education and training in the Sámi language.

The Finnmark Act (17 June 2005 no. 80) is a direct result of Norway's obligation to comply with ILO Convention No. 169 and thus an important instrument in the protection of Sámi rights to lands and nature resources. Interestingly, although the law group under the SRC concluded that the state was the owner of the outlying fields and mountainous areas of Finnmark, the Government proposed to discontinue that ownership in the bill of the Finnmark Act (Ot. prp. nr. 53 (2002-2003)). This was done on the basis of international legal obligations, recognition of the historical rights of the Sámi including perceptions that state ownership was based on historical misunderstandings that were now difficult to defend.

The Finnmark Act thus meant that the Norwegian Parliament transferred the ownership of about 95\% of the area in Finnmark (45,000 kms2) from the state to a new legal entity named Finnmarkseiendommen (The Finnmark Estate). This represents a cardinal change in the management of large lands in the Sámi areas, ending the state ownership regime which has existed for over 200 years. 
The purpose of the Finnmark Act (s.1) is to facilitate the management of land and natural resources in the county of Finnmark in a balanced and ecologically sustainable manner for the benefit of the residents of the county and particularly as a basis for Sami culture, reindeer husbandry, use of non-cultivated areas, commercial activity and social life. The Finnmark Act in s. 3 incorporates ILO Convention No. 169 within the scope of the Act. Of fundamental interest is s. 5, where para 1 states that "through prolonged use of land and water areas, the Sámi have collectively and individually acquired rights to land in Finnmark." The second paragraph states that this also applies to other residents in the county. To determine the scope and content of the rights held by Sámi and other people on the basis of prescription and immemorial usage, a commission shall be established to investigate rights to land and water in Finnmark and a special court to settle disputes concerning such rights, cf. chapter 5 .

The new ownership body, the Finnmark Estate, "is an independent legal entity with its seat in Finnmark, which shall administer the land and natural resources etc., that it owns in compliance with the purpose and other provisions of this Act" (s. 6).

The Finnmark Act in s. 29 (in ch. 5) authorises the establishment of the Finnmark Commission, which "on the basis of current national law, shall investigate rights of use and ownership to the land to be taken over by Finnmarkseiendommen pursuant to section 49." The majority of the Parliamentary Standing Committee of Justice chose the wording "current national law" to reveal that Sámi customs and legal opinions shall be emphasised in the clarification process. Such sources of law should thus have a significant place in the process.

As with the Finnmark Act itself, the founding of the Finnmark Commission and the Uncultivated Land Tribunal (s. 36) are justified under the same obligations agreed to by Norway in ILO Convention No. 169 Art.14.

The Finnmark Commission was established in March 2008 beginning its work on the two first investigation fields in the winter of 2009. In March 2012 the Commission submitted its report on field 1 "Seiland and Stjernøya." In this report however the reindeer herding Sámi's demands for property rights were rejected. Nevertheless, the locals and the reindeer owners did receive recognition for their rights in respect of immemorial usage. Such recognition did not however afford them rights beyond 
what the Finnmark Estate has extensive authority to regulate through the Finnmark Act, or the Reindeer husbandry administration is entitled to regulate through the Reindeer husbandry Act. The report for field 2 "Unjarga/Nesseby" was expected to be completed during the autumn of 2012 and was finally finished in February 2013.

The Reindeer Husbandry Act (15 June 2007 no. 40) aims to facilitate ecological, economic and culturally sustainable reindeer husbandry (s. 1, para 1). The Act places greater emphasis on Sámi culture, tradition and customs than the previous act of 1978, which among other things appears in s. 1 where it is stated that "reindeer husbandry is to be preserved as an important basis for Sámi culture and society." This is also reflected in the fact that the reindeer husbandry siida (the Sámi herding community) is recognised in law, with grazing rules prepared on the basis of "principles of good reindeer husbandry based on Sámi traditions and customs" (s. 59). Section 3 states that the Act should be applied according to the international law of indigenous peoples and minorities.

Chapter 3 deals with the content of reindeer husbandry rights. The most important of these rights are the grazing privileges for the reindeer in the mountainous areas and the other outlying fields, not depending on who is the owner of the land (s. 19). The grazing rights cover the right to suitable seasonal pastures, i.e., spring, summer, autumn and winter pastures, including migration routes, calving and mating areas (ss. 20 and 22). In addition, the reindeer husbandry rights include accessory rights to housing, use of motor vehicles, fences and other facilities, wood and timber, and hunting, trapping and fishing (ss. 21 and 23-26).

Of importance here is also the codification of laws that have grown out of case law. Interesting in that regard is s. 4 , para 1 which states that reindeer husbandry has its legal basis in immemorial usage, while para 3 notes that Sámi reindeer husbandry enjoys legal protection under the expropriation regulations. In addition, para 2 codifies the burden of proof.

The Consultation Agreement between the Norwegian Government and the Sámi Parliament signed 11 May 2005 is also worthy of note here. The agreement aims to contribute to the practical implementation of the state's international legal obligation to consult the Sámi: 
- To achieve agreement between state authorities and the Sámi Parliament when it considers introducing laws or measures that may affect Sámi interests.

- To facilitate the development of a partnership perspective between the state authorities and the Sámi Parliament, working to strengthen the Sámi culture and society.

- Through the development of a common understanding of the situation and development needs of the Sámi community.

In addition, the SRU II drafted a consultation Act in 2007, which is expected to be heard by the Parliament in the near future (NOU 2007:13).

The draft of the Finnmark Fishing Act, proposed by the Coastal Fishing Committee (NOU 2008: 5) was subject to extensive political debate and negotiation, although it was not adopted (and probably never will be). It has as its starting point the draft of the SRC (NOU 1997:4) where it was acknowledged that Sámi culture and traditions must be emphasised in the management of coastal and fjord fishing in Sámi areas. In the SRC draft it was also proposed that free fishing be available for boats under a certain size. The draft was not passed by the government in conjunction with the Finnmark Act (Ot. prp. nr. 53 (2002-2003)). This, in turn, led the Parliamentary Standing Committee of Justice to suggest a legal study on the Sámi peoples' and others' right to fish in the sea offshore the County of Finnmark (Innst. O. nr. 80 (2004-2005), 30-31).

That study was undertaken by the Coastal Fishing Committee, which in their recommendations concluded that people living along the fjords and by the coast in Finnmark, "on the basis of historical use and the international law of indigenous peoples and minorities, have the right to fish in the sea off the Finnmark" (NOU 2008:5, p. 14). A proposal was thus made to settle this question in terms of a "fjord right" to fish. The study of the Coastal Fishing Committee shows that the Norwegian Government position is, in this context, not as free as the Marine Resources Act (6 June 2008 No. 37) states in regulating access to fisheries in its northern seawaters.

The Stoltenberg Government has refused to follow up on the Coastal Fishing Committee's unanimous recommendation but has instead adopted a rather dismissive position on the bill. An Agreement between the Norwegian Government and the Sámi Parliament was concluded in 2011 in 
which the latter gained recognition for the right to land 3,000 tons of cod, but did not received any recognition in respect of its claim over historical fishing rights.

\subsubsection{Case Law Concerning the Rights to Lands and Waters}

The Norwegian Courts long considered Sámi use of land and water as a socalled "innocent beneficial right of use." A fundamental change in the case law however came about through two important Supreme Court judgments during a 14 day period in the spring of 1968.

In the Brekken Case (Norsk Retstidende (NRt.) 1968:394), the Supreme Court found that the Sámi use of lands and waters "for a long time had been attached to the place and that it in its core is so fastened that it cannot simply be equated with the exercise of an innocent beneficial right of use or a public access to land" (401). This led to the Sámi gaining legal recognition for their rights to use their traditional hunting and fishing sites on private land in the Southern Sámi areas.

In the Altevann Case (NRt. 1968:429) the Supreme Court confirmed the lower courts' decision and stated that the flooding of Lake Altevann was "an interference with such a firm and concentrated use of pastures and fishing sites at Altevann that the acquiring authority must pay compensation" (438). The Sámi from the Swedish Sámi Communities of Talma and Saarivuoma using these pastures and fishing sites in Norway were thus awarded compensation for expropriation in line with the prior recognition of immemorial usage.

Although the Supreme Court recognised that Sámi use could lead to the recognition of a right, it should still take several decades before Sámi reindeer husbandry use will lead to the confirmation of pastoral rights in disputes with landowners. The main reason for that was no longer that the use was not considered to establish rights, but rather that it was not considered to be sufficiently regular and intensive to meet the condition for the acquisition of the right. In three separate Supreme Court judgements on the Southern Sámi areas (NRt. 1981:1215, NRt. 1988:1217 and NRt. 1997:1608), the Court evaluated the requirements of regularity and intensity in respect of the use of lands from a norm established by the 
farmers' use of lands. Rules that under other circumstances could have led to the confirmation of the rights of the Sámi reindeer herder thus emerged as obstacles to the recognition of such rights.

In the landmark Selbu Case (NRt. 2001:769) the Supreme Court set the views of the three previous judgments aside. This was done by emphasising the characteristics of reindeer husbandry and the Sámi use of lands and Sámi cultural characteristics when assessing the acquiring of pastoral rights. On adopting such an approach to the legal evaluation of such questions, the Supreme Court found that the reindeer husbandry districts of Essand and Riast-Hylling had acquired pastoral rights in the disputed areas in Selbu municipality due to immemorial usage of reindeer pastures. By virtue of being a plenary judgment, the Selbu case is an important source of law in disputes relating to the confirmation and extension of reindeer husbandry rights. It can, as such, be deemed to represent a norm in respect of how Norwegian property law should be applied, not only in reindeer husbandry disputes, but also more generally in disputes relating to confirmation and recognition of use and ownership rights in the Sámi areas.

In this judgment, a unified Supreme Court stated that reindeer husbandry law imposes a burden on landowners to prove that pastoral rights do not exist in the reindeer husbandry areas, and that the right to practice reindeer husbandry has an independent legal basis grounded in immemorial usage.

Of particular importance here is the fact that the entire Supreme Court stated that in testing the rules of immemorial usage, the characteristics of the rights had to be emphasised, which means that the requirements for the confirmation of rights must be adapted to the Sámi's use of land in the Sámi areas. This also meant that while Sámi reindeer herders have enjoyed a nomadic way of life, similar practices in respect of other grazing animals cannot automatically be transferred to reindeer husbandry. More precisely, the first voting judge, who represented the majority of the Court, stated that reindeer husbandry demands a significant amount of land, and that the use of lands varies from year to year depending on weather, wind and the condition of the pastures: 
"It can thus not be claimed that the reindeer have grazed in a particular area every year. Both for this reason and because of the Sámi's nomadic way of life can interruption of use not prevent acquisition of right even if it is of considerable length" (NRt. 2001:769 at 789).

As a consequence, the nature of reindeer herding must be taken into consideration with grazing patterns emphasised in the evaluation on the basis of the intensity of use. The surroundings, environment, topography, pasture conditions, weather, etc., thus each have significance.

The Supreme Court has in this way adapted rules of immemorial usage such that the legal norm is today that the requirements for intensity and regularity in the use must be evaluated against a standard issued by the characteristics of the rights, and where the acquisition of such rights is considered in relation to the practice of reindeer husbandry more generally.

In this context it is clear that the Selbu Case has produced a norm as shown in the decision on fishing rights for Sámi Reindeer Herders in Tydal (LF-2008-50209).

The clarification of the legal basis of reindeer husbandry and expropriation protection has taken place through case law. This is, as we have seen, now enshrined in s. 4 of the Reindeer Husbandry Act.

In addition to the judgments on reindeer husbandry rights, the Svartskog Case should also be highlighted (NRt. 2001:1229). Based on the rules of immemorial usage, the Supreme Court found here that the local people of Manndalen in the County of Troms, which is populated predominantly by people of Sámi origin, had acquired title to property registered to the Norwegian State as an owner. In assessing the current law, it should however be noted that the legislation relating to the Finnmark Act highlighted these judgments as a guideline for how the traditional Sámi use of these lands shall be considered as the basis for the acquisition of a right. 


\subsection{International Law}

\subsubsection{Article 27 of the International Covenant on Civil and Political Rights}

Through the Human Rights Act (May 21, 1999 No. 30), the ICCPR of 1966 was incorporated into Norwegian law with precedence over other legislation except for the Constitution. Article 27 of the ICCPR reads as follows:

In those States in which ethnic, religious or linguistic minorities exist, persons belonging to such minorities shall not be denied the right, in community with the other members of their group, to enjoy their own culture, to profess and practise their own religion, or to use their own language.

The provision states that minorities are free to use their own languages and enjoy their own cultures and religions. Statements from the UN Human Rights Committee (HRC), which is the monitory organ of the Covenant, show that this article not only provides protection against minorities being denied such rights, but that it also imposes an obligation on states to take positive measures to support minority languages and cultures. In its General Comment No. 23 the HRC (HRC, report, vol. 1, 1994), stated:

Although the rights protected under article 27 are individual rights, they depend in turn on the ability of the minority group to maintain its culture, language or religion. Accordingly, positive measures by States may also be necessary to protect the identity of a minority and the rights of its members to enjoy and develop their culture and language and to practise their religion, in community with the other members of the group (para. 6.2).

The Sámi Rights Committee II (NOU 2007:13, 190-1) emphasise that the statement shows the relationship between the ICCPR Art. 27 and Art. 110a of the Norwegian Constitution.

ICCPR Art.27 also includes protection of the substantial basis of the minority culture, i.e., pastures and other natural environments that are of importance for Sámi traditional livelihoods. In the same report, it is also stated that the committee understands culture to be manifested in many forms:

Including a particular way of life associated with the use of land resources, especially in the case of indigenous peoples. That right may include such traditional activities as fishing or hunting and the right to live in reserves protected by law (para.7). 
The provision thus sets up a threshold for intervention that could threaten the exercise of Sámi culture and livelihoods. The statement also points out that this protection from intervention applies in particular to indigenous peoples. In the 2008 White Paper on the Norwegian Sámi policy (St.meld. nr. 28 (2007-2008), 33), the Government endorsed this position as it approved the Ministry's statement that:

In relation to the Sámi as indigenous people, it is a common interpretation that the provision [ICCPR Art. 27] also covers the material premises for the Sámi overall cultural exercises, also referred to as the natural basis for Sámi culture.

The Comments of the HRC also show that modern ways of exercising traditional culture embedded in industries and livelihoods, such as coastal fishing and reindeer husbandry, also enjoy protection under Art. 27. As a former Chief Justice of the Supreme Court and head of the SRC Dr.Carsten Smith ironically replied to the Attorney's submission to the Coastal fishing Committee (NOU 2008: 5); "it cannot be claimed that the Sámi shall continue to use oars and sails to enjoy the protection of coastal fishing" (Smith 2010:22).

Article 27 of the ICCPR is an important legal provision with a content that provides protection against infringement in respect of natural resources and Sámi traditional lands, where it sets up a framework (even though it is not precise) for how far such interventions can go. The comments of the HRC show that it can be applied to interventions in Sámi coastal, river or inland fisheries. Article 27 also includes a protection against intervention in terms of the Sámi reindeer husbandry industry. This notwithstanding, it must be admitted that the obligation continues to have a greater practical significance in terms of legislative processes and political negotiations than in case law.

\subsubsection{ILO Convention No. 169}

As already noted, Norway ratified ILO Convention No. 169 in 1990. Even if the legislature omitted to incorporate it through the 1999 Human Rights Act, the convention remains a significant source of law which among other things sets up requirements for consultations, for indigenous customs to 
be emphasised in decision-making processes, and for indigenous land rights to be identified and recognised.

In Norway a broad consensus exists that the Sámi people are covered by the definition of indigenous peoples in Art. 1. By ratifying the Convention, Norway has thus committed itself to protect the Sámi lands and culture. Article 2 includes a governmental responsibility in respect of "developing, with the participation of the peoples concerned, co-ordinated and systematic action to protect the rights of these peoples and to guarantee respect for their integrity."

Article 6 encompasses the government's duty to consult indigenous peoples. According to para (1)(a), the obligation to consult includes all cases where public bodies are considering implementing legislative or administrative measures that may have a direct impact on indigenous people. This led to the agreement on consultations between the Norwegian Government and the Sámi Parliament in 2005, described above.

Article 8 encompasses the respect for indigenous customs and customary law. Paragraph (1) states that "In applying national laws and regulations to the peoples concerned, due regard shall be had to their customs or customary laws." This provision helps to actualise Sámi customs and customary law as a source of law (see below). This will in particular apply to the legal identification process in Finnmark, since the ILO Convention is incorporated in the Finnmark Act, and since the legislature has placed great emphasis on fulfilling its international obligations in framing the Finnmark Act. Article 8 (2) states that necessary procedures shall be established to resolve conflicts which may arise in the application of this principle.

Of particular interest here however is the question of the legal ranking of indigenous customary laws when they are in conflict with national statutory law. This is discussed by SR C II, which does argue that indigenous customs are not unconditionally entitled to prevail (NOU 2007:13, p. 222).

Article 14 states that indigenous peoples have rights of ownership and possession over their traditional lands. The purpose of this article is that the use of lands that indigenous people have traditionally used shall be recognised and given legal protection. The international law group under the Sámi Rights Committee has noted that "if the population has been sufficiently permanently settled in the area, and they have also been the only ones to use this area, the demands of actual possession can normally 
be regarded as having been fulfilled" (NOU 1997:5, p. 35). Article 14, especially 14 (2) and (3) has been of significant importance in the adoption of the Finnmark Act and the establishment of the Finnmark Commission. It reads: "Adequate procedures shall be established within the national legal system to resolve land claims by the peoples concerned." The Finnmark Commission is supposed to provide such an adequate procedure.

Article 15 encompasses indigenous peoples' rights to participate in the management of natural resources. It places restrictions on the state authorities in regulating the exploitation of land and natural resources in indigenous areas. In para 1, the article states that indigenous people have the right to participate in the use, management and conservation of such resources. In Art. 15 (2) the requirement for an extended consultation duty is set out.

\footnotetext{
"In cases in which the State retains the ownership of mineral or subsurface resources or rights to other resources pertaining to lands, governments shall establish or maintain procedures through which they shall consult these peoples, with a view to ascertaining whether and to what degree their interests would be prejudiced, before undertaking or permitting any programmes for the exploration or exploitation of such resources pertaining to their lands..."
}

Furthermore, this paragraph states that indigenous peoples shall, "wherever possible participate in the benefits of such activities."

It has however been questioned whether the 2009 Norwegian Minerals Act, which provides for increased landowner fees to the Finnmark Estate instead of providing direct benefits to the representative Sámi body (The Sámi Parliament), is consistent with Art. 15 (2), see Skogvang (2010:63-67).

\subsubsection{Other International Legal Obligations of Norway}

Norway has also endorsed the UN Convention on Biological Diversity, the European Charter on Regional or Minority Languages and the Council of Europe Framework Convention on the Protection of National Minorities. These obligations also have legal effect in relation to the Sámi people. It should also be noted that the UN Special Rapporteur Anaya has emphasised the importance of the fact that Norway has ratified these conventions. 
Other international instruments of interest include the 2007 United Nations Declaration on the Rights of Indigenous People. Since many of the commitments in this Declaration are also enshrined in ILO Convention No. 169 there is little need to discuss this issue here. However, we should note that Art. 21 of the Declaration follows Art. 27 of the ICCPR in requiring that states implement effective measures to ensure the development of the social and economic conditions of indigenous people. The $2005 \mathrm{draft}$ Nordic Sámi Convention will also likely prove to be an important international legal instrument at least if, in the near future, the negotiations end in a treaty in the form of the present draft. However, the analysis of that document is also beyond the scope of this chapter.

The 1950 European Convention on Human Rights (ECHR), Protocol 1 Art. 1, also retains some significance as a rule of law in the Norwegian courts when it comes to the legal protection of reindeer husbandry. For example, the Supreme Court decision NRt. 2006:1382 on a dispute between a reindeer owner and the Reindeer administration on the closing down of a reindeer herding unit, found that the Reindeer Administration under the Norwegian Ministry of Agriculture and Food was not entitled to proceed with the said closure because, among other things, it violated the protecting of property under ECHR, protocol 1, Art. 1.

The legal clarification Process (see section 15.2.3 above) enshrined in the Finnmark Act can also be discussed in relation to the obligations of the ECHR, including the provision for trials to be held within a reasonable time, contained in Article 6 (Ravna 2011).

\subsection{Sámi Law}

\subsubsection{Sámi Legal Traditions and Customary Law}

Sámi legal traditions and customary law such as Sámi internal autonomous regulations constitute Sámi law. Although this is not a written law it is binding in nature. It is important both in relation to Sámi autonomy and also in the application of national Norwegian law related to the Sámi. Moreover, it has significance for negotiations in respect of bilateral and 
multilateral agreements and treaties between states that have a Sámi population and the Sámi people (e.g., the Draft Nordic Sámi Convention).

Sámi law has an independent legal basis; it is complied because people who are subject to them feel bound by them. Norway's ratification of ILO Convention No. 169 and subsequent policy developments, have given Sámi law a formal place in Norwegian law. This means that Sámi customary law should be considered both in the legislative process and in the application of the law.

This legal development also meant that Sámi law has increasingly become a part of Norwegian statute (e.g., in parts of the reindeer husbandry legislation). The Finnmark Act is to some extent also built upon the foundations of Sámi legal traditions. Thus, in s. 5 it states that the Act does not infringe the "rights of the Sámi and others have gained by prescription or immemorial usage."

Except for the previous Finnmark land legislation and the general legislation on fishing and wildlife conservation, harvesting of outlaying fields in the Sámi areas has to a relatively small extent been regulated by statutory law. Customary law has thus played a significant role in its regulation. The well-known judge and legal scholar Erik Solem (1933), showed that the Sámi often had disputes regarding hunting grounds in respect of the snare trapping of grouse. In her study Elina Helander (2004) notes that Sámi informants claimed to have some sort of internal autonomy for the exercise of this trapping tradition, and that now they are in danger of losing it.

The right to build the Sámi guohti (a traditional Sámi turf hut), is another tradition that has largely been regulated by Sámi customs. This tradition was violated when the state forest company, which managed the unregistered state property of Finnmark, adopted a regulation in 1967 saying that such turf huts only could be raised with the permission granted by the state forest company and on certain conditions.

Other Sámi customs such as: conflict resolution, the importance of family relationships, child rearing and hereditary succession still play a role in the modern life of Sámi people (Skogvang 2009:85-93). 


\subsubsection{Sámi Law in the Norwegian Courts}

To date, the use of Sámi customary law as a source of law in the courts is still in its initial phase. It therefore remains difficult to draw robust conclusions on its ultimate legal significance. Thus far, case law points to the fact that Sámi law has faced significant problems in working harmoniously with Norwegian law as the two have often collided with considerable force, and where the Supreme Court has placed strict requirements on quality and clarity on Sámi customary law.

In its 2001 ruling (NRt. 2001:1116) the Supreme Court held that the tradition of letting dogs run free in the woods in the summer, was not of a quality that let it prevail over the Norwegian Wildlife Act. Additionally, a case brought in relation to the spring hunting of ducks in the Sámi municipality of Kautokeino failed as it was not considered to be a custom that deserved legal protection by the courts, (see: NRt. 1988:377).

The question of the significance of Sámi customary law in the slaughtering of reindeer has also been heard by the Supreme Court on two occasions (NRt. 2006:957 and NRt. 2008: 1789). In neither case did the Sámi parties claim that particular methods of killing the reindeer, namely, by shooting with a small-calibre rifle or killing with a knife to the heart (which was not in compliance with the 1974 Animal Welfare Act), were justified by Sámi customary law. It must, however, be noted that the government has shown some willingness to accept Sámi customary traditions, e.g., in regulations in respect of the methods of killing reindeer (Regulations 30 July 2008 on the use of the curved knife) and by regulating spring hunting for ducks (Regulation 2 May 1994 on the quota regulation of spring hunting for ducks).

In addition, when it comes to fishing for salmon, case law exists to show that Sámi customary law is set aside when it contradicts Norwegian law. For example, in a decision about fishing in the River Tana (NRt. 2006: 13), the Supreme Court, somewhat surprisingly, stated that the customary law saying that a person outside the household is allowed to fish with the authority (proxy) of the right holder, was contrary to Norwegian law and thus found such fishing unlawful. The above-mentioned Selbu Case (NRt. 2001:769) shows however that the Supreme Court has emphasised traditional Sámi knowledge and customs related to the use of the lands in settling a claim on rights to reindeer husbandry pastures. 
Beyond these examples, Sámi customary law has faced significant difficulty in being recognised by the courts. This can perhaps be explained by the fact that the courts of appeal are not yet sufficiently adapted to protect Sámi customary law. But it can probably also be explained by the fact that customs that have been tried in courts, have lacked the legal quality required to obtain legal protection (NRt. 2001:1116). According to Skogvang (2009:75-6), the Supreme Court in criminal matters, with the exception of the 2006 judgment on salmon fishing in Tana, has evaluated the legal sources correctly.

Finally, it should be noted however that the courts of law in the Sámi areas have over time become more aware of their duties in respect of familiarising themselves with Sámi customary law.

\subsection{Conclusion}

The Sámi people, including their legal culture, were subject to a grinding process of assimilation into the Norwegian state from the 1800s up to the post war period. Partly as a result of the focus on international human rights law after the Second World War, views in respect of Sámi culture, rights and customary law, slowly began however to change.

In the nearly 70 years that have passed since the end of World War 2 Sámi language and culture has gained increasing recognition and legal protection, both through national legislation, case law and in relation to international human rights obligations to which Norway step by step has committed itself. This also resulted in Sámi customary law being recognised as a source of law beyond the notion of Sámi internal autonomy. At the same time, Sámi Law can be interpreted through four sources of law: Norwegian statutory law, case law, customary law and international human rights treaties. These sources of law are framed within three legal systems: Norwegian national law, international law and Sámi law.

Norway is constitutionally committed to protect Sámi language, culture and society (Art. 110a). This commitment has among other things contributed to the establishment of the Inner Finnmark District Court in 2004, a court with a special responsibility to safeguard Sámi language, culture and legal traditions. Sámi legal traditions and land rights are also 
given protection and recognition through Norway's ratification of ILO Convention No. 169. This protection is strengthened by the incorporation of the convention into the Finnmark Act.

The Finnmark Act in itself represents the recognition of Sámi rights to lands and waters. The Act does however contain certain procedural deficiencies or inaccuracies, suggesting that its revision may be relevant. Ratification of ILO Convention No. 169 also implies that Sámi legal traditions should be given a more prominent place in Norwegian law than recent case law otherwise suggests.

Through case law, it has been acknowledged that reindeer pastures are protected legally in such a way that Sámi herders are given economic compensation in relation to encroachments on their pastures and that the legal basis for this is immemorial usage (and not the statutory law itself). These rules are now codified in the 2007 Reindeer Act. It is now also the law that, in cases of legal disputes, the landowner has the burden of proving that reindeer husbandry rights do not exist on their private land situated in the Sámi reindeer herding area. Case law shows that the Supreme Court has been able to adapt the provisions of Norwegian property law in such a way that they are now able, to a large extent, to protect Sámi lands, waters and rights to natural resources. In other areas of law however progress has not been as marked.

When the 1999 Human Rights Act was passed, the international human rights conventions were incorporated into Norwegian law and given precedence. Even if incorporation here did not specifically include ILO169 , this has contributed to the strengthening of the legal position of the Sámi, in particular through the ICCPR Art. 27.

Despite a solid foundation in law, there major challenges still remain in respect of gaining provision for Sámi law, both as a scholarly subject and as a legal instrument. One such challenge relates to the clarification of the hierarchy between Sámi law and other legal sources in cases where contradictions arise. There are also challenges to be faced in the implementation of the international conventions that protect Sámi language and substantial culture under Norwegian law.

A current question that challenges both obligations in international law and internal legislation concerns the right to fish in the coastal areas outside Finnmark. The Coastal Fishery Committee concluded that people 
living by the fjords and along the coast of Finnmark possess historical rights to fish in these areas but the government has been reluctant to acknowledge this. This means that rules noting that the concept of immemorial usage creates rights, an accepted norm when it comes to pastoral rights in the mountains and outlying fields, do not reach beyond the slopes of the shoreline. This also means that the debate on the right to fish in the coastal areas of Sápmi will continue into the future.

Questions about self-determination and the extent of the rights to both non-renewable and renewable natural resources on land have also not been resolved. The question of renewable resources leads us back to the Finnmark Act. Although the legislature here has shown a willingness to recognise Sámi rights to lands and waters, there is still a long way to go to actually achieving this goal in practice. One of the main problems here concerns the imprecise nature of the rules in relation to the Finnmark estate's management of land rights, which were, on occasion, practised in a contrary manner to local interests. Furthermore, the de facto extent to which Sámi rights to lands and waters in Finnmark are recognised by legislators ultimately depends on the legal identification processes initiated through the Finnmark Act and the Finnmark Commission. These processes are currently ongoing with both procedural and substantive questions remaining to be resolved. This means that we can surely agree with the Special Rapporteur on the Rights of Indigenous peoples, James Anaya, when he stated that "the adequacy of the established procedure is not yet known."

\section{Further reading/references}

Allard, Christina, “The Nordic Countries' Law on Sámi Territorial Rights," Arctic Review on Law and Politics, (2) 2011:159-183.

Anaya, James, The Situation of the Sami People in the Sápmi Region of Norway, Sweden and Finland, 2011 see http://unsr.jamesanaya.org/docs/countries/ 2011-report-sapmi-a-hrc-18-35-add2_en.pdf

Domstoladministrasjonen, "Den samiske dimensjon i rettsvesenet;" 2011 http://www.domstol.no/upload/DA/Internett/domstol.no/Aktuelt/2011/Rapp ort $\% 20$ samisk\%20dimensjon $\% 20 \mathrm{i} \% 20$ rettsvesenet.pdf

Fitzmaurice, Malgosia. "The New Developments Regarding the Saami Peoples of the North," International Journal on Minority and Group Rights 16 (2009):67-156.

Gauslaa, Jon. "Utviklingen av sameretten de siste 25 årene og betydningen for arealforvaltning og rettspleie" in Øyvind Ravna (red.), Areal og eiendomsrett, (Oslo: Universitetsforlaget, 2007):151. 
Helander, Elina. "Samiska rättsuppfatningar," Juridica Lapponica (30) 2004, Rovaniemi, Arctic Centre.

Innst. S. nr. 147 (1997-88) Innstilling fra Utenriks- og konstitusjonskomitéen angående ny $\$ 110$ a i Grunnloven om samiske rettigheter.

Innst. O. nr. 80 (2004-2005) Innstilling fra justiskomiteen om lov om rettsforhold og forvaltning av grunn og naturressurser i Finnmark fylke (finnmarksloven).

Ot.prp. nr. 53 (2002-2003) Om lov om rettsforhold og forvaltning av grunn og naturressurser i Finnmark fylke (Finnmarksloven).

NOU 1984:18 Om samenes rettsstilling.

NOU 1997:4 Naturgrunnlaget for samisk kultur.

NOU 1997:5 Urfolks landrettigheter etter folkerett og utenlandsk rett.

NOU 1999:22 Domstolene i første instans.

NOU 2007:1 Den nye sameretten; NOU 2008:5 Retten til fiske i havet utenfor Finnmark.

Ravna, Øyvind. "Hensynet til samisk språk og kultur ved organiseringen av domstolene," Kart og Plan (69) 4/2009:205-215(full text at: http://uit.no/ansatte/oyvind.ravna).

Ravna, Øyvind. "Sámi Legal Culture - and its Place in Norwegian Law," Rendervous of European Legal Cultures,(Bergen: Fagbokforlaget, 2010):149-165 (full text at: http://uit.no/ansatte/oyvind.ravna).

Ravna, Øyvind. "The Finnmark Act 2005 Clarification Process and Trial "Within a Reasonable Time'” Nordic Journal of Human Rights (29), 2-3/2011:184-205 (full text at: http://uit.no/ansatte/oyvind.ravna).

Ravna, Øyvind. "The Process of Identifying Land Rights in parts of Northern Norway: Does the Finnmark Act Prescribe an Adequate Procedure within the National Law?," The Yearbook of Polar Law, (3), 2011:423-453(full text at: http://uit.no/ansatte/oyvind.ravna).

Ravna, Øyvind. "Legal Protection of Coastal Sámi Culture and Livelihood in Norway," The Yearbook of Polar Law, (4), 2012:261-278.

Skogvang, Susann F. Samerett, $2^{\text {nd }}$ ed., (Universitetsforlaget: Oslo. 2009).

"Ny minerallov og samiske rettigheter," Lov og Rett, no. 1-2, 2010:47-67.

St.meld. nr. 28 (2007-2008) Samepolitikken.

Smith, Carsten. "Retten til fiske i havet utenfor Finnmark," Arctic Review on Law and Politics (1) 1/2010:4-27.

Solem, Erik. Lappiske rettsstudier, (Oslo: Inst. for sammenliknende kulturstudier, 1933).

\section{Websites}

Gáldu - Research Centre for the Rights of Indigenous People: http://www.galdu.org Research Group for Sámi and Indigenous Peoples law: http://en.uit.no/ansatte/ organisasjon/artikkel?p_document_id=184106\&p_dimension_id=88177\&p_ menu $=28713$ 


\section{Questions}

- Sámi Law is framed in three legal systems and can, as a concept, be understood in two main ways. What are these three legal systems and two ways?

- Why can the Selbu Supreme Court Case (NRt. 2001:769) be called a landmark case?

- What are the most important international treaties in relation to Sámi Law in Norway? 



\title{
Sammanfattning
}

\author{
Natalia Loukacheva
}

Utvecklingen i Arktis och Antarktis fortsätter att vara föremål för såväl allmänhetens växande intresse som den politiska, vetenskapliga och mediala diskursen. Omfattningen av de förändringar som äger rum $\mathrm{i}$ polartrakterna påverkar även rättsutvecklingen; Arktis och Antarktis växande betydelse inom såväl globala som nationella (och subnationella) utvecklingsområden påkallar vidare undersökningar om rättens roll för hanteringen av angelägna frågor av betydelse för bägge polerna. Även om rätten inte ger svar på alla frågor, har den en roll att spela i hanteringen av många av de problem som är aktuella i Arktis och Antarktis idag.

I den första läroboken i polarrätt, Polar Law Textbook (N. Loukacheva ed. Copenhagen: Nordic Council of Ministers, Tema Nord 538: 2010 (www.norden.org )), presenterades en bred översikt av de polarrättsliga frågorna. Denna nya lärobok bygger vidare på polarrätten som ett framväxande forskningsområde, nära sammankopplat med andra områden inom samhällsvetenskap och humaniora, som vinner allt större erkännande. Samtliga kapitel är skrivna under perioden september 2012 till februari 2013 och innehåller ett stort antal aktuella polarrättsliga frågor som inte diskuterades i 2010 års lärobok och presenterar därmed i hög grad ny polarrättslig kunskap.

Sedan det fruktsamma samarbetet med den första läroboken i polarrätt har Nordiska Ministerrådet, genom det arktiska samarbetsprogrammet, visat fortsatt ledarskap för de juridiska frågornas position inom det Nordiska, Arktiska och globala samhället genom att stödja framtagandet av ytterligare en lärobok i polarrätt. Idén till den nya boken väcktes 2012-2013 i Akureyri, Island, vid Mastersprogrammet i polarrätt. Som ledare för det läroboksprojektet utsågs Dr. Natalia Loukacheva, som även tjänat som redaktör för boken. Den nya läroboken är ett resultat av 
en bred samverkansprocess och ett effektivt lagarbete mellan en internationell grupp av 15 välkända experter inom polarrätt och närliggande områden, häribland akademiker, politiker, praktiker och representanter från arktiska urbefolkningar (se vidare författarbio-grafier). Detta samarbete var möjligt tack vare författarnas gemensamma övertygelse att det trots befintligt kunnande finns behov att ytterligare främja den globala spridningen av rättslig information och kunskap.

Generöst stöd för framtagandet av detta pedagogiska verktyg har lämnats av Nordiska Ministerrådet. Läroboken kan beställas i pappers-format och även kostnadsfritt laddas ner från Nordiska Ministerrådets hemsida i syfte att ge alla som är intresserade av polarrätt tillgång till boken. Förhoppningen är att detta kommer att göra det möjligt även för läsare i avlägsna arktiska områden, och över hela världen, att få tillgång till de pedagogiska verktyg och den information som presenteras i boken.

De viktigaste målen med denna lärobok är: att sprida ny kunskap om den mest aktuella juridiska och politiska utvecklingen i polarområdena; att ytterligare främja juridisk och tvärvetenskaplig utbildning i och för avlägsna nordliga områden; och att stärka samarbetet inom den nordiska regionen och med berörda parter (läroboken är t.ex. användbar för initiativ från Arktiska Rådet och dess arbetsgrupper, University of the Arctic, och för många utbildningsprogram globalt). Förhoppningen är också att läroboken ska kunna användas som utbildningsunderlag för framtida distansutbildningar i polarrätt, samt som stöd för Nordisk samverkan och tvärvetenskaplig dialog genom att främja ytterligare samarbete inom och utanför den Nordiska/Arktiska regionen.

Trots sin primära pedagogiska inriktning innehåller boken användbar information för såväl jurister som icke-jurister, liksom för andra som är intresserade av ämnet polarrätt. Författarna i boken utforskar en rad olika rättsliga frågor i Arktis och Antarktis, men även frågor berörs, t.ex. relevanta geopolitiska aspekter, säkerhet, styrelseformer, sjöräddning, resurser, biologisk mångfald och andra politiska frågor.

Boken är upplagd som en lärobok med 15 kapitel där varje kapitel, med viss variation, bygger på föreläsningsmaterial och innehåller tips om vidare läsning. Boken omfattar frågor inom områden som: polarrätt, geopolitik, säkerhet, och Arktiska Rådets arbete (se kapitel av Loukacheva, Heininen, Vasiliev och Koivurova); frågor om miljölagstiftning, klimatförändringar, 
resurser, energi, biologisk mångfald och kontinentalsockeln (se kapitel av Baker, Bankes, Bastmeijer, Fitzmaurice, Koivurova, McDorman och Pettersson) samt; utveckling av styrelseformer, mänskliga rättigheter och rättigheter för ursprungsbefolkningar (se kapitel av Alfredsson, á Rógvi, Penikett, Ravna och Lykke Thomsen). Trots sin omfattning är bokens räckvidd ändå begränsad och lämnar tvivelsutan utrymme för fortsatt forskning och samverkan inom det polarrättsliga området.

De åsikter som uttrycks i denna lärobok återspeglar inte nödvändigtvis Nordiska Ministerrådets ställningstagande. Bidragsgivarna hoppas att boken kommer att uppmuntra dem som är intresserade av polarrätt till fortsatta studier, forskning eller deltagande i något av de många pågående Arktis- och Antarktisrelaterade initiativen.

Ytterligare information om denna lärobok kan inhämtas av lärobokens redaktör Dr. Natalia Loukacheva på: natalial@unak.is eller n.loukacheva@ utoronto.ca eller från Nordiska Ministerrådets webbplats: www.norden.org 



\title{
Samantekt
}

\author{
Natalia Loukacheva
}

Vaxandi áhugi er á próun mála á norður- og suðurskautssvæðunum meðal almennings, vísinda- og fræðimanna, stjórnmálamanna og fjölmiðla. Hnattræn áhrif peirra umfangsmiklu breytinga sem nú eiga sér stað á heimskautasvæðunum ná einnig til lagalegrar próunar. Mikilvægi norðurog suðurheimskautsins fer vaxandi á ýmsum sviðum próunar á heimsvísu, í einstökum heimshlutum, ríkjum og svæðum innan ríkja. Í ljósi pess er full pörf á frekari athugun á hlutverki laga í viðbrögðum við mörgum peirra vandamála sem við blasa í tengslum við heimskautin bæði nú og í framtíðinni. Enda pótt lög leysi ekki öll vandamál hafa pau hlutverki að gegna við lausn margra peirra.

Víðtækt yfirlit yfir málefni heimskautaréttarins var veitt í brautryðjendaverkinu Kennslubók í heimskautarétti (Polar Law Textbook), N. Loukacheva ritstj. Kaupmannahöfn: Norræna ráðherranefndin, Tema Nord 538: 210 (www.norden.org). Í bókinni sem hér er fylgt úr hlaði er aftur leitað í smiðju heimskautaréttarins, en hann er vaxandi rannsóknarsvið sem nýtur síaukinnar viðurkenningar og snertir mörg önnur svið félagsvísinda og hugvísinda. Í pessari kennslubók í heimskautarétti er fjallað um fjölmörg ný málefni og próun sem ekki var til umræðu í bókinni sem kom út 2010. Allir kaflarnir voru samdir á tímabilinu september 2012 til febrúar 2013 og saman mynda peir auðlegð nýrra upplýsinga um heimskautarétt.

Í kjölfar gjöfullar samvinnu 2009-2010 hefur Norræna ráðherranefndin, undir formerkjum áætlunar sinnar um samvinnu á norðurslóðum, haldið áfram forystuhlutverki sínu við að ýta undir lagaleg gildi í norrænu, heimskauta- og hnattrænu samhengi með pví að styrkja verkefnið Kennslubók í heimskautarétti II. Petta verkefni var vistað 2012-2013 af meistaranámi í heimskautarétti við lagadeild Háskólans á Akureyri. Nýja kennslubókarverkefninu var stýrt af Dr. Natalíu Loukachevu, sem einnig 
ritstýrði bókinni. Kennslubókin er afrakstur víðtækrar og samhentrar samvinnu alpjóðlegs hóps 15 vel pekktra sérfræðinga á sviði heimskautaréttar og skyldra greina. Hópinn skipa meðal annars fræðimenn, stjórnmálamenn, aðilar sem starfa á vettvangi og frumbyggjar á heimskautasvæðum (sjá upplýsingar um höfunda). Pessi samvinna byggðist á sameiginlegri sannfæringu um að prátt fyrir að ýmsar heimildir séu til sé pörf á frekari frampróun lögfræðilegra upplýsinga og pekkingar á heimsvísu.

Norræna ráðherranefndin veitti veglegan styrk til gerðar pessa kennsluefnis. Hægt er að panta pað í bókarformi frá Norrænu ráðherranefndinni og einnig er mikils um vert að efnið er aðgengilegt á rafrænu formi á heimasíðu Norræna ráðherraráðsins svo að allir sem áhuga hafa á heimskautarétti hafi ókeypis aðgang að bví. Vonast er til að petta auðveldi lesendum á fjarlægum heimskautasvæðum og um heim allan aðgang að pví lögfræðilega kennsluefni og upplýsingum sem hér birtast.

Helstu markmið kennslubókarinnar eru: Að koma á framfæri nýrri pekkingu á lagalegri og stjórnmálalegri próun á heimskautasvæðnunum; að styrkja samvinnu á norrænum vettvangi og meðal hagsmunaaðila (svo dæmi sé tekið gagnast kennslubókin ýmsu framtaki Norðurskautsráðsins og starfshópa pess, Háskóla norðurslóða og mörgum menntastofnunum á heimsvísu). Ennfremur er vonast til pess að kennslubókin skapi grundvöll fyrir fjarkennd námskeið í heimskautarétti í framtíðinni og að hún efli pverfaglega umræðu með frekara samstarfi aðila á Norðurlöndum, norðurslóðum og víðar. Pótt megintilgangur bókarinnar sé menntunarlegur hefur hún að geyma gagnlegar upplýsingar fyrir lögfræðinga jafnt sem aðra og alla pá sem áhuga hafa á heimskautarétti. Í henni eru könnuð fjölmörg lögfræðileg álitaefni tengd norður- og suðurskautinu, en einnig skyld viðfangsefni á sviði alpjóðastjórnmála, öryggismála, stjórnskipunar, leitarog björgunarstarfa, auðlinda, líffræðilegs fjölbreytileika og annarra pátta stjórnmálapróunar.

Bókin er byggð upp sem kennslubók par sem allir kaflar hafa að einhverju leyti verið skrifaðir í formi fyrirlesturs og hafa að geyma ábendingar um frekara lesefni. Kennslubókinni er skipt í 15 kafla sem spanna viðfangsefni á eftirtöldum sviðum: Heimskautaréttur, alpjóðastjórnmál, öryggismál og Norðurskautsráðið (t.d. samningurinn um leit og björgun, aðgerðir vegna loftslagsbreytinga, o.s.frv.) (sjá kafla eftir Loukachevu, Heininen, Vasiliev og Koivurova); umhverfisréttur, loftslagsbreytingar, auðlindir, orka, fjölbreytile- 
iki lífríkis og meginlandsflekar (sjá kafla eftir Baker, Bankes, Bestmeijer, Fitzmaurice, Koivurova, McDorman og Pettersson); próun stjórnunarhátta (sjálfstjórn, góðir stjórnunarhættir, valddreifing), mannréttindi og réttindi frumbyggjapjóða (sjá kafla eftir Gudmundur Alfreðsson, Kari á Rógvi, Penikett, Ravna og Lykke Thomsen). Pótt kennslubókin spanni vítt svið er afmörkun óhjákvæmileg og bví skilur hún eftir rúm fyrir frekari rannsóknir og samvinnu á sviði heimskautaréttar.

pau viðhorf sem lýst er í pessari kennslubók fara ekki nauðsynlega saman við afstöðu Norrænu ráðherranefndarinnar. Höfundar bókarinnar vona að hún verði hvatning öllum peim sem áhuga hafa á heimskautarétti til að leggja í frekara nám, rannsóknir eða samvinnu um pau fjölmörgu verkefni sem starfrækt eru í tengslum við bæði norðurheimskautssvæðin og suðurskautið.

Frekari upplýsingar um kennslubókina fást hjá ritstjóranum dr. Nataliu Loukachevu í gegnum netfangið natalial@unak.is eða n.loukacheva @utoronto.ca, sem og á vefsíðu Norrænu ráðherranefndarinnar www.norden.org 


\section{nordan}

\section{Nordic Council of Ministers}

Ved Stranden 18

DK-1061 Copenhagen K

www.norden.org

\section{Polar Law Textbook II}

"Developments in the Arctic and Antarctica continue to be the subject of growing public interest and academic, political, scientific, and media discourse. The global magnitude of the changes that are currently taking place in the Polar Regions, also influence legal developments. Furthermore, the growing importance of both the Arctic and the Antarctica in various areas of global, regional, national and subnational development requires further inquiry into the role of law in dealing with many of the current and emerging issues relevant to both Poles. Although law is not a panacea for all issues, it has its own role to play in dealing with many of them."

This textbook represents the outcome of a cooperative process between an international group of well-known experts in the area of Polar law and related studies. Polar Law TextBook II further draws upon Polar law as an evolving and developing field of studies which is gaining increasing recognition and intersects with many other areas in the social sciences and humanities. It explores a variety of legal issues in the Arctic and Antarctica 